
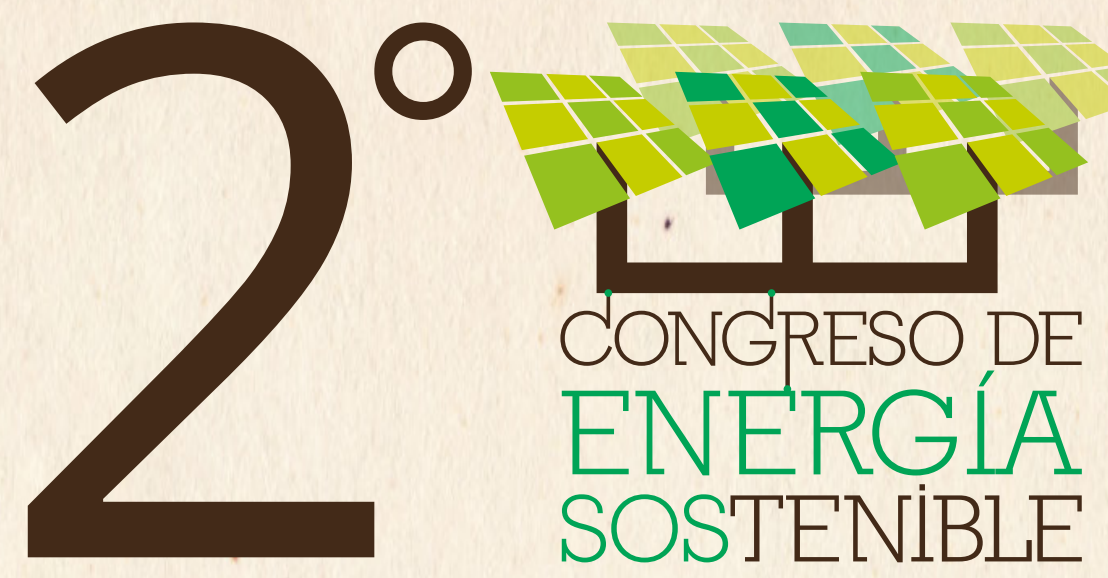

\title{
ENERGÍA SOSTENIBLE
}

EN COLOMBIA:

\section{RETOS Y BENEFICIOS \\ DE SU IMPLEMENTACIÓN}



ENERGÍA SOSTENIBLE EN COLOMBIA: RETOS Y BENEFICIOS DE SU IMPLEMENTACIÓN

Recopilación de artículos científicos, Segundo Congreso de Energía Sostenible 
Energía Sostenible en Colombia:

Retos y beneficios de su implementación.

Recopilación de artículos científicos

Segundo Congreso de Energía Sostenible

Congreso de Energía Sostenible, 2014

Bogotá, Colombia

www.congresoenergiasostenible.org

Todos los derechos reservados.

Se permite la reproducción total

o parcial de esta obra citando la fuente.

Compiladores

Ph.D. Dionisio Humberto Malagón Romero Universdad Santo Tomas

M.Sc. Luis Eduardo Garcia F.

Universidad Libre

Carlos A. Garzón Ramírez

Universidad ECCI

Editor general

Ph.D. Dionisio Humberto Malagón Romero Universdad Santo Tomas

Diseño de cubierta

Carlos E. Pachón

Asociación Akuaippa

Diagramación

Carlos E. Pachón

Asociación Akuaippa

Corrección de estilo

Andrea del Pilar Carrillo

Asociación Akuaippa

ISBN versión digital 978-958-57711-1-6

Bogotá, Colombia 
PAG.

7

PRÓLOGO

BIOMASA, BIOENERGÍA Y BIOCOMBUSTIBLES

10 BIOMASA Y BIOCOMBUSTIBLES EN LATINOAMÉRICA Y EL CARIBE (LAC)

11 AMPLIFICACIÓN Y CLONACIÓN DE LOS GENES QUE CODIFICAN PARA LA ENZIMA GLICEROL DESHIDRATASA (DHAB1) Y SU PROTEÍNA ACTIVADORA (DHAB2) A PARTIR DE UNA CEPA NATIVA DE Clostridium sp.

15 EVALUACIÓN DE UNA METODOLOGÍA DE COSECHA DE MICROALGAS PARA LA OBTENCIÓN DE METABOLITOS CON POTENCIAL DE VALOR

21 EVALUACIÓN DEL DESEMPEÑO EN UN MOTOR DIÉSEL DE MEZCLAS DE DIÉSEL CON BIODIESEL OBTENIDO A PARTIR DE ACEITE DE COCINA USADO MODELAMIENTO COMPUTACIONAL DE LA PRODUCCIÓN DE ENERGÍA RENOVABLE A PARTIR DEL BIOGÁS MEDIANTE LA CODIGESTIÓN ANAERÓBICA DE LA MEZCLA DE RESIDUOS CÍTRICOS Y ESTIÉRCOL BOVINO.

30 OBTENCIÓN DE FRACCIONES LÍQUIDAS MEDIANTE PIRÓLISIS DE BIOMASA RESIDUAL OBTENIDA DEL CULTIVO DE PALMA AFRICANA

SÍNTESIS DE BIOETANOL A PARTIR DE BIOMASA DE MICROALGA

\section{EFICIENCIA Y AUDITORÍA ENERGÉTICA}

40 EFICIENCIA Y AUDITORÍA ENERGÉTICA

41 EL ANÁLISIS DE OPORTUNIDADES Y DE COSTO BENEFICIO EN LA REALIZACIÓN DE AUDITORÍAS ENERGÉTICAS

EVALUACIÓN DE UN SISTEMA HÍBRIDO DE GENERACIÓN ELÉCTRICA RENOVABLE PARA UNA ZONA AISLADA DE COLOMBIA USANDO SOFTWARE HOMER EVALUACION ENERGETICA DEL SISTEMA DE GENERACION DE VAPOR DE UN INGENIO AZUCARERO

63 FALLOS MÁS REPRESENTATIVOS DE LOS MÓDULOS FOTOVOLTAICOS GESTIÓN ENERGÉTICA EN LA UNIVERSIDAD DEL ATLÁNTICO

73 INDICADOR DE HUELLA DE CARBONO PROVENIENTE DEL CONSUMO ELÉCTRICO EN LOS LABORATORIOS DE INGENIERÍA ELECTRÓNICA DE LA UNIVERSIDAD SANTO TOMÁS TUNJA. 


\section{ENERGÍAS ALTERNATIVAS}

91 ENERGÍA EN LATINOAMÉRICA Y EL CARIBE

92 APROVECHAMIENTO DE LAS FUENTES NO CONVENCIONALES DE ENERGÍA EN LA COSTA NORTE COLOMBIANA

99 CELDAS DE COMBUSTIBLE MICROBIANAS: DESARROLLO, APLICACIONES Y MEDIO AMBIENTE

105 ENERGÍA SOLAR EN LA CIUDAD DE QUIBDÓ: EXPERIENCIA EN SISTEMAS FOTOVOLTAICOS AUTÓNOMOS DE LA UNIVERSIDAD TECNOLÓGICA DEL CHOCÓ

113 ESTUDIO DE PRE FACTIBILIDAD PARA LA OBTENCION DE BIOETANOL COMBUSTIBLE DE SEGUNDA GENERACIÓN EN EL DEPARTAMENTO DE SANTANDER GENERACIÓN DISTRIBUIDA DE ENERGÍA ELÉCTRICA MEDIANTE ENERGÍA SOLAR FOTOVOLTAICA EN LA RED DE BAJA TENSIÓN DE LA UNIVERSIDAD DE BOGOTÁ JORGE TADEO LOZANO

134 MODELO DE SISTEMA SOLAR FOTOVOLTAICO PARA SUMINISTRO ELÉCTRICO BÁSICO COMO APOYO A PLAN NUTRICIONAL EN LA ESCUELA EL CARDONAL DE TIBANÁ (BOYACÁ)

\section{POLÍTICA Y EDUCACIÓN ENERGÉTICA}




\section{PRÓLOGO}

Han transcurrido dos años desde que se realizó la primera versión del Congreso de Energía Sostenible, y ello ha permitido la evolución de este evento que pretende ser el "evento energético más importante del país". En esta segunda versión se ha realizado nuevamente un trabajo intenso para alcanzar diversos sectores del país y del exterior, por lo cual se ha consolidado bajo el nombre de II Congreso Internacional de Energía Sostenible, como intento por demostrar que es posible encontrar intereses comunes a distintos profesionales y estudiantes alrededor del tema energético.

Este congreso promueve la utilización de diversas formas energéticas. No se afirma la superioridad de ninguna de las posibles fuentes de energía, ya que todas son valoradas por igual y pueden contribuir con soluciones particulares en distintos escenarios. En esta vía el congreso pretende ser una valiosa oportunidad para formar conciencia sobre la importancia de incrementar el acceso sostenible a la energía, el aprovechamiento de nuevos recursos naturales, la eficiencia energética y la energía renovable en el ámbito local, nacional, regional e internacional, ya que los servicios energéticos tienen un profundo efecto en la productividad, la salud, la educación, el cambio climático, la seguridad alimentaria e hídrica y los servicios de comunicación. La falta de acceso a la energía no contaminante, asequible y fiable, obstaculiza el desarrollo social y económico, y constituye un freno importante para el logro de los Objetivos de Desarrollo del Milenio.

La presencia de los invitados nacionales e internacionales constituye un punto de referencia para la generación de debate y discusión alrededor de saberes que siempre son problematizados. De esta manera la dinámica misma del congreso contribuye con el fortalecimiento de lazos y redes que consolidan la investigación a nivel interdisciplinario, interinstitucional e intersectorial. Fue precisamente en este Congreso donde se consolidó la Red de Energía Sostenible, como un esfuerzo por desarrollar proyectos conjuntos alredededor del tema energético con una visión de sostenibilidad y sustentabilidad.

Sumado a la grata experiencia de los invitados nacionales e internacionales, el evento es enriquecido por las presentaciones orales y pósters que actualizan el quehacer investigativo de las distintas Universidades, Empresas y Centros de Desarrollo Tecnológico. Es grato poder ver el ramillete de resúmenes enviados, la alta calidad de todos ellos, el esfuerzo por alcanzar estándares cada vez más altos y el compromiso en desarrollar el sector energético en el país. Agrupados en 4 líneas temáticas: política y educación energética, eficiencia y auditoría energética, energías alternativas y biomasa- bioenergía-biocombustibles ha buscado acoger todos los resúmenes realizados al interior de una sociedad que reflexiona y busca nuevas alternativas energéticas.

Este compendio de los resúmenes presentados en el II Congreso Internacional de Energía debe servir como referente para la consolidación de nuevas propuestas, que propendan por hacer una sociedad más equitativa en la administración de tan valioso recurso, como lo es la energía. Además debe ser el punto de partida para la presentación de nuevos trabajos investigativos en lo que será el III Congreso de Energía Sostenible en el año 2016. 



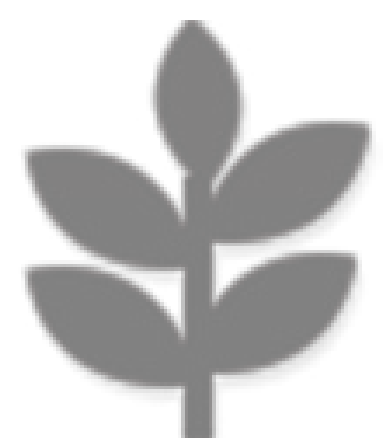

BIOMASA, BIOENERGÍA
Y BIOCOMBBUSTIBLES 


\title{
Biomasa y Biocombustibles en Latinoamérica y El Caribe (LAC)
}

\author{
E. Urresta ${ }^{1}$, P. Medina ${ }^{1}$, S. Quinchiguango ${ }^{1}$, D. Rodriguez ${ }^{1}$ \\ ${ }^{1}$ Instituto Nacional de Eficiencia Energética y Energías Renovables, Av. 6 de diciembre \\ N33-32 e Ignacio Bossano, Quito, Ecuador.
}

\begin{abstract}
RESUMEN
Como fuente de energía, la biomasa se puede utilizar directamente para generar calor mediante su combustión, o indirectamente a través de su conversión en biocombustibles (pirolisis, gasificación y digestión anaerobia). Las ventajas que la biomasa tiene sobre las energías no renovables son, el gran potencial para la reducción de las emisiones de gases de efecto invernadero, el incentivo al crecimiento de la agricultura y la disminución en la dependencia de combustibles fósiles. El incremento en el precio del petróleo ha renovado el interés en las energías renovables, en este sentido, la comercialización mundial de los combustibles provenientes de la biomasa fue 5 veces mayor en el 2010, en relación al año 2000. La biomasa contribuye con alrededor del $10 \%$ del consumo mundial de energía primaria, de este valor, casi las dos terceras partes son utilizadas por países en vías de desarrollo en actividades tradicionales como preparación de alimentos y calefacción. El resto, cerca del 38 \%, se destina a procesos denominados "modernos", como producción de electricidad, transporte terrestre, tecnologías de mayor eficiencia y temperatura de calentamiento. La investigación y el desarrollo sobre biocombustibles se distribuyen irregularmente en LAC, Brasil lidera estas iniciativas con la producción de bioetanol, superado en el continente únicamente por Estados Unidos; en Colombia existe también un gran esfuerzo de investigación con el apoyo del sector público y privado, al igual que en Argentina, donde el sector privado creó un centro de investigación. Costa Rica se ha sumado a estas actividades con un promisorio plan sobre el aprovechamiento del etanol. Para el resto de países de la región, los biocombustibles no son una prioridad. Un proyecto de gran impacto, aunque no involucra la generación a gran escala de biodiesel, se desarrolla en las Islas Galápagos, Ecuador; donde mediante la ejecución de la política "cero combustibles fósiles en Galápagos", se instalaron en la Isla Floreana dos grupos electrógenos que operan con aceite de piñón y cubren la totalidad del consumo eléctrico. En LAC, el principal productor de bioetanol es Brasil, con el $45 \%$ de la producción mundial en el 2006; seguido por Colombia, con un 0.5 \% de la producción mundial. Las condiciones necesarias para el crecimiento sostenible de la industria de los biocombustibles están presentes en LAC, abundante tierra cultivable, buenas condiciones climáticas y grandes cantidades de materia prima, hacen de la región un mercado potencial de importancia a nivel global.
\end{abstract}

Palabras clave: Biomasa en (LAC), Biocombustibles, Energías Alternativas. 


\title{
AMPLIFICACIÓN Y CLONACIÓN DE LOS GENES QUE CODIFICAN PARA LA ENZIMA GLICEROL DESHIDRATASA (dhaB1) Y SU PROTEÍNA ACTIVADORA (dhaB2) A PARTIR DE UNA CEPA NATIVA DE Clostridium sp.
}

\author{
Andrea Jaramillo Mesa ${ }^{1,2}$ \\ Bernal Morales Jose Mauricio ${ }^{1}$ \\ Montoya Castaño Dolly ${ }^{1}$ \\ ${ }^{1}$ Universidad del Bosque \\ ªndrea9jaramillo@hotmail.com
}

\begin{abstract}
RESUMEN
El biodiesel es obtenido a partir del proceso de transesterificación de aceites vegetales y metanol, originando glicerol como principal subproducto. Existen muchas formas de transformar el glicerol crudo en sustancias de mayor valor agregado y así darle mayor rentabilidad a la producción del biocombustible. Una de ellas, es usar la glicerina proveniente del proceso de transesterificación para que a través de un paso de fermentación pueda ser convertida en 1,3-Propanodiol. El 1,3-PD se ha sintetizado tradicionalmente por vías químicas como la hidrólisis de la acroleina y la reacción de etileno con monóxido de carbono e hidrógeno. Sin embargo, estas rutas suelen ser altamente costosas para la industria además de generar desechos tóxicos. Por esto, se ha incrementado el interés para investigar la conversión de glicerol a 1,3-PD hecha por diferentes especies de organismos. Este proceso biotecnológico representa una alternativa viable y más económica en comparación con procesos de tipo químico. El paso limitante en la ruta metabólica de glicerol a 1,3-Propanodiol es la conversión de glicerol en 3-hidroxipropionaldehído que es catalizado por la enzima Glicerol deshidratasa. Como consecuencia para llevar a cabo el presente estudio, se trabajó como punto de partida con la cepa Clostridium sp. IBUN 158B, perteneciente al banco de cepas y genes del IBUN, de la cual se extrae el ADN total y se amplifica mediante la técnica PCR de los genes que codifican para la enzima (dhaB1) y su proteina activadora (dhaB2). Se realizó previamente el diseño de primers específicos para dichas secuencias y la estandarización de la técnica. Una vez obtenido el amplímero, se determinó su tamaño utilizando enzimas de restricción (RFLP-PCR), comprobándose que el producto alcanzó las expectativas propuestas. Finalmente, el amplimero fue introducido en un vector de clonación

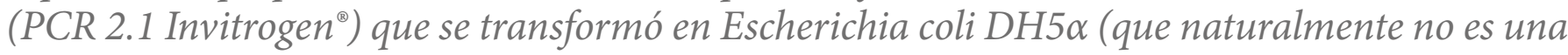
cepa productora de esta enzima) efectuándose así la clonación.
\end{abstract}

Palabras claves: Glicerol deshidratasa, Clostridium, PCR y Clonación. 


\section{INTRODUCCIÓN.}

En la actualidad alrededor del 90\% de la energía utilizada a nivel mundial proviene de los combustibles fósiles y de la energía nuclear. Estas reservas naturales de combustible fósil no son permanentes, es decir que su existencia en la naturaleza es limitada y además contaminante. A mediados del siglo XX, debido al aumento de la población y la alta producción industrial, la comunidad general empieza a preocuparse por el agotamiento de estas reservas de petróleo y por el deterioro ambiental. Es así, como del desarrollo de energías alternativas hechas a partir de recursos naturales renovables y más amigables con el medio ambiente han surgido productos como el biodiesel (Lede, 2007).

El biodiesel es obtenido a partir del proceso de transesterificación de aceites y metanol, originando glicerol como principal subproducto. En su producción, se generan como residuo, 10 toneladas de glicerol crudo por cada 100 toneladas de aceite utilizado (Zappi et al., 2003). Colombia desde el año 2007, ha iniciado la producción de biodiesel a partir de aceite de palma, y para el año 2012 programó producir 600 mil toneladas para consumo interno y exportaciones (Montoya, 2006).

Existen muchas formas de transformar el glicerol crudo en sustancias de mayor valor agregado y así darle mayor rentabilidad a la producción del biocombustible. Una de ellas, es usar la glicerina proveniente del proceso de transesterificación para que a través de un paso de fermentación pueda ser convertida en 1,3-Propanodiol, el cual, entre múltiples aplicaciones en la industria química, es usado como monómero de un nuevo poliéster; politrimetilentereftalato (PTT) (Montoya).

El 1,3-PD se ha sintetizado tradicionalmente por vías químicas como la hidrolisis de la acroleína y la reacción de etileno con monóxido de carbono e hidrógeno. Sin embargo, estas rutas suelen ser altamente costosas para la industria además de generar desechos tóxicos (Pérez). Por esto, se ha incrementado el interés para investigar la conversión de glicerol a 1,3-PD hecha por diferentes especies de organismos (vía biotecnológica) (Cárdenas et al., 2006), conociéndose hasta el momento que muy pocos, todos ellos bacterias, en su metabolismo son capaces de formarlo (Biebl et al., 1999).

Los microorganismos utilizados para producir 1,3-PD a partir de glicerol son las bacterias pertenecientes a los géneros Klebsiella (K. pneumoniae), Enterobacter (E. agglomerans) y Citrobacter (C. freundii), lactobacilos (L. brevis y L. buchneri) y clostridios como la especie C. butyricum y el grupo C. pasteurianum (Biebl et al., 1999). Especies clostridiales no patógenas tales como la especie C. butyricum, crecen en glicerol formando el 1,3-PD (Saxena et al., 2009).

Resultando que las enzimas involucradas en el metabolismo de glicerol, usado por estos microorganismos como sustrato para la producción de 1,3-PD, sean la Glicerol deshidratasa, 1,3-Propanodiol oxidorreductasa, Glicerol deshidrogenasa y Dihidroxiacetona-fosfato-quinasa (Saxena et al., 2009).

En la ruta metabólica el paso limitante de glicerol a 1,3PD es la conversión de glicerol en 3-hidroxipropionaldehído que es catalizado por la enzima Glicerol deshidratasa. En este paso se produce un radical intermediario que suele involucrar a la coenzima B12 como cofactor. La glicerol deshidratasa de Clostridium butyricum es una excepción en dicha familia enzimática, ya que está compuesta por sólo una subunidad y no requiere coenzima B12 como cofactor (Montoya et al., 2006). Esta enzima requiere de un cofactor diferente denominado SAM (S-adenosil-metionina) $(\mathrm{Cu}-$ caita, 2010).

Es así como se evidencia la relevancia de la enzima Glicerol deshidratasa en este proceso pues, de su expresión depende toda la ruta, permitiendo la conversión de glicerol en 3-hidroxipropionaldehído en la ruta bioquímica de producción de 1,3-PD (Montoya et al., 2006). Por esto, el objetivo del presente estudio es amplificar y clonar los genes que codifican para la enzima Glicerol deshidratasa (dhaB1) y su proteína activadora (dhaB2) a partir de una cepa nativa de Clostridium sp. productora de solventes.

\section{MATERIALES Y MÉTODOS.}

Como punto de partida para llevar a cabo este proceso, se trabajó con la cepa Clostridium sp. IBUN 158B que produce 1,3-PD, a la cual se le determinó la existencia del gen en estudios previos (Montoya, 2008). Esta cepa, fue previamente recuperada en medio $\mathrm{RCM}^{\circledast}$ en condiciones de anaerobiosis para garantizar la viabilidad de las células ha trabajar.

Seguido a esto, se realizó la extracción de su ADN total (Jaimes et al., 2006) para proceder a la amplificación de los genes que codifican para la enzima Glicerol deshidratasa (dhaB1) y su proteína activadora (dhaB2) mediante la reacción en cadena de la polimerasa (PCR). Para ello, se contó con un previo diseño de primers específicos para dicha secuencia.

Durante el proceso de amplificación, se realizaron varios ensayos para estandarizar la técnica PCR obteniéndose las siguientes condiciones: .

\begin{tabular}{|c|c|}
\hline Reactivos & $\begin{array}{c}\text { Concentración inicial } \\
\text { (para un Vol final 25ul) }\end{array}$ \\
\hline MgCl2 & $3 \mathrm{mM}$ \\
\hline TAQ polimerasa & $2.5 \mathrm{U} / \mu \mathrm{L}$ \\
\hline Buffer & $1 \mathrm{X}$ \\
\hline dNTPS & $0.25 \mathrm{mM}$ \\
\hline Primer A1 & $1 \mu \mathrm{L}$ \\
\hline Primer H1 & $1 \mu \mathrm{L}$ \\
\hline ADN & $100-200 \mathrm{ng} / \mu \mathrm{L}$ \\
\hline
\end{tabular}




\begin{tabular}{|c|c|c|c|c|c|c|}
\hline & $1 \mathrm{X}$ & \multicolumn{3}{|c|}{$30 \mathrm{X}$} & \multicolumn{2}{c|}{$1 \mathrm{X}$} \\
\hline Temperatura & $94^{\circ} \mathrm{C}$ & $94^{\circ} \mathrm{C}$ & $57^{\circ} \mathrm{C}$ & $72^{\circ} \mathrm{C}$ & $72^{\circ} \mathrm{C}$ & $8^{\circ} \mathrm{C}$ \\
\hline Tiempo & $4: 00 \mathrm{~min}$ & $0: 15 \mathrm{seg}$ & $0: 30 \mathrm{seg}$ & $4: 00 \mathrm{~min}$ & $4: 00 \mathrm{~min}$ & $\infty$ \\
\hline
\end{tabular}

Tabla 1. Estandarización de la técnica PCR, para un volumen final de la mezcla igual a $25 \mu \mathrm{l}$ y su respectivo ciclo para la amplificación de los genes dhaB1 y dhaB2.

Una vez se obtuvo la amplificación de los genes previamente mencionados, se realizó la purificación de las muestras utilizando un kit QIAquick PCR Purification Kit (50), para luego cuantificarlas por medio de la técnica de cuantificación visual que permite observar los $\mathrm{ng} / \mu \mathrm{l}$ de una muestra de ADN por una reacción de fluorescencia entre esta y el colorante.

El tamaño del amplímero se corroboró utilizando enzimas de restricción (RFLP-PCR), comprobándose que fuera el fragmento del tamaño esperado. Para dicha digestión, a un tubo eppendorf de $1.5 \mu \mathrm{l}$ se le agregó una muestra de ADN amplificado y purificado, un buffer de reacción (10X) y la enzima EcoRI, dejándola actuar durante 12 horas a $37^{\circ} \mathrm{C}$

Los puntos de corte de la enzima $(315,755,2074$ y 2238 $\mathrm{pb}$ ), previamente analizados de acuerdo a la secuencia que codifica para los genes de interés en bases de datos del NCBI e Insilico, se observaron separando el resultado de la digestión en un gel de agarosa al 1.5\% teñido con SYBR Safe.

Para llevar a cabo el proceso de ligación a un vector de clonación (PCR 2.1 Invitrogen ${ }^{\oplus}$ ), se utilizaron 100ng del amplimero (genes dhaB1 y dhaB2) y dicho vector, incubándose a $14^{\circ} \mathrm{C}$ durante 12 horas.

Una vez incertado el amplímero en el vector, se dio paso a la preparación de las células competentes, siendo sometidas a tratamientos con $\mathrm{CaCl} 2$, solución que permite que la membrana celular de paso al plásmido (PCR 2.1 Vector de Invitrogen) y se lleve a cabo la transformación. Para ello se trabajó con la cepa Escherichia coli DH5a, pues no contiene los genes que codifican para las enzimas previamente mencionadas (Ausubel et al., 2002).

La efectividad de la transformación de las células se determinó sembrando la cepa E. coli DH5a en medio LB con ampicilina, vector que presenta resistencia, de tal forma que una vez incubada la cepa durante 16 horas a $37^{\circ} \mathrm{C}$, se realizará el conteo de colonias para constatar la efectividad del procedimiento.

De igual forma, a la cepa transformada se le realizó extracción plasmídica utilizando el kit Plasmid Miniprep Kit 1 D6942-00 de Omega bio-tek, separándose en un gel de agarosa al $1.2 \%$ teñido con $\mathrm{SYBR}^{\oplus}$ Safe, para así comprobar que el vector de transformación estuviera dentro de la célula E. coli DH5a, junto con la observación del tamaño esperado.

\section{RESULTADOS}

El microorganismo fue recuperado exitosamente dentro de sus condiciones óptimas de crecimiento, logrando extraer ADN limpio con una concentración final de $200 \mathrm{ng} / \mu \mathrm{l}$. Por otra parte, la amplificación de los genes dhaB1 y dhaB2 mediante la técnica PCR contó con un total de 75 a $100 \mathrm{ng} /$ $\mu \mathrm{l}$ de amplímero, siendo el fragmento final de $3.782 \mathrm{pb}$.

$\mathrm{Al}$ correr los productos de reacción de la enzima de restricción, las bandas observadas en el gel tuvieron tamaños de 440, 1319, 164 y 1544 pb, correspondientes a los sitios de corte de la enzima descritos con anterioridad. De esta forma se rectificó que el tamaño esperado del amplímero inicialmente fue el obtenido.

Así mismo, la efectividad de la reacción de ligación se comprobó mediante un gel de agarosa teñido con SYBR Safe, observándose bandas correspondientes al tamaño del amplímero $(3.782 \mathrm{pb})$ más el tamaño del vector $(3.9 \mathrm{~Kb})$.

La transformación de las células pudo evaluarse mediante el conteo de colonias, pues al crecer en el medio LB con ampicilina, se observó un valor de aproximadamente 100 unidades formadoras de colonias para células transformadas y 5 unidades formadoras de colonias aproximadamente para las células no transformadas. Además los plásmidos extraídos se separaron en un gel de agarosa al 1,2\% teñido con $\mathrm{SYBR}^{\oplus}$ Safe para asegurar que el vector de transformación estuviera dentro de la célula $E$. coli. DH5a presentándose bandas de aproximadamente $7.682 \mathrm{pb}$ correspondiente al tamaño del vector una vez realizada la ligación. Es así, como finalmente, las estrategias de ligación y transformación arrojaron resultados positivos.

\section{CONCLUSIONES}

Fue posible clonar los genes que codifican para la enzima Glicerol deshidratasa (dhaB1) y su proteína activadora (dhaB2) en una cepa de E. coli DH5a que no tiene dentro de su genoma estos genes.

Al contar con primers específicos para el fragmento correspondiente a los genes de interés no fue necesario realizar su secuenciación; comprobándose que el producto de amplificación fue el esperado por medio de enzimas de restricción (RFLP-PCR), método que es más rápido e igualmente efectivo.

\section{REFERENCIAS}

Ausubel, F.M., Brent R., Kingston R.E., Moore D.D., Seidman J.G., Smith J.A., Struhl K. (2002). Short Protocols in Molecular Biology. a Compendium of Methods from Current Protocols in Molecular Biology. Published by John Willey \& Sons, Inc. Canada. (1), 3-32 UNIT 3.11. 
Biebl H., Menzel K., Zeng A.P., Deckwer W.D. (1999). Microbial Production of 1,3-propanediol, Appl Microbiol Biotechnol 52: 289-297, Mini review, @Springer-Verlag.

Cárdenas D.P., Pulido C., Aragón O.L., Aristizábal F.A., Suárez Z.R. y Montoya Dolly, (2006). Evaluación de la Producción de 1,3-propanodiol por Cepas nativas de Clostridium sp. Mediante Fermentación a partir de Glicerol USP y Glicerol Industrial Subproducto de la Producción de Biodiésel. Rev. Col. Cienc. Farm. 35(1), 120 - 137.

Cucaita, N.A. (2010). Separación y Caracterización Bioquímica de la Enzima 1,3-Propanodiol oxidorreductasa Proveniente de una Cepa Nativa de Clostridium spp IBUN 158, (Tesis de Master Scientae en Microbiología). Universidad Nacional de Colombia Sede Bogotá D.C., Instituto de Biotecnología.

INVITROGEN ${ }^{\oplus}$, (2009). Quant-iT Assays. Abbreviated Protocol. Recuperado de http://tools.lifetechnologies.com/ content/sfs/manuals/mp39808.pdf.

Jaimes C.P., Aristizábal F.A., Bernal J.M., Suárez Z.R. y Montoya D. (2006). AFLP fingerprinting of Colombian Clostridium spp strains, 3 multivariate data analysis and its taxonomical implications. Journal of Microbiological Methods. ELSEVIER. MIMET-02463; No of Pages 6.

Lede S., (2007). Los Biocombustibles, FCEyN UBA, Consejo Argentino para la Información y el Desarrollo de la Biotecnología (ArgenBio), Argentina.

Montoya D. (2006) Producción de 1,3-Propanodiol a partir de la industria de biodiesel. Rev. Colomb. Biotecnol. 10(1), 139-142.
Montoya D. Producción de 1,3-Propanodiol (1,3-PD) a partir de Glicerol Industrial Proveniente de la Industria de Biodiesel con Nuevas Cepas Colombianas de Clostridium sp. Resumen ejecutivo. Grupo de Bioprocesos y Bioprospección. Instituto de Biotecnología. Universidad Nacional de Colombia. Sede Bogotá D.C.

Montoya J.D., (2008). Determinación de la Secuencia de Genes Putativamente Involucrados en la Producción de 1,3-Propanodiol en la Cepa Nativa Colombiana Clostridium sp. IBUN 158B (Tesis para optar al título de Magister en Microbiología). Universidad Nacional de Colombia. Sede Bogotá D.C.

Montoya, J.D., Suárez Z.R., Montoya D. y Aristizábal F.A. (2006). Bioinformatic Analysis and Gene Prediction in Genomic Sequences from Clostridium sp. IBUN 22A. Rev. Colomb. Biotecnol. VIII(1); 57-64.

Pérez A.D. 1,3-Propanodiol de Origen Petroquímico u Obtenido vía Catálisis Química y/o Bioquímica: Diferentes Productos Obtenidos por medio Catalítico o un Bioproceso. Universidad Nacional de Colombia.

Saxena R.K., Anand P., Saran S y Isar J. (2009). Microbial Production of 1,3-Propanediol: Recent Developments and Emerging Opportunities, Biotechnology Advances, Research review paper, Biotechnology Advances 27(2009) 895-913.

Zappi M., Hernandez R., Sparkz D., Horne J., Brough M., Arora S. y Montsenbacker D. (2003). A Review of the Engineering Aspects of the Biodiesel Industry. Mississippi Biomáss Council, MSU, Jackson, Mississippi, August, 2003. [Consulta: 2009-04-27]. Recuperado de http://www.mississippi.org/assets/docs/library/eng_aspects_ch1.pdf 


\title{
EVALUACIÓN DE UNA METODOLOGÍA DE COSECHA DE MICROALGAS PARA LA OBTENCIÓN DE METABOLITOS CON POTENCIAL DE VALOR
}

\author{
Ana Maria Ardila Alvarez ${ }^{1,2}$ \\ Nelson Mena López ${ }^{1}$ \\ Manuel Ortegón Díaz ${ }^{1}$ \\ Andrés Fernando Barajas Solano ${ }^{1}$ \\ Paola Andrea Sanguino Barajas ${ }^{1}$ \\ Viatcheslav Kafarov ${ }^{1}$
}

${ }^{1}$ Universidad Industrial de Santander

22mona1any@hotmail.com

\begin{abstract}
RESUMEN
En los últimos años se ha incrementado el uso de biocombustibles a partir de biomasa microalgal. Se conoce que uno de los retos a vencer en la producción de biocombustibles y coproductos de microalgas, consiste en la concentración o cosecha de la biomasa, dado que el proceso de cosecha aumenta entre 20-40\% el costo total de la producción. Por ello, es importante establecer las variables que intervienen en cada una de las etapas, hacer una selección adecuada de las operaciones unitarias, aumentar el volumen de cultivo, minimizar el consumo de energía, garantizar la mayor recuperación de biomasa y reducir los costos de operación. El presente estudio evaluó la implementación de una metodología de floculación de biomasa, teniendo en cuenta el efecto del $\mathrm{pH}$, la concentración de floculante (AlCl3) y la concentración de biomasa. Se realizó un pretratamiento del medio de cultivo para el ajuste del $\mathrm{pH}$ y se determinó la influencia del mismo en la velocidad de floculación antes de la adición del floculante. Posteriormente se llevó a cabo un análisis de cenizas con el fin de determinar la cantidad de floculante presente en la biomasa concentrada y en el medio de cultivo residual. Se evaluó la velocidad de floculación de la biomasa de Chlorellavulgaris, variando la concentración del floculante, la concentración de la biomasa y el pH del medio mediante un diseño experimental de composición central no factorial 33 de 17 pruebas utilizando el software STATISTICA 7.0. Los ensayos se realizaron en un volumen inicial de $100 \mathrm{ml}$ y se escaló hasta $500 \mathrm{ml}$. Los resultados mostraron el incremento de la recuperación de biomasa en los tratamientos realizados en medio básico $(p H=10)$, utilizando una relación (floculante/biomasa) de $100 \mathrm{mg} / \mathrm{l}$ de medio de cultivo.
\end{abstract}

Palabras claves: Microalga, AlCl3, pH, floculación, sedimentación, eficiencia. 


\section{INTRODUCCIÓN}

Las microalgas son una fuente atractiva y alternativa de metabolitos como lípidos, proteínas, carbohidratos, pigmentos y vitaminas, consideras un recurso valioso para la industria farmacéutica, alimentaria (Borowitzka, 1995 \&Borges et al. 2011) y para la producción de biocombustibles (Wijffels et al.2010, \&Chisti et al. 2007).

Según Chisti et al., (2007) las microalgas poseen la capacidad de producir más lípidos que la mayoría de plantas oleaginosas y debido a su alta eficiencia pueden llegar a suplir la demanda mundial de biodiesel. Sin embargo, para llevar a cabo la producción de biodisel a partir de microalgas primero, se necesita recuperar la biomasa del medio de cultivo utilizando varias tecnologías como la centrifugación (Knuckey, et al 2006), la filtración (Zhang et al., 2010), la flotación (Chen et al. 1998) y la floculación (Vandamme et al., 2013).

Uno de los puntos cruciales en la obtención sostenible de los diferentes subproductos es la reducción en el consumo energético en los diferentes procesos. (Greenwell et al., 2010. Para el caso de la concentración de biomasa, la floculación es la opción preferida, ya que: a) permite la recolección de biomasa en grandes cantidades y a bajo costo [2] y; b) es fácilmente escalable y se puede usar para una gran variedad de especies de microalga (Uduman et al., 2010). La floculación actúa en la agregación de células en suspensión a partículas más grandes cuando el floculante interactúa con la carga de superficie de las células, estas son neutralizadas, logrando su desestabilización y facilitando su sedimentación (Molina et al., 2003).

Se ha demostrado que la floculación por sales metálicas puede llevarse a cabo bajo condiciones ácidas o alcalinas (Wu et al., 2012). Wu et al. evaluaron la floculación inducida por aumento de $\mathrm{pH}$ en tres especies de microalgas de agua dulce y dos especies marinas, logrando una eficiencia superior al $90 \%$ en concentraciones medias y bajas de biomasa. Esto puede ser explicado debido a que en condiciones alcalinas, cationes de sales de magnesio presentes en el medio forman hidróxido de magnesio precipitado, el cual atrapa las células y facilita la sedimentación. Este fenómeno es conocido como floculación de barrido (Granados et al 2012., \&Gregory et al., 2001). En pH ácidos es preferible el uso de sales metálicas de hierro o aluminio y según Uduman et al. (Molina et al., 2003), el pH óptimo de floculación con aluminio para las microalgas oscila entre 5.3 y 5.6. Además, la efectividad de sedimentación con este tipo de coagulantes depende de la concentración de biomasa inicial y dosis de floculante (Wu et al., 2012).

Uno de los mayores inconvenientes del uso de estas sales es que requieren de altas concentraciones para llevar a cabo una floculación efectiva (Rwehumbiza et al., 2010) y, debido a su toxicidad generan riesgo de contaminación y pueden afectar la calidad de los lípidos extraídos.
Debido a que factores como el pH, la concentración de biomasa, el tipo y la cantidad de floculante empleado influyen en la eficiencia de la floculación de las microalgas y en la extracción (Wu et al., 2012, Gregory et al., 2001, Griffiths et al 2011), el objetivo de este trabajo fue evaluar el efecto de la floculación con sal metálica $\mathrm{AlCl} 3$ en la producción de lípidos para la especie de agua dulce C. vulgaris UTEX 1803, evaluando el escalamiento de estos efectos en el cultivo.

\section{MATERIALES Y MÉTODOS}

Chlorella vulgaris UTEX 1803 fue adquirida de la colección de cepas de la Universidad de Texas (Texas, USA) y fueron cultivadas en medio Bold Basal.

Para el desarrollo del diseño, se cultivaron microalgas con un inóculo de $1 \mathrm{~g} / \mathrm{l}$ de biomasa húmeda para C. vulgaris. Las microalgas se mantuvieron en crecimiento en reactores de vidrio de 12 litros. Los reactores se acoplaron a un sistema de aireación por burbujeo para la inyección de aire $\mathrm{y}$ tuvieron un ciclo luz-oscuridad 12:12h.

Para el diseño experimental se tomaron como referencia los datos de Garzón-Sanabria et al. (Garzon-Sanabria et al., 2012), y se utilizó el programa STATISTICA 7.0., basado en una composición central, factorial 33 de 17 experimentos (ver tabla 1). Este fue realizado para evaluar el efecto de la variables de tiempo de cultivo (5, 10 y 15 días), $\mathrm{pH}$ (4, 7 y 10) y concentración de floculante (50, 100 y $150 \mathrm{mg} / \mathrm{l})$.

Tabla 1. Diseño experimental

\begin{tabular}{|c|c|c|c|}
\hline Prueba & $\begin{array}{c}\text { Tiempo } \\
\text { Cultivo (días) }\end{array}$ & $\begin{array}{c}\text { Dosis de } \\
\text { floculante } \\
(\text { mg/l) }\end{array}$ & $\mathrm{pH}$ \\
\hline 1 & 1,63 & 100 & 7 \\
\hline 2 & 5 & 50 & 4 \\
\hline 3 & 5 & 50 & 10 \\
\hline 4 & 5 & 150 & 4 \\
\hline 5 & 5 & 150 & 10 \\
\hline 6 & 10 & 16,3 & 7 \\
\hline 7 & 10 & 100 & 1,9 \\
\hline 8 & 10 & 100 & 7 \\
\hline 9 & 10 & 100 & 7 \\
\hline 10 & 10 & 100 & 7 \\
\hline 11 & 10 & 100 & 7 \\
\hline 12 & 10 & 183,6 & 4 \\
\hline 13 & 15 & 50 & 10 \\
\hline 14 & 15 & 50 & 7 \\
\hline 15 & 15 & 100 & \\
\hline 16 & 15 & 100 & 10 \\
\hline 17 & 18,3 & 100 & \\
\hline
\end{tabular}

\section{Experimentación para las mejores condi- ciones de floculación}

Determinadas las mejores condiciones de floculación mediante el diseño experimental, se evaluó el escalamiento del proceso en volúmenes de cultivo de 250, 500 y 1000ml. 
Al volumen de $1000 \mathrm{ml}$ se le separó la biomasa floculada del sobrenadante por medio de decantación para llevarla al proceso de extracción de lípidos.

\section{Influencia de la cantidad de metales y otros químicos presentes en la floculación}

Para ajustar el pH, se requirió el uso de floculante y otros compuestos que contienen hidróxidos, sales metálicas y otros componentes químicos que hicieron necesario realizar el procedimiento de cenizas para determinar la influencia de los mismos en el proceso. Primero, se pesaron crisoles vacíos. Luego, se tomaron muestras de sobrenadante y de biomasa floculada para depositarlas en los crisoles y pesarlos nuevamente. También, se tomaron muestras de control con biomasa y sobrenadante sin floculante. Las muestras se llevaron al horno por 24 horas a $105^{\circ} \mathrm{C}$ y luego a un horno mufla para la obtención de cenizas. En este punto, primero, se calentaron las muestras a $105^{\circ} \mathrm{C}$ por 12 minutos, luego a $250^{\circ} \mathrm{C}$ por 30 minutos y por último, a $575^{\circ} \mathrm{C}$ por 180 minutos. Finalmente, las cenizas se pesaron y se realizó el correspondiente balance:

$$
\% \text { Cenizas }=\frac{(\text { Masa del crisol }+ \text { Masa de cenizas })-(\text { Masa del crisol })}{\text { Masa de la muestra inicial }} \times 100
$$

\section{RESULTADOS}

Con el diseño planteado, se lograron varios experimentos con eficiencias por encima del 95\%. Según los datos encontrados (ver tabla 2), los resultados más relevantes son la prueba 8 con una recuperación del 99,5\% y la prueba 17 con un $99,7 \%$ de eficiencia. Ya que las condiciones de $\mathrm{pH}$ y concentración de floculante fijadas inicialmente son las mismas para ambas, se tomó como sobresaliente la prueba 17 por su mejor recuperación de biomasa. Este experimento tiene como característica más días de cultivo (18 días) y su $\mathrm{pH}$ permanece neutro. Para todas las pruebas al finalizar el proceso, el valor de $\mathrm{pH}$ permaneció casi constante con respecto al pH fijado al inicio de la floculación.

Tabla 2. Eficiencia de la floculación y pH al finalizar el proceso.

\begin{tabular}{|c|c|c|c|c|}
\hline Prueba & $\begin{array}{c}\text { Tiempo de } \\
\text { cultivo (días) }\end{array}$ & $\mathrm{AlCl}_{3}(\mathrm{mg} / \mathrm{l})$ & $\mathrm{pH}$ & Eficiencia (\%) \\
\hline 1 & 1,63 & 100 & 7,5 & 98,6 \\
\hline
\end{tabular}

\begin{tabular}{|c|c|c|c|c|}
\hline Prueba & $\begin{array}{l}\text { Tiempo de } \\
\text { cultivo (días) }\end{array}$ & $\mathrm{AlCl}_{3}(\mathrm{mg} / \mathrm{ll})$ & $\mathrm{pH}$ & Eficiencia (\%) \\
\hline 2 & \multirow{4}{*}{5} & 50 & 4,1 & 66,2 \\
\hline 3 & & 50 & 4,0 & 63,3 \\
\hline 4 & & 150 & 9,7 & 93,8 \\
\hline 5 & & 150 & 9,9 & 95,2 \\
\hline 6 & \multirow{7}{*}{10} & 16,3 & 7,4 & 98,9 \\
\hline 7 & & 100 & 2,0 & 78,6 \\
\hline 8 & & 100 & 6,6 & 99,5 \\
\hline 9 & & 100 & 6,6 & 99,5 \\
\hline 10 & & 100 & 6,6 & 99,5 \\
\hline 11 & & 100 & 11,8 & 97,7 \\
\hline 12 & & 183,6 & 7,2 & 99,1 \\
\hline 13 & \multirow{4}{*}{15} & 50 & 4,3 & 67,2 \\
\hline 14 & & 50 & 4,2 & 61,4 \\
\hline 15 & & 100 & 9,5 & 88,8 \\
\hline 16 & & 100 & 9,8 & 94,7 \\
\hline 17 & 18,3 & 100 & 7,5 & 99,7 \\
\hline
\end{tabular}

En los experimentos con pH 7 (Figura 1; (A), (C), (E)), los altos valores de eficiencia se deben a que en este caso la floculación se da por neutralización de cargas y también por una rápida formación de hidróxidos precipitados (Henderson et al., 2008). En los pH alcalinos (Figura 1; (B), (C), (D)), ocurre una alta remoción de células debido a que el uso de base para el ajuste de $\mathrm{pH}$ a estos valores, forma hidróxidos polinucleares de aluminio. Estos son producto de la neutralización de la sal de aluminio y reducen las cargas positivas de las partículas coloidales de hidróxido que puedan estar presentes, contribuyendo a la formación de hidróxidos precipitados (Duan et al., 2003). Este planteamiento es consistente con la experimentación realizada por Ohman\&Wagberg para la neutralización de aluminio adicionando base (Ohman et al., 1997), cuyas pruebas evidenciaron que por este método los sólidos sedimentables se forman a $\mathrm{pH} 7 \mathrm{y}$ a valores más altos. También, hay que tener en cuenta los estudios realizados por Henderson et al. 2008 quienes demostraron que no se necesita la neutralización de cargas para obtener eficiencias por encima del $90 \%$, permitiendo que la sedimentación se desarrolle principalmente por floculación de barrido. Estas pruebas se realizaron utilizando aluminio como coagulante para C. vulgaris. La eficiencia se ve disminuida en los pH ácidos (Figura 1; (B), (C), (D)) debido a que probablemente no se encuentran un valor de carga en donde la desestabilización de las células sea suficiente para dar altos valores de eficiencia. 
Figura 1. Comportamiento de C. vulgaris en la etapa de floculación para el diseño experimental. 1.63 días (A);

5 días (B); 10 días (C); 15 días (D); 18.36 días (E).

a)

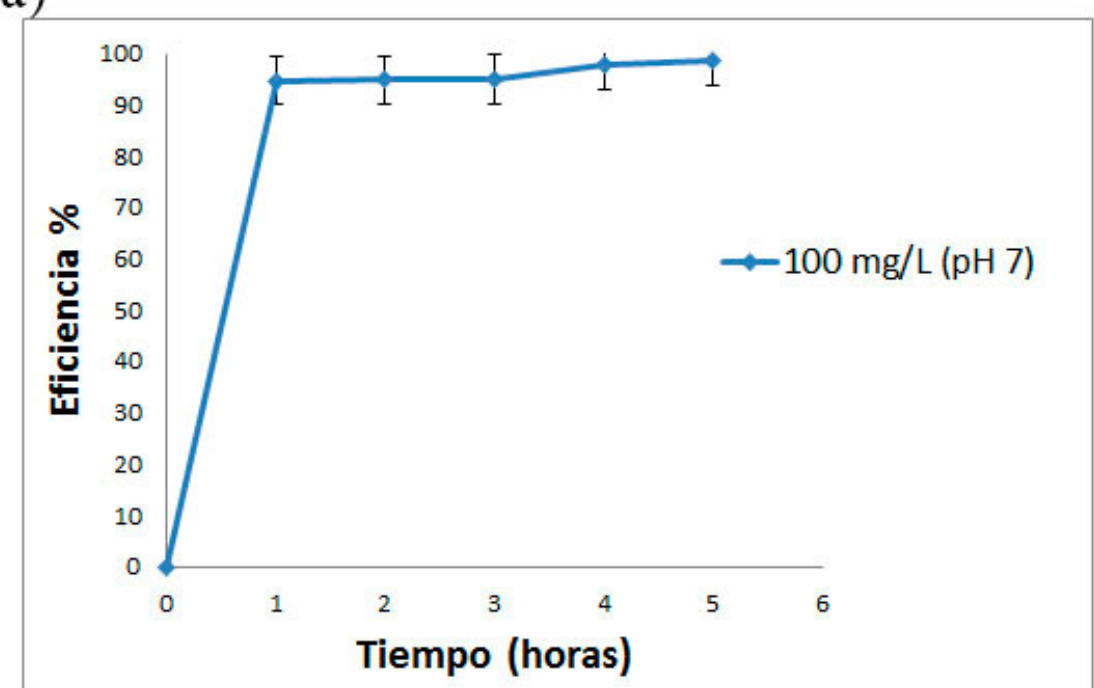

c)

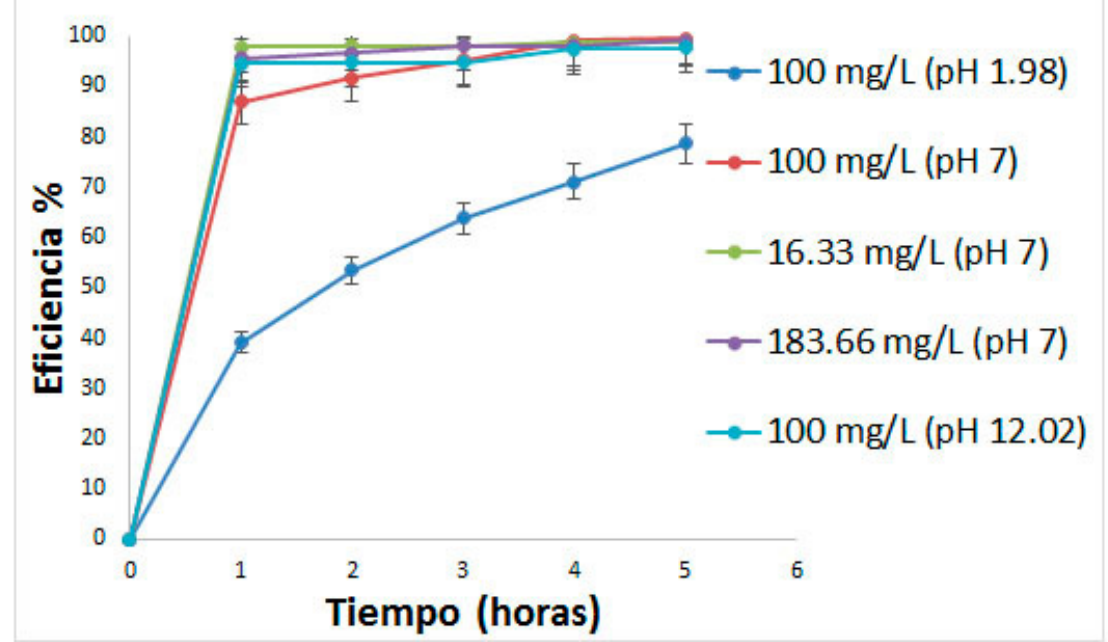

b)

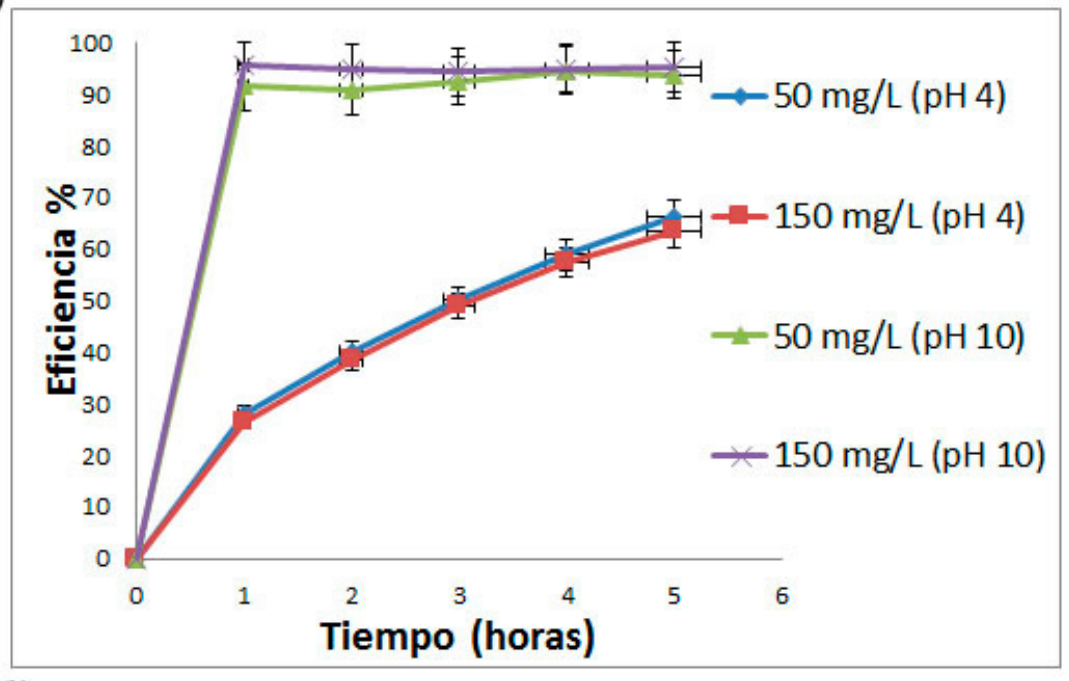

d)

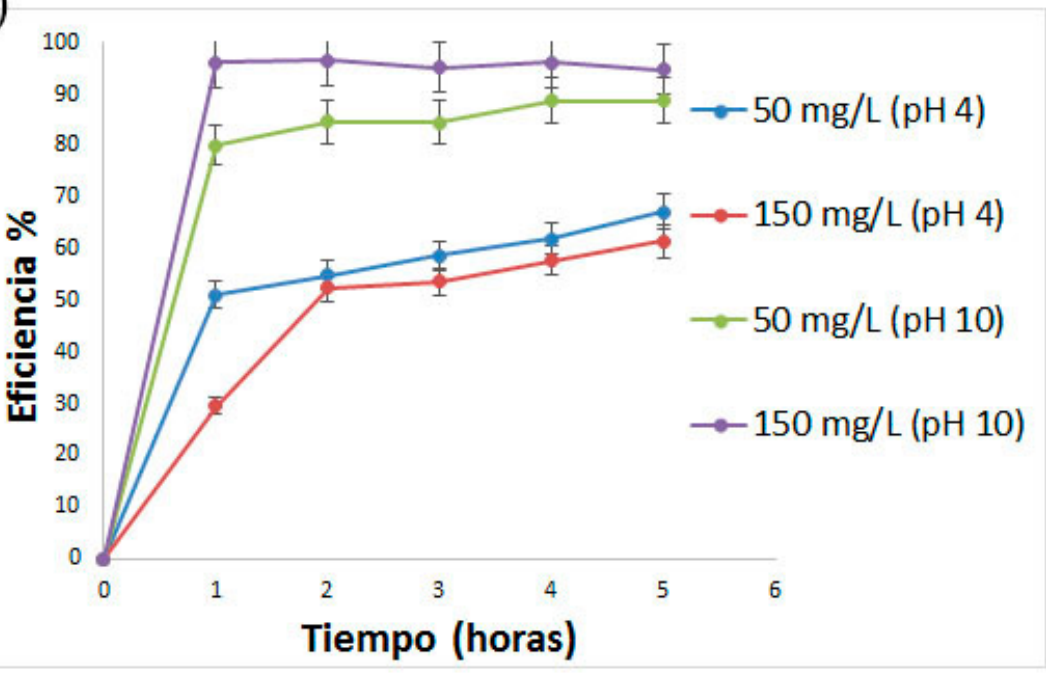

e)

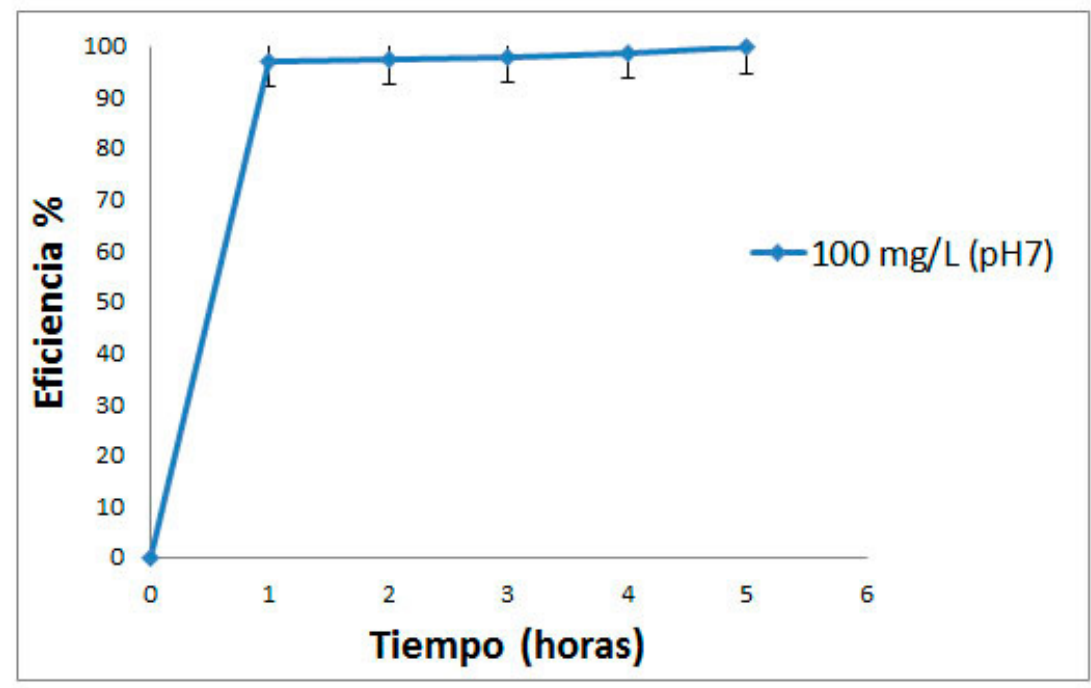




\section{ANÁLISIS ESTADÍSTICO}

Para poder ver la influencia de todas las variables evaluadas en el diseño experimental para la obtención de la mayor cantidad de biomasa recuperada, se desarrolló el diagrama de Pareto presentado en la Figura 2.

Figura 2. Diagrama de Pareto para la biomasa recuperada.

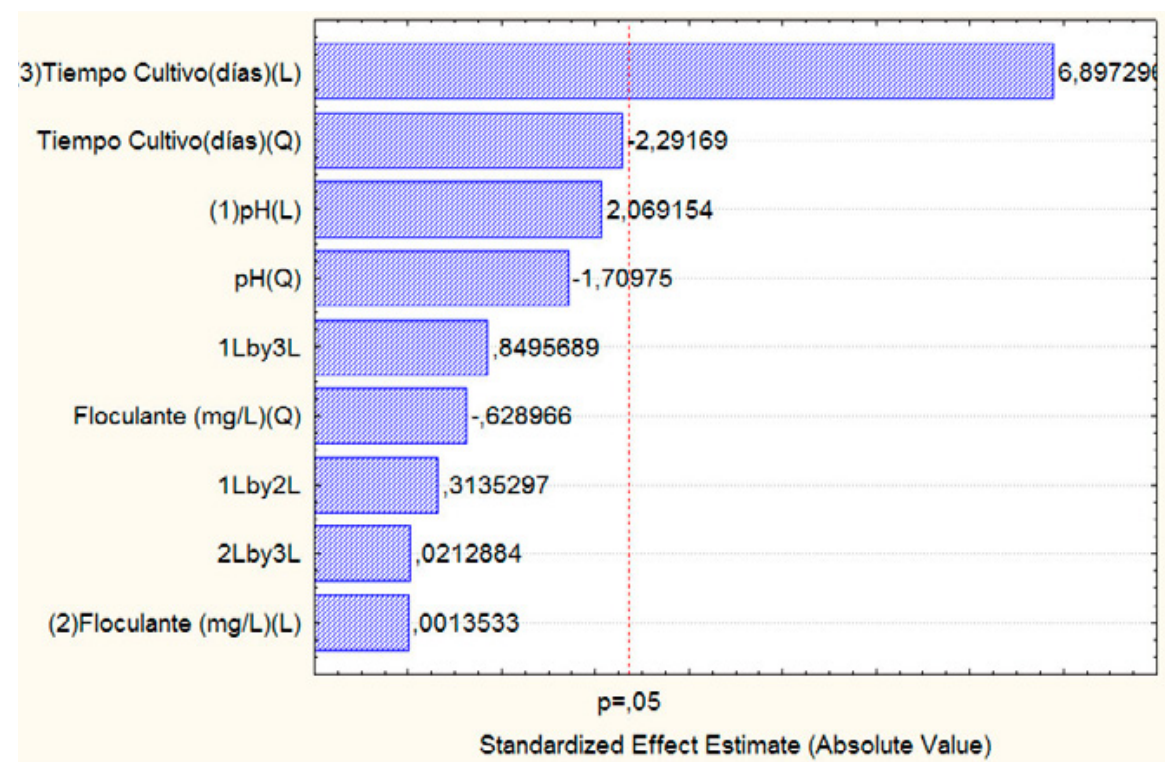

Según los resultados, la variable más significativa es el tiempo de cultivo, lo que nos lleva a deducir que la concentración de biomasa inicial es el factor más importante que influye en la cantidad de biomasa recuperada.

La superficie de respuesta (Figura 3) muestra que la mayor recuperación de biomasa para el diseño experimental se da en los tiempos más grandes y a un $\mathrm{pH}$ aproximadamente entre 7 y 14 .

Figura 3. Superficie de respuesta para la biomasa recuperada. $\mathrm{PH}$ vs Tiempo de cultivo.

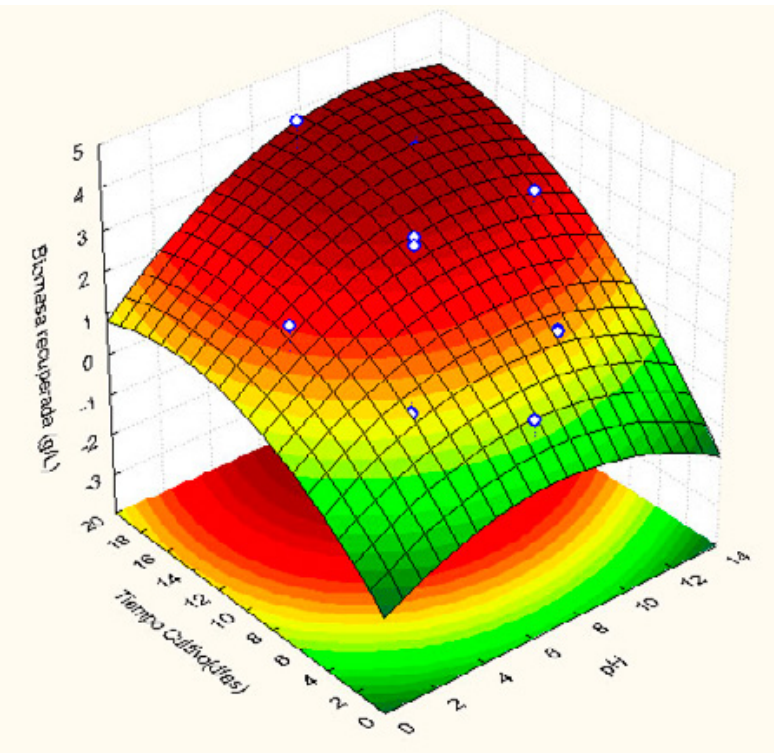

Como ya se mencionó, la mejor eficiencia de floculación fue la evaluada al día 18 de cultivo, a un $\mathrm{pH}$ de 7 y a una concentración de floculante de $100 \mathrm{mg} / \mathrm{l}$. Comparando este resultado con la superficie de respuesta, se encuentran en concordancia la cantidad de floculante empleado y el tiempo de cultivo además de que el $\mathrm{pH}$ se encuentra en el rango obtenido.

\section{Evaluación de la floculación para las me- jores condiciones a diferentes volúmenes de muestra}

Con la experimentación realizada las mejores condiciones, se demuestra que el proceso es fácilmente escalable a volúmenes más grandes que $100 \mathrm{ml}$ sin que haya cambios significativos en la eficiencia de floculación. La tabla 3 muestra que los valores de eficiencia son invariables para todos los volúmenes evaluados y tienen una recuperación de más del 99\%.

Tabla 3. Eficiencia de floculación y cantidad de biomasa recuperada para distintos volúmenes de muestra.

\begin{tabular}{|c|c|c|}
\hline Volumen $(\mathbf{m l})$ & Eficiencia $(\%)$ & Biomasa recuperada $(\mathrm{g} / \mathrm{l})$ \\
\hline 100 & 99,7 & 4,2 \\
\hline 250 & 99,5 & 4,2 \\
\hline 500 & 99,5 & 4,2 \\
\hline 1000 & 99,6 & 4,2 \\
\hline
\end{tabular}

\section{Metales e hidróxidos presentes en la flocu- lación}

El contenido de cenizas no es afectado en diferentes volúmenes de muestra. El aumento de las cenizas, en comparación con la muestra de control, es debido al uso de floculante para el proceso y de hidróxido se sodio para el acondicionamiento de $\mathrm{pH}$. Se encontró mayor cantidad de cenizas en la biomasa que en el sobrenadante de las muestras floculadas debido a la precipitación de hidróxidos responsables de la sedimentación de las células.

Tabla 4. Porcentaje de cenizas presentes en las muestras a volúmenes variados.

\begin{tabular}{|c|c|c|c|}
\hline \multirow{2}{*}{$100 \mathrm{ml}$} & $\begin{array}{c}\text { Muestra floculada } \\
\text { \% cenizas }\end{array}$ & $\begin{array}{c}\text { Muestra de } \\
\text { control \% cenizas }\end{array}$ \\
\cline { 2 - 4 } & Sobrenadante & 0,18 & 0,02 \\
\hline \multirow{2}{*}{$250 \mathrm{ml}$} & biomasa & 0,40 & 0,08 \\
\cline { 2 - 4 } & Sobrenadante & 0,15 & 0,02 \\
\hline \multirow{2}{*}{$500 \mathrm{ml}$} & biomasa & 0,32 & 0,08 \\
\cline { 2 - 4 } & Sobrenadante & 0,16 & 0,02 \\
\hline \multirow{2}{*}{$1000 \mathrm{ml}$} & biomasa & 0,35 & 0,08 \\
\cline { 2 - 4 } & Sobrenadante & 0,16 & 0,02 \\
\hline
\end{tabular}

\section{CONCLUSIONES}

Ajustar el pH después de adicionar floculante es el mejor método para lograr altas eficiencias de floculación

La floculación disminuye el costo de recuperación de la biomasa debido a que presenta una recuperación mayor al $90 \%$.

Para obtener la mejor eficiencia de floculación, el proceso debe aplicarse a la mayor concentración de biomasa. De esta manera, se recuperó para C. vulgaris hasta un 99,7\% de biomasa de los medios de cultivo, usando $\mathrm{AlCl} 3$ como floculante. 
Con el presente trabajo se pudo reducir el tiempo, el costo y la energía empleada en la recuperación de biomasa y los metabolitos de valor agregada.

\section{AGRADECIMIENTOS}

Este trabajo se realizó en el Centro de Investigación para el Desarrollo Sostenible de la Industria y la Energía (CIDES) de la escuela de Ingeniería Química de la Universidad Industrial de Santander con apoyo del Proyecto titulado Creación y fortalecimiento de una red de transferencia de conocimiento y tecnología entre Estados Unidos y Colombia mediante el desarrollo de procesos de biorefinería para la obtención de biocombustibles y productos de alto valor agregado a partir de biomasa de microalgasy financiado por el Departamento Administrativo de Ciencia, Tecnología e Innovación (COLCIENCIAS) y la Universidad Industrial de Santander (UIS).

\section{REFERENCIAS}

Borowitzka. (1995). Microalgae as sources of pharmaceuticals and other biologically active compounds. J. Appl. Phycol, 7, 3-15.

Borges, L., Morón -Villarreyes, J. A., Montes D’Oca, M. G., Abreu, P. C. (2011). Effects of flocculants on lipid extraction and fatty acid composition of the microalgae Nannochloropsisoculata and Thalassiosiraweissflogii.Biomass and bioenergy, 35, 4449-4454.

Wijffels, R.H., Barbosa, M.J., (2010). An outlook on microalgal biofuels.Science, 329, 796-799.

Chisti, Y., (2007). Biodiesel from microalgae.Biotechnol. Advances, 25, 294-306.

Knuckey, R.M., Brown, M.R., Robert, R., Frampton, D.M.F., (2006). Production of microalgal concentrates by flocculation and their assessment as aquaculture feeds. Aquacult. Eng, 35 (3), 300-313.

Zhang, Y., Tian, J.Y., Nan, J., Gao, S.S., Liang, H., Wang, M.L., Li, G.B., (2010). Effect of PAC addition on immersed ultrafiltration for the treatment of algal-rich water. J. Hazard. Mater, 186, 1415-1424.

Chen, Y.M., Liu, J.C., Ju, Yih-Hsu., (1998). Flotation removal of algae from water. Colloids and Surfaces B: Biointerfaces, 12, 49-55.

Vandamme, D., Foubert, I., Muylaert, K. (2013). Flocculation as a low-cost method for harvesting microalgae for bulk biomass production. Trends in Biotechnology, xx, 1-7.
Greenwell, H.C., Laurens, L.M.L., Shields, R.J., Lovitt, R.W., Flynn, K.J., (2010). Placing microalgae on the biofuels priority list: a review of the technological challenges. J. R. Soc. Interface, 7, 703-726.

Uduman, N., Qi, Y., Danquah, M.K., Forde, G.M., Hoadley, A., (2010). Dewatering of microalgal cultures: a major bottleneck to algae-based fuels. J. Renew. Sustain, Energy 2, 0127011-0127015.

Molina Grima E, Belarbi E, Acién Fernández FG, Robles Medina A, Chisti Y. (2003). Recovery of microalgal biomass and metabolites: process options and economics. Biotechnol Adv., 20(7-8), 491-515.

Wu, Z., Zhu, Y., Huang, W., Zhang, C., Li, T., Zhang, Y., Li, A., (2012). Evaluation of flocculation induced by $\mathrm{pH}$ increase for harvesting microalgae and reuse of flocculated medium. Bioresour. Technol., 110, 496-502.

Gregory, J., Duan, J., (2001). Hydrolyzing metal salts as coagulants. PureAppl. Chem., 73, 2017-2026.

Granados, M.R., Acién, F.G., Gómez, C., Fernández-Sevilla, J.M., Molina Grima, E. (2012). Evaluation of flocculants for the recovery of freshwater microalgae.Bioresource Technology, 118, 102-110.

Rwehumbiza, M.V., Harrison, R., Thomsen, L. (2012). Alum-induced flocculation of preconcentratedNannochloropsissalina: Residual aluminium in the biomass, FAMEs and its effects on microalgae growth upon media recycling. Chemical Engineering Journal, 200-202, 168-175.

Garzon-Sanabria, A. J., Davis, R.T., Nikolov Z. L. (2012). Harvesting Nannochlorisoculata by inorganic electrolyte flocculation: Effect of initial cell density, ionic strength, coagulant dosage, and media pH.Bioresource Technology, 118, 418-424.

Griffiths, M. J., Garcin, C., van Hille, R.P., Harrison S.T.L. (2011) Interference by pigment in the estimation of microalgal biomass concentration by optical density. Journal of Microbiological Methods, 85, 119-123.

Duan, J., Gregory, J., (2003) Coagulation by hydrolysing metal salts.Advances in Colloid and Interface Science, 100102, 475-502.

Henderson, R.K., Parsons, S.A., Jefferson, B., (2008). Successful removal of algae through the control of zeta potential. Sep. Sci. Technol., 43, 1653-1666.

Ohman, L.-O., Wagberg, L., Pulp Pap. J., (1997).Sci. 23, J475. 


\title{
EVALUACIÓN DEL DESEMPEÑO EN UN MOTOR DIÉSEL DE MEZCLAS DE DIÉSEL CON BIODIESEL OBTENIDO A PARTIR DE ACEITE DE COCINA USADO
}

\author{
Carlos Andrés Quintero ${ }^{1,}$ \\ Carlos Julio Camacho López ${ }^{1,}$ \\ Dionisio Malagón Romero, ${ }^{1,}$ \\ ${ }^{1}$ Universidad Santo Tomás
}

${ }^{2}$ Correo contacto: dionisiomalagon@usantotomas.edu.co

\begin{abstract}
RESUMEN
La búsqueda de nuevas fuentes de aceite que permitan reducir los costos de producción de biodiesel ha llevado a usar el aceite e cocina usado como una alternativa. En el presente trabajo investigativo se presenta la caracterización del desempeño de mezclas de diésel de origen petroquímico con biesel obtenido a partir de aceite de cocina usado. El biodiesel se obtuvo mediante transesterificación, usando como catalizador hidróxido de potasio, relación molar alcohol: aceite 6:1, porcentaje de catalizador $1 \%$ y tiempo de reacción 2 horas. Se realizaron las mezclas B30, B50, B70, B90, B100, y como referente se usó diésel comercial, denominado BCOM (diésel con biodiesel al 7\%). Se determinó la opacidad de los gases de combustión, el consumo de combustible y la potencia eléctrica generada. Se encontró que las mezclas de biodiesel-diésel presentan un consumo entre el $0.71 \%$ y el $22.8 \%$ menor al observado con el BCOM y un consumo específico de combustible entre el 7.44\%-24.23\% mayor que con el combustible de referencia BCOM. Se evidenció un incremento de un rango entre el $0.18 \%$ y $4.9 \%$ en las curvas de potencia y por último, se muestra una reducción de 35\% - 59\% en las pruebas de opacidad. Lo anterior demuestra que la producción de biodiesel a partir de aceite de cocina usado es una posibilidad tecnológica para ser implementada, entre otros aspectos, debido a que su uso no afecta considerablemente la potencia del motor.
\end{abstract}

Palabras claves: biodiesel, transesterificación, aceite usado de cocina, motor diésel. 


\section{INTRODUCCIÓN}

Los niveles de emisiones nocivas al ambiente se incrementan peligrosamente cada año. Según la Organización Mundial de la Salud (OMS) la contaminación atmosférica constituye un riesgo medioambiental para la salud y se estima que causa alrededor de dos millones de muertes prematuras al año en todo el mundo (Pereira et al., 2007), (Valente et al., 2010), a lo que se suma el hecho del deterioro ambiental producido por este tipo de emisiones. Los niveles actuales de contaminación en Bogotá están por encima de los registrados en otras ciudades de Colombia, e incluso, de otras capitales latinoamericanas (Montoya y Rojas, 2009). Según un informe divulgado por la secretaria del medio ambiente, los vehículos de transporte emitieron cerca de 4'831.225 toneladas de CO2 en Bogotá durante el año 2008 (Castellanos, 2012). Con miras a resolver este problema, desde el año 2004, el gobierno nacional promovió la Ley 939 donde se establece el uso de biodiesel como aditivo para el diésel de origen petroquímico. Sin embargo, en la actualidad existe una tendencia global a usar aceites vegetales que no se emplean en alimentación humana. Dentro de estos aceites, uno que ha venido ganando importancia es el aceite de cocina usado. En los países de la Unión Europea, alrededor de 700000 a 1 Mt de aceite de cocina usado es producido al año; el Reino Unido y Japón generan alrededor de 200000 toneladas y $400000 \mathrm{a} 1 \mathrm{Mt}$ de aceite de cocina usado al año, respectivamente (Fazal et al., 2011).

Adicional a la obtención del biocombustible, es necesario evaluar la potencia generada en motores diésel con diferentes porcentajes de mezcla con diésel de origen petroquímico, debido a la prevención existente por la pérdida de potencia en los motores por el cambio de diésel a biodiesel. En el presente documento se presenta la potencia, el consumo específico al freno y la opacidad de diferentes mezclas de biodiesel tales como B30, B50, B70, B90 y B100 que fueron realizadas con biodiesel obtenido a partir de aceite de cocina usado y diésel. Con base en los resultados obtenidos, se puede observar que la obtención de biodiesel a partir de aceite de cocina usado no ocasiona mayor efecto que el causado por adicionar biodiésel de aceite virgen al diésel de origen petroquímico.

\section{MATERIALES Y MÉTODOS}

\subsection{Obtención de Biodiésel.}

La materia prima empleada para la obtención de biodiesel fue aceite vegetal usado, procedente del Club de Suboficiales. La caracterización de este aceite mostró que el contenido de ácidos grasos libres era menor al 5\%, por lo cual se realizó la transesterificación de forma directa. Los reactivos utilizados para la producción de biodiesel fueron metanol (Panreac, Barcelona, España), hidróxido de pota- sio (MERCK, Darmstadt, Alemania) y diésel (donado por Ecopetrol). Las condiciones para la transesterificación fueron determinadas previamente por el Grupo de Estudios y Aplicaciones en Ingeniería Mecánica (GEAMEC ) de la Universidad Santo Tomás: catalizador hidróxido de potasio, relación molar alcohol: aceite 6:1, porcentaje de catalizador $1 \%$, tiempo de reacción 2 horas. Una vez transcurrido este tiempo, el biodiesel se sometió a decantación durante 24 horas hasta total separación de fases, se recuperó la fase rica en biodiesel, se lavó, se neutralizó el pH mediante lavados sucesivos, se secó en estufa a $50^{\circ} \mathrm{C}$ durante 24 horas y se almacenó hasta posterior uso.

\subsection{Evaluación de la generación de poten- cia eléctrica.}

Para la determinación de la potencia eléctrica generada por la combustión de distintas mezclas de diésel y biodiesel, se usó una planta eléctrica tal como lo plantea Pereira et al. (2010), y para determinar la potencia eléctrica se usó un banco de resistencias, siguiendo el planteamiento de Valente et al. (2010). El banco de pruebas está conformado por una planta eléctrica marca Kipor E6500, un tablero de control de potencia y toma de datos por medio de un amperímetro y voltímetro, un medidor de variación de consumo, resistencias de carga y el analizador de opacidad. En la figura 1 se muestra el esquema del montaje. Se prepararon varias mezclas de diésel-biodiesel (B30, B50, B70, B90, B100) y BCOM, las cuales se colocaron en el tanque de la planta eléctrica. Para determinar la potencia eléctrica se colocaron varias resistencias eléctricas desde $300 \mathrm{~W}$ hasta $2700 \mathrm{~W}$, se recolectaron valores de voltaje (multímetro marca Ex Tool Kit), corriente (pinza amperimétrica marca Extech), temperatura (pinza amperimentrica marca Extech) (motor y ambiental) y consumo de cada mezcla (mediante una probeta milimetrada).

Figura 1. Diagrama esquemático de la evaluación de potencia eléctrica para mezclas de biodiésel-diésel.

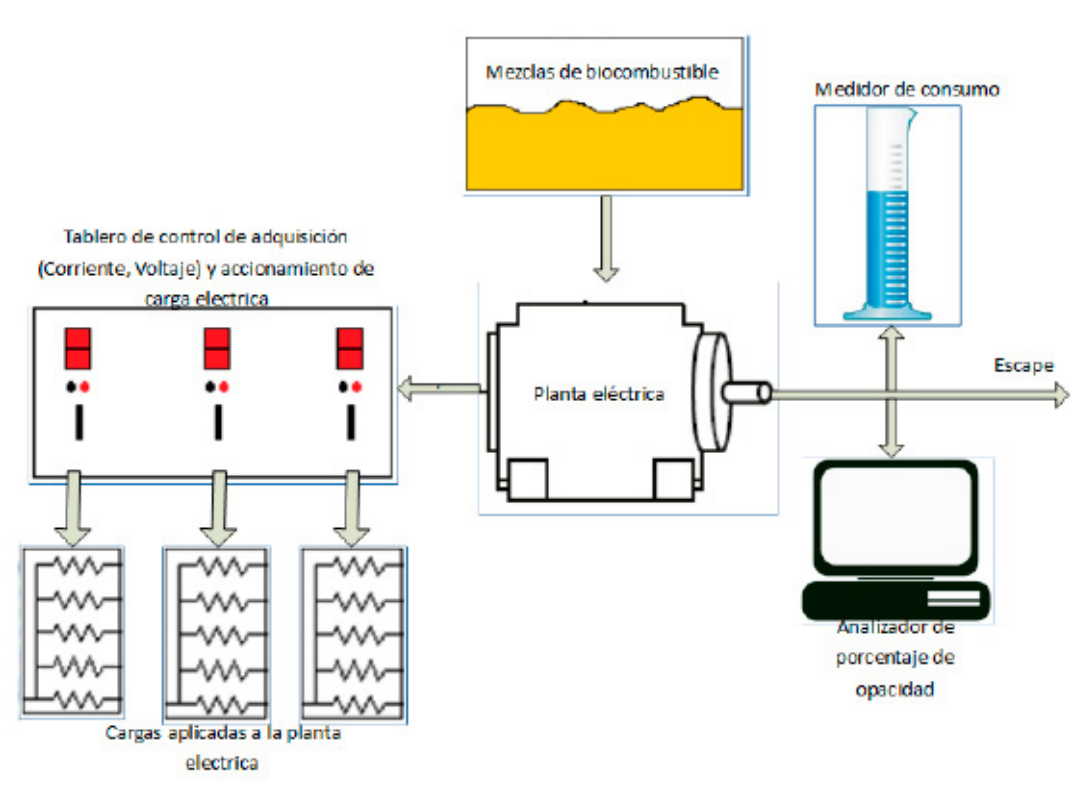

Fuente: Autores. 


\section{RESULTADOS}

\subsection{Consumo}

En las mezclas de biodiesel y diésel hubo disminución en el consumo de combustible cuando se evaluaron mezclas de biodiesel/diésel, tomando como combustible de referencia el BCOM(B7 a partir de aceite de palma); dicha disminución llegó a ser del 23.3 \%apara B100 a bajas potencias (300 $\mathrm{W})$.en el corior implica que para una misma potencia, se requiere una menor ayor cantid combustible y se debe a que el poder calorífico del biodiesel obtenido a partir de aceite de cocina usado es más alto que el del biodiesel obtenido a partir de aceite de palma (Montoya y Rojas, 2009).. Estos reultados son diferentes a los similares a los con loontoya y Rojas (2009)3 quienes evaluaron el consumo de biodiesel producido a base de aceite de palma, higuerilla y aceite de cocina usado y encontraron un incremento de consumo de combustible entre el $5.20 \%$ y el $8.13 \%$ respecto al B0 (diésel de origen petroqus que $\mathrm{C} 2$ ) [4 esincrembase

\subsection{Consumo específico al freno}

Los resultados de consumo específico del combustible al freno (BSFC) para diferentes mezclas B100, B90, B70, B50 y B30 reportan valores de consumoĺespecífico del combustible al freno (BSFC) entre 7.44\%-24.23\% inferiores del combustible de referencia (BCOM). Lo anterior es distinto a lo reportado por Fazal et al. (2011) quienes reportan incrementos del combustible entre Al563\% y 4.4\%; esto q5] y Anlra las mezclaento entre 3. et al. (20114) es debido aque [88], se daqueeneralmente posee un poder calorífico inferior, sin embargo por tratarse de biodiésel obtenido a partir de aceite usado su poder calorífico es más alto que el diésel de origen petroquímico. Este mayor cons

\subsection{Potencia de salida}

.En este ensayo se sometió a la planta a una determinada carga (resistencia eléctrica) y se determinó la potencia entregada. Se observó que no existe diferencia significativa $(p<0.05)$ en la potencia entregada por la planta eléctrica para cada una de las mezclas evaluadas. La literatura reporta incrementos hasta un 6,1\% en la potencia entregada ( $\mathrm{Fa}-$ zal et al., 2011 para las mezclas con altas concentraciones de éster metílico (B50, B60 y B70).

\subsection{Opacidad}

La medición de la opacidad en los gases de combustión de las diferentes mezclas evaluadas reveló una disminución del porcentaje de opacidad en la medida en que aumenta el porcentaje de biodiesel en la mezcla evaluada. La Figura 2 muestra la disminución de opacidad en la medida en que se incrementa el porcentaje de biodiesel. El porcentaje de reducción llega a ser del $45 \%$, tomando como referencia en BCOM (B7).
Figura 2. Porcentaje de opacidad para distintas mezclas de biodiesel obtenido a partir de aceite de cocina usado $\mathrm{y}$ diésel de origen petroquímico

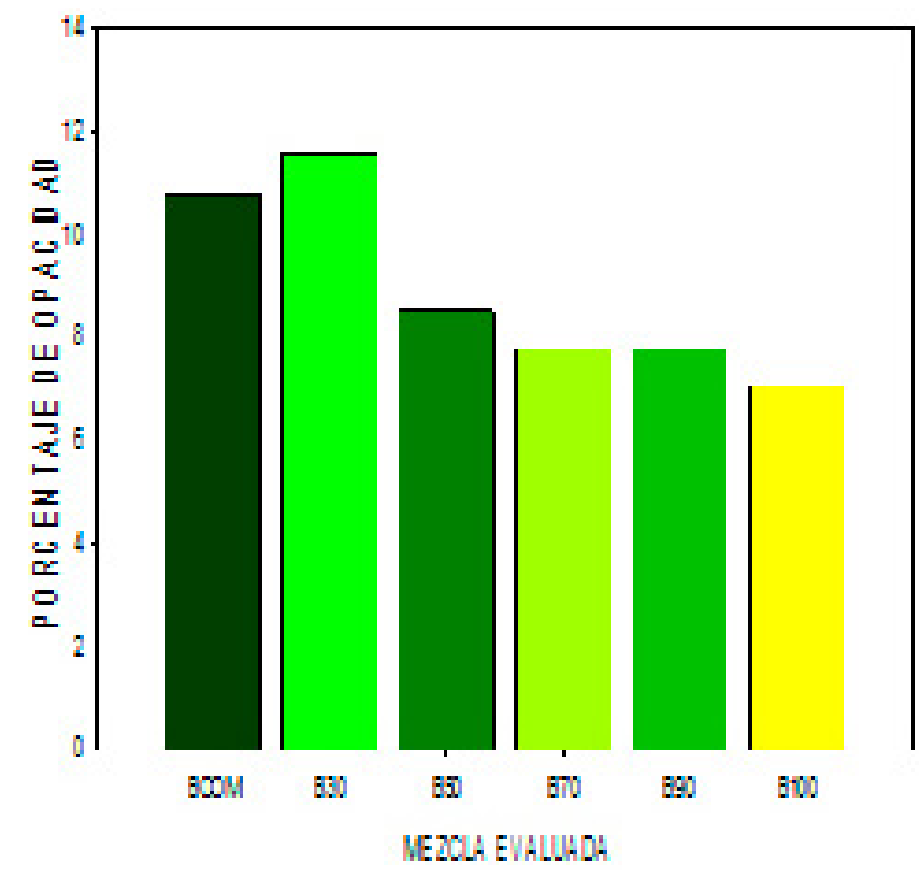

Los resultados son comparables a los obtenidos por $\mathrm{Lu}$ et al. (20089 quienes presentan reducciones entre el 35\% y $44 \%$ para un rango medio de potencia aplicada al motor, y además muestran que para valores de potencia mayores, el porcentaje de opacidad se reduce aún más con reducciones entre el $75 \%$ y $85 \%$, donde el combustible que presenta el menor porcentaje de opacidad es el B100 (producido a partir de aceite usado). Esto refleja que el uso de biocombustibles contribuye con la disminución de material particulado arrojado al ambiente.

\section{CONCLUSIONES}

Mediante este trabajo se puede evidenciar que técnicamente la utilización de biodiesel obtenido a partir de aceite de cocina no conlleva a la pérdida de potencia en motores diésel. Se presenta disminución en el consumo de combustible, debido fundamentalmente al alto poder calorífico que puede tener el biodiesel obtenido a partir de aceite usado; dicha disminución puede llegar a ser del 23.3\% para B100 a baja potencia $(300 \mathrm{~W})$. El consumo específico de combustible al freno (BSFC) es menor que el BCOM debido fundamentalmente a que el biodiesel obtenido a partir de aceite usado posee un mayor poder calorífico que el diésel de origen petroquímico. La reducción en la opacidad de los gases de combustión llega a ser del $45 \%$, lo cual justifica el uso de biodiesel desde una perspectiva ambiental ya que implica una menor emisión de material particulado al ambiente. Los resultados de este trabajo han confirmado la posibilidad de utilizar cualquier proporción de las mezclas de biodiesel (a partir de aceite de cocina usado)-diésel en motores diésel.

El uso de biodiesel a partir de aceite usado puede reemplazar el diésel con el fin de reducir la contaminación del aire, promover el reciclaje de aceite usado y conservar significativamente la potencia del motor. 


\section{BIBLIOGRAFÍA}

Castellanos, J.D. (2012). Evaluación de la mezcla de biodiesel obtenido a partir de Jatropha curcas y ULSD. Tesis en Ingeniería Mecánica. Bogotá, Universidad Santo Tomás.

Fattah, R., Masjuki, H., Kalam, M., Wakil, M., Ashraful, A. \& Shahir, S. (2014). Experimental investigation of performance and regulated emissions of a diesel engine with Calophyllum inophyllum biodiesel blends accompanied by oxidation inhibitors,» Energy Conversion and Management, 83, 232-240.

Fazal, M.A., Haseeb, A.S. \& Masjuki, H. H. (2011). Biodiesel feasibility study: An evaluation of material compatibility; performance; emission and engine durability. Renewable and Sustainable Energy Reviews, 15, 1314-1324.
Lu, X., Ma, J., Ji, J., Huang, Z. (2008). Simultaneous reduction of NOx emission and smoke opacity of biodiesel-fueled engines by port injection of ethanol, Fuel, 87, 1289-1296.

Montoya, A. F., \& Rojas, A. (2009). Efecto de la proporción de mezcla biodiesel/petrodiesel en el desempeño mecanico ambiental de motores. Ingeniería y Competitividad, $11,63-78$.

Pereira, R. G., Oliveira, C. C., Oliveira, J.L., Oliveira, P. C. P., Fellows, C. E. \& Piamba, O. E. (2010). Exhaust emissions and electric energy generation in stationary engine using blends of diesel and soybean biodiesel. REVISTA, 32 (2454).

Valente, O. S., Silva, M. J., Pasa, V. M., Bechior, C. R. \& Sodre, J. R. (2010). Fuel consumption and emission from a diesel power generator fuelled with castor oil and soybean biodiesel. REVISTA, 89 (3638).. 


\title{
MODELAMIENTO COMPUTACIONAL DE LA PRODUCCIÓN DE ENERGÍA RENOVABLE A PARTIR DEL BIOGÁS MEDIANTE LA CO-DIGESTIÓN ANAERÓBICA DE LA MEZCLA DE RESIDUOS CÍTRICOS Y ESTIÉRCOL BOVINO.
}

\author{
Edwin Darío Cendales Ladino ${ }^{1,2}$ \\ Silvio Alejandro Jiménez Castellanos ${ }^{1,3}$ \\ ${ }^{1}$ Fundación Universitaria Los Libertadores \\ ²edcendalesl@libertadores.edu.co \\ ${ }^{3}$ sajimenezc@libertadores.edu.co
}

\begin{abstract}
RESUMEN
En esta investigación se llevó a cabo la simulación computacional del proceso de digestión anaeróbica de la mezcla homogeneizada de estiércol bovino y residuos cítricos, con el fin de evaluar la viabilidad de la generación de energía renovable a partir de la co-digestión de estos residuos. Tomando como base los resultados obtenidos en la etapa experimental, donde se realizaron mediciones periódicas de las variables de control del proceso de biodegradabilidad anaeróbica, como $\mathrm{pH}$, alcalinidad, demanda química de oxígeno (total y soluble), entre otras; se establecieron los parámetros de desempeño del proceso y se determinaron los valores de comparación entre los resultados experimentales y los resultados computacionales. Adicionalmente, se realizó la simulación del proceso de digestión anaeróbica bajo condiciones similares a las establecidas previamente en otra investigación mediante la implementación del modelo ADM-1. Con base en los resultados obtenidos a través las mediciones experimentales y las simulaciones, se evaluó la precisión del modelo respecto a los valores de las mediciones experimentales. Finalmente, se implementó un modelo simplificado para la evaluación de la energía producida por una instalación a escala piloto que realiza el tratamiento anaeróbico del residuo orgánico bajo estudio. El modelo mostró que inicialmente existe un déficit energético para que el proceso ocurra, sin embargo, una vez la producción de biogás inicia, el proceso se hace autosustentable y el sistema entrega una cantidad creciente de energía disponible.
\end{abstract}

Palabras Clave: Digestión anaeróbica, biodegradabilidad, estiércol bovino, residuos cítricos, biogás, metano. 


\section{INTRODUCCIÓN}

La digestión anaeróbica de los residuos agropecuarios provenientes de las explotaciones ganaderas representa una opción viable como fuente de energía, sin embargo, la producción reducida de biogás a partir de estos residuos no justifica el costo de inversión de los sistemas de tratamiento. No obstante, la productividad de biogás y metano puede ser incrementada drásticamente mediante la co-digestión de los residuos ganaderos y los desechos que se generan durante la cosecha o procesamiento de los productos agrícolas, debido a la acción sinérgica que presentan el gran contenido de nutrientes disponibles para el desarrollo de las poblaciones microbianas responsables del proceso (Nordberg \& Edstrom, 2005), (Callaghan, Wase, Thayanithy, \& Forster, 1999), (Neves, Oliveira, \& Alves, 2004), (Gunaseelan, 2007).

El aumento en el costo de los combustibles convencionales ha acentuado el interés en el desarrollo de nuevas fuentes de energía renovable. La utilización del metano contenido en el biogás puede llegar a reemplazar gradualmente los combustibles fósiles, debido a la rentabilidad específica que genera la producción de este biocombustible y la característica de carbono neutro que presenta (Moller, Sommer, \& Ahring, 2004). Debido a que la cantidad de metano generado y el porcentaje de reducción de la demanda química de oxigeno durante la digestión anaeróbica depende de la eficiencia del proceso bioquímico, es necesario realizar la optimización operacional de las instalaciones destinadas al tratamiento de aguas residuales y residuos orgánicos biodegradables. Hace algunas décadas los estudios dedicados a establecer los parámetros óptimos de tratamiento y la evaluación de la influencia de algunas de las variables del proceso eran desarrollados a escala de planta piloto, lo cual requería una gran cantidad de energía y largos periodos de operación. A partir de la década de 1970, surgió la necesidad de utilizar modelos matemáticos para la predicción del comportamiento del tratamiento anaeróbico dentro del amplio rango de las condiciones de operación. Por tal razón, se desarrollaron modelos matemáticos compuestos por un número limitado de ecuaciones y aplicabilidad específica (Thamsiriroj \& Murphy, 2011), (Andrews \& Graef, 1971), (Hill, 1982). Estos primeros modelos desarrollaban la simulación de los procesos bioquímicos mediante la simplificación de las cinéticas de las reacciones bioquímicas y la composición de los sustratos complejos. La necesidad de predecir el comportamiento del sistema con una precisión confiable, motivó el desarrollo de modelos más sofisticados que permitieran representar el impacto de las condiciones transitorias sobre las especies químicas y biológicas.

Como respuesta a la necesidad de un modelo genérico para la simulación del proceso anaeróbico, en el año 2002 se desarrolló por parte del grupo de trabajo de modelamiento matemático de la digestión anaeróbica perteneciente a la Asociación Internacional del Agua (IWA, por sus siglas en inglés), el modelo ADM-1 (Modelo de Digestión Anaeró- bica, por sus siglas en inglés). Este modelo fue desarrollado bajo la consideración de generar una base común para la generación de modelos subsecuentes y la capacidad de permitir la comparación de resultados entre diferentes estudios sobre sustratos similares (Batstone, y otros, 2002), (Batstone, High rate anaerobic treatment of complex wastewater, 2000), (Blumensaat \& Keller, 2005), (Parker, 2005). Las principales aplicaciones del modelo ADM-1 son la simulación de procesos en estado transitorio y el modelamiento en las etapas de diseño, operación y optimización de plantas de tratamiento de diversos residuos orgánicos biodegradables.

\section{MATERIALES Y MÉTODOS}

El objetivo central de esta investigación es evaluar la producción y composición del biogás generado durante la digestión anaeróbica de la mezcla homogeneizada de residuos cítricos y estiércol bovino, mediante la utilización de los ensayos de biodegradabilidad anaeróbica que están basados en metodologías estandarizadas (ISO, 1995), (ASTM:, 1992), (Owens \& Chynoweth, 1993), (Palmowski \& Muller, 2000). Simultáneamente, se implementó el modelo ADM-1, tomando como referencia las mediciones realizadas sobre el sustrato para los parámetros de control del proceso como $\mathrm{pH}$, alcalinidad, contenido de ácidos grasos volátiles, demanda química de oxigeno total y soluble. El modelo ADM1 fue implementado en la plataforma de Matlab/Simulink, en forma de diagramas de bloques para la representación de las ecuaciones que conforman el modelo. Inicialmente, se evaluó la precisión numérica de esta simulación respecto a otra implementación en la misma plataforma pero desarrollada mediante código $\mathrm{C}$ y funciones C-S-MEX para el caso base del modelo (Rosen, Vrecko, Gernaey, Pons, \& Jeppsson, 2006).

Posteriormente, se estableció la implementación del modelo con el fin de simular el proceso de digestión anaeróbica bajo condiciones similares a las existentes durante el desarrollo de la fase experimental. Con base en esta última implementación, se compararon los resultados que genera el modelo y los resultados obtenidos de las mediciones desarrolladas. Finalmente se implementó un modelo simplificado para estimar el potencial energético de generación en una instalación a escala piloto, con base en los resultados obtenidos de la simulación del modelo.

El desarrollo experimental consistió en la instalación de los sistemas requeridos para la determinación de la biodegradabilidad anaeróbica de la mezcla homogeneizada de residuos cítricos y estiércol bovino, como una adaptación de las técnicas propuestas por diversos autores, (Battersby \& Wilson, 1988), (Shelton \& Tiedje, 1984), (Field, 1987) así como en la norma ISO 11734 (1995) (ISO, 1995), (ASTM:, 1992). Esta técnica desarrollada a una temperatura constante permite evaluar los parámetros de control del proceso de digestión anaeróbica de un residuo en particular durante un 
periodo de 30 a 45 días. El método consiste en la medición del gas metano y del biogás generado en los reactores anaeróbicos con alimentación por tandas (tipo batch) en los cuales se depositan las muestras de lodo metanogénico activo, el residuo a evaluar y las soluciones minerales. Adicionalmente, se instalan reactores de control que contienen lodo metanogénico activo y el volumen de residuo se reemplaza por un volumen equivalente de soluciones del medio mineral.

\section{RESULTADOS}

El modelo energético fue implementado como un subsistema de ecuaciones en la plataforma utilizada para la simulación del modelo ADM-1 debido a que algunos de los términos que conforman la ecuación de balance energético requieren la interacción con las variables que se evalúan dentro del modelo del proceso de digestión anaeróbica. Para la implementación de la ecuación de balance de energía para el sistema compuesto por el tanque reactor con agitación semi-continua y los sistemas auxiliares de calentamiento, alimentación y generación combinada de potencia y calor, se requiere establecer puntualmente los valores de cada una de las variables que están presentes en los términos de la ecuación de balance.

Los términos que determinan la producción de energía eléctrica y energía térmica, a partir de la combustión del metano generado, se calculan tomando como referencia el valor del caudal de biogás () y la fracción de metano () presente en el biogás que se estiman mediante la implementación desarrollada del modelo ADM-1. Para los valores poder calorífico inferior del metano se utilizó el valor (10.26 $\mathrm{kWh} / \mathrm{m} 3$ ). De acuerdo con Lubken et al. [81], las unidades CHP generalmente presentan una eficiencia de conversión de energía mecánica/eléctrica de alrededor de 30\% ( $\eta_{-}$ elect $=0.3$ ) y la eficiencia de generación de energía térmica es de aproximadamente $50 \%\left(\eta \_\right.$term $\left.=0.5\right)$. Por lo tanto, se estima que aproximadamente el $20 \%$ de la energía contenida en el gas metano se disipa en forma de irreversibilidades del sistema electromecánico CHP. Estas eficiencias de conversión se muestran en el diagrama de Sankey (Figura 1), desarrollado para la distribución de energía a través del sistema CHP. En el mismo diagrama se observan los porcentajes relativos de los consumos energéticos requeridos para el funcionamiento de la instalación, estos fueron calculados con base en la fracción que representa cada término respecto a la energía eléctrica total y la energía térmica total generadas por el sistema CHP.

Para el término potencia consumida durante la alimentación del sustrato al reactor mediante una bomba hidráulica, se utilizaron los valores referidos en la tabla 1 para el caudal de ingreso al reactor, altura del punto de ingreso del sustrato en el reactor y la densidad del sustrato medida durante la etapa experimental. El tiempo promedio de bombeo y la eficiencia de la bomba tornillo se estimaron en $15 \mathrm{~min} /$ día y ( $\left.\eta \_B o m b a-t o r n i l l o=0,5\right)$, respectivamente (Lubken, Wichern, Schlattmann, Gronauer, \& Horn, 2007).

Figura 1. Diagrama de Sankey para la energía del sistema a escala piloto.

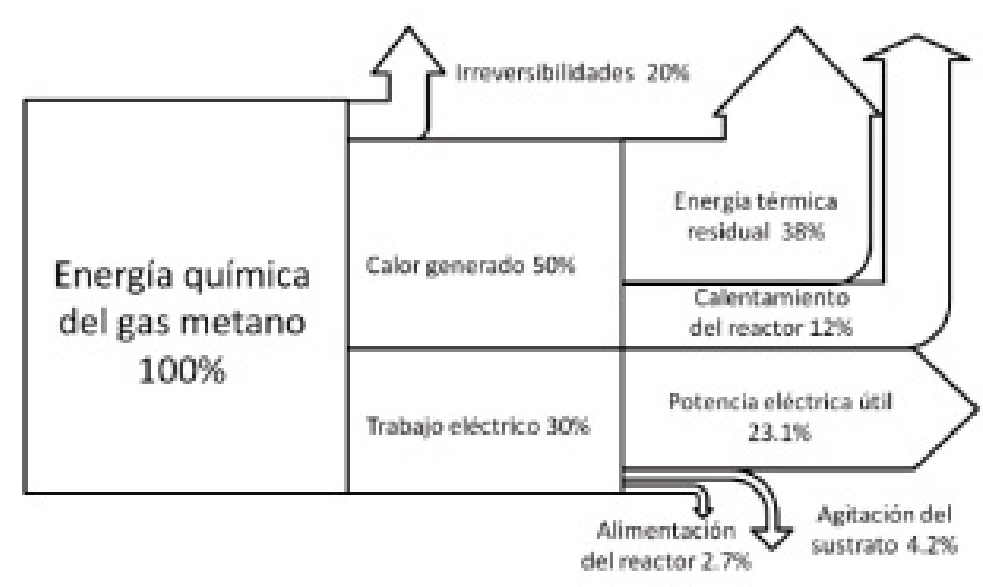

Tabla 1. Características del sistema a escala piloto.

\begin{tabular}{|c|c|c|}
\hline Variable & Símbolo & Valor \\
\hline Volumen tobal del reactor & $\mathrm{V}_{T}$ & $1.89 \mathrm{~m}^{3}$ (500 Galones) \\
\hline Volumen líquido del reactor & $\mathrm{V}_{L}$ & $1.51 \mathrm{~m}^{3}$ (400 Galones) \\
\hline Tiempo de retención hidráulica & IIRT & $40 \mathrm{dias}$ \\
\hline Caudal de ingreso al reactor & $\dot{V}_{\text {in }}\left[\mathrm{V}_{L} / \mathrm{HRT}\right]$ & $37.85 \mathrm{~L} / \mathrm{dia}$ \\
\hline Altura del reactor & $\mathrm{H}$ & $2.7 \mathrm{~m}$ \\
\hline Área efectiva del reactor & $\Lambda$ & $1.97 \mathrm{~m}^{2}$ \\
\hline Densidad del sustrato & $\rho$ & $1145 \mathrm{Kg} / \mathrm{m}^{3}$ \\
\hline Calor especifico del sustrato & $C_{p}$ & $4.13 \mathrm{~kJ} / \mathrm{kg}$ \\
\hline
\end{tabular}

Figura 2. Geometría del tanque reactor simulado.

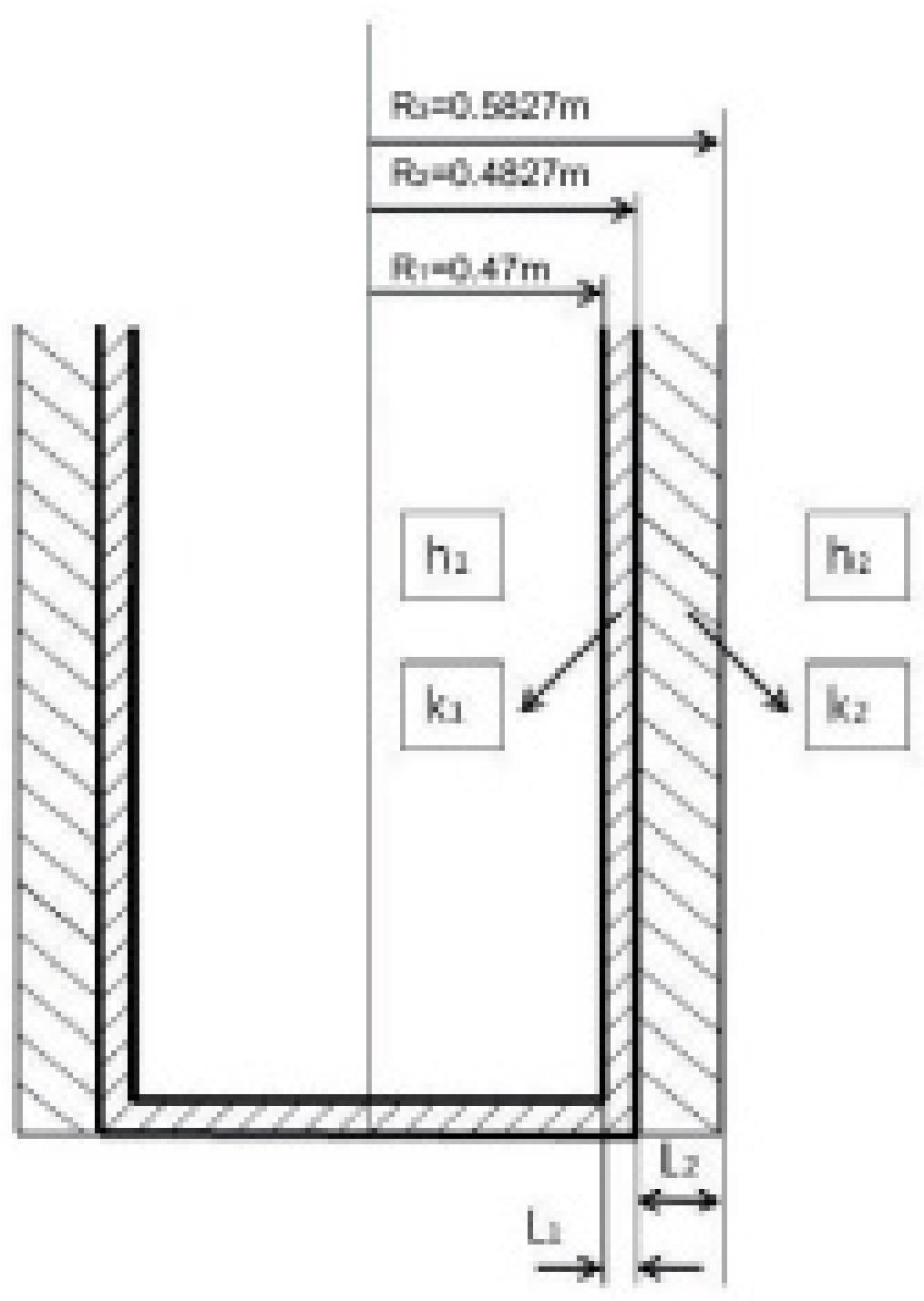


Figura 3. Curva obtenida mediante la simulación numérica para la energía neta y razón de cambio de la energía neta generada.

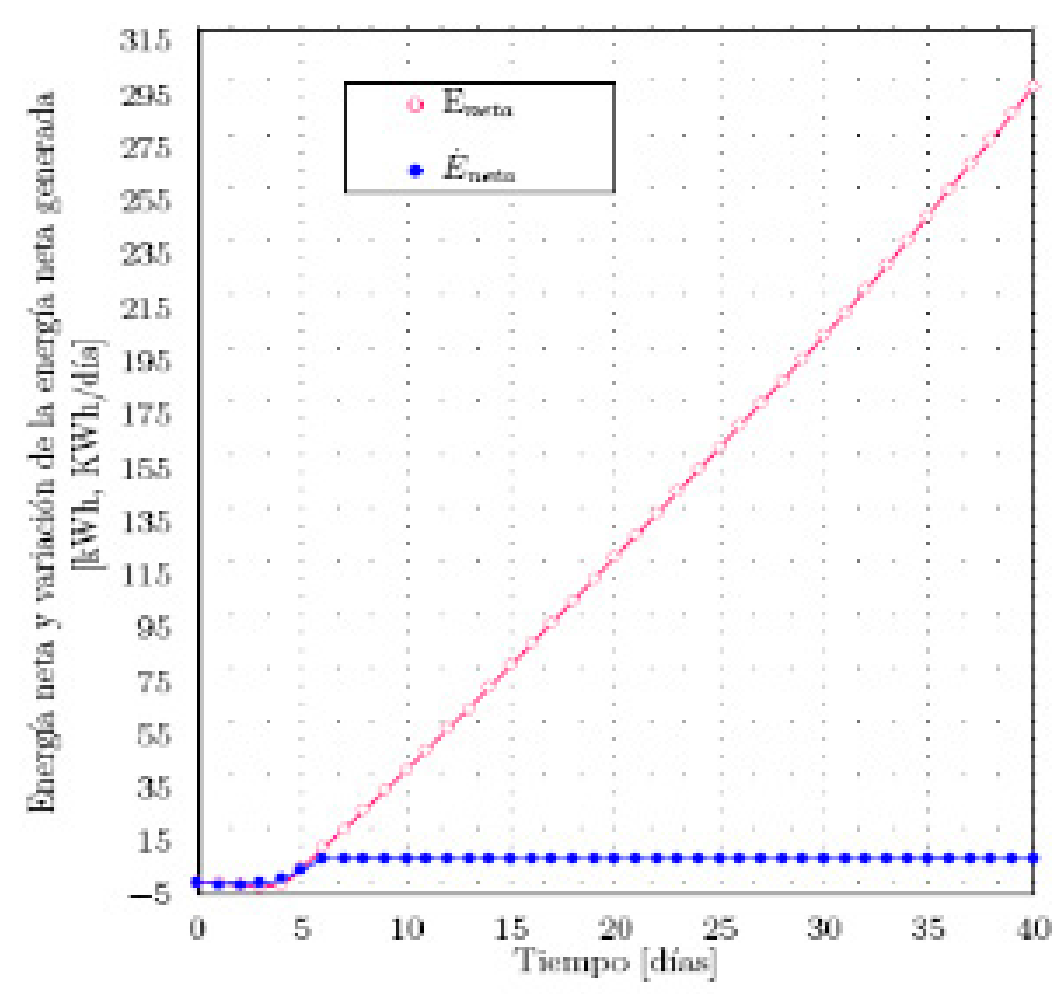

(a)

El término energía consumida durante la agitación del sustrato fue establecido con base en el volumen liquido del reactor establecido en la tabla 1 y los parámetros reportados para la energía específica de agitación y el tiempo promedio diario que dura la agitación $(0.005 \mathrm{~kW} / \mathrm{m} 3$ y $8 \mathrm{~h} /$ día respectivamente). El término energía requerida para el calentamiento del sustrato se estableció mediante los parámetros de caudal de ingreso al reactor y el calor específico del residuo obtenido de una investigación desarrollada sobre un sustrato similar [37]. Estos parámetros se muestran en la tabla 1. Adicionalmente, se estimó una temperatura ambiental promedio de $18^{\circ} \mathrm{C}$ para las condiciones locales y una temperatura del reactor de $30^{\circ} \mathrm{C}$ de acuerdo a las condiciones en las que se desarrolló el ensayo de biodegradabilidad anaeróbica.

La figura 2. muestra un esquema del reactor modelado donde se observan las dimensiones de la pared del reactor y del aislamiento térmico. El término correspondiente a la energía perdida debido al calor transferido por conducción y convección desde el reactor se calculó utilizando los valores $17 \mathrm{~W} / \mathrm{mK}$ y $0.55 \mathrm{~W} / \mathrm{mK}$ como los coeficientes de conductividad térmica para los materiales acero inoxidable y lana mineral respectivamente. Estos materiales se asumieron como capas cilíndricas con un espesor de $0.0127 \mathrm{~m}$ $(1 / 2 ")$ para la pared de acero inoxidable y $0.1 \mathrm{~m}$ para la lana mineral. De igual forma se utilizaron los valores $1 \mathrm{~W} / \mathrm{m} 2 \mathrm{~K}$ y $4 \mathrm{~W} / \mathrm{m} 2 \mathrm{~K}$ para los coeficientes de transferencia de calor desde el sustrato hacia la pared interna del reactor y entre la pared externa del reactor al aire exterior (Bohn, Bjornsson, \& Mattiasson, 2007).

Como resultado de la implementación del modelo energético se obtuvo la figura 3. en la que se muestra la evolu- ción de la variable que representa la energía neta generada y la razón de cambio de la energía generada por el sistema de tratamiento a escala piloto. A partir de estas gráficas se puede inferir la notable capacidad de generación de energía que presenta este sistema de tratamiento de residuos orgánicos biodegradables. De acuerdo a estos resultados, en una instalación a escala piloto con el funcionamiento descrito anteriormente, el sistema genera aproximadamente $200 \mathrm{KWh} /$ mes, que corresponde a la energía promedio de consumo mensual de una vivienda en el área urbana, y aproximadamente 4 viviendas en el sector rural en Colombia (Deloitte, 2009).

\section{CONCLUSIONES}

De acuerdo al modelo energético desarrollado en conjunto con la implementación del modelo ADM-1, se puede establecer el potencial que presenta esta tecnología de tratamiento de los residuos orgánicos biodegradables como fuente de energía renovable. Como se observó en los resultados obtenidos mediante este modelo, durante los primeros estadios del desarrollo del proceso, el sistema presenta un balance energéticamente negativo. Sin embargo, a medida que se desarrolla el proceso de digestión anaeróbica del sustrato y se inicia la producción del gas metano, se obtiene una generación neta de energía que supera ampliamente el requerimiento energético del sistema a escala piloto que fue modelado.

El aporte de esta investigación se basa en la determinación de la biodegradabilidad anaeróbica de la mezcla de residuos orgánicos, de acuerdo con un protocolo estandarizado, demostrando la factibilidad que presenta la tecnología de digestión anaeróbica para la generación de energía renovable. Este estudio es una primera aproximación al desarrollo de una estrategia óptima tanto para el tratamiento de residuos orgánicos biodegradables de origen agroindustrial, como para la obtención de biocombustibles como bioetanol y biogás a partir de procesos biotecnológicos como la fermentación alcohólica y la digestión anaeróbica.

\section{REFERENCIAS}

Andrews, J., \& Graef, S. (1971). Dynamic modeling and simulation of the anaerobic digestion process. Anaerobic Biological Treatment Processes. Advances in Chemistry Series-Amer. Chemical Soc., Washington (105), 126-162.

ASTM:. (1992). Standard Test Method for Determining the Anaerobic Biodegradation Potential of Organic Chemicals. American Society for Testing and Materials West Conshohocken, PA.

Batstone, D. (2000). High rate anaerobic treatment of complex wastewater. Universidad de Queensland, Brisbane, Tesis de Doctorado. 
Batstone, D., Keller, J., Angelidaki, I., Kalyuzhnyi, S., Pavlostathis, S., Rozzi, A., . . Vavilin, V. (2002). Anaerobic Digestion Model-1,(ADM1). IWA Task Group for Mathematical Modelling of Anaerobic Digestion Processes IWA Publishing London.

Battersby, N., \& Wilson, V. (1988). Evaluation of a serum bottle technique for assessing the anaerobic biodegradability of organic chemicals under methanogenic conditions. Chemosphere (17), 2441-2460.

Blumensaat, F., \& Keller, J. (2005). Modelling of two-stage anaerobic digestion using the IWA Anaerobic Digestion Model No. 1 (ADM1). Water Research (39), 171-183.

Bohn, I., Bjornsson, L., \& Mattiasson, B. (2007). The energy balance in farm scale anaerobic digestion of crop residues at $11-37^{\circ} \mathrm{C}$. Process Biochemistry (42), 57-64.

Callaghan, F., Wase, J., Thayanithy, K., \& Forster, C. (1999). Co-digestion of waste organic solids: batch studies. Bioresource Technology, 117-122.

Deloitte, A. y. (2009). Informe ejecutivo de gesti' on Codensa S.A. Codensa S.A. E.S.P.

Field, J. (1987). Parametros operativos del manto anaerobios de lodos de flujo ascendente - Arranque y operaci' on de sistemas de flujo ascendente con mantos de lodo UASB. Univalle-Universidad Agr' 1 cola de Wageningen. Cali, Colombia. (3), 409-414.

Gunaseelan, N. (2007). Regression models of ultimate methane yields of fruits and vegetable solid wastes, sorghum and napiergrass on chemical composition. Bioresource Technology (98), 1270-1277.

Hill, D. (1982). A comprehensive dynamic model for animal waste methanogenesis. Trans. ASAE (25), 1374-1380.

ISO. (1995). Water quality-evaluation of the ultimate anaerobic biodegradability of organic compounds in digested sludge. Method by measurement of the biogas production. International Organization for Standardization, Seattle.
Lubken, M., Wichern, M., Schlattmann, M., Gronauer, A., \& Horn, H. (2007). Modelling the energy balance of an anaerobic digester fed with cattle manure and renewable energy crops. Water Research (41), 4085-4096.

Moller, H., Sommer, S., \& Ahring, B. (2004). Methane productivity of manure, strawand solid fractions of manure. Biomass and Bioenergy (26), 485-495.

Neves, L., Oliveira, R., \& Alves, M. (2004). Influence of inoculum activity on the biomethanization of a kitchen waste under different waste/inoculum ratios. Process Biochemistry (39), 2019-2024.

Nordberg, A., \& Edstrom, M. (2005). Codigestion of energy crops and the source sorted organic fraction of municipal solid waste. Water science and technology, 217-222.

Owens, J., \& Chynoweth, D. (1993). Biochemical methane potential of MSW components. Water Sci. Technol. (27), $1-14$.

Palmowski, L., \& Muller, J. (2000). Influence of the size reduction of organic waste on their anaerobic digestion. Water Sci. Technol. (41), 155-162.

Parker, W. (2005). Application of the ADM-1 model to advanced anaerobic digestion. Bioresour. Technol. (96), 1832-1842.

Rosen, C., Vrecko, D., Gernaey, K., Pons, M., \& Jeppsson, U. (2006). Implementing ADM-1 for plant-wide benchmark simulations in Matlab/Simulink. Wat. Sci. Tech. (54), 11-20.

Shelton, D., \& Tiedje, J. (1984). General method for determining anaerobia biodegradation potential. Applied and enviromental microbiology (47), 850-857.

Thamsiriroj, T., \& Murphy, J. (2011). Modelling mono-digestion of grass silage in a 2-stage CSTR anaerobic digester using ADM1. Bioresource Technology (102), 948959. 


\title{
OBTENCIÓN DE FRACCIONES LÍQUIDAS MEDIANTE PIRÓLISIS DE BIOMASA RESIDUAL OBTENIDA DEL CULTIVO DE PALMA AFRICANA
}

\author{
José Leonardo Martinez Niño ${ }^{1}$ \\ Cristian Fernando Vargas Sierra ${ }^{1}$ \\ Luis Eduardo García Fernández ${ }^{1,2}$ \\ ${ }^{1}$ Universidad Libre \\ ${ }^{2}$ luise.garciaf@unilibrebog.edu.co
}

\section{RESUMEN}

La industria de los biocombustibles en Colombia presenta un crecimiento vertiginoso y se presenta como un sector industrial representativo en el sector de los combustibles, promovida por el estado y sus políticas de desarrollo sostenible. En Colombia la producción de biodiesel está basada en el cultivo de palma africana, como resultado del proceso productivo se obtienen residuos del cultivo. En la actualidad la disposición y tratamiento de este residuo orgánico generado, cuesco de palma, es una problemática para la industria aceitera, tanto en Colombia como en cualquier otro país del mundo que base su producción en este tipo de cultivo.

Entre los años 2012 y 2013 se obtuvieron 489.991 toneladas de biodiesel provenientes de 973.000 toneladas de fruto de palma africana, de las cuales el cuesco representa el del 7 al $10 \%$ del fruto (77.840 toneladas), el tiempo requerido para la descomposición de este tipo de biomasa de forma natural es prolongado, llegando a ser necesario varios meses, generando contaminantes en las plantaciones y dando lugar a problemas de disposición en las plantas de procesamiento.

Una alternativa de interés en la actualidad para el aprovechamiento de este tipo de recurso es el proceso de pirólisis, por su potencial de obtención de productos combustibles en diferentes estados de la materia, esta investigación tiene como principal objetivo la obtención de fracciones liquidas mediante pirólisis de biomasa residual a partir del cuesco de la palma africana. Como eje central se tiene la determinación de parámetros óptimos para maximizar la producción de dichas fracciones liquidas como resultado del proceso.

Palabras claves: Bio-oil, pirolisis, poder calorífico, cuesco de palma de aceite. 


\section{INTRODUCCIÓN}

Este artículo se centra en la determinación de la influencia de los parámetros en el proceso de pirólisis de cuesco de palma africana, con el fin de hacer una primera aproximación se lleva a cabo la determinación de los parámetros que influyen en mayor proporción, los cuales han sido reportados en estudios similares realizados por otros autores.

En primera instancia se realizan pruebas de caracterización de cuesco de palma africana obtenido a partir de las plantaciones existentes en Colombia. De la misma forma se plantea la realización de pruebas de TGA, para establecer la cinética de reacción química en diferentes condiciones de procesamiento. Estos resultados serán empleados en labores posteriores de simulación del proceso.

Posteriormente, se llevarán a cabo experimentos de pirólisis de lecho fluidizado encaminados a maximizar la obtención de fracciones liquidas como resultado del proceso. Para tal fin se lleva a cabo un plan experimental, con el fin de establecer la influencia de modificación de parámetros en el desarrollo del proceso.

Finalmente, se llevarán a cabo labores de caracterización de los productos obtenidos con el fin de determinar el potencial uso de dichos productos y la factibilidad de implementación de procesos de generación de energía eléctrica mediante el uso de los mismos.

\section{MATERIALES Y MÉTODOS}

Como paso inicial se realiza la adecuación de la biomasa a procesar mediante procesos de molido, esto con el fin de obtener diferentes tamaños de partícula y evaluar su influencia en el desarrollo del proceso. De la misma forma se realiza la eliminación del contenido de humedad de la misma, mediante el uso de hornos tipo mufla. No se considera de interés el estudiar la influencia de este parámetro. De la misma forma con el fin de dar soporte a posteriores labores de modelado y simulación se realizan pruebas de TGA, con el fin de establecer los parámetros cinéticos y velocidad de pérdida de masa durante el desarrollo del proceso.

Con el fin de obtener fracciones liquidas y establecer su poder calorífico, y usos potenciales. Para esto se propone la siguiente metodología:

\section{Obtención de la materia prima y puesta a punto de los equipos a usar}

Durante ese paso se deberá obtener la materia prima y se deben hacer las pruebas para verificar el debido funcionamiento del pirolizador.

\section{Pruebas fisicoquímicas y caracterización de la biomasa}

Se realizan pruebas fisicoquímicas con el fin de obtener nuestras variables de entrada (porcentaje de humedad, den- sidad, tamaño de partícula y de más características que hay que tener en cuenta).

\section{Diseño y desarrollo de plan experimental de pirolisis de biomasa}

Desarrollar un plan experimental con los parámetros establecidos para la pirolisis de biomasa.

\section{Obtención y análisis de resultados}

Análisis de producto obtenido.

\section{RESULTADOS}

A partir de la revisión bibliográfica, se determinó que, la tecnología ideal para la obtención de fracciones liquidas de alto valor energético, a partir de la pirólisis de biomasa, es la pirólisis rápida en un reactor de lecho fluidizado (Raja, 2010; Yu, 2011), esto debido a que las altas velocidades de calentamiento promueven la generación en alta proporción de fracciones liquidas (Bio-oil). A continuación se enuncian los valores establecidos para los parámetros de interés durante la realización de la fase experimental:

La humedad de la biomasa juega un papel determinante en la generación de fracciones liquidas de alto nivel energético, ya que, a mayor humedad el rendimiento energético a diversas temperaturas se verá gravemente disminuido (Giraldo, 2012; Miranda, 2009). Por lo cual la biomasa deberá pasar por un proceso de pre-secado con el fin de eliminar dicho contenido, el nivel de humedad que posee es alto.

En cuanto al tamaño de partícula se muestra que, el tamaño adecuado para la pirólisis rápida son todos los menores a $3 \mathrm{~mm}$, en donde el rango del tamaño de partícula esta entre 0.3 y $1.5 \mathrm{~mm}$ para diferentes biomasas (Gómez, 2008; Mohan, 2006). Siendo estos los indicados para la generación de fracciones liquidas; esto debido a que, al incrementar el tamaño de partícula (superando los $3 \mathrm{~mm}$ ) se incrementa la resistencia a la transferencia de calor, limitando la pirólisis completa de biomasa y favoreciendo la producción de carbonizados y productos gaseosos, por lo que el tiempo de permanencia en el reactor se hace mayor, incrementando el consumo energético del proceso.

La atmosfera de control debe ser inerte, esto con el fin de evitar que en el proceso de pirólisis se generen reacciones segundarias que promuevan el craqueo de las fracciones liquidas obtenidas (Zhang, 2010; Zuttel, 2008). La atmosfera indicada para esta investigación es nitrógeno, debido a que este gas permite incrementar las fracciones liquidas y es de bajo costo.

El rango de temperaturas ideal para la generación de fracciones liquidas resultantes del proceso de pirólisis rápida esta entre 450 y $550^{\circ} \mathrm{C}$, con velocidades de calentamiento altas (a mayor rata de calentamiento, mayor producción de Bio-oil.), en donde los periodos de residencia de la partícula 
dentro del reactor deben ser menores a 2 segundos (Gil-Lalaguna, 2014; Kirubakaran, 2009); todo esto, con el fin de minimizar la producción de fracciones gaseosas y reduciendo al máximo la producción de carbonizados, teniendo en cuenta que es indispensable realizar el proceso bajo una atmosfera inerte, la cual evita reacciones secundarias durante el proceso de pirólisis, favoreciendo la obtención de fracciones liquidas y el contenido energético de las mismas.

\section{CONCLUSIONES}

El tamaño de partícula óptimo para la generación de Bio-oil proveniente de la pirólisis de biomasa es de $0.5 \mathrm{~mm}$, por lo cual, en esta investigación se usaran tamaños de 0.5 , 1 y $2 \mathrm{~mm}$ con el fin de determinar el efecto de esta variable en la producción de fracciones liquidas a partir del cuesco de palma africana.

El efecto de las variables térmicas en la pirólisis rápida de biomasa es de gran importancia, por lo cual, para esta investigación la rata de calentamiento usada será de $1000^{\circ} \mathrm{C} /$ min con el fin de maximizar la producción de fracciones liquidas en el proceso. Además el proceso se llevará a cabo con temperaturas de reacción de 450 y $550^{\circ} \mathrm{C}$ con el fin de determinar el efecto de la temperatura en la producción de Bio-oil a partir de la pirólisis rápida de biomasa obtenida del cuesco de palma africana.

A partir del diseño experimental, el cual se realizó con el fin de determinar el número de corridas necesarias, para que los resultados obtenidos tras la pirólisis rápida del cuesco de palma africana sean de confiabilidad del 97\%. Se determinó que el número necesario de corridas es de 3 para cada tratamiento.

Para maximizar los resultados, debe realizarse un secado de la biomasa, ya que esta es separada por un hidro-ciclón, lo que produce que la biomasa utilizada en esta investigación tenga un alto porcentaje de humedad que va a entorpecer la producción de Bio-oil de alto poder energético. Por esta razón, se realizó un secado de la biomasa (sin moler) a temperatura ambiente $\left(20^{\circ} \mathrm{C}\right)$, durante un periodo de tiempo de 2 horas, ya que de no hacerse este tratamiento previo la selección del tamaño de partícula, las partículas de tamaño menor a $0.25 \mathrm{~mm}$ se aglomeraran en el molino dificultando la salida de las partículas de mayor tamaño. Esto debido a que la fuerza y la velocidad que estas partículas adquieren, gracias a las aspas del molino, y a su alta humedad, hace que estas se compacten en las paredes y en la salida del equipo. Es importante resaltar este aspecto ya que, si se in- troducen partículas húmedas en el equipo de pirólisis, estas van a tener un comportamiento similar al que presentan en el molino; se aglomerarán a tal punto que el proceso se hace menos eficiente en la generación de fracciones liquidas, lo que dificulta la fluidización del proceso (pirólisis rápida en lecho fluidizado).

\section{REFERENCIAS}

Gil-Lalaguna, N. et. al. (2014). Air-steam gasification of sewage sludge in a fluidized bed. Influence of some operating conditions. Chemical Engineering Journal, vol 129. pp. 147-155.

Giraldo, O. (2012). Conversión de biomasa recalcitrante originada en la producción de etanol a partir de la planta de banano y su fruto en combustibles mediante procesos de pirólisis. Universidad nacional de Colombia.

Gómez, A. et. al. (2008). Pirólisis de biomasa, cuesco de palma africana. Universidad de Kassel - Alemania.

Kirubakaran, V. et al. (2009). A review on gasification of biomass. Renewable and Sustainable Energy Reviews, vol. 13, pp. 179-186.

Miranda, I., Amaris, O. (2009). Aprovechamiento del potencial energético de la biomasa residual obtenida de la extracción de aceite de palma en Colombia. Facultad de Ingenierías Fisicoquímicas. Universidad Industrial de Santander - UIS.

Mohan, D. et al. (2006). Pyrolysis of Wood/Biomass for Bio-oil: A Critical Review. Energy \& Fuels,

vol. 20 , pp. 848-889.

Raja, S. A. et. al. (2010). Flash pyrolysis of jatropha oil cake in electrically heated fluidized bed reactor. Energy, vol. 35, pp. 2819-2823.

Yu, J. et. al. (2011). Biomass pyrolysis in a micro-fluidized bed reactor: Characterization and kinetics State Key Laboratory of Multi-phase Complex System. Institute of Process Engineering, Chinese Academy of Sciences, Beijing, China.

Zhang, H. et. al. (2010). Biomass fast pyrolysis in a fluidized bed reactor under $\mathrm{N} 2, \mathrm{CO} 2, \mathrm{CO}, \mathrm{CH} 4$ and $\mathrm{H} 2$ atmospheres. Bioresource technology, vol 102 (5), pp. 4258-4264.

Zuttel, A. et. al. (2008). Hydrogen as a future energy carrier. Wiley-VCH Verlag GmbH \& Co. 


\title{
SÍNTESIS DE BIOETANOL A PARTIR DE BIOMASA DE MICROALGA
}

\author{
Velásquez Torres Mónica ${ }^{1,2}$ \\ Quintero Dallos Viviana ${ }^{1,3}$ \\ Silva Archila Ginna ${ }^{1}$ \\ Kafarov Viatcheslav ${ }^{1}$ \\ ${ }^{1}$ Universidad Industrial de Santander \\ 22monica23velasquez@gmail.com \\ ${ }^{3}$ viviana0520@gmail.com
}

\begin{abstract}
RESUMEN
En la actualidad, la biomasa de microalga constituye una alternativa promisoria en la obtención de biocombustibles debido a que es una fuente de energía renovable. El objetivo de este trabajo fue sintetizar una ruta de procesamiento para la obtención de bioetanol a partir de biomasa de microalgas. Para tal fin, en primera instancia, se seleccionó la cepa de Chorella Vulgaris como fuente de biomasa; posteriormente, se analizaron las diferentes tecnologias propuestas en la literatura y a partir de un ejercicio de síntesis de procesos por programación matemática, se estableció una ruta de procesamiento para el bioetanol. En la etapa de cultivo se obtuvo la fermentación utilizando vinazas con una productividad de $1 \mathrm{~g} / \mathrm{L} /$ dia, la cosecha con centrífuga, la hidrólisis, la fermentación simultánea y la separación del bioetanol de su medio de cultivo con tamices moleculares. Se obtuvo un rendimiento de 63 Litros de bioetanol/tonelada de biomasa
\end{abstract}

Palabras claves: Bioetanol, Chorella Vulgaris, Sintesis de Procesos. 


\section{INTRODUCCIÓN}

El auge de los biocombustibles se ha solidificado últimamente debido a diversos factores, como son la disminución de disponibilidad y el incremento en el costo de combustibles fósiles, junto con el impacto de las emisiones de $\mathrm{CO} 2$ en el cambio climático. En la búsqueda de nuevas fuentes de energía, las microalgas constituyen una opción viable debido a su alta productividad por unidad de área, habilidad para el secuestro de $\mathrm{CO} 2$ y acumulación de altas cantidades de lípidos y carbohidratos (Delrue, Setier, Sahut, Cournac, Roubaud, Peltier \& Froment, 2012). Las microalgas como Chlorella, Dunaliella, Chlamydomonas, Scenedesmus y Spirulina contienen gran cantidad ( $>50 \%)$ de almidón y glucógeno, los cuales son útiles como materia prima para la producción de bioetanol (Gouveia, 2011).

El bioetanol es usado como un aditivo de combustible, o directamente como fuente de combustible, y se ha popularizado debido a las preocupaciones ambientales, pues no emiten gases contaminantes en alta proporción como lo hacen los combustibles fósiles (Mussatto, Dragone, Guimarães, Silva, Carneiro, Roberto, Vicente, Domingues \& Teixeira, 2010).

La producción de bioetanol a partir de microalga es un tema de investigación novedoso. En este trabajo se deter- mina una ruta de síntesis para su obtención, teniendo en cuenta tanto la eficiencia de sus tecnologías como los costos involucrados en las mismas.

\section{MATERIALES Y MÉTODOS}

La microalga seleccionada para la producción de bioetanol fue Chorella vulgaris, que posee una composición de 49,5\% de carbohidratos, $17,5 \%$ de lípidos y $28,2 \%$ de proteínas (Handler, Canter, Kalnes, Lupton, Kholiqov, Shonnard \& Blowers, 2012).

El esquema de producción de bioetanol a partir de biomasa de microalgas presenta 5 etapas principales: cultivo, cosecha, hidrólisis, fermentación y separación (Mussatto et al., 2010). La ruta de procesamiento fue el resultado de un ejercicio de síntesis por programación matemática. La solución del modelo de optimización se determinó por un modelo de programación lineal, entera y mixta (MILP, por sus siglas en inglés). Para establecer la ruta de síntesis de bioetanol se planteó una superestructura, como se muestra en la figura 1. Esta superestructura fue la base para programar, en el Software de modelamiento LINGO 14.0, la programación lineal, no lineal e integrada.

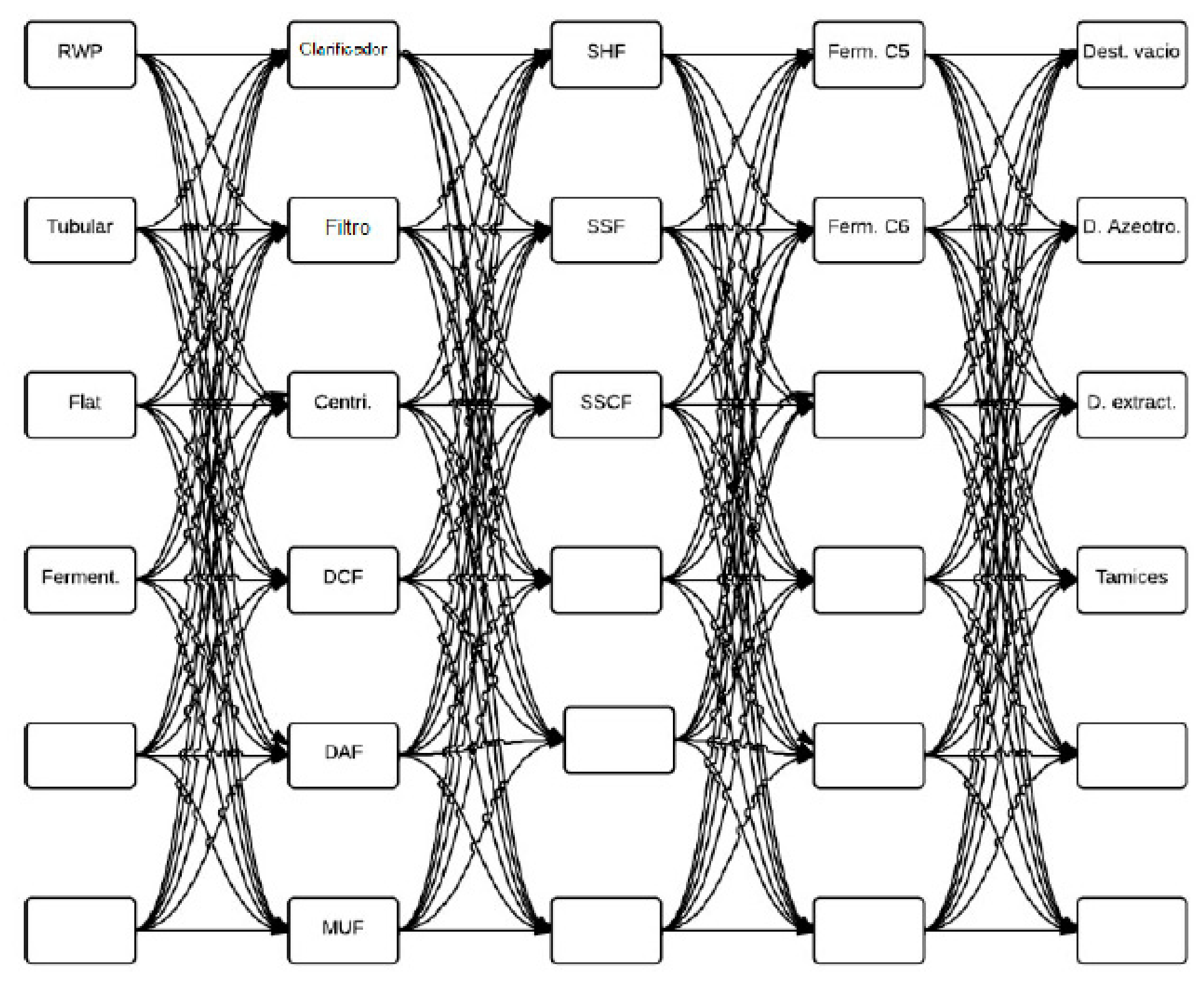

Figura 1. Superestructura para la ruta de síntesis de bioetanol a partir de microalga. 
La estructura del modelo matemático se definió con un flujo de biomasa como materia prima. Los insumos necesarios en cada bloque tecnológico entraban al sistema como corrientes laterales, llamadas corrientes extras. Las corrientes a la salida de cada bloque que no continuaban en la corriente principal se definieron como corrientes paralelas. Este esquema se presenta en la figura 2.

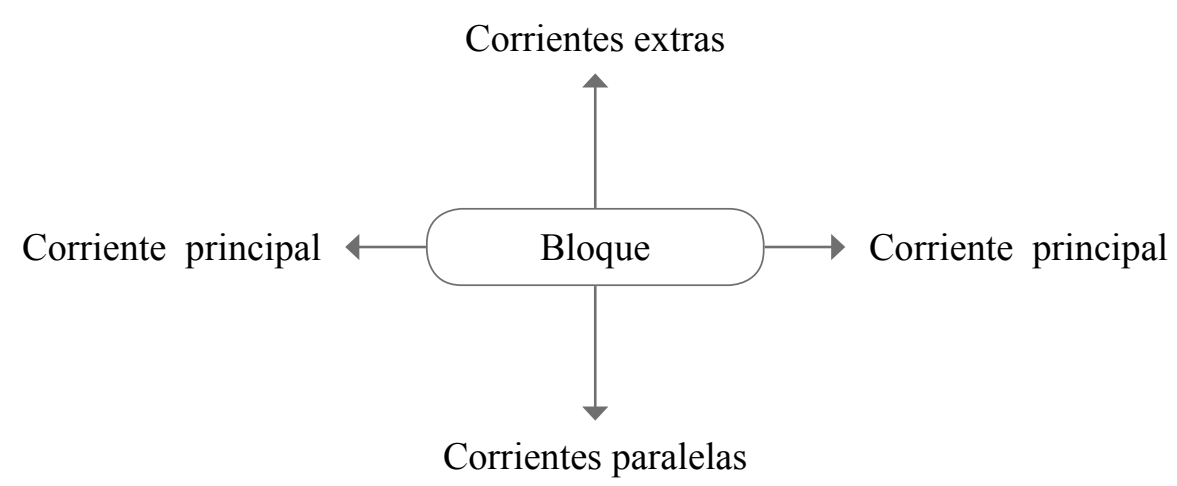

Figura 2. Esquema de los bloques de la superestructura.

La nomenclatura utilizada para este trabajo es la siguiente: las capas son las etapas necesarias para la producción de bioetanol y los operadores son cada una de las tecnologías que se propusieron en cada capa.

Para la capa del cultivo de biomasa se tuvieron en cuenta cuatro tecnologías. Para el cultivo fototrófico se utilizaron raceway pond (RWP, por sus siglas en inglés), fotobiorreactor tubular y fotobiorreactor de panel plano; mientras que para el cultivo heterotrófico se utilizó un fermentador. Las fuentes de energía en el cultivo fototrófico son la luz solar y el dióxido de carbono, mientras que en el cultivo heterotrófico son los azúcares fermentables.

En la capa de cultivo, las corrientes extras para el raceway pond, fotobiorreactor tubular y fotobiorreactor de panel plano fueron agua y $\mathrm{CO} 2$, adicionando urea al raceway pond. Para el fermentador, las vinazas se definieron como una corriente extra.

Para la capa de cosecha de microalga se plantearon las siguientes tecnologías: clarificador, filtro prensa, centrifuga, microfiltración de flujo cruzado (DCF, por sus siglas en inglés), flotación por aire disuelto (DAF, por sus siglas en inglés) y ultrafiltración con membrana (MUF, por sus siglas en inglés).

Para la capa de cosecha, el total de sólidos supendidos (TSS) en la salida de las tecnologías determinaron la cantidad de flujo que se separaba por la corriente paralela y, a la vez, concentraba el medio de cultivo. En esta capa se asumió que la biomasa se descomponía en carbohidratos, proteínas y lípidos.

Para la capa de hidrólisis de los carbohidratos de la microalga se contempla la hidrólisis enzimática, basada en diferentes tecnologías: la hidrólisis y fermentación separada (SHF, por sus siglas en inglés), la hidrólisis y fermentación simultánea (SSF, por sus siglas en inglés) y la hidrólisis y cofermentación (SSCF, por sus siglas en inglés). En la SHF y SSF se hidroliza los carbohidratos y se fermentan los azúcares de seis carbonos, con la opción de fermentar, también, los de cinco carbonos; mientras que en la SSCF en un biorreactor, se hidroliza y se fermentan los azúcares de cinco y seis carbonos (Taherzadeh \& Karimi, 2007).

En la capa de hidrólisis, los carbohidratos se descomponen en $35,28 \%$ de celulosa, $10,19 \%$ de hemicelulosa y $20,52 \%$ de almidón (Zhou, Zhang, Wu, Gong \& Wang, 2011). Después de esta transformación, la celulosa se transforma en glucosa y la hemicelulosa en xilosa. Dependiendo de cada tecnología, la fermentación de los azúcares simples se llevan a cabo en la capa de hidrólisis y/o en la capa de fermentación.

Para la capa de separación del bioetanol del medio de cultivo, se contempló un esquema de destilación convencional, seguido de una deshidratación, la cual se basó en cuatro tecnologías: la destilación azeotrópica, la destilación extractiva, la destilación al vacío y la adsorción con tamices moleculares.

En la capa de separación se obtiene el producto final, el bioetanol. La concentración en peso del caldo de la fermentación es un factor determinante para la eficiencia de cada tecnología en esta capa.

Después de estructurar el proceso con sus características y restricciones propias, se procedió a modelar matemáticamente para optimizar una función objetivo, basada en el rendimiento de cada tecnología y consideraciones económicas.

La función objetivo del modelo matemático, para determinar la ruta de síntesis de bioetanol a partir de microalga, es la siguiente:

$$
\begin{aligned}
& \frac{\text { Utilidad }}{\Lambda \tilde{\text { ño }}}=\left\{\left[\left(\sum_{0}^{O} M \int \mathrm{uul}_{C, \text { o,bioetanol }} * P M_{\text {bioetanol }}\right) * \text { Preciv }_{\text {bioetanol }}\right.\right. \\
& -\sum_{c}^{C} \sum^{o}\left(\text { Fin }_{c, o}+\text { Finex }_{c, o}\right) * \operatorname{Cop}_{c, o} \\
& -\sum_{c}^{c} \sum_{o}^{c} \sum_{e}^{D}\left(\text { Mfinex }_{c, 0, e} * \text { PM }_{e} * \text { Precio }_{e}\right)-\sum_{c}^{C} \sum_{o}^{O}\left(\text { Qenf }_{c, 0} *\right. \text { Cenf } \\
& \left.\left.+Q_{c a l} c_{c, o} *(c a l)-F m p * \text { Precio }_{m p}\right] * \frac{\text { dias }}{A \tilde{n} o}\right\} \\
& -\left[\sum_{c}^{c} \sum_{o}^{o}\left(N_{c, o} * C f i x_{c, o}\right) * \frac{1}{\Lambda \text { ños a difcrir }}\right]
\end{aligned}
$$

En donde c se refiere a la capa, o al operador y e al compuesto; Mfinex es el flujo molar de las corrientes extras y Mfout es el flujo molar de las corrientes de salida; Fin es el flujo másico de las corrientes de entrada, Finex es el flujo másico de las corrientes extras y Fmp el flujo másico de materia prima; $\mathrm{N}$ es la capacidad de referencia, determinado a partir del flujo de entrada total y PM es la masa molecular. En la tabla 1 se presentan las especificaciones de la función objetivo. 
Tabla 1. Especificaciones de la función objetivo

\begin{tabular}{|c|c|}
\hline Componentes de la función objetivo & Descripción \\
\hline$\left(\sum_{0}^{0} M\right.$ fout $\left._{\text {C.,.bioetanol }} * P M_{\text {bioetanol }}\right) *$ Precio $_{\text {bioetanor }}$ & Precio de bioetanol producido en la ruta \\
\hline$\sum_{c}^{C} \sum_{o}^{O}\left(\right.$ Fin $_{c, o}+$ Finex $\left._{c, o}\right) * \operatorname{Cop}_{c, o}$ & $\begin{array}{l}\text { Costo operacional teniendo en cuenta } \\
\text { las corrientes totales de entrada }\end{array}$ \\
\hline$\sum_{c} \sum_{o} \sum_{e}\left(\right.$ Mfinex $_{c, o, e} *$ PM $_{e} *$ Precio $\left._{e}\right)$ & Costo de los insumos \\
\hline$\sum_{c}^{c} \sum_{o}^{0}\left(Q e n f_{c, o} *\right.$ Cenf $\left.+Q c a l_{c, o} * C c a l\right)$ & Costo de los servicios industriales \\
\hline Fmp $*$ Precio $_{m p}$ & Costo de la materia prima \\
\hline$\sum_{c}^{c} \sum_{o}^{o}\left(N_{c, o} * C f i x_{c, o}\right)$ & Costo fijo de inversión \\
\hline
\end{tabular}

Esta función objetivo se basó en la tesis de pregrado de Pineda (2014), titulada Desarrollo de un modelo MILP para la síntesis de una ruta de procesamiento de bioetanol a partir de bagazo de caña.

\section{RESULTADOS}

La estructura de los bloques del proceso para la obtención de bioetanol a partir de microalgas se define en capas (etapas) y operadores (tecnologías), como se muestra en la tabla 2.

Tabla 2. Bloques para la determinación de la ruta de síntesis de bioetanol a partir de biomasa

\begin{tabular}{|c|c|c|c|c|c|c|c|c|}
\hline & & & \multicolumn{6}{|c|}{ OPERADORES } \\
\hline & & & 1 & 2 & 3 & 4 & 5 & 6 \\
\hline \multirow{5}{*}{ CAPAS } & Cultivo & 1 & Raceway & $\begin{array}{c}\text { Fotobiorreactor } \\
\text { tubular }\end{array}$ & $\begin{array}{l}\text { Fotobiorreactor } \\
\text { de Panel plano }\end{array}$ & Fermentador & & \\
\hline & Cosecha & 2 & Clarificador & Filtro prensa & Centrífuga & DCF & DAF & MUF \\
\hline & Hidrólisis & 3 & SHF & SSF & SSCF & & & \\
\hline & Fermentación & 4 & $\begin{array}{c}\text { Fermentación } \\
\text { de azúcares } \\
\text { de } 6 \text { carbonos }\end{array}$ & $\begin{array}{c}\text { Fermentación } \\
\text { de azúcares } \\
\text { de } 5 \text { carbonos }\end{array}$ & & & & \\
\hline & Destilación & 5 & $\begin{array}{c}\text { Destilación } \\
\text { al vacío }\end{array}$ & $\begin{array}{l}\text { Destilación } \\
\text { azeotrópica }\end{array}$ & $\begin{array}{c}\text { Destilación } \\
\text { Extractiva }\end{array}$ & $\begin{array}{c}\text { Tamices } \\
\text { moleculares }\end{array}$ & & \\
\hline
\end{tabular}

La capa de cultivo se basó en la productividad de biomasa de cada tecnología, como se muestra en la tabla 3.

Tabla 3. Densidad celular y productividad de las diferentes tecnologías en la etapa de cultivo

\begin{tabular}{|c|c|c|c|}
\hline Cultivo & $\begin{array}{c}\text { Densidad celular } \\
(\mathrm{g} / \mathrm{L})\end{array}$ & $\begin{array}{c}\text { Productividad } \\
(\mathrm{g} / \mathrm{L} / \mathrm{dia})\end{array}$ & Referencia \\
\hline Raceway Pond & 0,32 & 0,0493 & $\begin{array}{c}\text { Norsker et al. (2011), Pardo } \\
\text { Cárdenas et al. (2012) }\end{array}$ \\
\hline Fotobiorrector Tubular & 1,7 & 0,462 & Norsker et al. (2011) \\
\hline Fotobiorrector de panel plano & 2,01 & 0,55 & Norsker et al. (2011) \\
\hline Fermentator & 0,4 & 1 & Rios Cárdenas (2013) \\
\hline
\end{tabular}

La capa de cosecha se basa en el total de sólidos suspendidos (TSS), un factor que ha sido cuantificado en la literatura para las tecnologías de mayor aplicación, tal como se muestra en la tabla 4. Para esta capa se tuvo en cuenta la energía consumida por estas tecnologías para obtener el costo operacional. La energía consumida por las tecnologías en la capa de cosecha es presentada en la tabla 5. 
Tabla 4. TSS de las tecnologías de la cosecha

\begin{tabular}{|c|c|c|}
\hline Tecnología & TSS & Referencia \\
\hline Clarificador & $1,5 \%$ & Schreiber Pure Ingenuity \\
\hline $\begin{array}{c}\text { Filtro prensa } \\
\text { de correa }\end{array}$ & $9,5 \%$ & Molina Grima et al. (2003) \\
\hline Centrifuga & $25 \%$ & Richardson et al. (2014) \\
\hline $\begin{array}{c}\text { Microfiltración } \\
\text { de flujo cruzado }\end{array}$ & $15 \%$ & Ríos et al. (2013) \\
\hline $\begin{array}{c}\text { Flotación } \\
\text { por aire disuelto }\end{array}$ & $10 \%$ & Richardson et al. (2014) \\
\hline $\begin{array}{c}\text { Ultrafiltración } \\
\text { con membrana }\end{array}$ & $9 \%$ & Molina Grima et al. (2013) \\
\hline
\end{tabular}

Tabla 5. Energía consumida por las tecnologías de la cosecha

\begin{tabular}{|c|c|c|}
\hline Tecnología & $\begin{array}{c}\text { Energía } \\
\left(\mathrm{kWh} / \mathrm{m}^{3}\right)\end{array}$ & Referencia \\
\hline Clarificador & 0,10 & Uduman et al. (2010) \\
\hline Filtro prensa de correa & 0,45 & Molina Grima et al. (2003) \\
\hline Centrífuga & 8 & Uduma et al. (2010) \\
\hline $\begin{array}{c}\text { Microfiltración } \\
\text { de flujo cruzado }\end{array}$ & 0,4 & Bilad et al. (2012) \\
\hline $\begin{array}{c}\text { Flotación } \\
\text { por aire disuelto }\end{array}$ & 15 & Uduma et al. (2010) \\
\hline $\begin{array}{c}\text { Ultrafiltración } \\
\text { con membrana }\end{array}$ & $0,0769^{*}$ & $\begin{array}{c}\text { Richardson } \text { et al. (2014) } \\
{ }^{*} \mathrm{kWh} / \mathrm{kg} \text { biomasa seca }\end{array}$ \\
\hline
\end{tabular}

Las reacciones que se asumen en el proceso de la obtención de bioetanol a partir de microalga se presentan en la tabla 6 .

Tabla 6. Reacciones contempladas para la obtención de bioetanol a partir de microalga

\begin{tabular}{|c|c|c|}
\hline Reacción & Descripción & $\begin{array}{c}\text { Etapa } \\
\text { donde ocurre }\end{array}$ \\
\hline 1 & $\mathrm{C}_{6} \mathrm{H}_{10} \mathrm{O}_{5}+\mathrm{H}_{2} \mathrm{O} \rightarrow \mathrm{C}_{6} \mathrm{H}_{12} \mathrm{O}_{6}$ & Hidrólisis \\
\hline 2 & $\mathrm{C}_{5} \mathrm{H}_{8} \mathrm{O}_{4}+\mathrm{H}_{2} \mathrm{O} \rightarrow \mathrm{C}_{5} \mathrm{H}_{10} \mathrm{O}_{5}$ & Hidrólisis \\
\hline 3 & $\mathrm{C}_{6} \mathrm{H}_{12} \mathrm{O}_{6} \rightarrow 2 \mathrm{C}_{2} \mathrm{H}_{5} \mathrm{OH}+2 \mathrm{CO}_{2}$ & $\begin{array}{c}\text { Fermentación o Hi- } \\
\text { dríolisis }\end{array}$ \\
\hline 4 & $3 \mathrm{C}_{5} \mathrm{H}_{10} \mathrm{O}_{5} \rightarrow 5 \mathrm{C}_{2} \mathrm{H}_{5} \mathrm{OH}+5 \mathrm{CO}_{2}$ & Fermentación \\
\hline
\end{tabular}

Se contemplaron los bloques que conforman el proceso, como son el rendimiento de las tecnologías por sus características principales, los costos de los equipos y los costos operacionales, este último basado en el costo de la energía consumida y el costo de los insumos. Además de tener en cuenta el costo de la materia prima, de servicios industriales y el bioetanol, como producto obtenido, se procedió a optimizar la función objetivo en LINGO 14.0.

La ruta de síntesis para la producción de bioetanol a partir de microalga, determinada a partir de la optimización de un modelo matemático, es: Fermentador, centrífuga, hidrólisis y fermentación simultánea (SSF) y separación por medio de tamices moleculares.

Con la ruta de síntesis determinada, el rendimiento de bioetanol a partir de Chorella vulgaris es de 63 Litros de bioetanol/tonelada de biomasa.

\section{CONCLUSIONES}

La producción de bioetanol a partir de microalga es un tema de investigación promisorio. No obstante, las fuentes bibliográficas sobre este caso de estudio son limitadas y los resultados difieren según los países donde se estudian; esto se debe a que las condiciones climáticas afectan directamente la productividad de las microalgas en aquellos casos en que se cultivan fototróficamente.

La determinación de una ruta de síntesis de bioetanol a partir de microalga es importante para el campo de las energías renovables, pues ofrece un panorama general de las tecnologías seleccionadas para cada etapa necesaria en la obtención de este biocombustible. Las microalgas se tornan promisorias bajo el concepto de biorrefinería, pero resultan inviables si se direccionan a un sólo producto.

Aunque el rendimiento de bioetanol por tonelada de biomasa de entrada es bajo, se esperaría que en algunos años este rendimiento pueda alcanzar valores más altos gracias a los avances tecnológicos en la etapa del cultivo de la biomasa y/o la innovación en temas de ingeniería genética que busquen modificar las microalgas. Todo esto con la expectativa de para que aumente la productividad de carbohidratos y la eficiencia en la producción de bioetanol. Además, que incremente la posibilidad de utilizar nuevas tecnologías en todas las etapas del proceso, las cuales presenten menos costos de inversión, menos costos energéticos y/o con una mayor eficiencia.

\section{REFERENCIAS}

Bilad M.R., Vandamme D., Foubert I., Muylaert K. \& Vankelecom Ivo F.J. (2012) Harvesting microalgal biomass using submerged microfiltration membranes. Bioresource Technology, 111, 343-352.

Delrue F., Setier P., Sahut C., Cournac L., Roubaud A., Peltier G. \& Froment A. (2012) An economic, sustainability, and energetic model of biodiesel production from microalgae. Bioresource Technology, 111, 191-200.

Gouveia L. (2011) Microalgae as a Feedstock for Biofuels. London: SpringerBriefs in Microbiology, 10.

Handler R. M., Canter C. E., Kalnes T. N., Lupton S., Kholiqov O., Shonnard D. R. \& Blowers P. (2012) Evaluation of environmental impacts from microalgae cultivation in open-air raceway ponds: Analysis of the prior literature and investigation of wide variance in predicted impacts. Algal Research, 1, 83-92.

Molina Grima E., Belarbi E. H., Acién Fernández F.G., Robles Medina A. \& Yusuf Chisti Y. (2003) Recovery of microalgal biomass and metabolites: process options and economics. Biotechnology Advances, 20, 491-515.

Mussatto S. I., Dragone G., Guimarães P. M. R., Silva J. P. A., Carneiro L. M., Roberto I. C., Vicente A., Domingues L. 
\& Teixeira J. A. (2010) Technological trends, global market, and challenges of bio-ethanol production. Biotechnology Advances, 28, 817-830.

Norsker N., Barbosa M. J., Vermuë M. H. \& Wijffels R. H. (2011) Microalgal production -A close look at the economics. Biotechnology Advances, 29, 24-27.

Pardo Cárdenas Y., Herrera-Orozco I., González Delgado A. \& Kafarov V. (2013) Environmental assessment of microalgae biodiesel Production in Colombia: comparison of three oil extraction systems. Ciencia, Tecnología y Futuro, $5,85-10$.

Pineda Portilla R. M. (2014) Desarrollo de un modelo MILP para la síntesis de una ruta de procesamiento de bioetanol a partir de bagazo de caña. Tesis de pregrado, Universidad Industrial de Santander, Colombia.

Richardson J., Johnson M., Zhang X., Zemke P., Chen W. \& Hu Q. (2014) A financial assessment of two alternative cultivation systems and their contributions to algae biofuel economic viability. Algal Research, 4, 96-104.

Ríos Cárdenas O. A. (2013) Estudio del efecto de las vinazas en la composición de Chorella Vulgaris UTEX 1803 para la producción de biocombustibles y productos de valor agregado. Tesis de pregrado, Universidad Industrial de Santander, Colombia.

Ríos S. D., Torres C. M., Torras C., Salvadó J., Mateo-Sanz J. M. \& Jiménez L. (2013) Microalgae-based biodiesel: Economic analysis of downstream process realistic scenarios. Bioresource Technology, 136, 617-625.

Schreiber Pure Ingenuity. Recuperado el 12 de Agosto de 2014 de: http://www.schreiberwater.com/Clarifier.shtml

Taherzadeh M. J. \& Karimi K. (2007) Enzyme based hydrolysis processes for ethanol from lignocellulosic materials: a review. BioResources, 2(4), 707-738.

Uduman N., Qi Y., Danquah M. K., Forde G. M. \& Hoadley A. (2010) Dewatering of microalgal cultures: A major bottleneck to algae-based fuels. Journal of renewable and sustainable energy, 2, 13.

Zhou N., Zhang Y., Wu X., Gong X. \& Wang Q. (2011) Hydrolysis of Chlorella biomass for fermentable sugars in the presence of $\mathrm{HCl}$ and $\mathrm{MgCl} 2$. Bioresource Technology, $102,10158-1016$. 


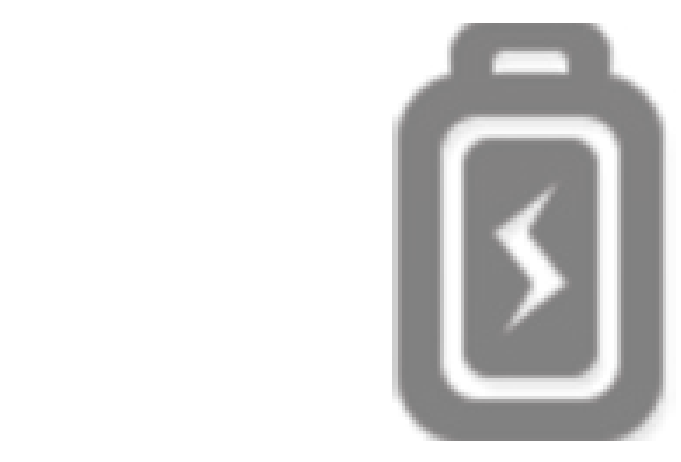

EFICIENCIA Y AUDITORÍA ENERGÉTICA 


\title{
Eficiencia y Auditoría Energética
}

\author{
J.R. Constante1 \\ 1 Instituto Nacional de Eficiencia Energética y Energías Renovables, Av. 6 de diciembre \\ N33-32 e Ignacio Bosano, Quito, Ecuador.
}

\section{RESUMEN}

Del total de la energía primaria utilizada en el mundo, el 63\% se pierde en los procesos de transformación y tan solo el $37 \%$ se lo aprovecha en un servicio entregado. La eficiencia energética (EE) se define como la capacidad para usar menos energía manteniendo o aun mejorando la producción y el confort, siendo un pilar fundamental para el desarrollo sostenible, el cual intenta satisfacer las necesidades energéticas de la presente generación sin comprometer las futuras, comprendiendo el medio ambiente, la economía y la equidad. La EE puede tomar medidas desde la oferta y la demanda. En el lado de la oferta, las medidas y políticas establecidas son relativamente fáciles de implementar, ya que dependen de la decisión de pocas personas o empresas. Implementar medidas en el lado de la demanda es sumamente complicado ya que depende de múltiples decisiones de los clientes y su tiempo de ejecución es amplio. La EE es aceptada como una fuente de energía, y para los últimos 35 años en Latinoamérica y el Caribe (LAC) ha venido siendo el principal recurso energético, ya que ha reducido el consumo de energía en aproximadamente un 35\%. Sin embargo, los países de LAC requieren de un sector energético más competitivo, y la planeación es indispensable para lograrlo. La Organización Latinoamericana de Energía (OLADE), tiene como politica hacer de la eficiencia energética un recurso sostenible en los países de la región, y tiene varias estrategias para cumplirlo. La norma ISO 50001, especifica los requisitos para implementar un sistema de gestión energética (SGEn) en organizaciones, junto al cual se crea una política energética, se establecen metas, planes de acción, acciones legales, y todo lo relacionado al uso significativo de la energía. Un SGEn permite alcanzar a la organización los compromisos de su política, tomar decisiones y mejorar el desempeño energético a satisfacción de la norma ISO 50001. La EE inicia su agenda en una etapa de diagnóstico o evaluación de las condiciones actuales del sistema, complementado con un análisis de su evolución histórica y sus perspectivas de expansión a futuro. El diagnóstico energético es el instrumento imprescindible para saber cuánto, cuándo, cómo, dónde y por qué se consume la energía, así como la forma para establecer el grado de eficiencia en su utilización. La Auditoría Energética tiene como objetivo verificar el cumplimiento de un programa de gestión de la energía previamente establecida, donde se definieron procesos y metas específicas respecto al ahorro y mejoramiento de la EE. Si el programa de gestión de la energía se encuentra certificado por la norma ISO 50001, la Auditoría Energética que exige dicha Norma, se encuentra estandarizada bajo la norma ISO 50002.

Palabras Clave: Eficiencia energética, auditoria energética, sistema de gestión de la energía. 


\title{
EL ANÁLISIS DE OPORTUNIDADES Y DE COSTO BENEFICIO EN LA REALIZACIÓN DE AUDITORÍAS ENERGÉTICAS
}

\author{
Enrique Posada Restrepo ${ }^{1,2}$ \\ Steven Ángel Cañas ${ }^{1}$ \\ Gilmar Saenz Tejada ${ }^{1}$ \\ Gabriela Valencia Galeano ${ }^{1}$ \\ Viviana Monsalve Nustes ${ }^{1}$ \\ ${ }^{1}$ INDISA S.A \\ ²enrique.posada@indisa.com
}

\begin{abstract}
RESUMEN
Son muchas las empresas que miden la sostenibilidad de sus procesos a través de indicadores del consumo de recursos como energía y agua y de indicadores de generación de residuos. Las posibilidades de sostenibilidad en los procesos industriales están intimamente relacionadas con la forma en que se maneje la energía y se racionalicen los consumos. La generación de valor agregado como resultado del manejo adecuado de la energía y de los recursos ambientales permite contar con patrimonio para financiar los desarrollos de tecnología, innovar y desarrollar proyectos pioneros en el uso de energías limpias y renovables. La complejidad del uso de la energía en las industrias de proceso da lugar a oportunidades de ahorro. Es así, como los estudios y auditorías de energía permiten acercarse a esta complejidad para descubrir posibilidades de cambio. En el presente escrito, se comparte una metodología de análisis de costo-beneficio, orientada hacia la generación de proyectos que materialicen proyectos y gestionen cambios. Dicha metodología está basada en la experiencia real de más de cincuenta casos desarrollados por los autores durante su trabajo en la empresa de ingeniería de proyectos INDISA S.A. Además, se incluye un modelo generalizado para descubrir beneficios basándose en datos estadísticos de producción.
\end{abstract}

Palabras claves: Auditorías energéticas, minimización, análisis de datos, consumo específico, producción media, ahorro, energía, sostenibilidad, costo-beneficio, indicadores. 


\section{INTRODUCCIÓN}

En los países desarrollados, se estima que alrededor del $40 \%$ del consumo de energía está relacionado con la actividad de las empresas. Por ello, la producción de energía y el consumo de recursos empresariales han sido identificados como factores importantes en asuntos de sostenibilidad, conservación y calentamiento global, teniendo en cuenta, además, que registran altos potenciales de crecimiento (Rosemarie \& Pascal, 2014).

Según el último reporte del Ministerio de Minas y Energía de Colombia, el consumo mensual de energía eléctrica es de 5025 GWh (Ministerio de Minas y Energía (UPME), 2012), cifra significativa que representa solamente una parte de los consumos de energía y que implica la necesidad de gestionar y racionalizar los consumos por su claro impacto medio ambiental. Las auditorías energéticas resultan ser un mecanismo esencial para valorar los consumos internos y para establecer metas y desafíos benéficos para la sostenibilidad. El principal valor agregado de la realización de auditorías de energía es que estimulan la formación de una mayor conciencia y de una cultura de la gestión de la energía, lo cual desata acciones de mejora, totalmente necesarias para la sostenibilidad.

Existe un rango amplio de acciones asociadas con las formas en que se definen las auditorías energéticas. Estas incluyen enfoques centrados en localizar excesos de consumos, es decir evaluar el nivel de «voracidad» energética de una instalación, aportando estudios para disminuir costes, gastos de explotación, mantenimiento y reposición y contribuyendo así a preservar el medio ambiente (García Sanz-Calcedo, Cuadros, \& López Rodríguez, 2011). En INDISA, se definen las auditorías como mecanismos de revisión y diagnóstico, realizados por agentes externos o internos, que permiten a la empresas contar con datos y evidencias sobre el consumo de energía, sobre la relación entre este y sus procesos y sobre la forma en que el manejo de la energía se está gestionando. Como herramienta de creación de conciencia y de praticidad del trabajo de revisión y auditoría, se sugiere contar siempre con instrumentos de análisis de costo-beneficio para incluir los aspectos económicos de la sostenibilidad.

INDISA SA es una empresa de ingeniería de proyectos donde laboran los autores de este trabajo, quienes hacen parte del Grupo de Procesos, Energía y Medio Ambiente. Este grupo especializado, realiza estudios y auditorías energéticas para clientes nacionales e internacionales. En estas actividades, existen aspectos importantes que son tenidos en cuenta:

- Aproximaciones a los balances de energía de componentes y sistemas importantes.

- Revisión de procesos desde lo energético, examinando sus aciertos e identificando las causas de ineficiencia.
- Revisiones de proceso desde el análisis de sus controles y de su funcionamiento.

- Establecimiento y revisión de indicadores energéticos.

- Revisión de acciones realizadas por la gerencia para mejorar los aspectos energéticos.

- Aproximaciones a la cultura y al nivel de concientización de las personas que tienen relación con el proceso y la energía en lo relativo a asuntos de gestión de energía.

Al realizar la auditoría energética, si se cuenta adicionalmente con la información adecuada, es decir, si está disponible y organizada toda aquella información que es resultado del trabajo realizado por la empresa en términos de energía (recolección de datos, disposición de equipos, implementación de estrategias de mejora, disponibilidad del recurso humano, económico y administrativo), resulta más efectiva la evaluación y permite con mayor acierto establecer metas claras para el mejoramiento.

\section{METODOLOGÍA}

Para llevar a cabo el desarrollo de una auditoría energética, es necesario precisar en algunos aspectos que son claves para llevar a cabo su ejecución. Es por esto, que se debe tener claro como punto de partida el tipo de auditoría que se va a realizar ya sea por áreas, por funciones, por uso de energía o por procesos. Para determinar el tipo de auditoría energética que se requiere, debería existir un conocimiento esencial del proceso por parte de operadores y de gestores. En este conocimiento hay que tener en cuenta el trabajo en equipo y estimular el intercambio de información y de conceptos entre la empresa y los auditores, con la idea de hablar un lenguaje común y establecer vínculos de confianza.

INDISA considera importante disponer de espacios de comunicación e intercambio de conceptos antes de dar inicio a las actividades de auditoría. Por ello, siempre se lleva a cabo una reunión con un grupo significante de personas de todos los niveles de la empresa, en donde:

- El auditor presenta de forma sencilla y comprensible para todos los asistentes los conceptos básicos de energía, sostenibilidad, eficiencia, balance, pérdida y consumo, buscando que participación y debate.

- Se exponen los objetivos, se explica el plan de trabajo a desarrollar en la auditoría y se pide participación y colaboración.

- Se lleva a cabo un taller para evaluar algunos aspectos elementales entre los participantes y localizar áreas de interés y aspectos culturales.

- Se lleva a cabo un taller de ideación para recoger sugerencias y propuestas sobre aspectos del manejo de la energía en la empresa. 
Esta actividad adicional y sus talleres hacen parte de las reflexiones y resúmenes que se entregan al cliente.

Por otra parte, dado que INDISA es una empresa de ingeniería de proyectos, su enfoque en las auditorías está centrado en los procesos, en la tecnología y en ofrecer valor agregado. Por ello, el énfasis se hace en recoger datos de proceso y de sus relaciones con la energía, sea como resultado del trabajo de campo del equipo auditor en sus visitas, o como resultado de la información que entregue la empresa sobre sus procesos productivos de forma espontánea o por solicitud de los auditores. Es evidente que este tipo de auditorías implica un trabajo importante de análisis de información, posterior a las visitas de campo.

\section{Niveles de la empresa y acciones de mejora asociados}

Para establecer las acciones de mejora, INDISA considera los siguientes tres niveles en las empresas:

- Nivel de piso (zona de operación) donde se realizan acciones inmediatas y de corto plazo.

- Nivel de dirección de planta de procesos individuales o generales. Donde se realizan acciones que toman semanas o meses (acciones de medio plazo basadas en proyectos de corta duración).

- Nivel de gerencia o de dirección general de planta. Donde se llevan a cabo acciones anuales (de largo plazo y de larga duración, que implican presupuestos importantes y proyectos significativos).

Las acciones anteriormente nombradas corresponden, a su vez, a los niveles de gasto, inversión y presupuesto. Para localizarlas en cada uno de los niveles se tiene en cuenta que las acciones a nivel operativo no asocian gastos de inversión altos, las acciones de mando y mejoramiento tecnológico pueden representar inversiones bajas y las acciones de cambio tecnológico, representan altas inversiones que se sustentan en el mejoramiento de la capacidad, aumento de la producción y cambios energéticos.

Las auditorías que hace INDISA intentan localizar y proponer acciones en los tres niveles y aproximarse en lo posible, a un primer análisis de costo-beneficio para los casos significativos que se logren detectar. En la experiencia que se tiene, se ha visto que se logran plantear varios proyectos en cada empresa donde es común generar ahorros y mejoras que permiten pagar las inversiones en plazos atractivos. Naturalmente, la realidad de estos cambios se logra definir con base en proyectos de ingeniería y en acciones que implican inversiones, trabajo y compromiso por parte de la empresa auditada.

\section{Manejo de los datos de consumo y sus rela- ciones con la energía y el proceso}

Los datos de consumo de energía en función de los procesos productivos, representan para las empresasuna fuente de indicadores para establecer acciones que permitan la disminución de sus consumos de energía, para el aprovechamiento de los recursos y para alcanzar ahorros significativos en el proceso mismo, no necesariamente de tipo energético. Es común encontrar en las compañías que la información recolectada de las actividades productivas, en función de los consumos de energía, es relativamente simple y básica, donde se cuenta normalmente con tablas manuales y algunos datos automáticos extraídos de la instrumentación del proceso, sin que sea utilizada con fines de mejoramiento como los que se han estado describiendo (Posada, 2008). Lo normal es registrar los datos con fines informativos e históricos, sin profundizar en las posibilidades de estos datos para aspectos como los siguientes:

- Construcción de indicadores que faciliten la optimización.

- Establecimiento de correlaciones entre variables para lograr mayor dominio de los procesos y desarrollar capacidades predictivas.

- Comparación de las situaciones con el estado del arte y con las mejores prácticas.

- Establecimiento y segumiento de metas basadas en la producción.

- Localización sistemática de zonas de trabajo que dan lugar a dificultades o, por el contrario, a altas calidades y rendimientos.

- Facilidad del análisis teórico de los procesos.

\section{Casos de estudio}

A través de diferentes proyectos de auditoría y estudios energéticos realizados en INDISA S.A, se ha logrado una aproximación acertada a empresas de diversos sectores industriales como el químico, de alimentos, de transporte, de cementos, entre otros. Las metodologías de las auditorías energéticas realizadas por INDISA S.A están conformadas por una serie de actividades que pretenden reunir la información necesaria para establecer planes de mejoramiento en cuanto a las estrategias de ahorro y disminución de consumo de energía.

La línea base de la metodología inicia con la formulación y presentación de un plan de actividades generales para la auditoría donde se dan a conocer los objetivos de la actividad, los alcances, la metodología, los recursos y la duración. Igualmente, se hace una primera recolección de información básica por medio de una encuesta sencilla, aplicada previamente a la visita de auditoría. Esta encuesta está orientada a recoger información sobre consumos de energéticos, motores y sus potencias, calderas, consumidores térmicos y sistema eléctrico. En lo posible, se recoge información sobre productos y procesos, sobre la categorización de los mismos, sobre el tipo de gestión energética que se hace, sobre el nivel en que se encuentra la gestión, sobre indicadores y consumos específicos y sobre las oportunida- 
des que la empresa o el equipo operador conocen y que desean explorar en la auditoría.

Sumado a lo anterior, hay que completar la información con visitas a la empresa y solicitudes de información posterior a las visitas, que permitan refinar el análisis. En las visitas, aplicadas en zonas de trabajo convenidas con las empresa, se realizan seguimientos y verificaciones del proceso objeto de la auditoría. La duración de la o las visitas técnicas puede tomar entre un día o una semana y está precedida de la reunión y el taller de contacto que ya se ha descrito. Los datos recolectados durante la visita son obtenidos a través de los instrumentos normales del proceso o en algunos casos, a través de instrumentos manejados por el auditor. La información recolectada generalmente son datos de procesos, de consumos y de producción, condensados en los registros de la empresa. Para retroalimentar los hallazgos encontrados, se realiza una sesión de reuniones donde los participantes son, generalmente, los responsables del proceso de gestión de energía. En estas reuniones, se explican generalidades sobre la energía y los procesos, los objetivos de la auditoría y su metodología, y se recogen inquietudes, ideas y aportes de quienes serán parte del proceso de auditoría.

Como complemento al trabajo de campo, el equipo auditor dedica tiempo importante al análisis de la información recolectada, intentando hacer una aproximación rigurosa a los datos, que si es del caso, deben ser completados a partir de comunicaciones y contactos adicionales con la empresa. Hace parte esencial del trabajo, el elaborar algunos modelos simples de comportamiento y de predicción para explorar posibles mejoras y el plantear aspectos de costo beneficio. Igualmente, examinar los hallazgos desde el punto de vista estratégico para encontrar las oportunidades de mejora y de ahorro que se van a constituir en importantes valores agregados del trabajo. Se realiza un informe con ilustraciones, gráficos y curvas, que es entregado a los responsables del proceso con las descripciones de los hallazgos y los análisis de ahorro y costo-beneficio para las oportunidades detectadas.

\section{RESULTADOS GENERALES OBTENIDOS EN LOS TRABAJOS DESARROLLADOS POR INDISA EN SUS ESTUDIOS DE ENER- GÍA PARA CLIENTES INDUSTRIALES}

INDISA ha realizado estudios y auditorías energéticas a más de treinta procesos y ha hecho una valoración a la riqueza de datos obtenidos para desarrollar una visión del comportamiento de los consumos específicos de energía en función de los datos de producción. Se parte del hecho que al estudiar, para cada proceso, el comportamiento histórico de los consumos específicos, como función de las producciones, se pueden establecer correlaciones significativas, a partir de las cuales se plantean metas de ahorro racionales en los procesos productivos. Como se ha mencionado an- teriormente, al trabajar bajo una amplia gama de industrias (cervecera, textil, cementera, cerámica, arrocera, de transporte, entre otras), el análisis generalizado permite plantear conclusiones que se puedan extender a muchas situaciones. Esto se logra a través del análisis de variables adimensionales.

Dentro de este análisis, se han establecido dos conjuntos de indicadores adimensionales: uno de producción (relación entre la producción respecto a la producción media) y otro de consumo específico (relación entre consumo específico respecto al consumo específico medio), para cada proceso. Las figuras 1a y $1 \mathrm{~b}$ muestran la correlación de los indicadores adimensionales determinados para treinta y cinco proyectos realizados en cuanto a consumo específico de energía eléctrica y gas.

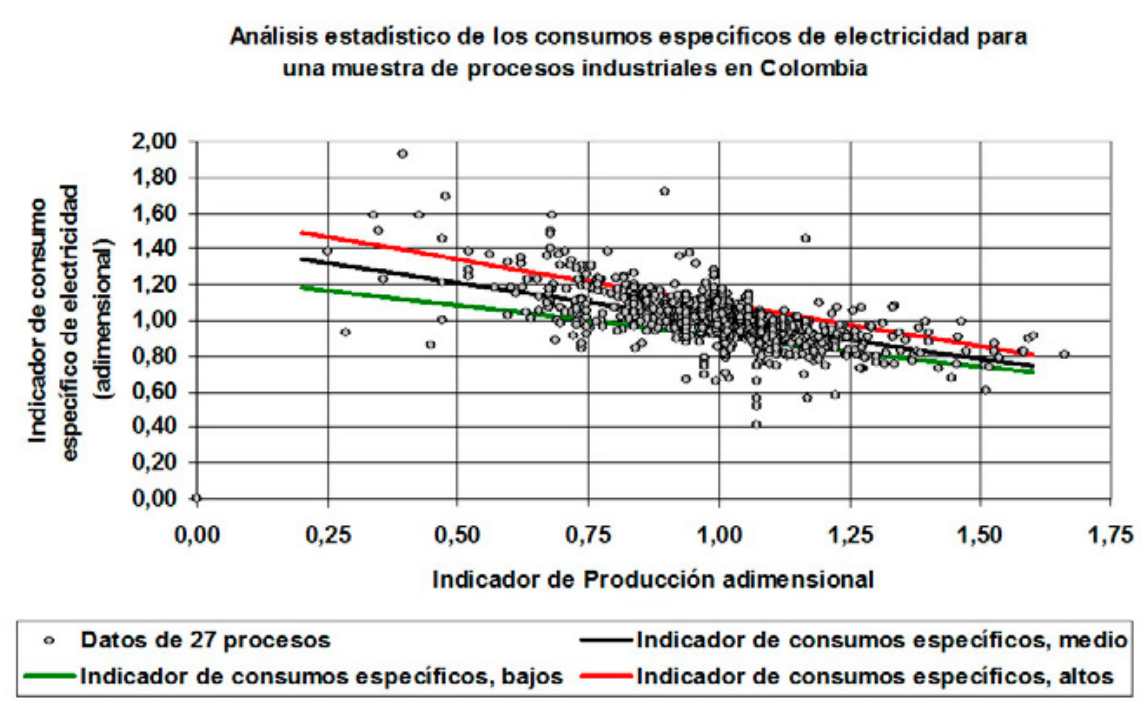

Figura 1a. Consumo específico de electricidad para una muestra de procesos industriales de Colombia.

Fuente: Cómo establecer metas racionales para minimizar consumos de energía basadas en los datos de producción. Enrique Posada Restrepo. 2008.

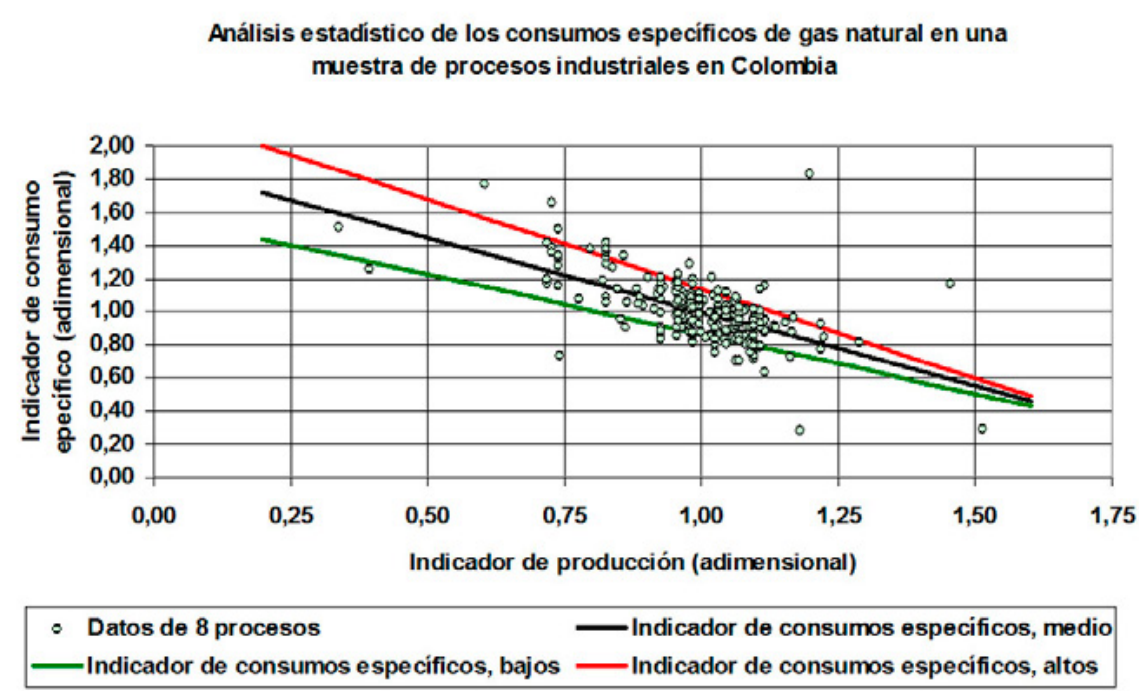

Figura 1b. Consumo específico de gas natural para una muestra de procesos industriales de Colombia.

Fuente: Cómo establecer metas racionales para minimizar consumos de energía basadas en los datos de producción. Enrique Posada Restrepo. 2008. 
Es evidente, la aparición de zonas de bajos consumos y zonas de altos consumos para todo el rango de producción, al igual que el comportamiento decreciente de los indicadores de consumo a medida que aumenta el indicador de producción. De tales correlaciones, se pueden deducir los ahorros potenciales que subyacen a las operaciones cuando estas se hacen de la mejor forma. Al emplear los indicadores adimensionales, se puede obtener un gráfico de comportamiento de los ahorros potenciales que pueden observarse en la Figura 2. En ella se advierte que los ahorros porcentuales factibles tienden a disminuir con la producción.

Lo más importante de estos comportamientos generalizados es el tamaño de los ahorros factibles, los cuales se podrían extrapolar a muchas de las empresas colombianas, en la medida en que se considere que la muestra estudiada es representativa. Se observa que se pueden esperar ahorros enteramente factibles del orden del $8.6 \%$ para los consumos eléctricos medios y del orden del $13.5 \%$ para los consumos de gas medios, con base en aspectos operativos de los procesos que no implican grandes inversiones en tecnología o esfuerzos económicos.

Estos aspectos operativos corresponden a acciones diarias, reforzadas con acciones mensuales administrativas, y su factibilidad depende esencialmente de la cultura de gestión energética que se desarrolle en las empresas. Además, en este punto se evidencian aspectos para reforzar y estimular a partir de las auditorías y estudios de energía.

Una herramienta de ayuda para el análisis de datos es la estadística, debido a la importancia que tiene entender grandes conjuntos de datos, como los que ha empleado INDISA para este estudio. Las variables estadísticas sencillas, tales como el rango de los valores, las desviaciones estándar, los promedios, las dispersiones y las capacidades de proceso permiten adentrarse en los datos y plantear posibilidades aplicables a las "poblaciones" estudiadas. Un ejemplo de esto se presenta en la Figura 3. donde los ahorros potenciales medios fueron correlacionados con el rango de los valores para el indicador de consumos específicos, expresado como porcentaje de la media.

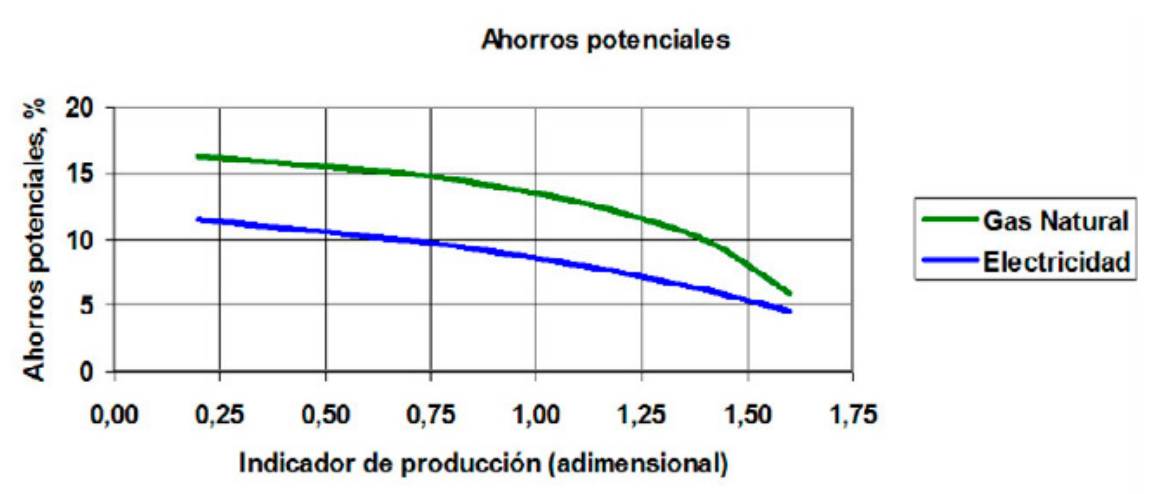

Figura 2. Comparación de ahorros de Potenciales.

Fuente: Cómo establecer metas racionales para minimizar consumos de energía basadas en los datos de producción. Enrique Posada Restrepo. 2008
Correlacción de los ahorros potenciales de electricidad y gas natural a producción media con el rango del indicador de consumos específicos

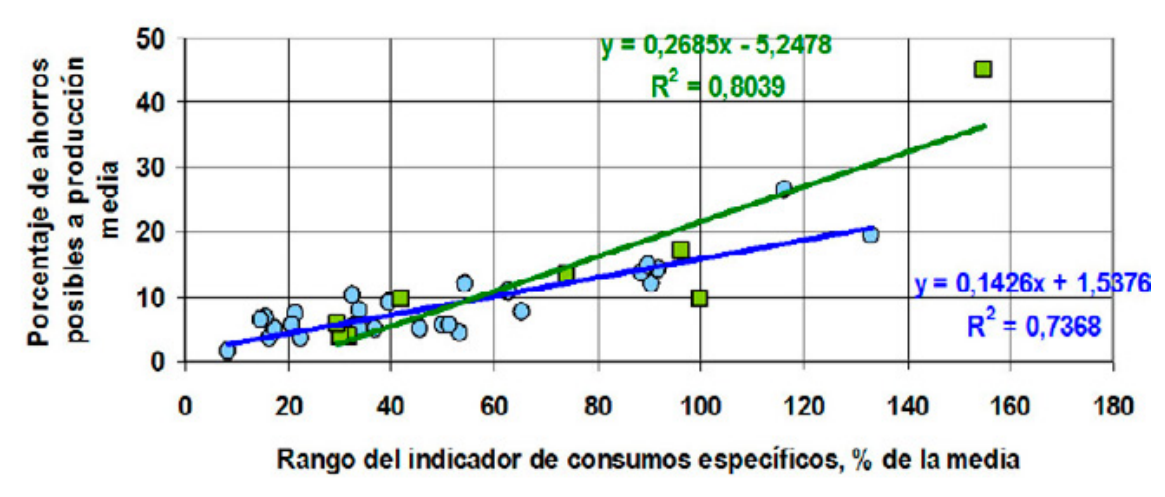

O Datos de electricidad media para 27 procesos $\square$ Datos gas natural medio para 8 procesos

Figura 3. Correlación de los ahorros potenciales.

Fuente: Cómo establecer metas racionales para minimizar consumos de energía basadas en los datos de producción. Enrique Posada Restrepo. 2008

Se aprecia que los ahorros factibles de naturaleza operativa son bajos, en la medida en que el proceso mantiene sus rangos de trabajo dentro de límites estrechos pero, tiene mayor relevancia vizualizar en qué punto se generan pérdidas al trabajar con altas desviaciones, ya que los ahorros factibles (que son el lado opuesto de las pérdidas) son del orden del 20 al $30 \%$ en estos casos.

Ahora, al observar en detalle casos de procesos, se encuentran oportunidades atractivas, como las que se muestran a continuación para el caso de sistemas de ventilación o de hornos en diversas empresas.

Ejemplos de metas factibles de ahorro de electricidad encontradas en el manejo de los ventiladores en las auditorías realizadas por INDISA

\begin{tabular}{|c|c|c|}
\hline Empresa & \% de ahorro & $\begin{array}{c}\text { Ahorro mes, } \\
\text { millones } \$\end{array}$ \\
\hline Metalmecánica 1 & ND & 3 \\
\hline Cerámica 1 & 5 a 35 & ND \\
\hline Arrocera 1 & 5 a 35 & 0,7 a 4,6 \\
\hline Arrocera 2 & 15,0 & 7,4 \\
\hline Arrocera 3 & 10.0 & 1,8 \\
\hline Cementos 1 & 9,5 a 41,0 & 11,4 a 44,3 \\
\hline Cementos 2 & 5,0 & 41,4 \\
\hline Cementos 3 & 5 a 10 & 17 a 34 \\
\hline Arrocera 4 & 15 & 1,5 \\
\hline Textiles 1 & 5 a 35 & ND \\
\hline
\end{tabular}

Ejemplos de metas factibles de ahorro de combustibles en el manejo de Hornos en las auditorías realizadas por INDISA

\begin{tabular}{|c|c|c|}
\hline Empresa & \% de ahorro & $\begin{array}{c}\text { Ahorro mes, } \\
\text { millones \$ }\end{array}$ \\
\hline Metalmecánica 1 & 29 a 60 & 11,4 a 13,9 \\
\hline Cerámica 1 & 2,8 & 25,1 \\
\hline Arrocera 1 & 10 & ND \\
\hline Cementos 1 (clinquer) & 10 & 88,6 \\
\hline Cementos 2 (secador) & 25 & 7,4 \\
\hline Cementos 3 (clinquer) & 8,4 & 59,1 \\
\hline
\end{tabular}




\section{CONCLUSIONES}

Las auditorías energéticas tienen como finalidad brindar a las empresas una visión interesante, útil y desafiante de su comportamiento energético para encontrar oportunidades de mejora, de ahorro en el proceso y de operación eficiente. Por ello, debe entenderse esta evaluación como un beneficio energético en el proceso.

De acuerdo a la muestra estudiada y a la metodología establecida para llevar a cabo una auditoría energética en compañías con vocación diversa, en la cual se presta especial atención a los datos del proceso en función de la producción y los consumos, se puede establecer que la industria nacional puede aspirar a ahorros de electricidad medios del $8.6 \%$ y de gas natural del $13.5 \%$. Ahorros que contribuirían grandemente a disminuir el aporte de Colombia al calentamiento global.

\section{AGRADECIMIENTOS}

Al equipo de trabajo de INDISA S.A. por haber colaborado en la realización del presente artículo a través de los informes realizados a las diferentes compañías.

\section{REFERENCIAS}

García Sanz-Calcedo, J., Cuadros, F., \& López Rodríguez, F. (2011). La auditoría energética: una herramienta de gestión en atención primaria. España: ELSEVIER.

Ministerio de Minas y Energía (UPME). (2012). REVISIÓN MENSUAL DE LA DEMANDA DE ENERGÍA ELÉCTRICA Y POTENCIA MÁXIMA. Bogotá.

Posada Restrepo, Enrique . (2014). Hacia una cultura de la gestión energética empresarial. Medellín. 697 pag. Publicado por ISAGEN.

Posada, E. (2008). Indisa Online. Cómo establecer metas racionales para minimizar consumos de energía basadas en los datos de producción. Medellín, Colombia.

Rosemarie, V., \& Pascal, N. (2014). A cognitive decision agent architecture for optimal energy management. Energy Conversion and Management, 831-847. 


\title{
EVALUACIÓN DE UN SISTEMA HÍBRIDO DE GENERACIÓN ELÉCTRICA RENOVABLE PARA UNA ZONA AISLADA DE COLOMBIA USANDO SOFTWARE HOMER
}

\author{
Yecid Muñoz ${ }^{1,2}$ \\ JulianGuerrero ${ }^{1,3}$ \\ Adalberto Ospino ${ }^{1,4}$ \\ ${ }^{1}$ Universidad Autónoma de Bucaramanga (UNAB) - Grupo de Investigación GIRES \\ 2ymunoz294@unab.edu.co \\ 3jguerrero9@unab.edu.co \\ ${ }^{4}$ Aospino8@cuc.edu.co
}

\begin{abstract}
RESUMEN
En el presente artículo se presenta un análisis de la implementación de tres sistemas alternativos de generación eléctrica, apoyado en el estudio realizado sobre la demanda energética y la evaluación de los recursos disponibles en Riosucio Chocó en Colombia, una zona aislada de la red eléctrica. Los tres sistemas analizados son: una micro central hidroeléctrica en el río Truando, diseñada gracias al software de simulación HOMER software, que además incluye, los costos de construcción e implementación y el porcentaje energético de participación en el mix energético; un arreglo de paneles fotovoltaicos, en configuración aislada, que incluirá el diseño por simulación de baterías, distribución de los paneles, inversores y conexiones con HOMER software, para un área específica aprovechable, teniendo como limitante el recurso solar de la zona; por último, la generación con energía eólica, sistema que incluirá la determinación de la turbina más apta en relación con el recurso eólico disponible en la zona, así como el análisis de la cantidad óptima de generadores eólicos teniendo en cuenta la participación energética y los costos.
\end{abstract}

De cada uno de los sistemas dimensionados se obtuvo un análisis financiero y de pre factibilidad, de acuerdo a la inversión, el porcentaje de participación energética y el ahorro de energía eléctrica para cada una de las viviendas.

Palabras claves: Energía Renovable, HOMER Software, Mix Energético, Diseños Simulados, Generación Zonas Aisladas. 


\section{INTRODUCCIÓN}

En la actualidad, Las energías renovables son la solución a la problemática ambiental y a la deficiencia energética que enfrenta el mundo. En las poblaciones aisladas los potenciales energéticos provenientes del sol, agua y aire son vitales para el desarrollo de sistemas sostenibles. Estos sistemas energéticos se justifican por el alto costo del transporte y la distribución de la energía a los que conllevan los sistemas tradicionales; por ende, representan la mejor alternativa en términos económicos y ambientales para las poblaciones aisladas.

Este proyecto busca aplicar los dimensionamientos de los sistemas fotovoltaicos, eólicos e hidráulicos, para optimizar las alternativas de suministro en aquellas regiones en que sea factible la realización de un proyecto de energía sostenible, en tanto presentan condiciones ambientales adecuadas: irradiancia, velocidades de viento, y caudales óptimos para la implementación. Todo esto con el fin de obtenerlos mejores resultados en costos, eficiencia energética (Givler \& Lilienthal, 2005) y retorno de inversión.

La selección del software de simulación HOMER se realizó a partir del estudio de (Georgilakis, 2005), en el que se hizo un análisis de las herramientas para la asistencia en la planeación energética, con especial énfasis en la utilización de energías renovables. En su primera selección, el autor considera los software HOMER, Hybrid2, INSEL, MATLAB, PROLOAD, RETScreen, RPM-Sim, SIMENERG, WDLTOOLS, WINSYS. Finalmente, enfoca su estudio en HOMER, Hibrid2 y RETScreen, pues tales softwares son los más citados en la literatura técnica y han sido desarrollados por organizaciones que presentan una amplia experiencia con temas de suministro energético en zonas aisladas y energías renovables. En las conclusiones de ese estudio se afirma que, aunque HOMER es menos detallado que otros modelos de simulación para sistemas de micro generación, es el software más detallado en sus modelos estadísticos y el más flexible en término de sistemas de simulación. Por tal motivo, se ha optado por HOMER software como herramienta metodológica para la planificación y operación de suministro energético en zonas aisladas.

Gracias a la información suministrada por el Instituto de Planificación de Soluciones Energéticas (IPSE), encargado del suministro energético a las zonas aisladas en Colombia, en la locación de Riosucio Chocó, Colombia, hay una deficiencia energética, pues solo el $38.7 \%$ de las viviendas tienen conexión a la energía eléctrica y no se cuenta con gas natu- ral. Rio Sucio, ubicado al occidente colombiano, tiene altas precipitaciones y se encuentra limitado por el rio Truando, lo cual le otorga un alto potencial para la adaptación de una micro central hidroeléctrica. Por otra parte, no sólo se analizará la posibilidad del recurso hídrico, sino también la de los recursos eólicos y solares, contando con información de las bases de datos de la NASA, el Instituto de Hidrología, Meteorología y Estudios Ambientales de Colombia IDEAM y la Corporación para la energía y el medio ambiente CORPOEMA; así como información de primera mano del IPSE.

\section{METODOLOGÍA}

Con el fin de lograr el mejor provecho de este trabajo, que es la base para el desarrollo de sistemas de electrificación para zonas aisladas, inicialmente se plantea una metodología general que aplica para todo tipo de zonas no interconectadas, para luego hacer énfasis en zonas de características similares a las del objeto de investigación de este trabajo.

Se comienza parte de la planificación energética la cual involucra la búsqueda y selección de fuentes y equipos de conversión, los cuales cumplan de forma óptima los requerimientos o demandas de todas las tareas (Hiremath, Shikha \& Ravindranath, 2007). Este nivel "óptimo" depende de los objetivos que se definan, que pueden ser minimizar el total de costos de energía anuales, minimizar los recursos no locales o maximizar la eficiencia global del sistema.

El diseño de sistemas híbridos se encuentra fuertemente influenciado por dos componentes, uno de ellos es el monto de energía esperada a partir de los recursos renovables; el otro es la habilidad del sistema de mantener un balance de potencia entre generación y consumo (Ackermann, 2005). En comparación con los sistemas interconectados, en los sistemas energéticos destinados para las regiones aisladas la relación entre el nivel de fiabilidad de suministro y el costo del sistema es mucho más pronunciada (University of Athens. 2004). De esta manera, al diseñar el sistema, las características de la futura carga y los modos de operación del sistema deben ser estudiados con el fin de evaluar la eficiencia de la operación futura y su impacto en el desempeño del proyecto.

La metodología que aquí se presenta tiene como objetivo principal la selección de las fuentes de generación que se adapten mejor a los recursos energéticos existentes y a la demanda de la zona, apuntando siempre a la optimización de los recursos y al balance optimo entre generación-demanda (ver figura. 1). 


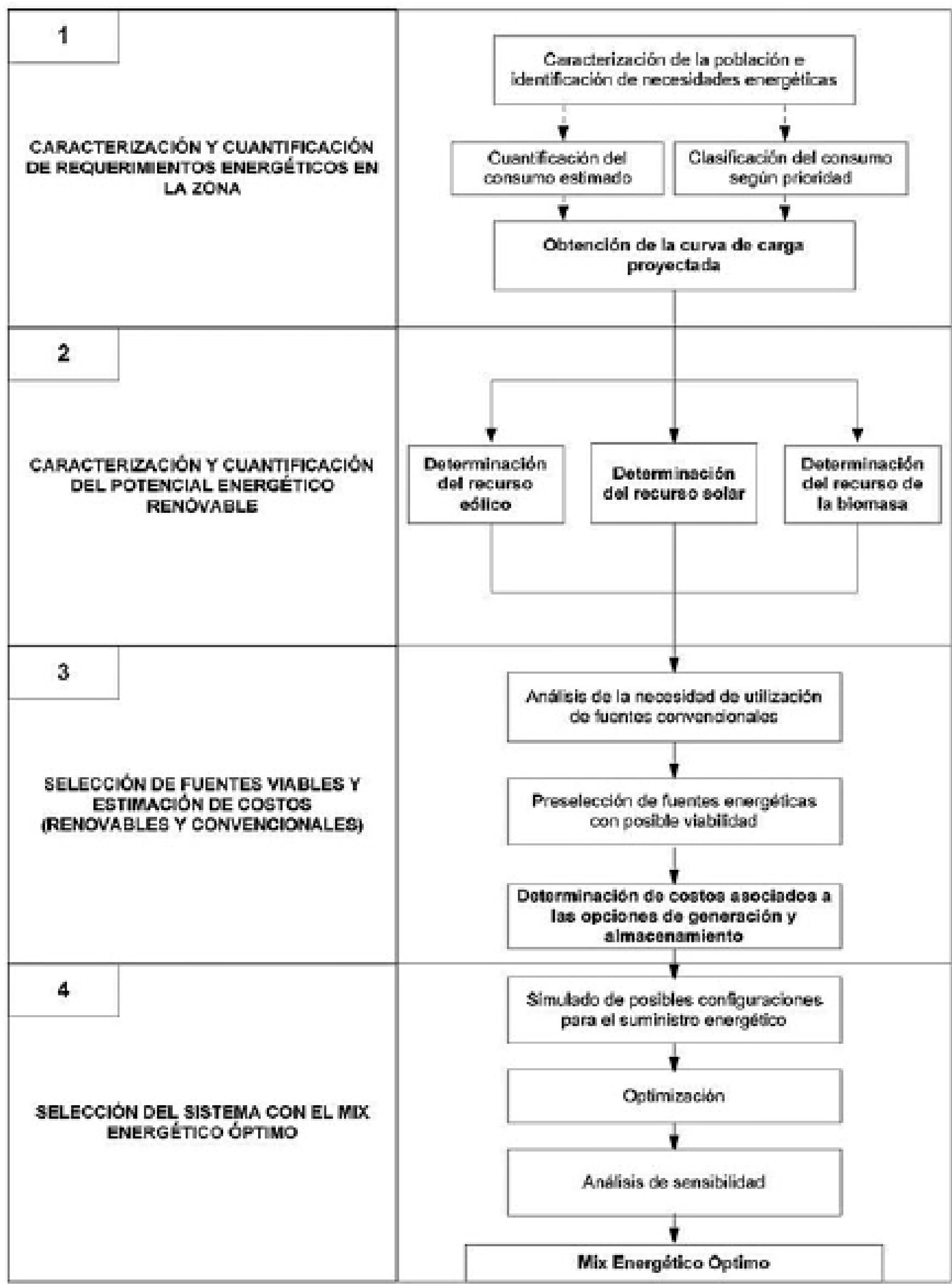




\section{Análisis de la demanda energética}

Según estadísticas del año 2005 del Departamento Administrativo Nacional de Estadística (DANE), la población de Riosucio es de 27.000 habitantes, de los cuales, sólo el $38,7 \%$ tiene acceso a la energía eléctrica. Esto quiere decir que la población objetivo para el suministro de energías renovables es de 16551 habitantes; cada hogar se compone de 4 personas en promedio, lo cual quiere decir que serían 3.850 los hogares que necesitarían abastecimiento energético (ver tabla 1.).

Tabla 1. Caracterización de la población

Fuente: DANE

\begin{tabular}{|c|c|}
\hline $\begin{array}{c}\text { Población Rio Sucio (habitantes) } \\
\text { Proporción de Población con Conexión a Energía } \\
\text { Eléctrica }\end{array}$ & 27.000 \\
\hline Población Objetivo & $38,7 \%$ \\
\hline Personas por Hogar & 46.551 \\
\hline Hogares Objetivo & 3849,1 \\
\hline Hogares Objetivo Total & 3850 \\
\hline
\end{tabular}

Una vez se conoció la cantidad de hogares que requerirían abastecimiento eléctrico, proseguimos a realizar una estimación de los consumos por hogar, de acuerdo con las características de consumos de la zona, para así hallar el consumo medio diario de la zona (véase tabla 2.)

Tabla 2. Estimación de la demanda en la zona

\begin{tabular}{|c|c|c|c|c|c|c|}
\hline \multicolumn{7}{|c|}{ CONSUMO RESIDENCIAL } \\
\hline Tipo & $\begin{array}{c}\text { Potencia Unitaria } \\
(\mathbf{W})\end{array}$ & Unidades & $\begin{array}{c}\text { Potencia } \\
\text { Vivienda (W) }\end{array}$ & $\begin{array}{c}\text { Total 3.850 } \\
\text { Viviendas (kW) }\end{array}$ & $\begin{array}{c}\text { Horas/día } \\
\text { Energía Diaria } \\
\text { (kWh) }\end{array}$ \\
\hline Bombillas & 60 & 5 & 300 & 1.155 & 7 & 8.085 \\
\hline Radio & 20 & 1 & 20 & 77 & 6 & 462 \\
\hline Nevera & 150 & 1 & 150 & 577,5 & 10 & 5.775 \\
\hline Ventilador & 70 & 2 & 140 & 539 & 5 & 2.695 \\
\hline T.V. & 120 & 1 & 120 & 462 & 5 & 2.310 \\
\hline Otros & 200 & 1 & 200 & 770 & 8 & 6.160 \\
\hline Totales & & & 930 & 3.581 & & 25.487 \\
\hline
\end{tabular}

Cada hogar consume un total de $930 \mathrm{~W}$, que corresponde a los servicios básicos de luz, televisión, radio, nevera, ventilador, entre otros. Por lo tanto, el consumo de 3.850 hogares es de $3.581 \mathrm{~kW}$, teniendo en cuenta que las condiciones socio-económicas no varían mucho de un hogar a otro.

\section{Proyección de la Curva de Carga}

Para la proyección de la curva de carga se han obtenido las curvas de carga de un día medio para otras zonas no in- terconectadas de Colombia. Estas curvas han sido contrastadas, encontrando que presentan un patrón similar para las zonas de Leticia y Puerto Carreño (véase figura 2). Por otro lado, mediante consulta al operador de la red eléctrica de Colombia (la compañía XM), se ha obtenido la curva de demanda diaria promedio de Colombia para un día laboral, expresada en porcentaje (véase figura 3 ). Si se contrasta esta curva con la de las zonas aisladas, se concluye que se conserva la similitud en el patrón de consumo y que es viable aplicar la curva de consumo nacional a la zona no interconectada.

Figura 2. Curvas de carga de dos zonas aisladas de Colombia. (a)Leticia. (b)Puerto Carreño.

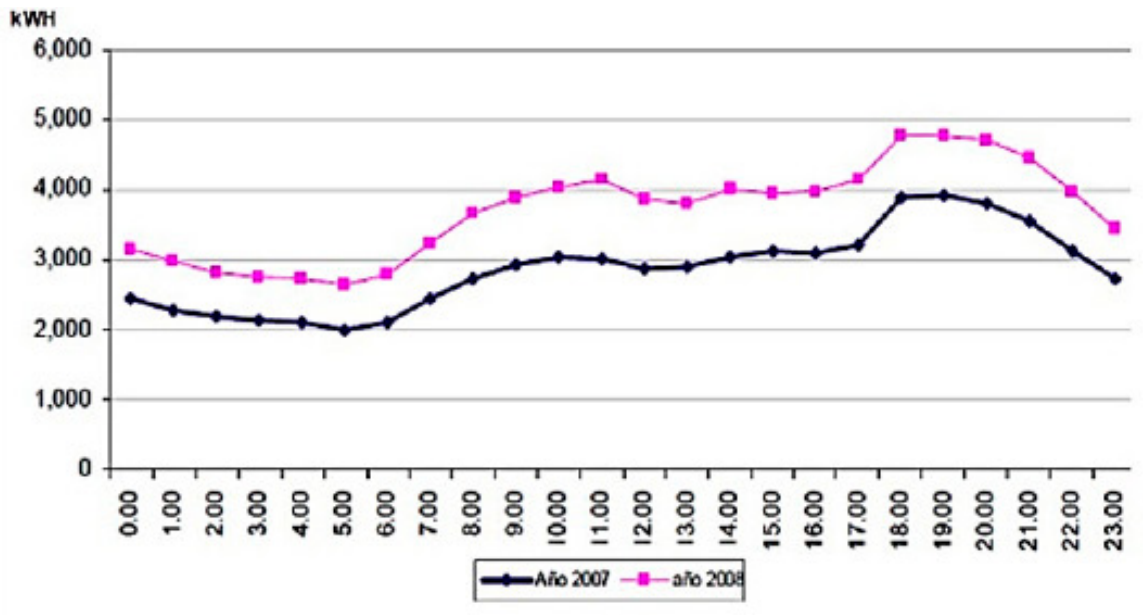

(a)

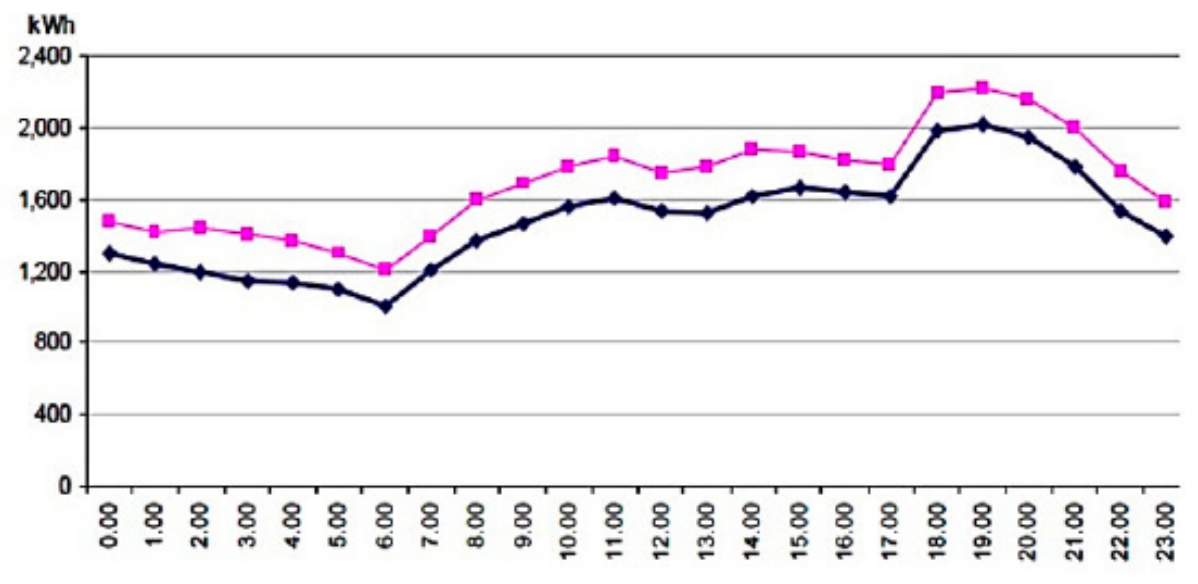

(b) 


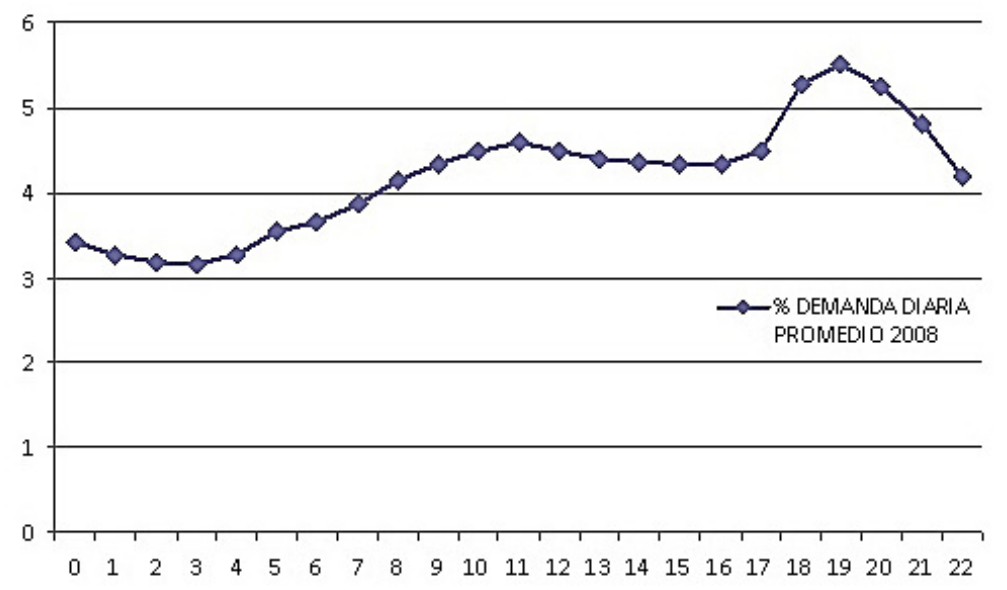

Figura 3. Curvas de demanda promedio de Colombia, expresada en porcentaje. (Cortesía Operador del mercado eléctrico en Colombia-XM).

Aplicando los porcentajes a la demanda calculada en la tabla 2 se obtiene la siguiente curva para la zona de estudio, y se evidencia que el promedio anual de consumo es de $25.487 \mathrm{kWh}$, con una carga pico diaria de $1450 \mathrm{~kW}$.

Demanda Rio Sucio

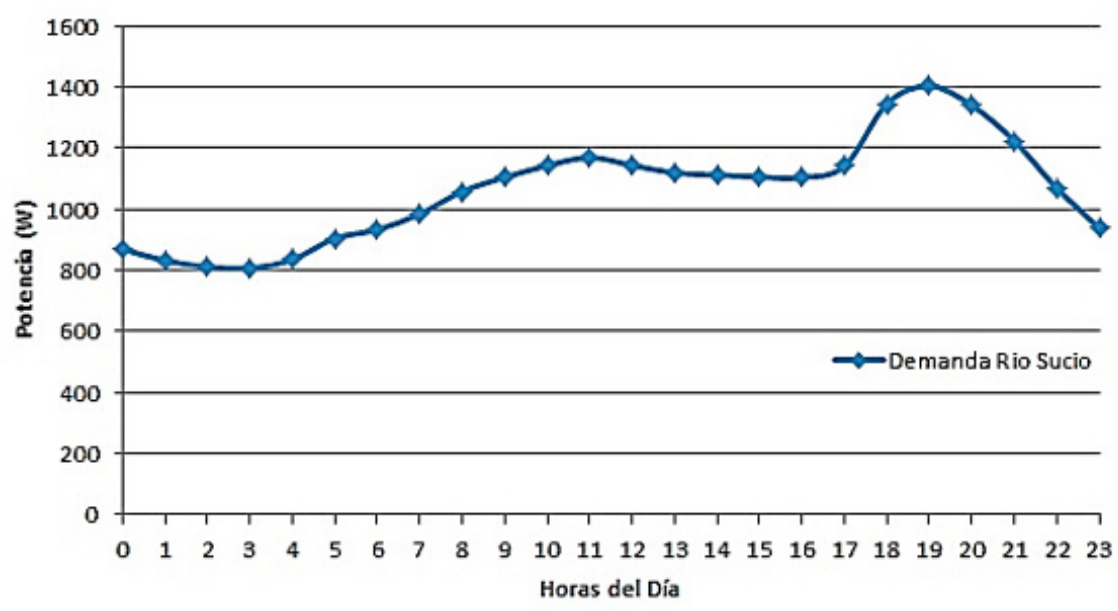

Figura 4. Demanda Energética - Perfil Diario.

\section{Análisis de los recursos energéticos}

\section{Recurso eólico}

Para determinar las velocidades medias mensuales de viento y la velocidad media anual en la zona acudimos a la base de datos meteorológicos de la NASA incluida en las bibliotecas de HOMER software. Para las coordenadas de Riosucio Choco, latitud 26.26/ longitud 07.08, el promedio anual de velocidad de los vientos es de $4,4(\mathrm{~m} / \mathrm{s})$, lo cual nos indica que la velocidad del recurso en la zona es baja.

Posteriormente, se modeló la frecuencia y velocidad del viento. Aplicando la distribución de Weibull se obtuvo que el mejor ajuste corresponde a $\mathrm{k}=1,99$ y $\mathrm{c}=4,99(\mathrm{~m} / \mathrm{s})$. Al introducir estos datos en el software, obtuvimos las gráficas de distribución mensual y distribución de Weibull (véase figura 5 y figura 6).

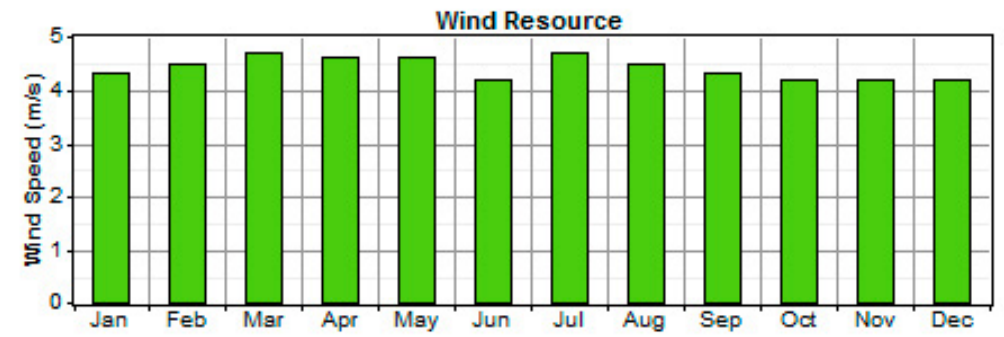

Figura 5. Distribución de velocidades del viento para la zona de estudio.

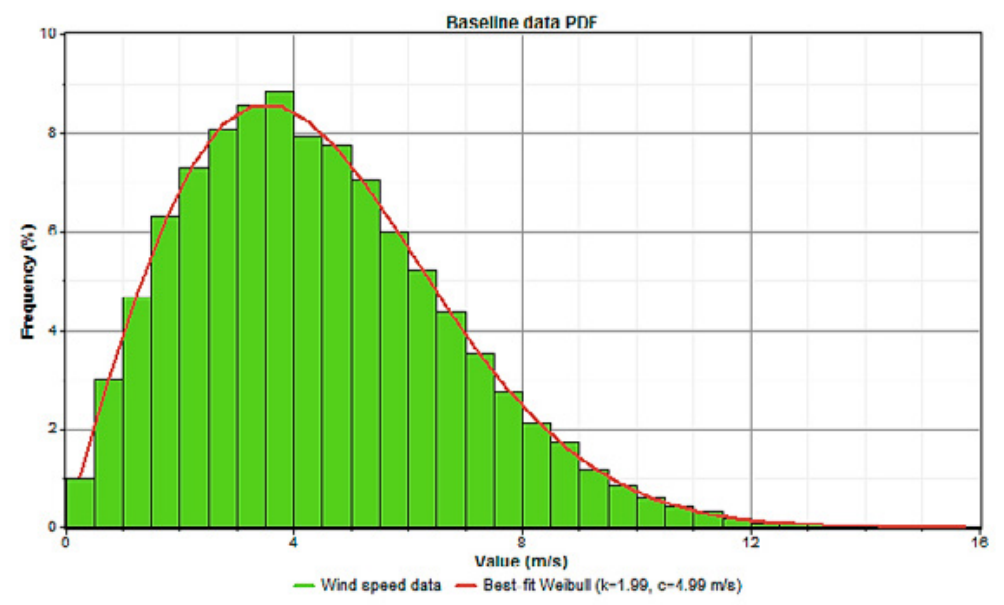

Figura 6. Ajuste de la distribución de Weibull.

En la Tabla 3 y Tabla 4 se exponen las características específicas de los aerogeneradores escogidos, teniendo en cuenta el comportamiento de las velocidades del viento (Kornbluth, Hinokuma, Johnson \& McCaffrey, 2009). Estos datos se basan en las gráficas de Weibull obtenidas con anterioridad (véase figura 5 y figura 6), en las que se observa que las velocidades bajas, con un rango entre (3-6) $(\mathrm{m} / \mathrm{s})$, son las que se presentan con mayor frecuencia. Por tal razón, los dos aerogeneradores escogidos deben ser de bajas velocidades; de lo contrario no se podrían tener en cuenta, pues no estarían aportando en la producción de energía.

Para establecer los costos de capital de inversión se tuvo en cuenta un factor de 1,5 euros por cada $\mathrm{kW}$ de potencia producido por cada aerogenerador. En este factor se incluyen trabajos de mampostería y obras civiles. Por otro parte, el costo de cada aerogenerador se estableció siguiendo los resultados publicados en revistas especializadas en proyectos energéticos.

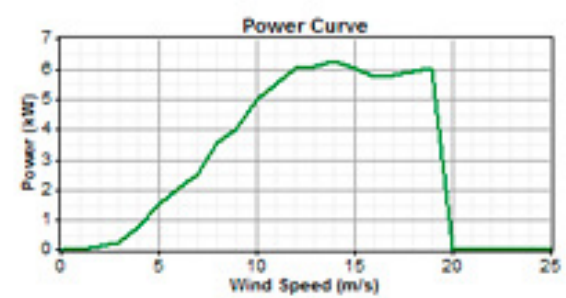

\begin{tabular}{|lc|c|}
\hline & & Bornay 6000 \\
\hline Nominal Power & $(\mathrm{W})$ & 6000 \\
\hline Hubheight & $(\mathrm{m})$ & 15 \\
\hline Rotor Diameter & $(\mathrm{m})$ & 4 \\
\hline Cut - in wind speed & $(\mathrm{m} / \mathrm{s})$ & 3,5 \\
\hline Cut - out wind speed & $(\mathrm{m} / \mathrm{s})$ & 20 \\
\hline
\end{tabular}

Tabla 3. Características de la Turbina Bornay 6000 


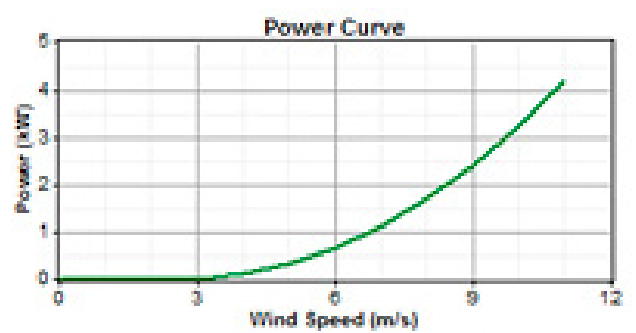

\begin{tabular}{|lc|c|}
\hline & & GEOK 4000 \\
\hline Nominal Power & $(\mathrm{W})$ & 4000 \\
\hline Hubheight & $(\mathrm{m})$ & 15 \\
\hline Rotor Diameter & $(\mathrm{m})$ & 2 \\
\hline Cut - in wind speed & $(\mathrm{m} / \mathrm{s})$ & 4 \\
\hline Cut - out wind speed $\quad(\mathrm{m} / \mathrm{s})$ & 11 \\
\hline
\end{tabular}

Tabla 4. Características de la Turbina Geok 400.

\section{Recurso hídrico}

Los datos del recurso hídrico en la zona fueron suministrados por el IPSE para las Zonas No Interconectadas, los cuales fueron tomados por el IDEAM a través de la estación (La Nueva) del rio Truando, aledaño al municipio de Rio Sucio Chocó. A partir de estos datos se hizo una proyección para 10 años y se utilizó para la simulación el promedio de caudales mensual (véase figura 7).

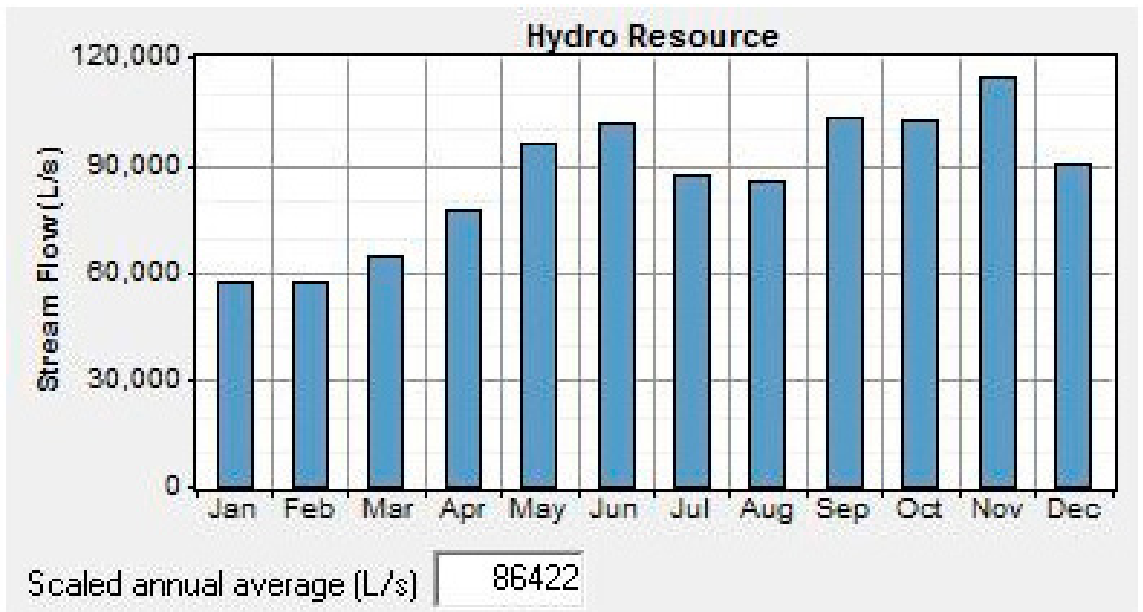

Figura 7. Promedio de recurso hídrico.

Para la simulación del recurso hídrico se toma un caudal ecológico de $11.362 \mathrm{~L} / \mathrm{s}$, si bien se puede asumir una planta hidroeléctrica de gran tamaño debido al caudal disponible esto incurriría en grandes costes, por tanto se selecciona una turbina Kaplan esto también debido al gran caudal que puede utilizar y a un salto de agua de menos de $10 \mathrm{~m}$ debido a la topografía de terreno (ver tabla 5).

Tabla 5. Características Turbina Kaplan

\begin{tabular}{|c|c|c|c|}
\hline OSSBERGER & $\mathrm{H}(\mathrm{m})$ & $\mathrm{Q}\left(\mathrm{m}^{3} / \mathrm{s}\right)$ & $\mathrm{N}(\mathrm{kW})$ \\
\hline Bulb turbines of the Kaplan type & 1 & 1,5 & 50 \\
\cline { 2 - 4 } model A Kaplan - Rohrturbine & - & - & - \\
\cline { 2 - 4 } Baufoorm A & 8 & 30 & 2000 \\
\hline
\end{tabular}

En la Tabla 5 se muestran las especificaciones de la Turbina Ossberger, que posee una eficiencia promedio del 85\%, manejando un flujo de canalización de $12 \mathrm{~m}^{3} / \mathrm{s}$ y un salto neto de teniendo en cuenta la curva de operación.
Los costos de la turbina, las obras civiles y el equipamiento son tomados del estudio de (Aggidis, Luchinskaya, Rothschild \& Howard, 2010), realizado en la Universidad de Lancaster de Inglaterra. Los autores desarrollaron una herramienta de evaluación de recursos hidráulicos, presentando las fórmulas para estimación del costo de la Turbina en Euros y su participación en los costos totales de implementación.

La fórmula para estimar los costos de una turbina Kaplan que maneje flujos entre $5.0 \mathrm{~m} 3 / \mathrm{s}-30 \mathrm{~m} 3 / \mathrm{s}$ viene dada por

$$
C_{k}=46000 \times(Q \times H)^{0,3}
$$

Donde Q y H son $12 \mathrm{~m} 3 / \mathrm{s}$ y $8 \mathrm{~m}$ respectivamente; Ck viene dado en Euros, por lo tanto se utiliza una tasa de conversión a dólares de 1,2865 USD/€.

Para determinar los costos de obras civiles y equipamiento se parte del costo de la turbina Ck que representa el $30 \%$ de los costos totales (Aggidis, Luchinskaya, Rothschild \& Howard, 2010), los costos de obras civiles y equipamiento representan el 55\% de los costos, sumando un 85\% de los costos totales, sin tener en cuenta los costos de Diseño e Impuestos (15\%) los cuales no hacen parte de la construcción y operación por tanto no son introducidos en HOMER (Lambert, Gilman \& Lilienthal, 2006), además los costos de operación y mantenimiento se mantiene en el $2 \%$ de los costos de capital, asimismo se tiene en cuenta un tiempo de vida útil de 30 años. Por tanto los costos totales del sistema hidráulico se presentan en la Figura 8.

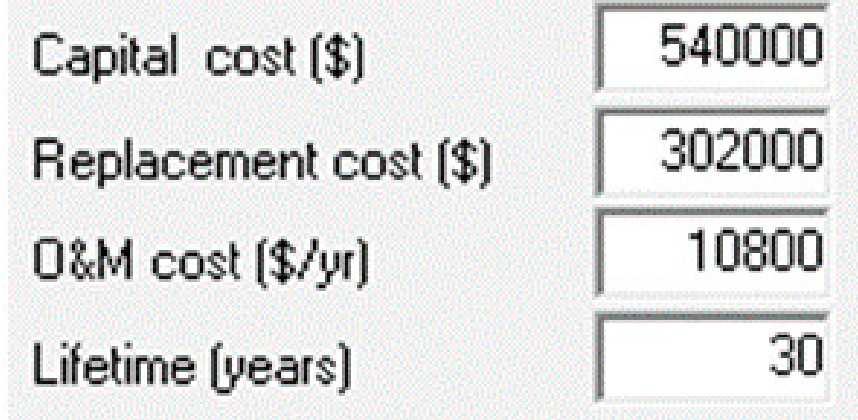

Figura 8. Aspectos Económicos.

\section{Recurso solar}

El recurso solar en la zona occidental colombiana es muy abundante. Sin embargo, se deben tener en cuenta las consideraciones climatológicas del lugar, como las precipitaciones que son ocasionadas por mucha nubosidad, pues conllevan a que el recurso solar se vea disminuido y no sea constante a lo largo del año. Por lo anterior, se puede pronosticar que la participación del sistema fotovoltaico en el mix energético no va a ser muy significativa.

Haciendo uso de la base de datos de la NASA, obtuvimos la irradiancia mensual de Riosucio Chocó hasta el año 2005, con las coordenadas $7^{\circ} 27^{\prime}$ Norte, $77^{\circ} 6^{\prime}$ Oeste y una temperatura promedio anual de $28 \mathrm{C}$ (véase figura 9). 


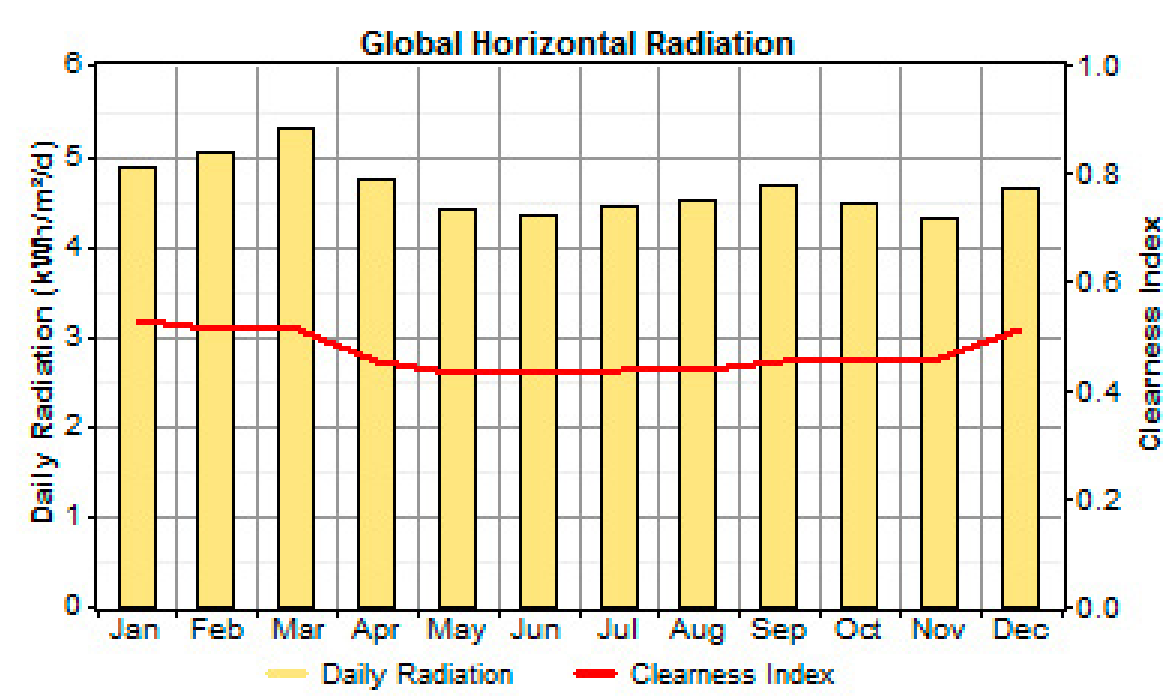

Figura 9. Irradiancia anual.

Las horas pico promedio mensuales son 4,64, a partir de las cuales se realiza el análisis de la energía total que el sistema puede producir. Basados en (Bernal \& López, 2009), el sistema total se diseñó con un performance ratio de 0,8 y un tiempo de vida de 20 años. Se consideraron los siguientes tamaños del arreglo fotovoltaico en $\mathrm{kW}:$ 0, 100, 200, 300, $400,500,600,700$. El ángulo de colocación de los paneles es de $7,45^{\circ}$, y el índice de claridad del terreno es del $20 \%$. No se consideró el efecto de la temperatura externamente, pues estas pérdidas están consideradas en la eficiencia global del sistema, el performance ratio.

Los costos del Watt instalado son de 2,5 USD, como costo de implementación, con un costo de reemplazo del $80 \%$ y un costo de operación y mantenimiento del $0,016 \%$ al año sobre el total de implementación.

Los costos se tomaron de los precios publicados por la compañía española fabricante de paneles solares ATERSA, en base a los paneles de tipo policristalino 250P, los cuales poseen una potencia de $250 \mathrm{~W}$ y tienen una eficiencia del $14 \%$ (ver figura 10).
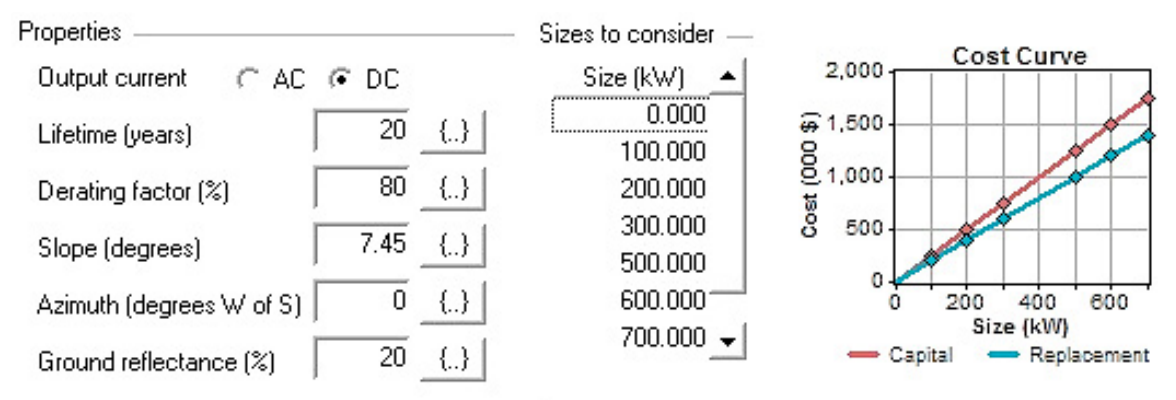

Figura 10. Variables del arreglo fotovoltaico.

\section{Componentes del sistema híbrido}

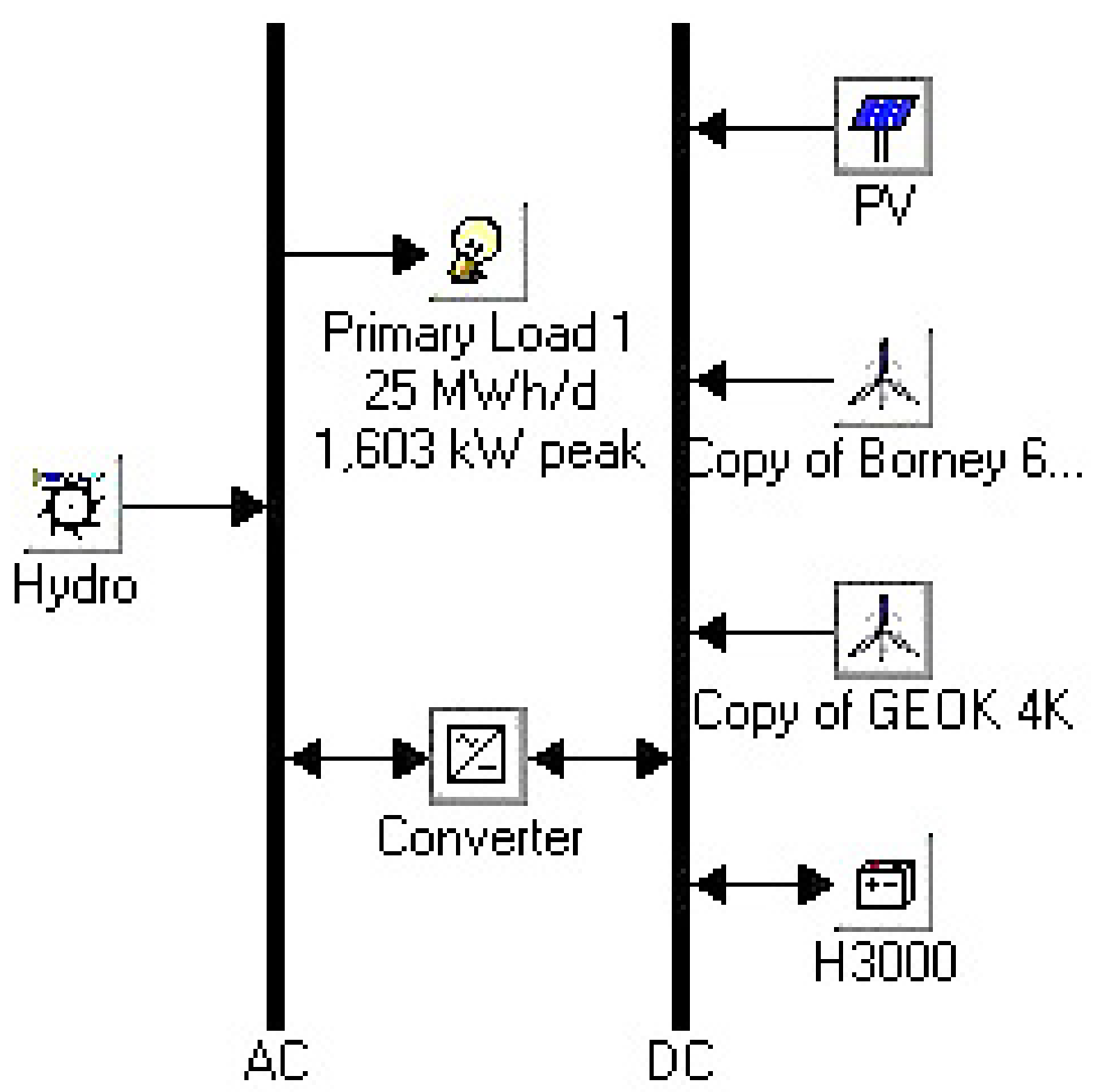

Figura 11. Sistema hibrido. 
El sistema hibrido mostrado en la Figura 11, está conformado por los generadores eólicos, sistema fotovoltaico, generador hidráulico, baterías y convertidor. En este contexto, las propiedades de los principales componentes debieron ser determinadas para suplir la carga AC (Kanase-Patil, Saini \& Sharma, 2010).

\section{Baterías}

Se escogieron las baterías Hoppecke 24 OPzS 3000, cuyas características nominales se presentan en la figura 12. El costo de una batería es del orden de 1286 USD; dicho valor es usado por HOMER para realizar una curva de economía a escala que determina el costo del total de las baterías necesarias. Los tamaños de cadenas a considerar van de 0 a un valor máximo de 200; cada cadena tiene 6 baterías conformando un voltaje total de $12 \mathrm{~V}$.
Nominal capacity:

Nominal voltage:

Round trip efficiency:

Min. state of charge:

Float life:

Lifetime throughput:

Suggested value:

Max. charge rate:

Max. charge current:
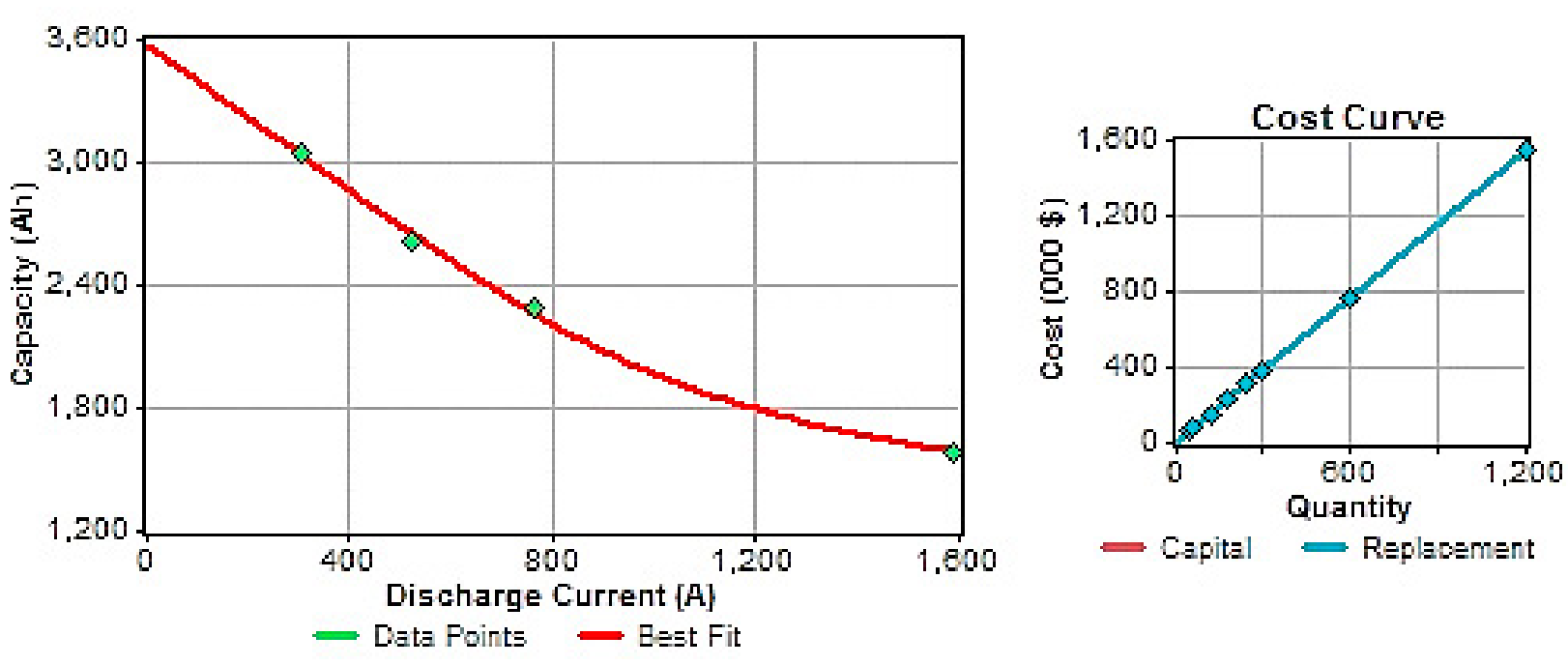

Figura 12. Especificaciones de Baterías.

\section{Convertidor}

Se usó un convertidor con una eficiencia del 90\% y una vida útil de 15 años. Los costos de inversión son de aproximadamente 3 USD por $\mathrm{kW}$, con un costo de reemplazo del $100 \%$ y un porcentaje de mantenimiento del $0,016 \%$ al año del costo total de inversión del sistema en DC.

La variación del tamaño en $\mathrm{kW}$ considerada, tiene un valor máximo de 700 y mínimo de 10.

Principios de operación del sistema híbrido

El sistema diseñado tendrá en cuenta las siguientes consideraciones:

- Las turbinas de viento y el arreglo fotovoltaico cargaran las baterías, para proveer la energía en AC, por medio de un convertidor.

- El sistema tiene una confiabilidad del $98 \%$ al año, es decir el cubrimiento por todas energías renovables sólo deja de cubrir un $2 \%$ de la demanda total anual.

- Si el arreglo fotovoltaico y las turbinas de viento no pueden soportar la demanda, el banco de baterías no se cargará, en cambio entregara la energía necesaria junto con el generador hidráulico.

- La reserva operativa de carga horaria es del $10 \%$. Mientras que las reservas operativas de generación renovable son del 20\% para energía solar y del 30\% para energía eólica. Se debe aclarar que la reserva operativa es el margen que permite que se pueda suplir con un sistema confiable, sin importar la variación de la carga, el recurso solar o el recurso de viento.

- En el análisis de sensibilidad se varió la velocidad del viento en un rango de $3 \mathrm{~m} / \mathrm{s}$ hasta $4,42 \mathrm{~m} / \mathrm{s}$, por su naturaleza variable en la zona.

- Se considera que la vida útil del proyecto es alrededor de 25 años.

- Se considera una tasa de interés anual del $8 \%$ para Colombia.

- La fracción de recursos renovables para el sistema hibrido es del $100 \%$.

\section{RESULTADOS}

Según la optimización del sistema hibrido, la combinación más óptima, con una velocidad de viento de $4,2 \mathrm{~m} / \mathrm{s}$, comprende un arreglo fotovoltaico de $100 \mathrm{~kW}, 50$ aerogeneradores de $6 \mathrm{~kW}$, un generador hidráulico de $800 \mathrm{~kW}$, un convertidor de $600 \mathrm{~kW}$, un arreglo de 300 baterías con el VPN más bajo (3'086,735 USD), y un costo de energía de $0,026 \mathrm{USD} / \mathrm{kWh}$. 


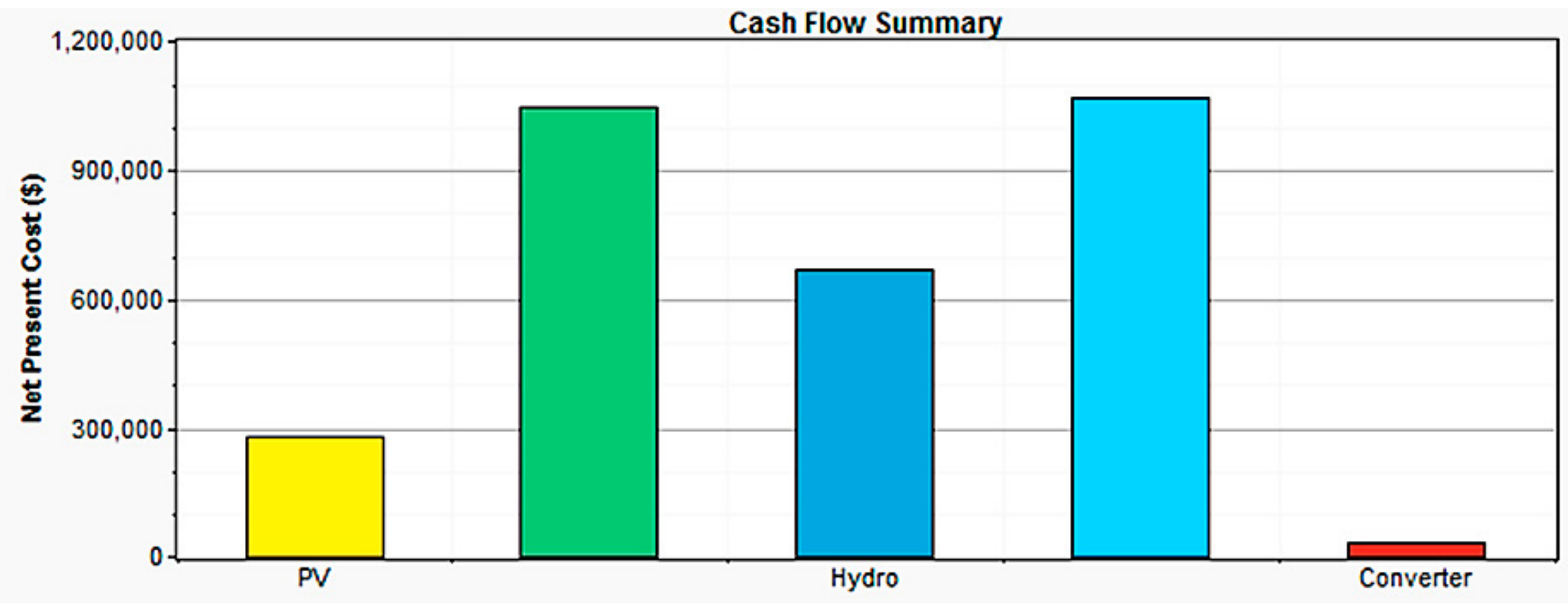

Figura 13. Flujo de caja.

En la figura 13 se observa que el mayor costo de capital lo tiene el banco de baterías (en color verde), seguido por los aerogeneradores de $6 \mathrm{~kW}$ (en color azul). El porcentaje de participación de costos es: convertidor 0,9\%, sistema fotovoltaico $9 \%$, costos hidráulicos $21,5 \%$, generadores eólicos $33,8 \%$ y banco de baterías $34,8 \%$.

Cuando las velocidades de viento son inferiores a 3,5 $\mathrm{m} / \mathrm{s}$, el sistema de generador eólico no entra en el mix energético y la carga es sostenida únicamente por el sistema fotovoltaico e hidráulico.

El sistema tolera un aumento de carga hasta de un $9 \%$ de la demanda de energía; sin embargo, cabe resaltar que la población en esta zona ha ido decreciendo en los últimos 5 años.
El arreglo fotovoltaico tiene una participación muy limitada, del 7\%. Esto se debe al alto porcentaje de sombras causadas por las precipitaciones, pues es uno de los lugares más lluviosos de Colombia.

Debido a que se tiene una parte de la carga no cubierta del $2 \%$ como principio de operación, esta se aumenta los días de baja irradiación y la energía eólica no es suficiente para cargar las baterías a causa de las condiciones climatológicas.

Cuando el viento se encuentra a velocidad de $4 \mathrm{~m} / \mathrm{s}$, el mix energético tiene en cuenta todas las fuentes de energía (eólica, solar, hídrica y baterías), cada una con un porcentaje de participación: $17,2 \%$ eólica, 55\% hídrica, 7\% solar, $20,8 \%$ baterías para la carga pico (ver figura 14 ).

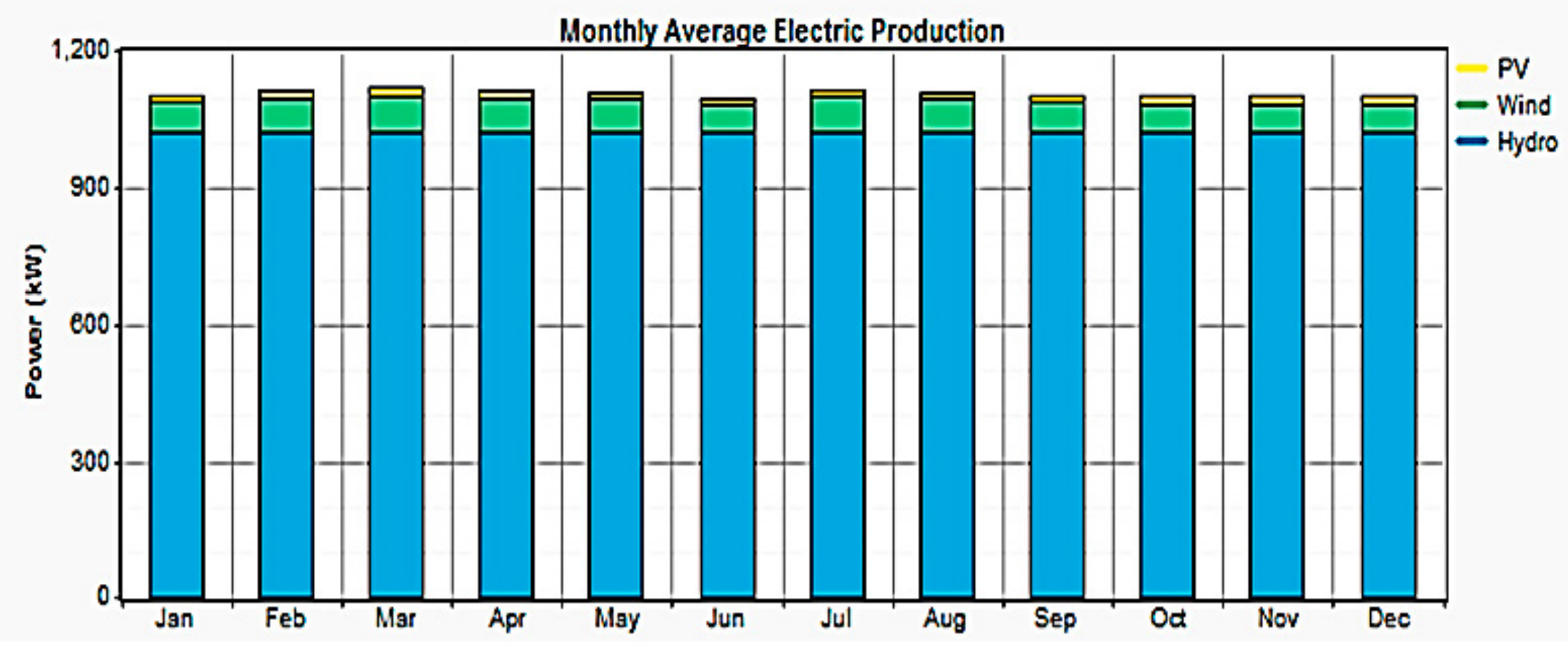

Figura 14. Producción energética del sistema. 
Cuando el viento se encuentra a velocidad de $3 \mathrm{~m} / \mathrm{s}$, las turbinas eólicas no pueden generar energía, como se muestra en la Figura 15, pues la generación empieza una vez se alcanza un valor mayor a $3,5 \mathrm{~m} / \mathrm{s}$. Por lo tanto, el sistema será soportado por el arreglo fotovoltaico, con un $27 \%$ de participación en el mix energético, por un generado hidráulico, con un 55\%, y por baterías, con un $18 \%$ de la carga pico.

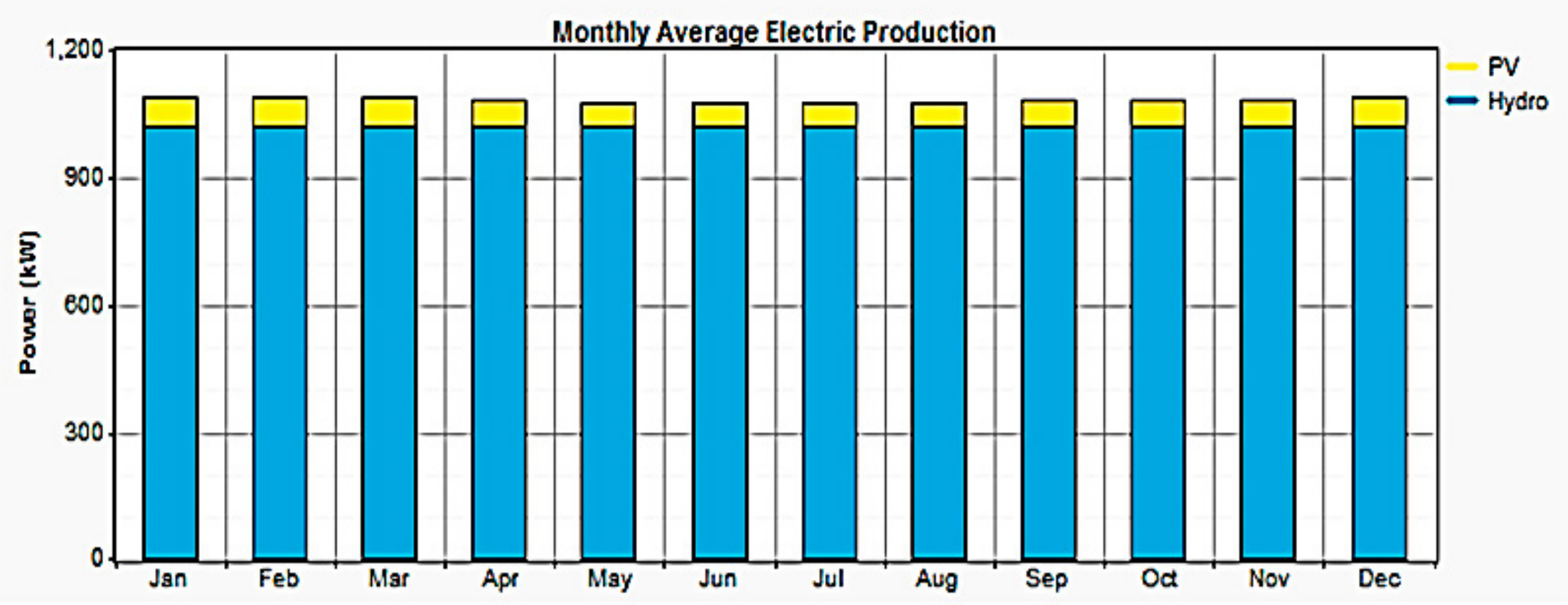

Figura 15. Producción energética del sistema (viento $=3 \mathrm{~m} / \mathrm{s}$ ).

El análisis de sensibilidad realizado se basó en la variación de velocidad del viento, que va desde $3 \mathrm{~m} / \mathrm{s}$ hasta 4,2 $\mathrm{m} / \mathrm{s}$, y el incremento de la carga en un $8 \%$. Tomando en cuenta la gráfica de sensibilidad (ver figura 17). Se concluye que a partir de velocidades de viento de $3.5 \mathrm{~m} / \mathrm{s}$ el sistema puede estar conformado por los tres recursos: hidráulico, fotovoltaico con baterías y eólico, de otro lado, cuando la velocidad del viento es menor a $3.5 \mathrm{~m} / \mathrm{s}$, no se deben considerar los aerogeneradores.

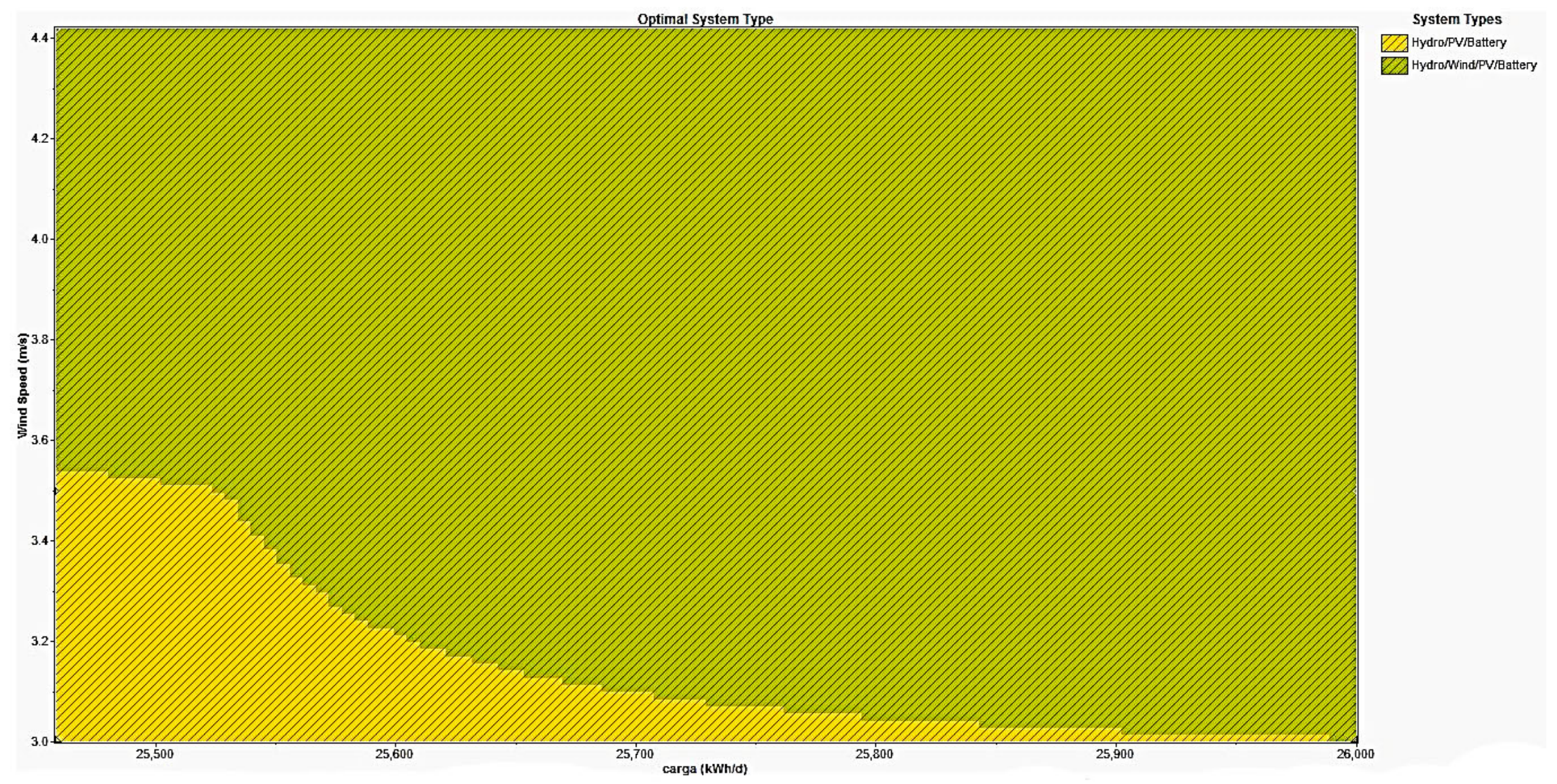

Figura 16. Análisis de sensibilidad. 
La simulación se realizó en dos versiones diferentes de HOMER: una versión anterior, v2.68 beta, y la versión más reciente, la 2.81. Esta última versión mostró varias inconsistencias en los resultados, pues con velocidades de viento muy bajas, en las cuales ninguno de los aerogeneradores puede producir energía, los resultados sugirieron una combinación con aerogeneradores incluidos. Observamos que, a diferencia de la versión más antigua, que es consistente en sus resultados respecto a las velocidades de viento, la última versión de HOMER es poco fiable y debe estar sujeta a mejoras.

\section{CONCLUSIONES}

En este artículo se planteó una metodología para seleccionar los componentes que conformarían el sistema óptimo de generación de energía eléctrica, considerando los aspectos técnicos, económicos y sociales que se involucran en la planificación y operación de las zonas aisladas. Investigamos acerca de las herramientas y técnicas de planificación existentes, encontrando que el software HOMER es la herramienta más adecuada para la aplicación de la metodología planteada. Sin embargo, tras el análisis realizado con la versión 2.81 del software HOMER encontramos inconsistencias en los resultados, las cuales no se presentaron en su versión anterior, la v2.68 beta.

La metodología ha sido aplicada a la zona aislada de Riosucio Colombia, concluyendo que la implementación de un sistema que combine energía fotovoltáica, mini hidráulica y minieólica, es altamente sensible a la velocidad del viento. Por tal razón, resulta necesario tener datos de velocidad de viento que sean mayores a dos años, para así reducir la incertidumbre frente al potencial de generación de energía de este recurso.

El estudio también muestra que las curvas de carga de sistema de las zonas aisladas en Colombia son muy similares entre sí, y similares a la curva de carga del sistema interconectado nacional; esto se puede deber a que la carga del sistema esta es impuesta por el comportamiento del sector residencial. De acuerdo con lo anterior, es posible considerar el comportamiento del sistema interconectado para predecir la demanda en una zona aislada.

\section{AGRADECIMIENTOS}

Los autores agradecen especialmente a Diana Zafra y Sebastián Rivas por facilitar información valiosa para este estudio.

\section{REFERENCIAS}

Givler, T., \& Lilienthal, P. (2005). Using HOMER ${ }^{\oplus}$ software, NREL's micro power optimization model, to explore the role of gen-sets in small solar power systems. Case Study: Sri Lanka, National Renewable Energy Laboratory, Golden, Colorado.

Georgilakis, P. S. (2005). State-of-the-art of decision support systems for the choice of renewable energy sources for energy supply in isolated regions. International Journal of Distributed Energy Resources, 2(2), 129-150.

Hiremath, R. B., Shikha, S., \& Ravindranath, N. H. (2007). Decentralized energy planning; modeling and application-a review. Renewable and Sustainable Energy Reviews, 11(5), 729-752.

Ackermann, T. (Ed.). (2005). Wind power in power systems (Vol. 140). Chichester, UK: John Wiley.

National Technical University of Athens. (2004). Renewables for isolated systems energy supply and waste water treatment. Technical Annex. European Commission, Sixth Framework Programme, RISE Project.

Kornbluth, K., Hinokuma, R., Johnson, E., \& McCaffrey, Z. (2009). Optimizing Wind Energy for a Small Hybrid Wind/Diesel Grid in the Galapagos Islands. University of California, Davis Energy Efficiency Centre.

Aggidis, G. A., Luchinskaya, E., Rothschild, R., \& Howard, D. C. (2010). The costs of small-scale hydro power production: Impact on the development of existing potential. Renewable Energy, 35(12), 2632-2638.

Lambert, T., Gilman, P., \& Lilienthal, P. (2006). Micropower system modeling with HOMER. Integration of alternative sources of energy, 1.

Bernal-Agustín, J. L., \& Dufo-López, R. (2009). Simulation and optimization of stand-alone hybrid renewable energy systems. Renewable and Sustainable Energy Reviews, 13(8), 2111-2118.

Kanase-Patil, A. B., Saini, R. P., \& Sharma, M. P. (2010). Integrated renewable energy systems for off grid rural electrification of remote area. Renewable Energy, 35(6), 13421349. 


\title{
EVALUACION ENERGETICA DEL SISTEMA DE GENERACION DE VAPOR DE UN INGENIO AZUCARERO
}

\author{
María Isabel Gutiérrez López ${ }^{1,2}$ \\ Natalia Perea ${ }^{1,3}$ \\ Judith Rodriguez ${ }^{1,4}$ \\ ${ }^{1}$ Universidad Nacional de Colombia - Sede Palmira \\ ²migutierrezl@unal.edu.co \\ ${ }^{3}$ npereav@unal.edu.co \\ 4jrodriguezs@unal.edu.co
}

\begin{abstract}
RESUMEN
Frente a la actual tendencia de la industria azucarera de aumentar su producción de energía a partir de bagazo de caña a más de 350MW en 2017 (Asocaña, 2014), la aplicación de herramientas de gestión aparece como una alternativa para gestionar y optimizar la producción del recurso energético. El objetivo de la investigación fue aplicar las herramientas del Modelo de Gestión Integral de la Energía (UPME, 2008) a los registros de consumos de bagazo y producción de vapor de un ingenio del Valle del Cauca. La aplicación de las herramientas permitió establecer un potencial de ahorro energético de 6,89\% (31.746.865,41 lb bagazo/año), el cual se puede alcanzar a partir de medidas de gestión en la producción y operación. En el primer caso, se requiere mantener producciones superiores al 67\% de la capacidad del equipo generador de vapor. En el segundo caso, a nivel operacional es necesario mantener la humedad del bagazo inferior al 50\%. Esto teniendo en cuenta que la humedad del bagazo es impactada en un 71\% por la variabilidad estacional del clima y en un 29\% por los mantenimientos realizados a los equipos de molienda de la caña. De esta manera, la aplicación de herramientas de gestión permite monitorear procesos, establecer indicadores y metas, enfocandose en la productividad y competitividad del sector.
\end{abstract}

Palabras claves: Gestión energética, Bagazo, eficiencia energética. 


\section{INTRODUCCIÓN}

El sector industrial tiene una alta demanda de energía en sus actividades, lo que genera altos costos economicos y ambientales que ponen en riesgo la sostenibilidad de los procesos y competitividad de las organizaciones (Serna, 2010; Perez \& Vera, 2011). En la industria azucarera, la energia es uno de los principales recursos para sus operaciones de fábrica. El sector demanda gran cantidad de energía para su operación, dado que los procesos requieren tanto energía térmica como eléctrica. En respuesta a esto, se ha desarrollado la cogeneración para producir energía eléctrica a partir de la combustión de bagazo en calderas de vapor, permitiendo de esta manera suplir las necesidades de consumo propio y tener excedentes de electricidad que se puedan entregar a la red de interconexión nacional. En 2009, el sector azucarero colombiano presentaba una capacidad instalada de 114 MW de cogeneración; en el 2013, aumentó a 187 MW, y para el 2017 se proyecta un incremento a $360 \mathrm{MW}$, lo que contribuye a la sostenibilidad y autosuficiencia de las actividades industriales (Asocaña, 2014)

Frente a esta tendencia, el sector ha venido preparando un desarrollo en la infraestructura de calderas de mayor presión y un mejor aprovechamiento energético, principalmente del vapor. Esto significa un aprovechamiento más eficiente de la energía que contienen los combustibles que se planean a usar (en su mayoría bagazo), sobretodo en las fábricas (De Boeck, 2011; Asocaña, 2014).

Para el aprovechamiento eficiente del bagazo de caña, se ha establecido que la calidad determinará la cantidad de energía que se puede obtener de este combustible. Se requiere que el bagazo ingrese con una humedad menor al 50\% para optimizar el proceso de la combustión, mejorando así el aprovechamiento del combustible. Esta variable se puede ver afectada por las temporadas invernales, ya que estas temporadas dificultan el proceso de cosecha y molienda por el alto contenido de suelo (Larrahondo, 1995; Orellana, Rivas \& Velez, 2009; Colombres, Golato, Morales, Aso \& Paz, 2010).

Frente a estas metas sectoriales, el Modelo de Gestión Integral de la Energía (MGIE) es una herramienta que contribuye a gestionar el recurso energético a través del análisis de variables externas e internas, usando indicadores energéticos que permitan la identificación de fallas a tiempo y un proceso de mejora continua que conduzca a la productividad y/o competitividad de una organización. El objetivo de este trabajo fue aplicar las herramientas del MGIE a los registros de consumo de bagazo y producción de vapor de un ingenio azucarero, asociándolo a variables como la humedad y el clima de la región, y determinando la incidencia de la estacionalidad y el potencial de ahorro energético.

\section{MATERIALES Y MÉTODOS}

\section{Descripción del área de estudio}

Se tomó como objeto de estudio una caldera acuotubular marca Distral de 150.000 Lbvapor/h a 350 PSI, alimentada con bagazo como combustible. La caldera se encuentra ubicada en un ingenio azucarero del Valle geográfico del Rio Cauca, y abastece los procesos de producción de azúcar y un turbogenerador, durante las 24 horas del día, los 7 días de la semana, exceptuando las paradas de mantenimiento preventivo y correctivo. Se tomó como periodo de análisis el año 2011.

\section{Caracterizacion del proceso}

\section{Linea base}

Se aplicó el método de los mínimos cuadrados relacionando el consumo de bagazo (E) en función de la producción de vapor $(\mathrm{P})$ en cada periodo de tiempo, para determinar la ecuación lineal que correlaciona estas variables, y obtener una ecuación de tipo:

$$
E=m P+E o
$$

Donde,

E: Consumo de bagazo;

P: Producción asociada en el período seleccionado;

$\mathrm{m}$ : Pendiente de la recta que significa la razón de cambio medio del consumo de bagazo respecto a la producción;

E0: Intercepto de la línea en el eje y que significa el bagazo no asociado a la producción.

\section{Indicador de consumo versus Produccion (IC vs. P)}

El diagrama IC vs $\mathrm{P}$, es una herramienta para estandarizar el proceso de generación asociado al consumo de bagazo y se identifica el punto crítico de producción, en el cual el consumo de energia no varía significativamente en relación con la producción.

El grafico se construyó a partir de la línea base encontrada (E vs P) usando las siguientes ecuaciones:

$$
\begin{gathered}
E=m P+E o \\
I C=\frac{E}{P}=m+\frac{E_{0}}{P} \\
I C=m+\frac{E_{0}}{P}
\end{gathered}
$$

Siendo IC el índice de consumo teórico (ICt), el cual representa el consumo energetico esperado de acuerdo a la tendencia encontrada con la línea base. 
Posteriormente se determina el IC real (ICr), que representa el consumo de bagazo medido, usando la siguiente ecuación:

$$
I C r=\frac{E}{P}
$$

\section{Indicador de eficiencia Base 100 (IB100)}

Se generó el indicador de gestión para monitorear el comportamiento del consumo energetico con respecto a la tendencia alcanzable. Este indicador se calculó a partir de la relación de las E tendencia de la ecuación de la línea base con respecto a las E medida (UPME, 2008):

$$
\mathrm{IB} 100=\frac{E_{\text {tendencia }}}{E_{\text {medida }}} \boldsymbol{x} \mathbf{1 0 0} \frac{E_{\text {tendencia }}}{E_{\text {medida }}} \boldsymbol{x} \mathbf{1 0 0}
$$

El valor obtenido representa el consumo esperado de bagazo respecto a al registro real para el mismo valor de producción. Entonces, para días en los cuales el indicador resulta ser menor a 100 se presentan ineficiencias que contribuyen al sobreconsumo de bagazo, pues los datos medidos sobrepasan la tendencia establecida. Mientras que los dias en que los valores son mayores a 100, son días en los cuales se presentan sucesos que contribuyen a la eficiencia.

\section{Cusum}

Se utilizó el gráfico de tendencia o sumas acumulativas (CUSUM) para monitorear la tendencia del consumo de energia, con respecto a la ecuación de la línea base estimada (UPME, 2008). Para la construcción de este grafico se realizó la diferencia entre los consumos de bagazo estimados del periodo 2011 (E) y la tendencia de los consumos a partir de la expresión de la línea base (E’); luego se realizó la suma acumulativa que fue graficada en función del tiempo.

El grafico se realiza en un sistema de coordenadas X, Y, donde la $\mathrm{X}$ es el periodo o tiempo de monitoreo y el eje $\mathrm{Y}$ corresponde al valor de la suma acumulativa.

\section{Potencial de ahorro}

Es importante contar con una meta alcanzable que estimule el uso final eficiente de energía y un indicador que evalúe cuantitativamente esa meta. La Meta de consumo para un nivel de producción dado se calcula con la ecuación de línea de tendencia del gráfico consumo vs. Producción hallada para los niveles por debajo de la media, así:

$$
\text { Emeta }=\text { mmeta }{ }^{\star} P+\text { Eometa }
$$

\section{Dónde;}

Emeta $=$ Consumo meta para un nivel de producción dado;

mmeta $=$ Nueva pendiente para la línea meta de tendencia;

Eometa $=$ Nuevo intercepto para la línea meta de tendencia y

$\mathrm{P}=$ Producción programada.

\section{RESULTADOS}

\section{Caracterización del proceso}

La ecuación lineal de la figura 1, representa la función para estimar el CE del proceso de generación de vapor para un determinado valor de producción del mismo. La función representa una explicación del $71 \%$, un grado de relacion aceptable entre los datos que, indica que el proceso de acondicionamiento de la caldera, con cero producción de vapor, requiere 304.447 LbBagazo/día, y, que representa el el 23,25\% promedio de bagazo al dia. Mientras que la relación de bagazo por cada unidad de vapor producida es de 0,39Lb Bagazo/Lb Vapor.

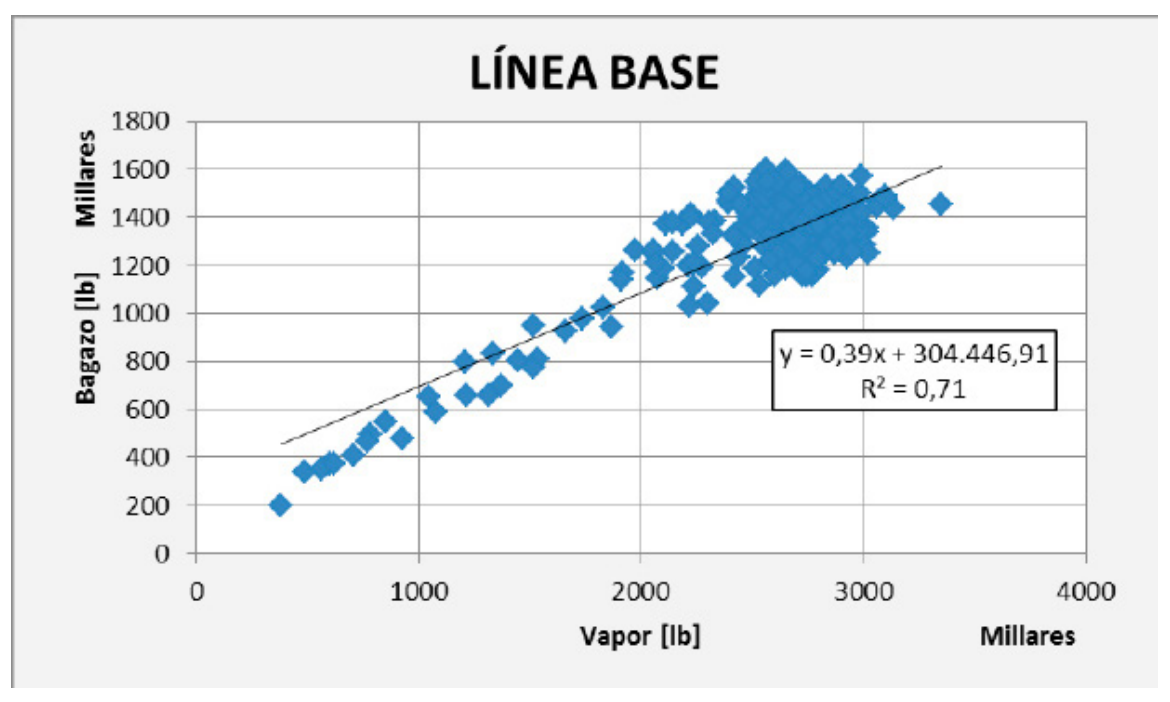

Figura 1. Consumo de bagazo vs Produccion de vapor

En condiciones ideales, el total del bagazo alimentado debe liberar toda la energia para la generacion de vapor. Sin embargo, la falta del control del proceso genera ineficiencias que pueden ser producto de problemas operacionales, calidad del combustible y cambios climaticos, que influyen significativamente sobre el proceso. Por lo tanto, será necesario un exceso de bagazo para obtener la energía que mantenga el nivel de producción de vapor que requiere el ingenio, impactando tanto la economia y las variables ambientales, asi como el incremento de emisiones atmosfericas.

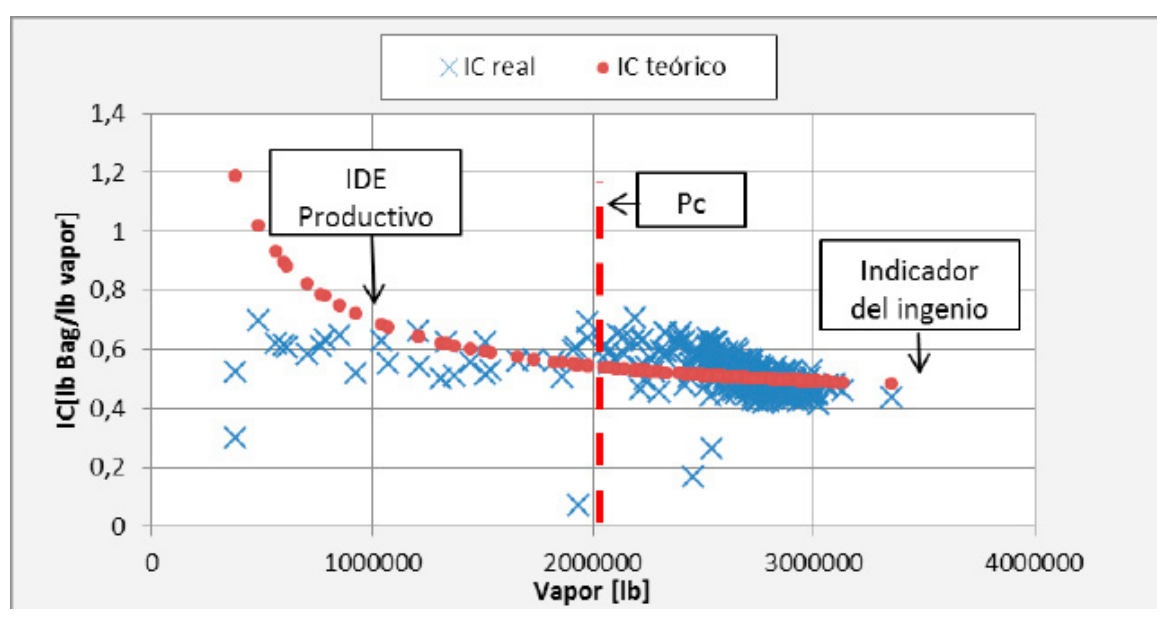

Figura 2. Indice de consumo asociado a la produccion de vapor 
En la figura 2 se observa que el indice de consumo de la caldera varia entre 0,1 y $0,7 \mathrm{lb}$ bagazo/lb de vapor. Se evidencia que se presentan niveles de produccion por debajo del punto critico $(\mathrm{Pc})$, en donde se alcanza el menor valor; aunque este no varia significativamente con la produccion. Es decir que a producciones mayores a $2.000 .0000 \mathrm{lb}$ de vapor, el peso relativo de la energia no asociada a la produccion disminuye.

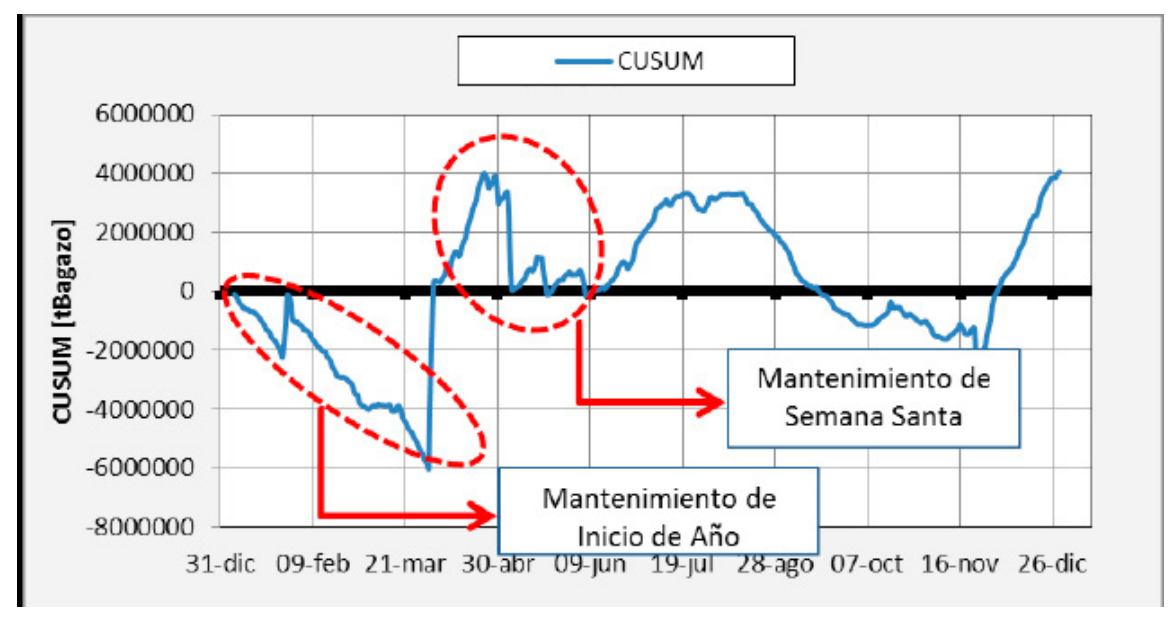

Figura 3. Grafico de sumas acumulativas respecto a la energia de tendencia

El análisis del comportamiento de E en el tiempo se obtiene por el método de sumas acumulativas (cusum) (ver Figura 3), donde se encontró un comportamiento variable en las tasas de consumo a lo largo del año. Desde enero hasta marzo, se observa una tendencia a la disminución del consumo, debido a las operaciones de mantenimiento que se realizan al inicio del año.

A partir de marzo, se observa un incremento que genera un pico de consumo, que se mitiga gracias al mantenimiento que se realiza en semana santa. Este incremento del consumo coincide con la primera temporada de lluvia (abril-mayo), ya que bajo altos regímenes de lluvia se incrementa el contenido de ME mineral en el bagazo debido a una mayor cantidad de suelo adherido en la caña por el alto gradod e humedad del terreno durante la cosecha. En consecuencia, aumentan los inquemedos en la combustion, siendo un proceso ineficiente (Garcés \& Martínez, 2008; Larrahondo, 2009; Aroca y Peña, 2011).

De julio a noviembre, el proceso tiende a la eficiencia; contrario a lo que se esperaría para la segunda temporada de lluvias (octubre-noviembre) del año. Por el contrario, para los últimos días del año, el incremento de las emisiones es considerable; esto asociado a que se registraron condiciones extremas de precipitación en el valle geográfico del río Cauca a finales de 2011 y principios de 2012, como producto del fenómeno de La Niña (Asocaña, 2013; Cortez \& Barrios, 2010).

Otro de los parametros altamente impactados por las condiciones climaticas es la humedad, pues se relaciona directamente con el contenido de ME en el bagazo, debido a que el aumento de dicha variable incrementa el desgaste de los molinos lo que hace menos eficiente el proceso de extraccion. Esto genera, ademas de ineficiencia, un aumento en las emisiones por presencia de material incombusto, ya que, cuando el bagazo tiene una humedad muy alta, la temperatura de combustión no es suficientemente elevada como para completar las reacciones químicas del proceso (Trujillo, 2011).

El nivel de humedad que maneja el ingenio, según datos proporcionados, esta entre 50 y $44 \%$, un valor aceptable para la industria. Pero los estudios demuestran que ante una reducción de la humedad de hasta el 40\% aumenta el PCI en un $19 \%$ y disminuye en un $22 \%$ el bagazo quemado en el horno, acercandose más a la optimizacion del proceso (Paz \& Cardenas, 2001).

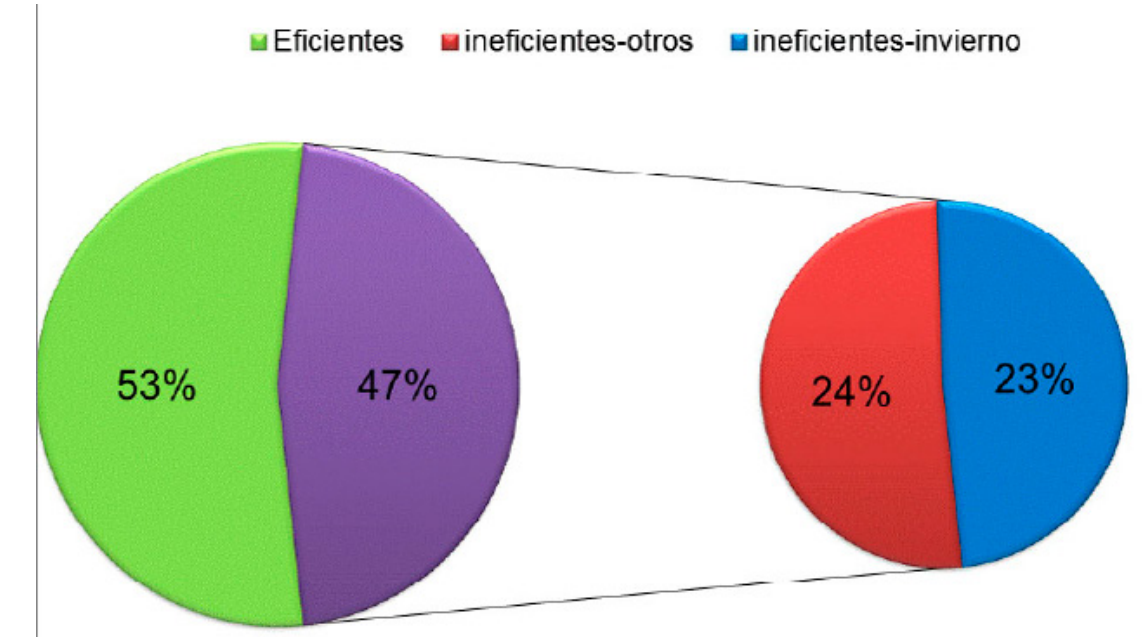

Figura 4. Porcentaje de dias eficientes e ineficientes en cuanto al proceso de generacion de vapor

Se determinó que el 47\% de los días resultan ineficientes (dadas las emisiones por encima de la tendencia), un valor alto que sugiere un proceso con altos costos ambientales y económicos. De estos días, el 23\% pertenecen a las dos temporadas anuales de lluvia que se presentan en el Valle del Cauca, validando la relación existente de la precipitación con el proceso de generación a partir del modelo. Es importante mencionar que, debido al cambio climático, los regímenes de precipitación han variado considerablemente, en especial por fenómenos climáticos como La Niña, que afecta temporal y espacialmente la ocurrencia de la precipitación; esto genera un grado de incertidumbreen. Sin embargo, el modelo puede responder a esta variabilidad, pues se diseño dando respuesta a este tipo de eventos, que se observaron en los últimos días del año y que presentaron precipitaciones extremas y atípicas.

\section{Potencial de ahorro}

Como resultado de la identificacion de los datos que se encuentran por debajo de la recta de la línea base, se puede obtener una meta de reduccion, analizando los factores que llevaron a influenciar positivamente el consumo de bagazo para una determinada producción de vapor.

En la figura 4 se observa que,si se logra operar de manera eficiente, se llega a un mayor ajuste de la nueva línea 
(línea meta) en función de los datos, lo cual se refleja en el nuevo índice de correlación (95\%). Esto indica que si logra ajustar o estandarizar las variables criticas de control del proceso, se podría tener una mayor precisión en la futura línea base, con lo cual disminuiría el grado de error en estimaciones de tendencias de consumo energéticos que el ingenio necesite. En relación con la energía no asociada a la producción, se encontró que con una operación eficiente, se estima un potencial de ahorro de 90.446,91 lb Bagazo/día, lo que indica una reduccion del $6,9 \%$ en relacion al consumo actual. Anualmente se hablaría de una reduccion del consumo 14.400,38 ton de bagazo al año, que representan \$136.511.521,26 (ver Tabla 1).

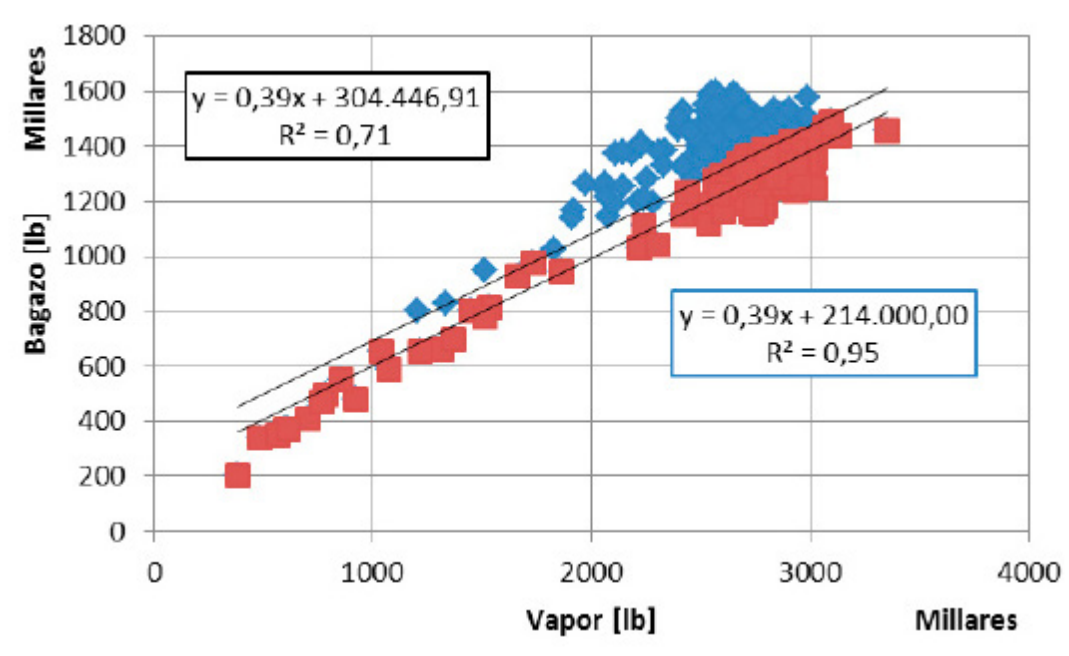

Figura 4. Línea base y meta de datos de consumo de energía Vs. Producción

Tabla 1.

\begin{tabular}{|c|c|}
\hline EoLB [lb Bagazo/día] & $304.446,91$ \\
\hline EoLM [lb Bagazo/día] & $214.000,00$ \\
\hline Ahorro Eo [lb Bagazo/día] & $90.446,91$ \\
\hline Ahorro Eo [lb Bagazo/año] & $31.746 .865,41$ \\
\hline Consumo de bagazo [lb/año] & $460.863 .843,10$ \\
\hline Sobre consumo bagazo [\%] & 6,89 \\
\hline Costo Bagazo [\$/lb] & 4,3 \\
\hline Sobre consumo bagazo [\$/año] & $\$ 136.511 .521,26$ \\
\hline Sobre consumo bagazo [\$/ía] & $\$ 388.921,71$ \\
\hline
\end{tabular}

\section{CONCLUSIONES}

Con la aplicación de herramientas del MGIE se estableció que existe un potencial de ahorro de 6,89\% (31.746.865,41 lb bagazo/año), el cual se puede alcanzar a partir de medidas de gestión en la producción y operación. Se encontró que en aquellas producciones por encima del $67 \%$ de la capacidad del equipo disminuyen el peso relativo de la energia no asociada a la produccion. De igual manera, se identificó que la temporada invernal impacta en un 23\% la eficiencia del proceso de generacion, incidiendo principlamente en la calidad del bagazo y afectando el control de la humedad con que éste entra a la generacion.

Se estableció el modelo como una herramienta que acerca la industria cada vez más al control del proceso. También al manejo y la toma de decisiones correctivas y preventivas, gracias a la identificacion temprana de puntos criticos.

\section{REFERENCIAS}

Aroca, R. \& Peña, D. (2011). Análisis de recubrimientos duros para molinos de cana de azúcar. Tesis de Maestria, Escuela Superior Politécnica del Litoral-ESPOL, Guayaquil, Ecuador

Asocaña. (2014). Aspectos generales del sector azucarero 2013-2014. ISSN: 0121-991X. Disponible en: http://www. asocana.org/modules/documentos/10572.aspx

Asocaña. (2013). Aspectos generales del sector azucarero 2012-2013. ISSN: 0121-991X. Disponible en: http://www. asocana.org/modules/documentos/10179.aspx

Colombres, F. F., Golato, M. A., Morales, W. D., Aso G., \& Paz, D. (2010). Monitoreo de un sistema de secado de bagazo acoplado a una caldera en un ingenio de México. Revista Industrial y Agrícola de Tucumán. 87 (2), 33-44

Cortes, E. \& Barrios, C. (2010). Nuevo calendario de temporadas secas y lluviosas en el Valle del rio Cauca. Carta Trimestral, 32 (3-4), 4-5.

De Boeck, G., Garolera L. P., Colombres, F. F., Paz, D \& Octaviano, M. (2011). Simulación de sistemas de cogeneración en la industria azucarera de Tucumán. Revista Industrial y Agricola de Tucuman. 88(1), 29-36

Garcés, R. V. \& Martínez, S. V. (2007). Estudio del poder calorífico del bagazo de caña de azúcar en la industria azucarera de la zona de Risaralda. Trabajo de grado para optar por el título de Tecnólogas químicas. Universidad Tecnológica de Pereira.

Orellana J. L.; Rivas J. R. \& Vélez J. (2009). Aplicación de un modelo de dispersion de material particulado generado en calderas bagazeras. Trabajo de Grado, Facultad de Ingeniería y Arquitectura. Universidad Centroamericana “ JOSE SIMEON CANAS”, Antiguo Cuscatlan, El Salvador.

Paz, D. \& Cardenas, G. J. (1999). Secadero de bagazo o economizador: análisis comparativo de su influencia en el rendimiento energético neto de una caldera bagacera. Revista Industrial y Agrícola de Tucumán, 76 (1-2), 17-26

Perez, C. A., \& Vera, F. (2011). Resultados de la caracterización energética de un proceso estándar para el beneficio de feldespato. Scientia et Technica, Año XVI, No 48.

Serna, C. A. (2010). Gestión energética empresarial una metodología para la reducción de consumo de energía. Revista Produccion + Limpia, 5 (2), 107-126.

UPME. (2008). Herramientas para el analisis de caracterizacion de la eficiencia energetica . Unidad de Planeación Minero Energética. Bogotá, Colombia 


\title{
FALLOS MÁS REPRESENTATIVOS DE LOS MÓDULOS FOTOVOLTAICOS
}

\author{
Juan D. Oliveros T. ${ }^{1,2}$ \\ ${ }^{1}$ INGEREMA, S.A.S. \\ ingerema@ingerema.es
}

\section{RESUMEN}

Se mencionan los fallos más representativos en los módulos fotovoltaicos, que pueden aumentar el riesgo de inversión de un proyecto energético con energía solar, en base a la experiencia de INGEREMA, S.A:S. como consultora internacional.

Defectos de amarilleamiento, delaminación, puntos calientes o PID, entre otros que se mencionan, son observados solo después de estar en funcionamiento un proyecto fotovoltaico. Una implementación adecuada de los procesos de Quality Assurance y Quality Control, necesarios para el desarrollo de un proyecto renovable, puede reducir el riesgo técnico del mismo.

Palabras claves: Módulos fotovoltaicos, Yellowing, Hot spot, PID, TCO. 


\section{INTRODUCCIÓN}

A medida que va desarrollándose la curva de aprendizaje de determinada tecnología, también son superados algunos retos en el desarrollo de nuevos materiales/productos.

INGEREMA, S.A.S., a través de su experiencia como consultora en proyectos energéticos con fuentes renovables de gran escala recopila, para el sector fotovoltaico en Colombia, los fallos más representativos que han presentado y siguen presentando los módulos fotovoltaicos, los cuales pueden aumentar el riesgo de inversión de un proyecto.

Los fallos que se mencionan, en su mayoría solo son observados varios meses después de la puesta en marcha del proyecto fotovoltaico. Si bien son fallos usuales, no significa que suceda en todos los proyectos

\section{RESULTADOS}

\section{Amarillamiento o "Yellowing"}

Es el efecto de amarilleamiento del EVA y TEDLAR. INGEREMA ha detectado gran cantidad de módulos fotovoltaico que fueron fabricados en su mayoría entre los años 2005 y 2010.

El EVA o Etileno Vinil Acetato, es un polímero termoplástico conformado por unidades repetitivas de etileno y acetato de vinilo. El TEDLAR o Fluoruro de Polivinilo (PVF), protege la parte posterior del módulo fotovoltaico ante rayos UV, humedad y temperaturas extremas.

En los módulos FV, el EVA se utiliza como encapsulante de las células fotovoltaicas. Éstas se depositan en un soporte cristalino y se encapsulan para evitar la entrada de aire o humedad.

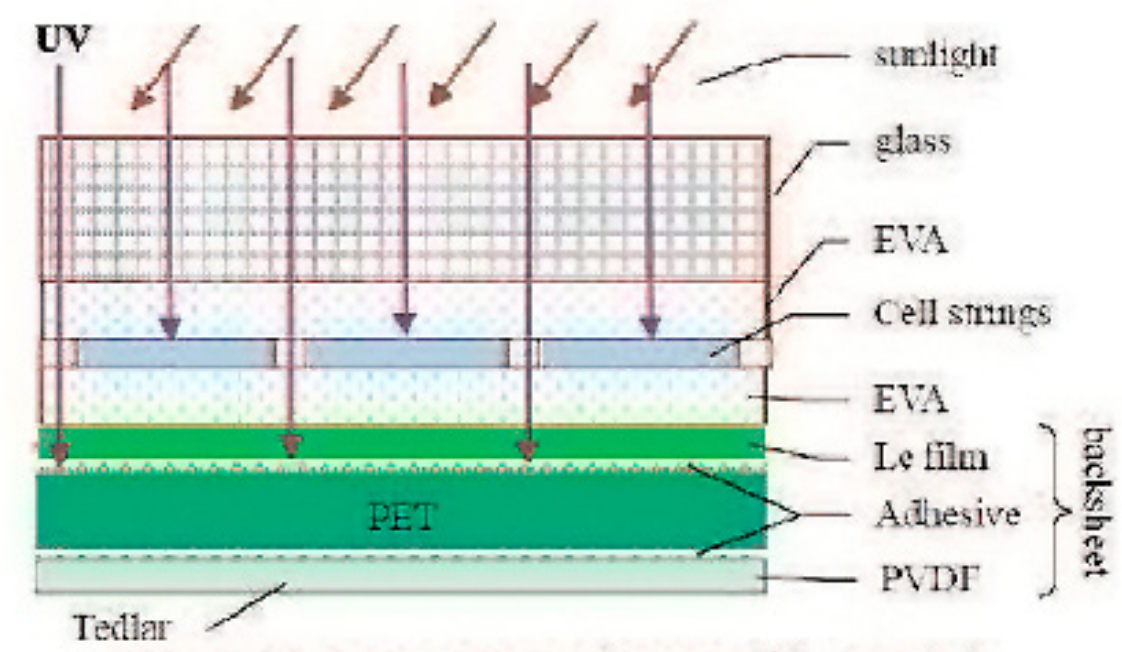

Fig. 1: Cross section of a Yingli's module.

Figura 1. Capas de un modulo de silicio cristalino

Una vez obtenido el conjunto de células encapsuladas en EVA, se recubren por encima y debajo con láminas de Tedlar-Poliéster-Tedlar o Tedlar-Poliéster-EVA, dependiendo del fabricante. El fin de estas láminas es proteger a las células fotovoltaicas de los efectos degradantes de la radiación ultravioleta, y para que el módulo fotovoltaico cuente con un adecuado aislante eléctrico.

La coloración amarilla se debe al ácido acético que se produce en la reacción química de descomposición del EVA por la radiación ultravioleta. El principal efecto del amarilleamiento del EVA es la reducción de su transmitancia que provoca una disminución de la Isc y, por consiguiente, de la potencia máxima de salida del módulo.

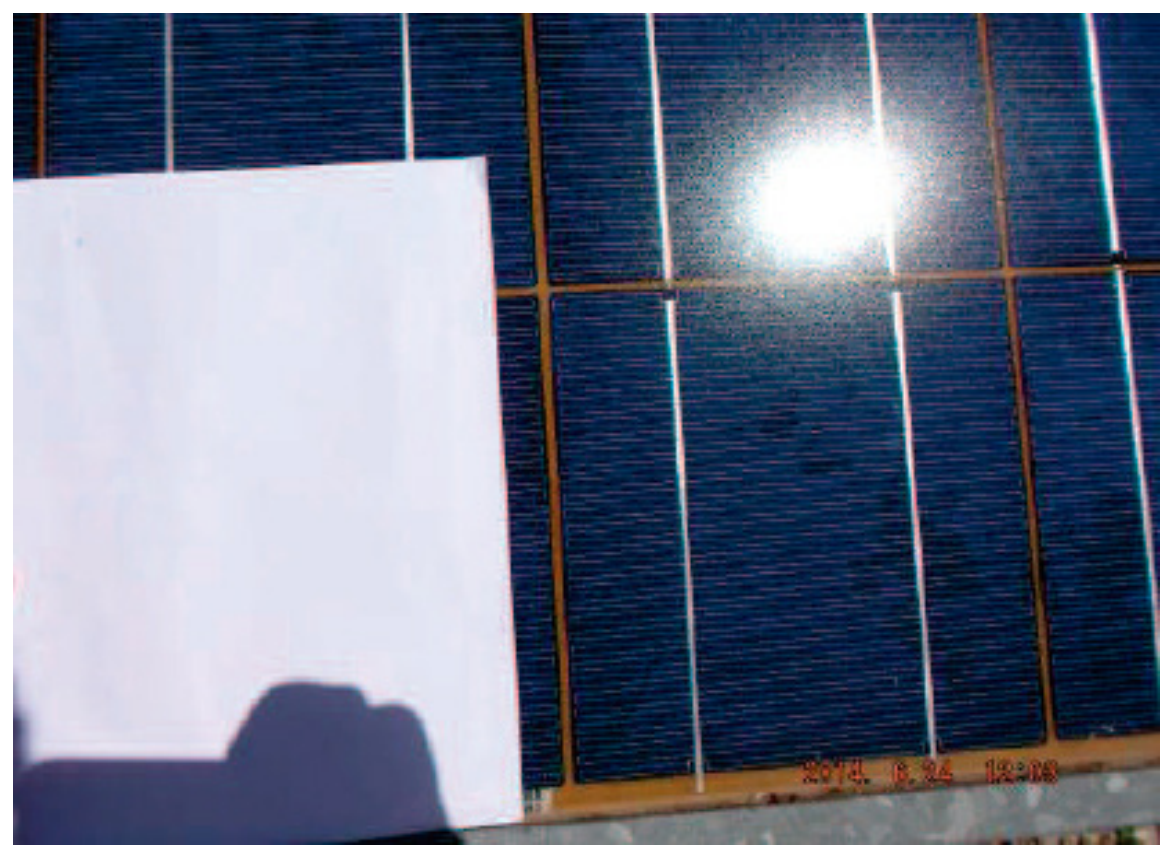

Figura 2. Amarillamiento en un modulo FV

Diversos fabricantes (Yingli Solar, Suntech, Canadian Solar Inc, etc.) han realizado pruebas sobre sus módulos con el fin de obtener las causas y problemas derivados del amarilleamiento. Asimismo, varios organismos independientes han realizado pruebas sobre el amarilleamiento de los módulos fotovoltaicos.

Dependiendo de la fuente de las pruebas de laboratorio, los problemas ocasionados por el amarilleamiento pueden ser desde prácticamente despreciables, hasta tener un impacto en la potencia de salida de un $30 \%[1]$, por causas directas o indirectas del amarilleamiento.

El amarilleamiento de los módulos FV se produce en la mayoría de los módulos fotovoltaicos comerciales, sin descartar años de fabricación posteriores a 2010.

\section{Delaminación o "Burbujas"}

La delaminación es el resultado de la pérdida de adhesión del encapsulante con la superficie frontal de las células fotovoltaicas. La delaminación se produce con mayor frecuencia y en mayor medida en climas cálidos con humedad e incluso a veces a partir del $5^{\circ}$ año de exposición. 

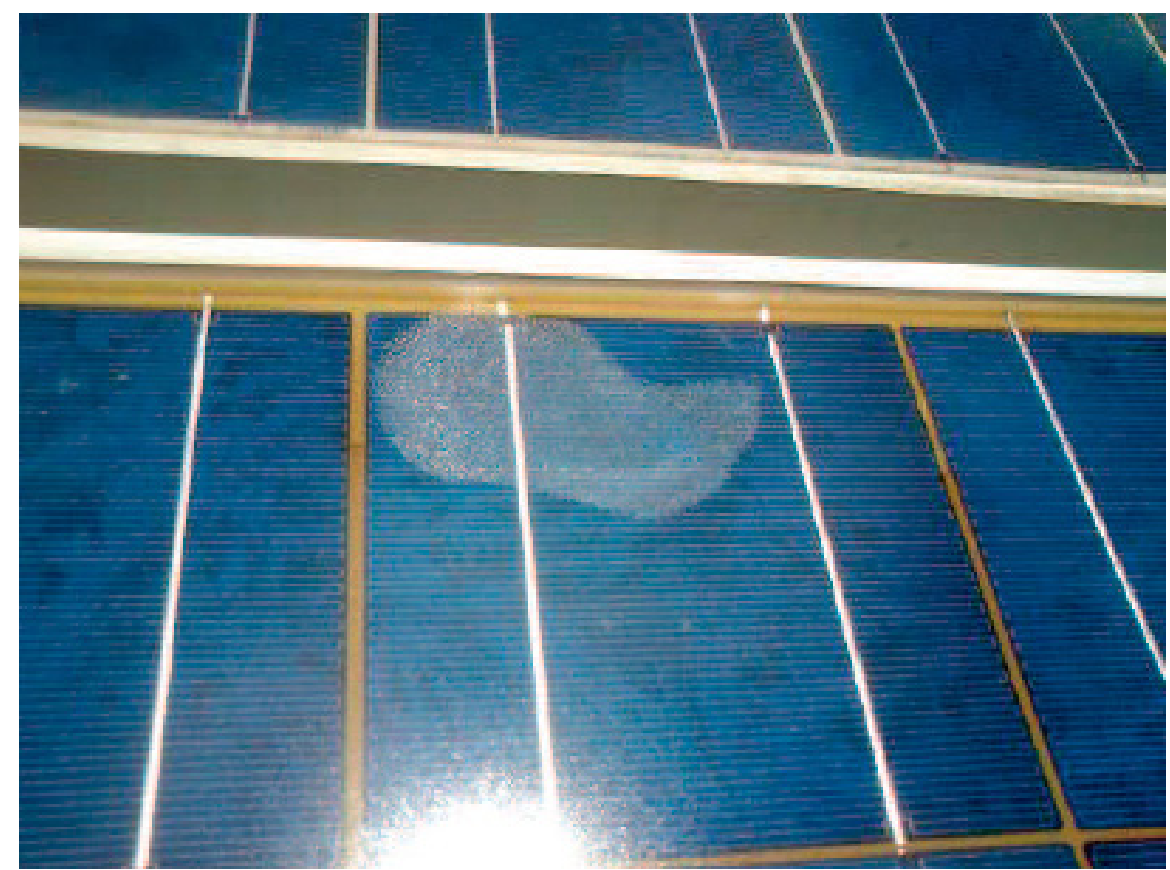

Figura 3. Delaminación en un módulo fotovoltaico

La delaminación incrementa el riesgo de corrosión y fallo en los contactos metálicos debido a la disminución del aislamiento. Según un estudio realizado por el Florida Solar Energy Center[2], la delaminación es difícil de cuantificar y no es fácil de comprobar sus causas y prejuicios sobre los módulos.

\section{Oxidación}

Un mal aislamiento del módulo puede provocar la pérdida de estanqueidad. Se puede dar el caso de fallo de aislamiento debido a la fabricación o en el transcurso de los años de exposición solar, por degradación de los componentes aislantes.

El oxígeno está presente en el aire (21\%) y en el agua (33\%), por lo que si fallan el Tedlar y el EVA, la oblea de silicio entrará en contacto muy fácilmente con el oxígeno, formando dióxido de silicio y oxidándose.

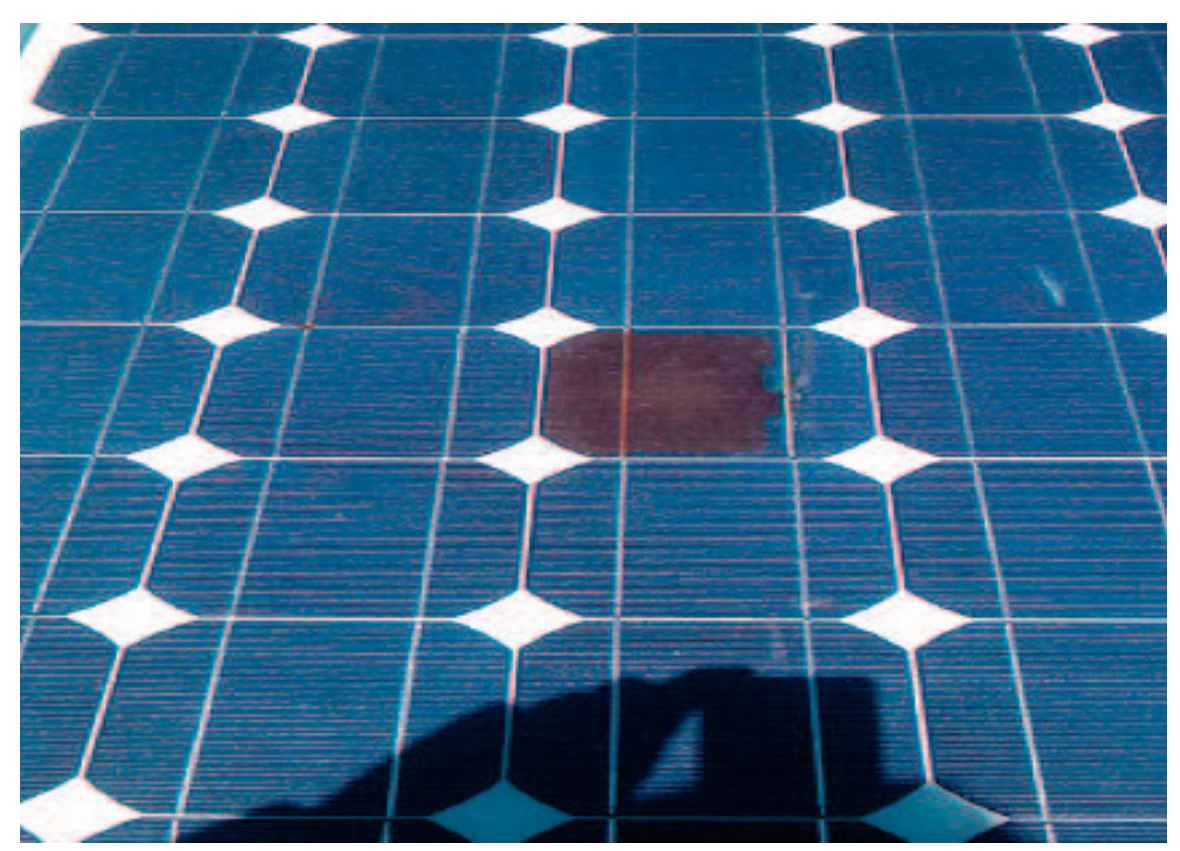

Figura 4. Oxidación en un módulo fotovoltaico

La oxidación en la célula tenderá a extenderse por todo el módulo. Cuando la corrosión cubra dos o más células co- nectadas en serie, puede producirse un fallo eléctrico debido a la capacidad dieléctrica del oxígeno. El fallo rompe la continuidad de la serie y puede que algunas células queden aisladas del circuito, por lo que no podrían evacuar la energía que generan.

Debido a que la oxidación puede romper el circuito serie en el que se encuentra el resto de módulos instalados, la energía generada por los módulos conectados aguas abajo del módulo con problemas de oxidación no podrá ser entregada.

\section{Babas de caracol o "Snail Trails"}

Las babas de caracol son un problema reciente, que continúa en proceso de análisis por parte de fabricantes y organismos externos. No obstante, se considera que es debido a micro rupturas en las células $\mathrm{FV}$, donde posteriormente se produce una oxidación, ocasionadas por la forma de manipulación de los módulos después de su fabricación.
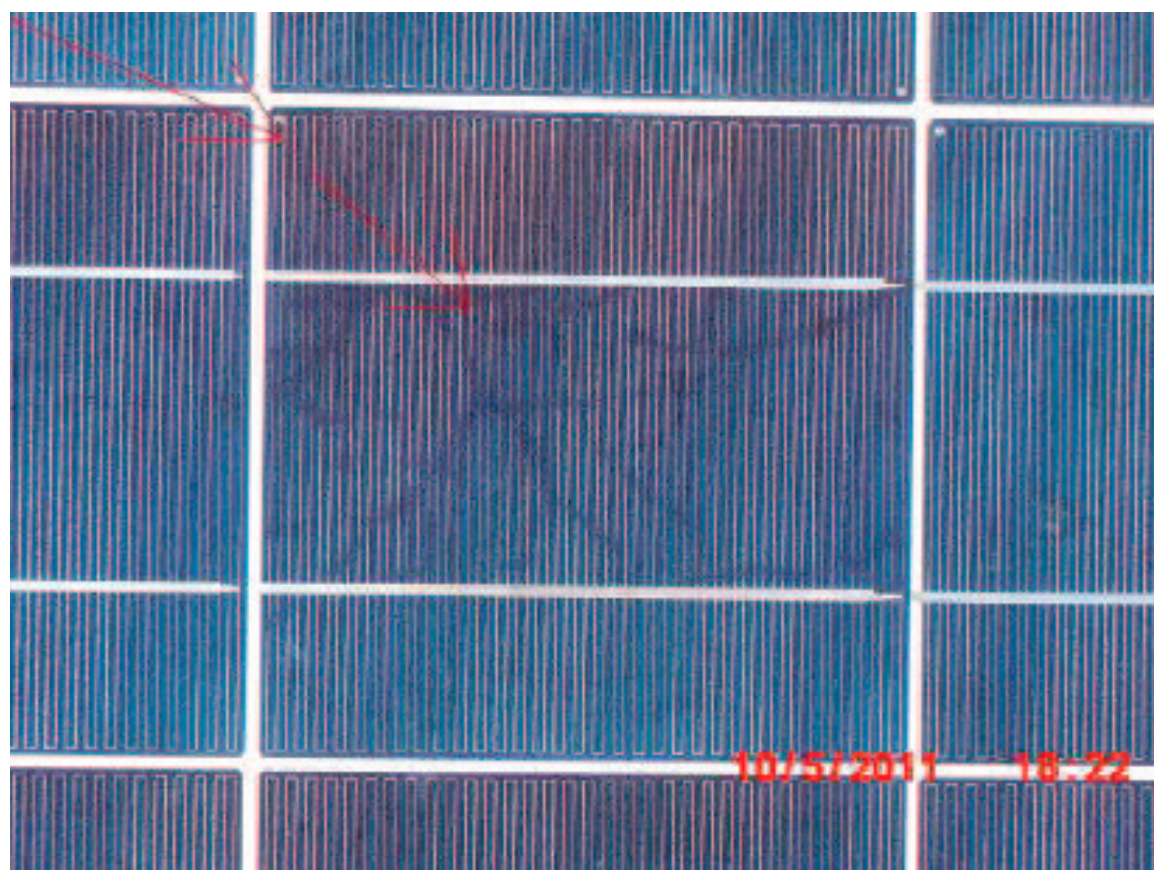

Figura 5. Babas de caracol en un módulo fotovoltaico

Un estudio llevado a cabo por TÜV RHEINLAND[3] muestra el comportamiento de los módulos fotovoltaicos frente a las babas de caracol, en cuanto a su producción y condiciones estándar.

El estudio se realizó con 15 módulos afectados y 15 módulos sin babas de caracol, todos ellos de la misma planta fotovoltaica, y concluyó que los 30 módulos estudiados superaron los requisitos de la norma EN (IEC) 61215:2005.

De acuerdo a la experiencia de INGEREMA, si las babas de caracol cortan los conectores metálicos de una célula, ésta no puede entregar la totalidad de energía que produce. En este sentido, la forma de las babas de caracol influye en el la potencia de salida del módulo FV.

\section{Puntos Calientes o "Hot Spot"}

Los puntos calientes pueden ser ocasionados en fábrica o después del montaje de los módulos FV. 


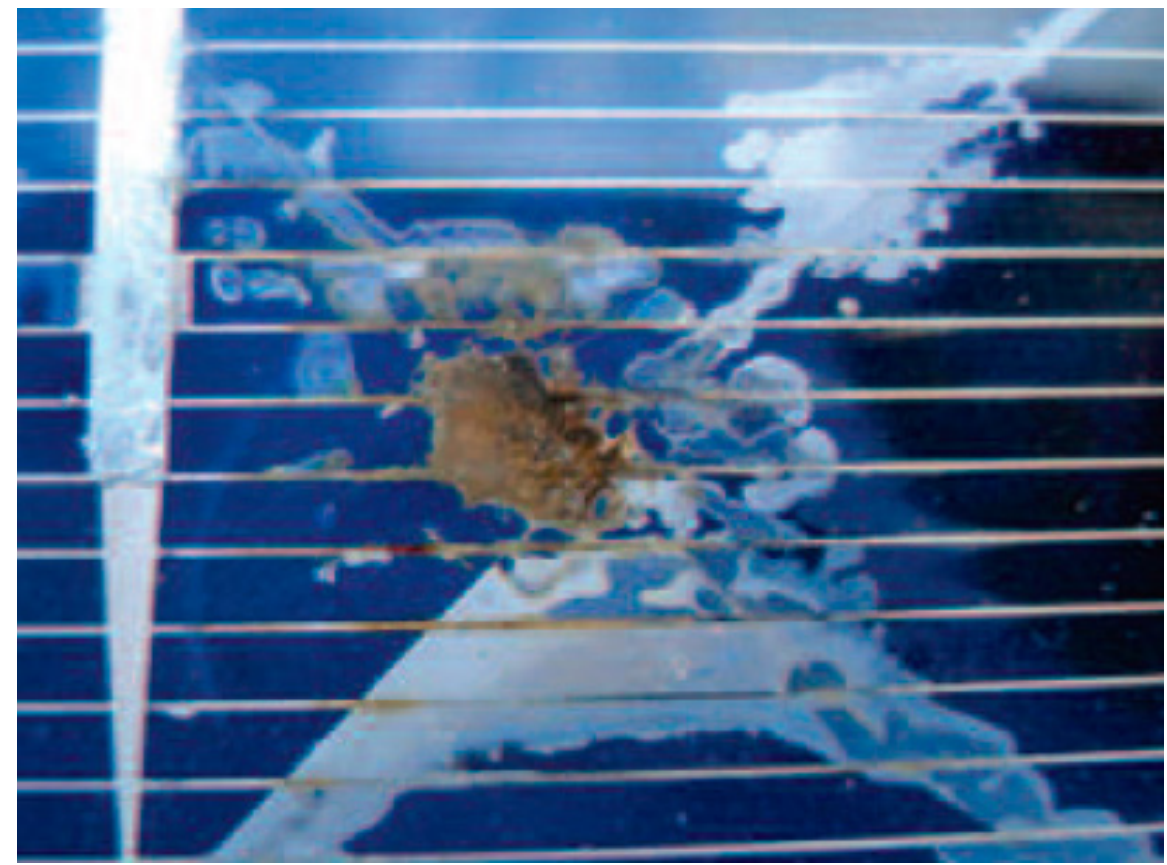

Figura 6. Punto caliente en un módulo fotovoltaico

En fábrica es debido a los materiales empleados para la fabricación de la célula FV. Un caso usual es la utilización de silicio metalúrgico con un contenido alto en hierro.

Los puntos calientes se generan después del montaje cuando hay sombreado en una sola célula fotovoltaica. Dicha célula se comporta como una resistencia óhmica y se puede calentar hasta el punto de destruirse, al fluir por ésta la corriente de las demás células FV en serie. En este caso, la célula afectada se quema como una resistencia sobrecargada.

Por otra parte, el sombreado de una célula FV puede provocar un voltaje inverso en ella. Esta célula consumiría por tanto potencia generada por las demás en serie con ella, produciéndose un calentamiento indeseado en la célula sombreada.

Este calentamiento indeseado será mayor cuanto mayor sea la radiación incidente sobre el resto de células en serie y menor la que reciba la célula afectada, debido a la sombra. En un caso extremo, la célula podría llegar a romperse por sobrecalentamiento.

\section{Degradación inducida de la potencia o "PID"}

Es la degradación de la potencia a la salida de un módulo FV debido a la fuga de corriente por otras vías diferentes a los terminales del módulo, la cual es originada por la diferencia de potencial entre la superficie del módulo, el marco y la célula FV.

La fuga de corriente ocurre cuando los iones de sodio fluyen desde el vidrio hacia la capa antireflectante de la célula FV y permanecen allí. Estos iones acompañados de cargas negativas crean un campo eléctrico que repele los electrones y éstos buscan una vía diferente para salir, por lo que terminan atravesando las diferentes capas del módulo en forma de corrientes de fuga[4].

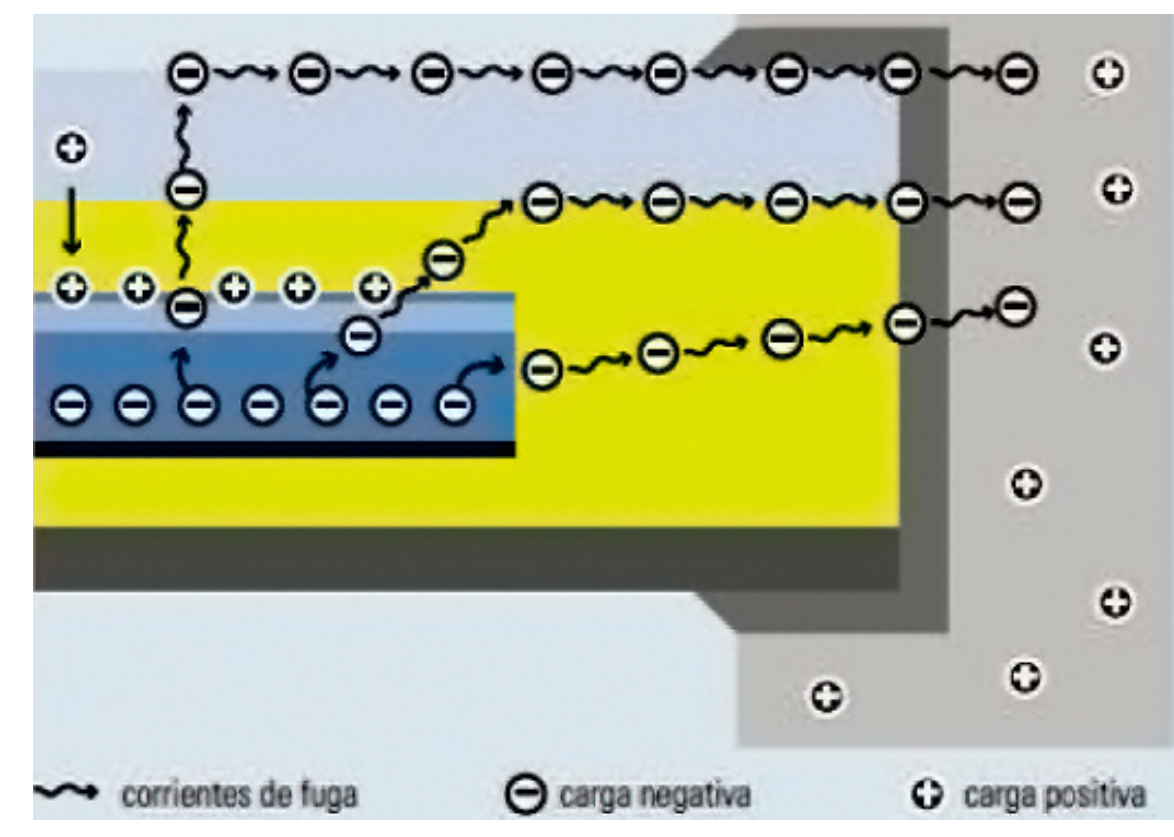

Figura 7. Corrientes de fuga en un módulo fotovoltaico

El PID depende en gran medida de la posición del módulo respecto al terminal negativo de la serie y aumenta según incrementa la temperatura ambiente y la humedad relativa en el emplazamiento.

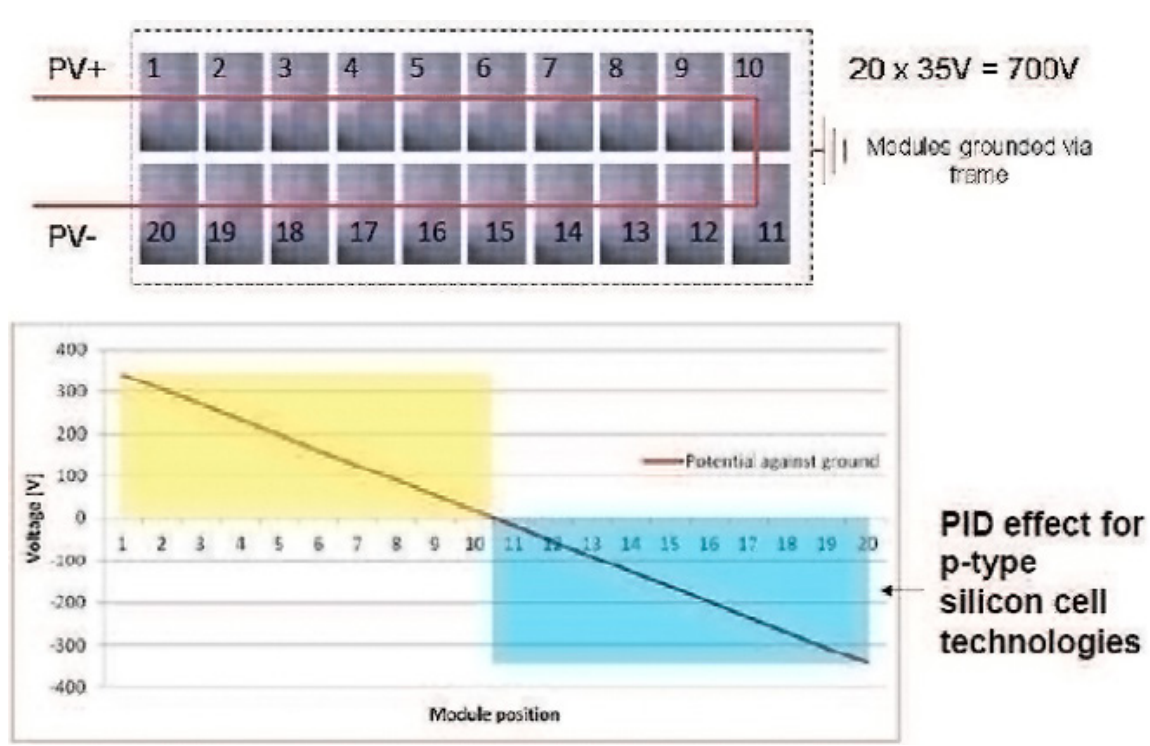

Figura 8. PID según la posición del módulo en una serie

\section{Corrosión de la capa o "TCO”}

Este problema afecta a los módulos de capa fina, sobre todo a los módulos de Silicio Amorfo (a-Si) y de Telurio de Cadmio (CdTe).

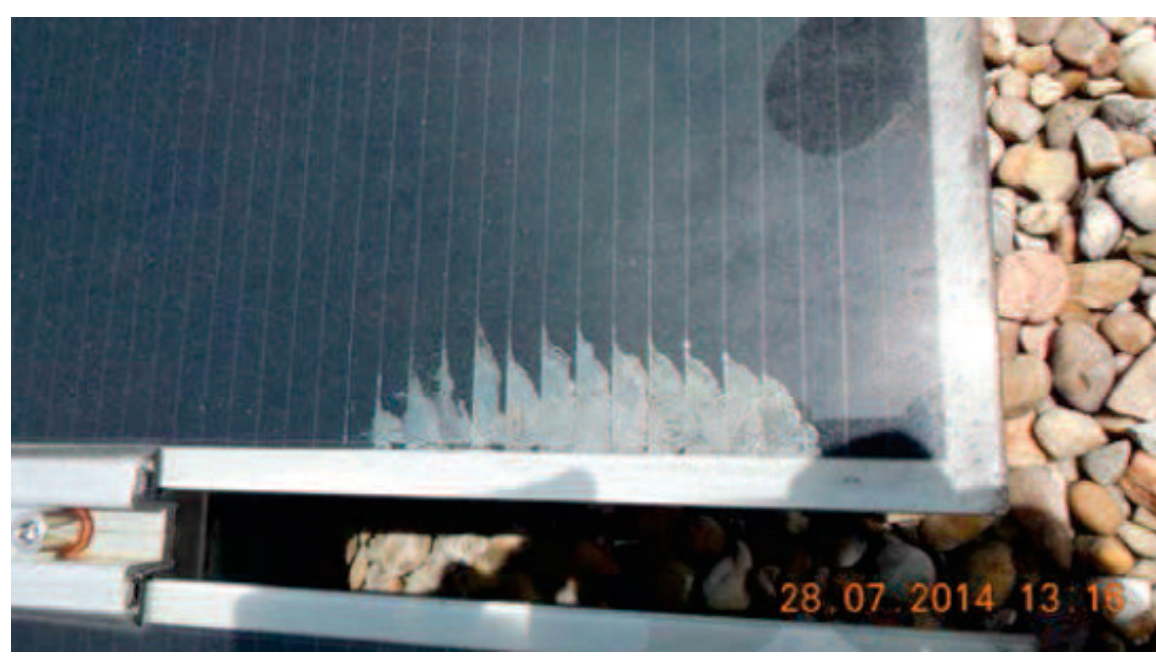

Figura 9. Corrosión en un módulo fotovoltaico de capa fina 
La corrosión se debe a la migración de los iones de Sodio de la capa de vidrio frontal a la capa de TCO del módulo, cuando las células de capa fina están en potencial negativo respecto al resto de componentes del módulo.

La humedad, temperatura y los potenciales creados entre las capas son los principales factores de la corrosión. No obstante, el TCO es más frecuente en los módulos con marco de aluminio (usualmente los de a-Si) debido al campo eléctrico creado entre el marco y el módulo que acelera la corrosión.

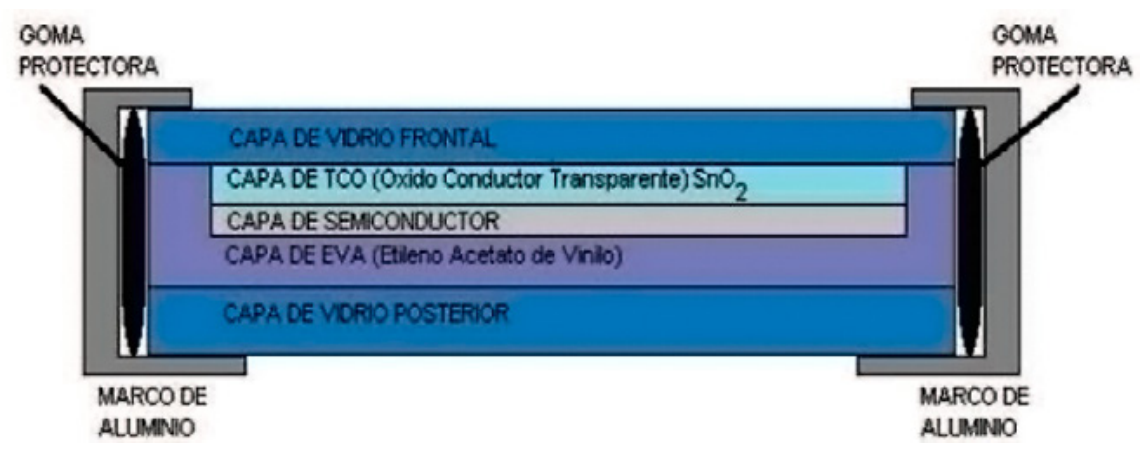

Figura 10. Capas de un módulo FV de capa fina de a-Si

\section{CONCLUSIONES}

Los certificados usuales a tener en cuenta dependen de la tecnología del módulos fotovoltaico en la que se desee invertir.

Para los módulos fotovoltaicos de silicio cristalino, los fabricantes deben contar con los siguientes certificados usuales: IEC 61215 Ed.2, IEC 61730, IEC 61705, CE, PV CYCLE, ISO 9001, ISO 14001 y OHSAS 18001 (últimas versiones).

Para los módulos de capa fina, los fabricantes deben contar con los siguientes certificados usuales: IEC 61646,
IEC 61730, IEC 61701, IEC 60068-2-68, CE, PV CYCLE, ISO 9001, ISO 14001 y OHSAS 18001 (últimas versiones).

Los fallos mencionados han ocurrido en módulos fotovoltaicos que cuentan con sus correspondientes certificados. Es por esto que, si bien INGEREMA valora de forma positiva que un fabricante de módulos fotovoltaicos cuente con los certificados indicados, y que las especificaciones técnicas del módulo a instalar sean acorde al diseño óptimo deseado para el proyecto fotovoltaico, es importante evaluar el alcance de garantías que ofrece el fabricante, la calidad/ precio de su producto, el track record en Colombia o Latinoamérica y la calidad de su servicio post-venta.

Todo lo anterior es considerado por INGEREMA como factores determinantes para la elección de los módulos fotovoltaicos durante la etapa de factibilidad de un proyecto.

Asimismo, durante la fase previa a la construcción de un proyecto fotovoltaico, INGEREMA recomienda verificar la calidad del proceso de fabricación de los módulos fotovoltaicos, flash test, embalaje, acopio y posterior transporte.

\section{REFERENCIAS}

[1] Mariano Sidrach de Cardona; Paula Sánchez: Degradación de módulos fotovoltaicos de silicio cristalino tras 12 años de operación en España - Octubre 2010

[2] Neelkanth G. \& Pandit: Study of Delamination in Acceleration Tested PV Modules - October 2001

[3] TÜV Report 21215028 snail tracks_bw_red. Report No. 21215028 - June 2011

[4] Artículo de 2012 de la revista Photon 


\title{
GESTIÓN ENERGÉTICA EN LA UNIVERSIDAD DEL ATLÁNTICO
}

\author{
Natalia Nuñez Fuentes ${ }^{1}$ \\ Adriana Palencia Salas ${ }^{1}$ \\ Guillermo Valencia Ochoa ${ }^{1}$ \\ ${ }^{1}$ Grupo de Gestión Eficiente de Energía - Universidad del Atlántico. \\ ${ }^{2}$ nataly1026@hotmail.com
}

\begin{abstract}
RESUMEN
En la actualidad, el tema de la eficiencia energética juega un papel crucial, es además de ser el factor clave para mantener la competitividad en el futuro, tiene el propósito de minimizar el impacto ambiental, maximizar el aprovechamiento de recursos y mantener la calidad de los productos o servicios ofrecidos por las organizaciones empresariales. En las instalaciones de la Universidad del Atlántico se están adelantando estudios de eficiencia energética, con lo que se pretenden utilizar los recursos de forma racional, responsable y eficiente, gestionando la consecución de los mismos para así garantizar la prestación del servicio. Con ello se busca, además, prevenir la contaminación, mejorar el desempeño energético y mitigar los impactos ambientales, promoviendo una cultura de uso eficiente de la energía en la institución. Como primera medida, se llevó a cabo una revisión energética o diagnóstico inicial, que incluye una descripción de las instalaciones (actividad que se realiza, número de estudiantes, área construida, horarios de funcionamiento), identificación de fuentes de energía y usos de la misma. Se identificaron las áreas y equipos de uso significativo de energía, teniendo en cuenta un inventario de cargas de las instalaciones de la institución. Luego, se procedió a construir diagramas de Pareto por áreas y equipos, con el fin de visualizar aquellos que representan los mayores consumos de energía. Además, se calcularon potenciales de ahorro por buenas prácticas de uso de los equipos y mantenimiento de los mismos. Igualmente, se realizó una revisión de los consumos de energía eléctrica, análisis de su tendencia, meses de mayores y menores consumos, potencia reactiva etc. Se verificó el régimen tarifario de la institución, encontrando que la Universidad está en un régimen regulado y tiene la posibilidad de ser recategorizado como usuario no regulado; de esta forma se propusó seleccionar un plan tarifario más económico, que implique un ahorro aproximado de \$50.000.000 al año. Actualmente la institución cuenta con un programa de gestión eficiente de la energía, y próximamente contará con un Sistema de gestión de la energía enmarcado en la ISO 50001:2011. Actualmente se siguen realizando actividades para la reducción de los consumos y mejoramiento del desempeño energético. Los resultados obtenidos son la disminución en los consumos de energía, costos y de emisiones de Gases de Efecto Invernadero.
\end{abstract}

Palabras claves: Gestión energética, energía, universidad, ahorro, eficiencia. 


\section{INTRODUCCIÓN}

La educación es un factor clave y uno de los pilares en que se fundamenta la sociedad. Es por esto que se deben dedicar todos los medios, esfuerzos y acciones posibles para su mejora continúa. Las instituciones educativas cuentan para su funcionamiento con un potencial de ahorro económico y energético, lo cual resulta ser muy importante y de total relevancia. de igual manera, se ha demostrado que la responsable de una gran cantidad de problemas asociados al uso no eficiente de la energía no es la capacidad o actualización de la tecnología productiva o de servicios existente, sino la inadecuada gestión en la administración de estos recursos.

En la actualidad, la gestión energética a nivel mundial puede aconcebirse como la necesidad de asegurar el uso racional de la energía en todo el planeta, ya que el alto consumo de combustibles fósiles ha creado una dependencia energética cada vez mayor. Dado que este tipo de combustibles son los causantes de la emisión de gases de efecto invernadero que dan lugar al cambio climático, generan un gran desequilibrio mundial, problemas medioambientales y agotamiento de recursos energéticos, entre otros aspectos. Según la Convención del año 2009 de la Organización de Naciones Unidas (ONU) sobre cambio climático (Copenhagen Climate Change Conference, 2009) el límite de crecimiento de la temperatura global del planeta estaría alrededor de los $2{ }^{\circ} \mathrm{C}$; según el Panel Intergubernamental de Cambio Climático (IPCC, 2007), un calentamiento superior a dos grados sería catastrófico para el ser humano y la naturaleza.

El principal responsable del incremento de la temperatura global es la alta concentración atmosférica de Gases de Efecto de Invernadero (GEIs).Frente a la tasa de crecimiento actual de estos gases, existen al menos un $77 \%$ de posibilidades de que el aumento de la temperatura media global exceda los $2^{\circ} \mathrm{C}$ en el año 2035.3. De los gases citados en el Protocolo de Kyoto como GEIs, el dióxido de carbono (CO2) representa las tres cuartas partes; más del 90\% del mismo tiene su origen en las transformaciones energéticas que se ponen de manifiesto en los medios de transporte, la industria, las residencias y los centros comerciales. [3]. Hoy día no existe una tecnología viable capaz de absorber las emisiones de CO2. La única forma de limitarla es a través del uso eficiente de la energía y el incremento de la masa verde del planeta.

Según los estudios realizados del Panel Intergubernamental de Cambio Climático en 2011, la eficiencia energética en el uso final de la energía utilizada por las organizaciones puede contribuir a reducir el $38 \%$ de las emisiones de gases de efecto de invernadero (GEI), lo cual resulta necesario para el control del cambio climático [4].

Los Sistemas de Gestión de la Energía (SGEn) ofrecen un enfoque sistemático para controlar y reducir el consumo energético y lograr un incremento de la eficiencia energética de un amplio rango de organizaciones. La implementación de un SGEn nace en nuestra institución como un proyecto que luego se constituye como parte del Sistema de Gestión Ambiental, el cual está conformado por un programa de gestión eficiente de energía y del agua, gestión integral de residuos y construcciones sostenibles, todos ellos enmarcados en el plan estratégico institucional 2009- 2019 de la Universidad del Atlántico. Es por esto, que se hizo necesario la implementación de un sistema de gestión robusto y flexible, capaz de adaptarse a las nuevas tendencias de globalización, manteniendo el bienestar de la sociedad y controlando los impactos ambientales generados.

Por esta razón, se decide que el camino correcto a lograr estos beneficios es seguir los lineamientos de la Norma ISO 50001, que especifica los requisitos necesarios para establecer una política energética, determinar una línea base del uso de la energía, identificar las áreas críticas del desempeño energético y definir unas metas y objetivos adecuados para cada organización, todo con el fin de mejorar continuamente los aspectos energéticos significativos, los indicadores de desempeño energético, el control operacional, el diseño, el seguimiento, la medición y las acciones de mejora.

Al implementar la Norma ISO 50001 se obtienen diferentes ventajas como son: la reducción energética, la reducción de emisiones, el aumento de la confiabilidad de los procesos, las ventajas competitivas, la mejora de la productividad, las oportunidades de acceso a beneficios gubernamentales, el cumplimiento de exigencias ambientales y el cumplimiento de requisitos del mercado, de requisitos legales y de otro tipo. Además de todo esto, se busca el reconocimiento por parte de las partes interesadas.

En el presente artículo se encuentran los lineamientos para el diseño e implementación del Sistema de Gestión de la Energía en la Universidad del Atlántico, de acuerdo a los requisitos de la norma NTC-ISO 50.001.

\section{MATERIALES}

Para la consecución de las actividades enmarcadas en el diseño e implementación del SGEn en la Universidad del Atlántico, se cuenta con un equipo especializado en el área energética, con el departamento de Gestión Ambiental de la institución y con el apoyo del Grupo de Investigación en Gestión Eficiente de la Energía KAÎ. Se utilizaron diferentes estrategias para el ahorro de energía, tales como las campañas de sensibilización del personal uniatlanticense y las capacitaciones; también las charlas de motivación para el cuidado del medio ambiente y del uso racional de recursos naturales, entre otros temas.

\section{METODOLOGÍA}

La metodología que se llevó a cabo en este proceso fue la del Ciclo PHVA (Planear, Hacer, Verificar y Actuar), de- 
clarado por, W. Edward Deming como una herramienta de simple aplicación, que, cuando se utiliza adecuadamente, puede ayudar mucho y de manera organizada y eficaz en la realización de las actividades. Por tanto, adoptar la filosofía del ciclo PHVA proporciona una guía básica para la gestión de las actividades, los procesos y la estructura básica de un sistema; además, es aplicable a cualquier organización. [7].

De manera resumida, el ciclo PHVA se puede describir así:

1. Planificar: Establecer los objetivos y procesos necesarios para obtener los resultados, de conformidad con los requisitos del cliente y las políticas de la organización.

2. Hacer: Implementar procesos para alcanzar los objetivos.

3. Verificar: Realizar seguimiento y medir los procesos y los productos en relación con las políticas, los objetivos y los requisitos, reportando los resultados alcanzados.

4. Actuar: Realizar acciones para promover la mejora del desempeño del (los) proceso(s).

Las actividades que se llevaron a cabo en el proceso de implementación del Sistema de Gestión Integral en la Universidad del Atlántico fueron las siguientes:

- Identificar las fuentes de energía: realizar visita e inspección a las instalaciones, contactar con el personal de mantenimiento y solicitar la información requerida, que para este caso son las facturas de los energéticos que use la instalación.

- Analizar los consumos de energía: Revisar, analizar y evaluar los consumos de al menos el último año de los diferentes tipos de energía utilizados en la institución. Se evalúan los consumos mensuales, diarios y horarios; energía reactiva, días y meses de mayores y menores consumos.

- Identificar las áreas, equipos y personal de uso significativo de energía (USE): Las áreas y equipos de USE son aquellas que más consumen energía, por lo tanto tienen mayor impacto en la variación de la facturación energética. Estas son las que generalmente presentan los mayores potenciales de ahorro y mejora. El procedimiento definido es el siguiente:

Identificar y clasificar los equipos por sistemas de energía. (Ej. refrigeración, ventilación, iluminación, fuerza, ofimática, otros).

Verificar los consumos por cada sistema y analizar sus comportamientos y demandas energéticas. En caso de inexistencia de medición por sistema se realiza una estimación de los consumos teniendo en cuenta la cantidad de los equipos, potencia y horas de funcionamiento.

Algunos de estos datos pueden obtenerse por medio de la placa de equipos o realizando mediciones con pinzas, vatímetros u otros instrumentos de medida.

Graficar en diagramas circulares, de barras, Pareto, sankey u otros; los consumos por cada área o sistema identificado.

Revisar el porcentaje de consumo energético que representa cada área o sistema.

Aquellas áreas o equipos que representen la mayor cantidad de uso o consumo de energía serán las de usos significativos de energía. Estas representan el mayor potencial de ahorro.

- Identificar las variables significativas de los USE: Una variable significativa es aquella que determina el mayor consumo en el USE. Generalmente es el servicio o la producción para la cual fue diseñado el equipo o proceso que usa la energía. Puede ser una unidad productiva ( $\mathrm{m} 3, \mathrm{ml}$, unidades de producto, etc.), unidad de uso: personas, habitaciones, días de ocupación, unidades de clima: Heating degree day (HDD), Cooling degree day (CDD).Los pasos definidos para identificar la variable significativa son:

Identificar los procesos o áreas en los cuales se desea conocer la variable significativa

Analizar los objetivos del sistema, área o proceso.

Elegir aquella variable que representa el objeto del proceso.

Graficar el consumo de energía Vs la variable en un diagrama de correlación $\mathrm{X}-\mathrm{Y}$.

Analizar el resultado de este gráfico, su correlación y que tan relevante es con los consumos. Si el coeficiente de correlación es alto, significa que la variable elegida si es significativa y representa el consumo de energía.

Identificar, priorizar y registrar oportunidades de mejora en el desempeño energético.

Luego se procede a determinar La línea de base energética (LB) que es aquella que representa el comportamiento cotidiano de un proceso, área o actividad. Es una referencia cuantitativa con la que se mide el desempeño energético y es registrada y actualizada periódicamente.

Se construye a partir de los datos de consumo energético y de la variable que más influencia ese consumo.

Para la Universidad del Atlántico (frontera bloques académicos) se eligió a los días hábiles académicos (días de 
clase) como la variable que más influye en el consumo de energía.

La línea base fue construida a partir de los datos de consumo $(\mathrm{kWh} / \mathrm{mes})$ y días de actividad académica/mes para el periodo comprendido entre marzo de 2012 a marzo de 2014. El resultado obtenido se expone en la gráfica 1

Gráfico 1. Línea Base de Energía Eléctrica UA

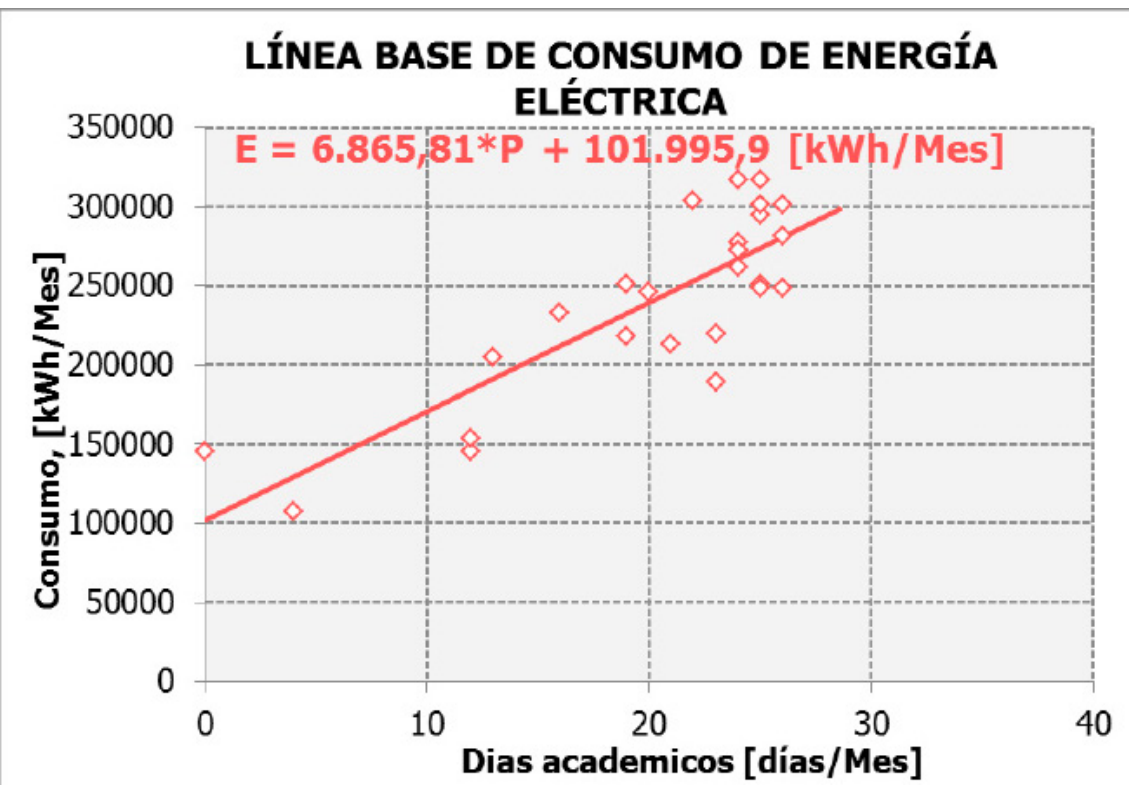

La ecuación de la línea base es la siguiente:

$$
\mathrm{E}=\mathrm{mP}+\mathrm{E} \text {. }
$$

Dónde $\mathrm{E}=$ Consumo de energía en el período seleccionado; $\mathrm{P}=$ Producción asociada o la variable significativa en el período seleccionado; $\mathrm{M}=$ Pendiente de la recta que significa la razón de cambio del consumo de energía respecto a la variable significativa; Eo= Intercepto de la línea en el eje y que significa la energía no asociada a la variable significativa; $\mathrm{mP}=$ Es la energía utilizada en el proceso.

A partir del gráfico 1 se realizan las siguientes observaciones: la correlación existente entre el consumo de energía eléctrica con los días académicos es de un 70\%. Esto indica que las variaciones en el consumo se ven determinadas y afectadas de manera fuerte por las variaciones de los días de actividad académica. El modelo matemático que representa el consumo de energía eléctrica en función de los días de actividad académica se encuentra expresado en la siguiente ecuación y se denomina Línea Base:

$$
E=6.865,81 P+101.995,9\left(\frac{k W h}{m e s}\right)
$$

El modelo muestra que existe una energía no asociada a la actividad académica de 101.995,9 kWh/mes. Esta energía representa el 42,5\% de la energía eléctrica promedio consumida mensualmente. La variabilidad de este consumo depende de la operación de los equipos y sistemas, no de la tecnología empleada. Por lo tanto, se puede reducir este consumo sin cambios tecnológicos.

Luego se procede a determinar la línea meta de Energía eléctrica que representa el comportamiento de los datos por debajo de la línea base; es decir, aquellos que consumieron menor cantidad de energía que la promedio expresado por el modelo. En este caso se puede decir que estos valores corresponden a las mejores operaciones.

Para la Universidad del Atlántico el modelo de consumo de energía eléctrica de los mejores

desempeños o línea meta está representado por la siguiente ecuación:

$$
E=6.865,81 P+67.582,11\left(\frac{k W h}{m e s}\right)
$$

Gráfico 2. Línea Meta de Consumo de Energía Eléctrica

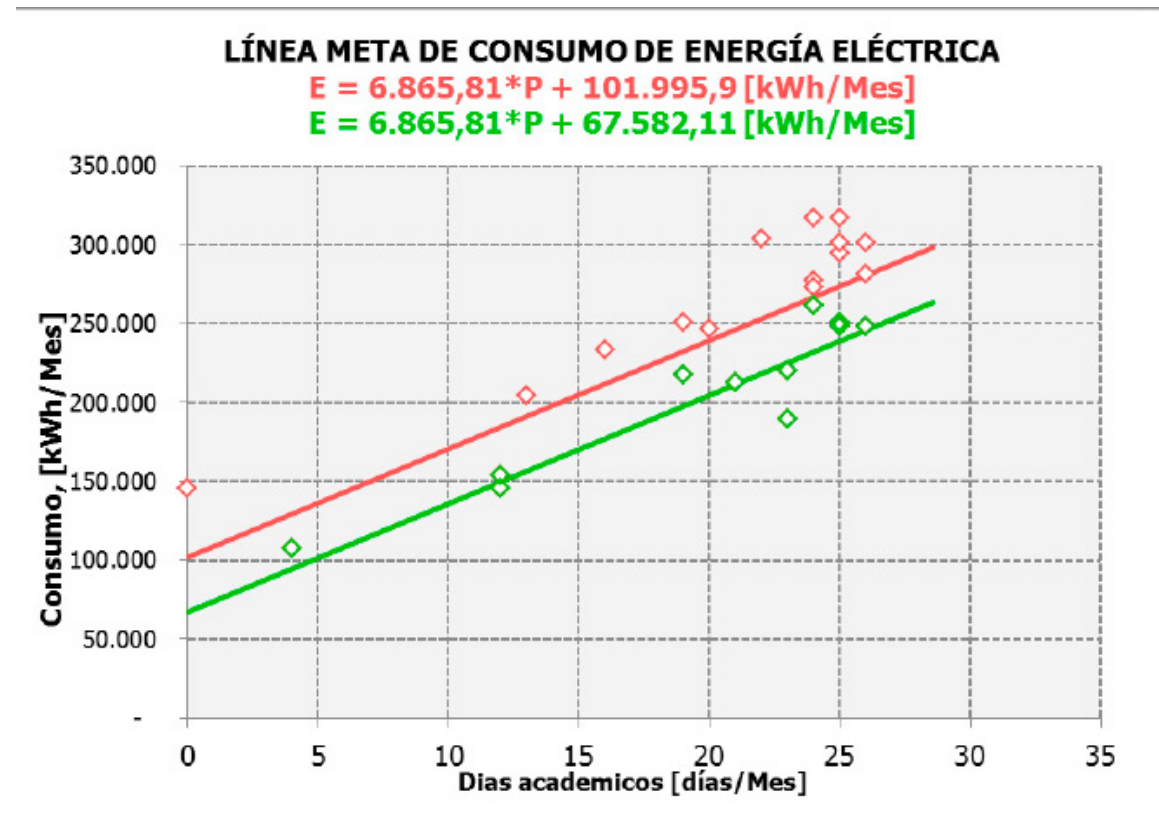

En el gráfico 2 se representa la línea meta y línea base de energía eléctrica. La línea meta (línea verde), representa el promedio de los valores situados por debajo de la línea base (línea roja), que se da debido a la existencia de mejores prácticas operacionales para un mismo nivel de la variable significativa (días de actividad académica). La comparación del valor de la línea base con respecto al correspondiente a ese mismo nivel de producción en la línea meta permite identificar el potencial de ahorro alcanzable.

\section{Potencial de ahorro por variabilidad ope- racional y gestión del mantenimiento.}

El término independiente de las ecuaciones anteriores (línea base y línea meta), es la energía no asociada a la actividad académica y lo días hábiles de uso del edificio. Representa la energía que se consume, que no tiene relación directa con el uso académico de los edificios y que es susceptible a reducciones por mejoramiento de las acciones operativas y de mantenimiento.

Esta energía no asociada, equivale a un 42,5\% (101.995,9 $\mathrm{kWh} / \mathrm{mes}$ ) del consumo de energía eléctrica promedio, y que, para las operaciones más eficientes, representa un $28,1 \%(67.582,11 \mathrm{kWh} / \mathrm{mes})$. 
En la universidad del Atlántico se realizaron campañas de concientización a toda la comunidad estudiantil, personal de servicios generales, de mantenimiento y administrativo, por medio de charlas, mensajes alusivos al uso racional de energía, capacitaciones y concursos.

\section{RESULTADOS}

El potencial de ahorro existente en la Universidad del Atlántico equivale a un $14 \%(42,5 \%-28,1 \%)$ del consumo promedio, es decir $34.414 \mathrm{kWh} / \mathrm{mes}$.

Los equipos que representan los mayores consumos de energía son: Aires Acondicionados (60\%), Equipos de cómputo y ofimática (20\%) e Iluminación (15\%).

Los meses de mayores consumos de energía del 2013 fueron Abril, Septiembre y Noviembre.

El Factor de potencia de la Universidad es 0.96 (dando cumplimiento a la normatividad $(0,95<\mathrm{FP}<1)$. El Factor de carga de los Bloques académicos es igual al 75\%.

Debido a que el número de estudiantes permanece constante, al igual que el número de salones y horas de clase diarias, se eligieron como variable significativa el número de días de clases al mes. Se logró identificar excesiva iluminación en los salones del bloque F (15 lámparas por salón), que incrementan el consumo innecesariamente. Por esto se debe desinstalar el número de lámparas que permitan el cumplimiento de la cantidad de luxes requeridos en los salones de clase $(750 \mathrm{~lx})$.

Se está realizando la sustitución del uso de lámparas T12 $\mathrm{Y}$ balastos electromagnéticos por lámparas $\mathrm{T} 5 \mathrm{Y}$ balastos electrónicos regulables. Se detectó la falta de aislamiento en tuberías de los sistemas de refrigeración.No hay regulación y control de temperatura (algunos termostatos en $50 \mathrm{~F}$ ). La tensión de línea y fase más alta que las otras dos, superando reiteradamente los límites permitidos por la normatividad colombiana. Los períodos de baja carga (por la noche y los fines de semana) permanece un valor de corriente de entre 90 y 150 Amperios.Se detectaron consumos de energía (20
$\mathrm{kW}$ ) durante las noches y fines de semana innecesarios. No se estában apagando todas las cargas. Condensadores no ajustados a las cargas o en exceso.

\section{BIBLIOGRAFÍA}

[1] UNFCCC Executive Secretary. (December 2009). Copenhagen Climate Change Conference . 28 de Noviembre de 2013], de Copenhagen Climate Change Sitio web: http://unfccc.int/meetings/bonn_mar_2009/meeting/6312. php

[2] IPCC. (2007). PCC Fourth Assessment Report. citado el 28 de Noviembre de 2013, de PCC Fourth Assessment Sitio web: http://www.ipcc.ch/publications_and_data/ar4/ syr/en/main.html

[3] Veronica Lipperheide. (2007). Protocolo de Kyoto. 15 de Marzo de 2014, de Nueva Revista Net Sitio web: IPCC. (2007). PCC Fourth Assessment Report. citado el 28 de Noviembre de 2013, de PCC Fourth Assessment Sitio web: http://www.ipcc.ch/publications_and_data/ar4/syr/ en/main.html

[4] Stern, N. . (2006). Stern Review on the Economics of Climate Change. . 28 de Noviembre de 2013, de The National Archives Sitio web: http://webarchive.nationalarchives. gov.uk/20140328100059/http://www.environment-agency. gov.uk/research/library/data/145758.aspx

[5] Campos J., Prías O., Quispe E; Vidal J.; Lora E., et al.Proyecto "Programa de Gestión Integral de la energía para el sector productivo nacional". Segundo Informe Parcial. Proyecto UPME, Colciencias, U. del Atlántico y U. Autónoma de Occidente. Diciembre 2006.

[6]. Campos J., Prías O., Vidal J., E; Lora E., Propuesta de un modelo de gestión energética para el sector productivo colombiano. Memorias II Congreso internacional sobre Uso Racional y Eficiente de la Energía, Ciuree 2006. Cali Colombia 2006.

[7]. Abril C., Palomino. E., Sanchez. J. Manual para la integración de sistemas de gestión. FC Editorial, 2006. 


\title{
INDICADOR DE HUELLA DE CARBONO PROVENIENTE DEL CONSUMO ELÉCTRICO EN LOS LABORATORIOS DE INGENIERÍA ELECTRÓNICA DE LA UNIVERSIDAD SANTO TOMÁS TUNJA.
}

\author{
William Fernando Álvarez Castañeda ${ }^{1,2}$ \\ Laura Alejandra Martínez TejadaSergio ${ }^{1,3}$ \\ Armando Hernandez Peñuela ${ }^{1,4}$ \\ Yadir Fernando Medina Rincón ${ }^{1,5}$ \\ ${ }^{1}$ Universidad Santo Tomás - Sede Tunja \\ ${ }^{2}$ william.alvarez01@usantoto.edu.co \\ laura.martinez@usantoto.edu.co \\ ${ }^{4}$ sergio.hernandez@@santoto.edu.co \\ ${ }^{5}$ yadir.medina@hotmail.com
}

\begin{abstract}
RESUMEN
El presente documento expone la realización de un equipo para medir la expulsión de $\mathrm{CO}_{2}$ al ambiente, denominada huella de carbono, producida específicamente en edificaciones y medida en tiempo real. El equipo calcula la huella de carbono generada por la casa, empresa, universidad u oficina en lo relacionado al consumo de energía. Para lograrlo, se considera que la configuración eléctrica de una construcción es en paralelo, por lo que la principal variable es la corriente. Censado el valor de corriente, se puede obtener el valor de potencia en $\mathrm{Kw} / \mathrm{h}$ que demanda en ese momento la edificación y se tiene su equivalente en $\mathrm{Kg} \mathrm{CO}_{2}$. El objetivo es visibilizar esta información a todos los usuarios de la edificación, agregando además, la relación existente entre $\mathrm{Kg} \mathrm{CO}_{2}$ producidos por la distancia recorrida de un automóvil donde se evidencia la proximidad de la huella de carbono generada por el vehiculo y la edificación, esto para dar una idea más clara al observador de cuánto se está contaminando. Principalmente, este equipo busca crear conciencia ambiental y promover la práctica del uso racional de la energía y posteriormente un uso eficiente de la energía.
\end{abstract}

Palabras claves: Huella de carbono, contaminación, potencia, relación, concientización. 


\section{INTRODUCCIÓN}

La presente investigación aborda el tema de la huella de carbono que se define como la medición de la cantidad de emisión de gases de efecto invernadero al medio ambiente por parte de un individuo ya sea de manera directa o indirecta.

La característica principal de este tipo de impacto ambiental radica en su secuela en el calentamiento global y en los cambios climáticos.

Para analizar esta problemática es necesario mencionar sus causas. Una de ellas y en la que nos enfocaremos, es la producción de $\mathrm{CO}_{2}$ como el resultado de la incineración de combustibles fósiles (carbón, petróleo, gas natural). Es importante resaltar la implicación que tiene el uso irracional de la energía eléctrica ya que, en su mayoría es producida por turbinas a base de vapor (obtenido por la quema de gas, petróleo, carbón, etc. para calentar el agua).

La investigación de esta problemática ambiental se realiza por el interés de generar conciencia en la población de la Universidad Santo Tomás seccional Tunja, sobre el uso responsable de la energía eléctrica, para evitar una mayor incineración de combustibles fósiles.

\section{MATERIALES Y MÉTODOS}

- Arduino MEGA 2560

- Pantalla Touch TFT-320QVT

- Sensor de corriente SCT 013-100

- Sensor de corriente ACS714LLC-30

- Pantalla LCD de 2x16

- DSPIC4013

En el marco de la ingeniería electrónica, la investigación se realizó a través de documentación teórica que buscó establecer el concepto básicos de huella de carbono y la forma en que esta se encuentra relacionada con el consumo de potencia de cualquier circuito o dispositivo electrónico; Dicha documentación, permitió extraer una ecuación que relaciona la corriente consumida por un dispositivo (cuya alimentación es contante) con la huella de carbono producida por el mismo.

Luego se implementó un circuito para censar la corriente consumida por cualquier dispositivo electrónico conectado a una fuente de alimentación AC. Posteriormente, estos datos fueron llevados a un sistema micro-controlado con el cual no sólo se interpretaron los datos arrojados por el sensor, sino también, se realizó su equivalencia a producción de huella de carbono. La visualización de estos datos se llevó a cabo en una pantalla LCD.
El funcionamiento del dispositivo medidor de huella de carbono, se verificó comparando los datos otorgados por este con los datos generados por la relación existente entre la huella de carbono y la corriente medida por un amperímetro con gran trazabilidad. El sistema sobre el cual se realizaron las mediciones corresponde a una tabla de potencia en donde se han dispuesto 6 cargas, activadas de manera alternante, variando así el consumo de corriente y por ende, la producción de huella de carbono.

\section{RESULTADOS}

Se elaboró un primer prototipo del dispositivo medidor de huella de carbono, compuesto por un sensor ACS714LLC-30 y un sistema micro controlado con el cual se visualiza en una pantalla LCD de 2x16 los niveles de hulla de carbono (en gramos) producidos por cualquier dispositivo o circuito electrónico; Del mismo modo y con la finalidad de otorgar al operario una lectura más intuitiva, se hizo posible que al pulsar un interruptor, no apareciera en la pantalla LCD la producción de $\mathrm{CO}_{2}$ del dispositivo sino, el equivalente de este al movimiento un vehículo por cierto tiempo.

Con el objetivo de mejorar el primer prototipo decidió remplazar la pantalla LCD $2 \times 16$ por una pantalla touch de 3.2" .Esta pantalla ha permitido generar una interfaz constituida por un menú donde se selecciona la unidad en la cual se desea observar la medida realizada, Aún no se visualizan los datos corresponidetes a dicha medida,

\section{CONCLUSIONES}

Es necesario diseñar e implementar una nueva etapa de censado para obtener datos en tiempo real, con mayor resolución y más exactos. Para lo anterior se va a hacer uso del sensor de corriente XiDi Technology modelo SCT-013-000, que tiene mayor sensibilidad y tiene un mayor rango para lectura de corriente.

Crear una apariencia llamativa del dispositivo para el usuario es indispensable si se quiere ejecutar un proyecto de impacto; De esta manera se está trabajando en el diseño e implementación de la etapa de visualización de datos mediante una pantalla táctil.

Debido al sensor y al uso de la pantalla, proponemos usar la interfaz de arduino para acoplar el sensor y la pantalla táctil, dando lugar a la fácil adquisición y transmisión de los datos.

\section{REFERENCIAS}

[1] Z. Wen-ting, T. Kiyotaka, "Carbon footprint calculation for disposal of household solid waste in Suzhou," IEEEX-Plore, China, pp.5. 
[2] Grupo de Generación, "Calculo del factor de emisión de dióxido de carbono del Sistema electric interconectado Colombiano", unidad de planeación minero energética, ministerio de minas y energía, pp.23.

[3]J. Luis, L. José, "Manual del cálculo y reducción de huella de carbono en el sector industrial", OSE, Observatorio de la Sostenibilidad en España, pp.65.
[4]T. Woong, J. Hee, "A study on U-City Footprint Calculation Method to prepare for Carbon Emissio Trading System", IEEEX-Plore, Korea, pp.5. 


\title{
INGENIERÍA DE PROYECTOS Y PROYECTOS DE INVESTIGACIÓN EN ENERGÍA SOSTENIBLE
}

\author{
Enrique Posada Restrepo ${ }^{1,2}$ \\ Steven Ángel Cañas ${ }^{1}$ \\ Gilmar Saenz Tejada ${ }^{1}$ \\ Pablo Hernández Arango ${ }^{1}$ \\ Gabriela Valencia Galeano ${ }^{1}$ \\ Ricardo Posada Pineda ${ }^{1}$ \\ ${ }^{1}$ INDISA S.A \\ ²enrique.posada@indisa.com
}

\begin{abstract}
RESUMEN
Los proyectos de investigación universitaria en Colombia están enfrentando cada vez más temáticas relacionadas con el uso sostenible de la energía y con la producción sostenible de energéticos y productos relacionados. Estos proyectos eventualmente entran a fases de desarrollo donde es importante que sean sometidos y revisados a la luz de disciplinas como la ingeniería conceptual, la ingeniería básica, la ingeniería de detalle, la ingeniería de ejecución y la ingeniería de puesta en marcha; todas estas enmarcadas dentro de la ingeniería de proyectos.. De esta manera, se generan ciclos de retroalimentación favorables que permiten orientar los proyectos de investigación universitaria hacia su materialización, reducir significativamente sus tiempos de maduración y facilitar el trabajo investigativo. Los autores han desarrollado cerca de una decena de proyectos con grupos de investigación universitarios en temas relacionados con la sostenibilidad. A continuación, se presentan e ilustran las metodologías desarrolladas, incluyendo el análisis de costo beneficio, esencial en este tipo de trabajo.
\end{abstract}

Palabras claves: Energía, sostenibilidad, proyectos investigativos, ingeniería de proyectos, universidad, empresa. 


\section{INTRODUCCIÓN}

En los últimos años, se ha desarrollado en Colombia una importante dinámica de trabajo en los grupos universitarios de investigación, enfocada hacia el desarrollo de proyectos de aplicación real de desarrollo sostenible. En diversas ocasiones, los grupos universitarios cuentan con el apoyo de entidades que tienen especial interés en transformar los resultados del trabajo de investigación en actividades que generen ingresos y prosperidad y que resuelvan retos y necesidades comunitarias.

El concepto de desarrollo sostenible se ha convertido en asunto fundamental en la elaboración de proyectos desde la Conferencia de las Naciones Unidas sobre el Medio Ambiente y el Desarrollo (Río de Janeiro, 1992), conocida también como Cumbre para la Tierra. En ella, se convino que la protección del medio ambiente y el desarrollo económico y social son esenciales para lograr el ideal del desarrollo sostenible, con el cual se quiere cubrir las necesidades de las actuales generaciones sin poner en riesgo la capacidad de las próximas generaciones para satisfacer a su vez sus propias necesidades. La denominada Agenda 21, aprobada por la cumbre, señala 27 principios como guía hacia el logro de este ideal. Los grupos universitarios de investigación de Colombia, conformados por jóvenes estudiantes de de posgrado, bajo la dirección de profesores investigadores, se ajustan al principio 21 que convoca a movilizar la creatividad, los ideales y los valores de los jóvenes; al principio 9, que propone aumentar el saber científico y el intercambio de conocimientos científicos y tecnológicos; y al principio 6 , que señala la importancia de dar especial prioridad a la situación y las necesidades especiales de los países en desarrollo, como el nuestro.

Por otra parte, este trabajo universitario debe ajustarse a lineamientos de tipo económico. El principio 12 señala la importancia de promover que el sistema económico internacional sea favorable y abierto, lo cual indica que un proyecto exitoso deba ajustarse en términos de competitividad y atractivo económico en el contexto internacional; mientras que el principio 3 señala la importancia de equilibrar las necesidades del desarrollo (relacionadas con asuntos económicos) y las implicaciones ambientales de las generaciones presentes y futuras.

En consecuencia, se genera una tensión potencial en el trabajo de los grupos universitarios enfocados a este tipo de proyectos. Por una parte, hay que enfrentarse a las complejidades del trabajo científico y de investigación para desarrollar conocimiento novedoso, que rompa esquemas y que genere avances académicos y oportunidades tecnológicas. Al mismo tiempo, hay que afrontar los desafíos propios de aplicar estos descubrimientos y avances en el sistema económico y productivo actual con ayuda de entidades interesadas en el desarrollo sostenible

Un caso claro de participación en la gestión del desa- rrollo sostenible es el expuesto en Colombia desde el sector minero energético, en el cual se ha venido dando una parametrización a nivel de legislación de forma creciente, lo que ha ido contribuyendo con el mejoramiento de indicadores a nivel del uso de energía de forma sostenible y que se espera permita a futuro contar con políticas energéticas claras para el desarrollo del ecosistema minero energético.

Desde el Ministerio de Minas y Energía, bajo la resolución 90325 del 25 de marzo de 2014, se ha considerado tener en cuenta a Colombia como un país con una excepcional riqueza natural, característica que le permite participar con mayor propiedad en el desarrollo de los diferentes sectores económicos y en este caso, del desarrollo del sector minero energético, donde es prioridad el adelantar acciones encaminadas al desarrollo sostenible y a lograr el equilibrio entre el desarrollo de dicho sector y la protección del ambiente. Para ello, se han venido establecido diversas herramientas de gestión que darán lugar a proyectos e iniciativas de investigación y desarrollo para crear realidades ejecutables, factibles y atractivas.

Estas aplicaciones prácticas van a ser llevadas en su mayor parte a los sectores productivos y han de ser objeto de diseños, fabricaciones, montajes, manufactura y comercialización de bienes y servicios para generar una oferta tecnológica rentable y próspera para la sociedad. Se advierte entonces la conveniencia de contar con metodologías de desarrollo de proyectos a través de la ingeniería desde los niveles conceptuales hasta los niveles prácticos.

Los autores de este trabajo hacen parte de la empresa de ingeniería de proyectos INDISA S.A, que cuenta con un grupo de trabajo especializado en procesos, energía y medio ambiente, a través del cual se han realizado trabajos y suscrito convenios con diversas universidades, organismos gubernamentales y empresas del sector privado para ejecutar y desarrollar aplicaciones competitivas, rentables y reales.

En el siguiente documento, se describen detalladamente las etapas que han de ser ejecutadas y para la obtención de proyectos a nivel de gestión energética sostenible y se exponen formas prácticas para estimular y perfeccionar esta importante asociación entre el sector investigativo, las empresas de ingeniería y el sector productivo y empresarial. Se describirán en el desarrollo del artículo algunos de los proyectos desarrollados con universidades que han logrado pasar por las diferentes etapas de ingeniería que se trabajan en INDISA S.A.

\section{METODOLOGÍA}

\section{Aspectos especiales de la ingeniería aplica- da a proyectos de investigación universita- ria de naturaleza sostenible}


Las posibilidades de que una empresa de ingeniería de proyectos entre a ser parte del desarrollo de proyectos de investigación universitaria, que requieren de soporte de ingeniería, dependen de la aplicación de los siguientes principios:

- Establecimiento de relaciones entre la empresa de ingeniería y los grupos de investigación. Es importante que haya una relación establecida que se base en el respeto y en el aprecio mutuo, en la participación de la empresa de ingeniería en congresos, foros y actividades académicas y en el desarrollo de pasantías y visitas. Un programa de prácticas académicas de estudiantes universitarios destacados en la empresa de ingeniería y de formación avanzada de los ingenieros de la empresa en las universidades contribuyen significativamente. Además, conviene establecer relaciones entre los grupos, el estado y las empresas de ingeniería, para generar convenios y retro-alimentar las necesidades y avances del sector investigativo a nivel global.

- Establecimiento en las empresas de ingeniería de grupos de trabajo especializados y capaces de recibir e interpretar la información científica generada en las investigaciones, donde se interactúa adecuadamente con los grupos de investigación, aportando valor agregado en los aspectos conceptuales. Desde la etapa de desarrollo del concepto, las empresas de ingeniería pueden participar en estos proyectos.

- Capacidad para participar en la elaboración de cotizaciones, gestión de contratación, elaboración de acuerdos de confidencialidad y demás asuntos que puedan tener cierto nivel de laboriosidad mayor que el que existe en las relaciones con otros sectores.

Flexibilidad al momento de elaborar las premisas de diseño para definir y convertir datos de laboratorio e informes de investigación en conjuntos de datos aplicables al diseño y escalado de equipos y de procesos.

En este tipo de proyectos, la empresa de ingeniería de proyectos debe acercarse al proceso investigativo, donde existen una serie de variables que se deben conectar con el desarrollo de la ingeniería y que presentan algún grado de complejidad a nivel de sostenibilidad y por ello, se hace preciso entenderlas en su dominio para vincularlas al sistema de manera coherente y precisa.

En INDISA, se entiende a la investigación como la "realización de actividades intelectuales y experimentales de modo sistemático con el propósito de aumentar los conocimientos sobre el tema de estudio" (Valencia, 2013). Se debe entender entonces, que el objetivo principal de la investigación para INDISA es trabajar en el desarrollo de ideas hasta convertirlas en conceptos claros, demostrables y prometedores. Es entonces, desafío de la empresa de ingeniería, transformar estos desarrollos en lo que se denomina "concepto", como base de la ingeniería conceptual, siendo la primera etapa de la ingeniería de proyectos.

Respecto a la complejidad que presentan algunas variables a nivel de sostenibilidad, se puede decir que está, radica en las acciones que se deben establecer dentro de los diseños de ingeniería, para contribuir a convertir datos obtenidos bajo condiciones ideales de laboratorio, a su interpretación y aplicación en proyectos de ingeniería en los cuales habrá que tener en cuenta aspectos como los siguientes, entre otros:

- Presencia de residuos

- Presencia de pérdidas de calor y energía

- Posibilidades de reciclajes y de aprovechamientos

- Manejo de materiales de calidad inferior

- Emisión de contaminaciones, olores y descargas nocivas

- Formas optimizadas de uso de la energía

- Dificultades de manejo asociados con los materiales y sus propiedades

- Asuntos relacionados con la corrosión, el mantenimiento, el desgaste y las limpiezas

- Todo lo relacionado con aspectos de costo beneficio y factibilidad del proyecto

- Aspectos de carácter normativo y administrativo que no suelen considerarse en etapas investigativas de los nuevos desarrollos.

Es así como, la empresa de ingeniería, con base en su experiencia y sus métodos de trabajo deberá velar por que se genere información relacionada con este tipo de asuntos para tenerlos en cuenta en el diseño. En muchas ocasiones será necesario realizar ensayos adicionales por parte de los investigadores para completar la definición de los conceptos.

En términos generales, los desafíos de la sostenibilidad tienen que ver con:

- La tendencia a realizar procesos de manera acelerada, como parte de una competencia tecnológica que asegure primacía y novedad.

- La exigencia de lograr la producción con un valor agregado ecológico.

- El conocimiento de los costos reales de los recursos naturales y su conservación.

- La garantía de que el proyecto ejerce prácticas ambientales, energéticas y de responsabilidad social empresarial. 
- La innovación y responsabilidad del proyecto con los intereses de las poblaciones y los grupos de interés social, en aras de la construcción de una sociedad menos consumista

En INDISA S.A, se trabaja una metodología donde los proyectos atraviesan una serie de etapas para entregar un trabajo de calidad. El propósito es avanzar de la idea y del concepto hacia el proyecto ejecutado y exitoso (Posada, 2012). Apoyada en la ingeniería de proyectos, la tecnología ha permitido un crecimiento exponencial de las aplicaciones y los procesos. Este hecho debe ser complementado con nuevas visiones que consideren los vacíos tecnológicos y conceptuales para así, lograr que estos crecimientos sean sostenibles y respetuosos con el ambiente y los recursos.

\section{Etapas de la ingeniería para el desarrollo de proyectos}

Mediante el trabajo por proyectos, la ingeniería convierte el concepto prometedor en realidad. Esta metodología implica:

- Planeación basada en el establecimiento de objetivos claros del proyecto y de cada una de las tareas.

- Ejecución de las actividades del proyecto para alcanzar el objetivo.

- Control y vigilancia de los costos presupuestados y la calidad requerida del proyecto, conforme avanza. (INDISA SA, 2009).

INDISA S.A. propone en su metodología seis etapas básicas para la ejecución de un proyecto de ingeniería.

La primera etapa es aquella referente a la ingeniería conceptual, utilizada por los grupos de investigación. En ella se aclara el objetivo del proyecto mediante el planteamiento de alternativas de solución para cada uno de los aspectos involucrados. Se inicia con la comprensión de la idea y el estudio de los reportes de investigación. Comprende una etapa de contacto entre la empresa de ingeniería y el grupo de investigación, que incluye presencia en los laboratorios, entrenamiento y acercamiento a los ensayos que se realizan y elaboración de ensayos complementarios para recoger información y confirmar ciertos parámetros. La primera parte de la ingeniería conceptual es la definición del concepto. La segunda parte es el análisis de alternativas. La tercera parte es la selección de las alternativas que conforman el proyecto. Luego, se desarrolla el diseño conceptual, utilizando diagramas de flujo, balances de masa y energía, determinación esencial de tamaños y dimensiones y elaboración de una disposición de planta para el tamaño productivo deseado. Se elaboran cálculos y estimados de los consumos de energía, de las necesidades de materiales, de los requisitos de personal y de otros costos de producción. Se estiman las emisiones contaminantes y se establecen formas de control y mitigación para las mismas. Finalmente se realizan es- timados presupuestales de las inversiones necesarias (con aproximaciones que se estiman en un $30 \%$ ) y se presenta un análisis de costo beneficio y de factibilidad económica.

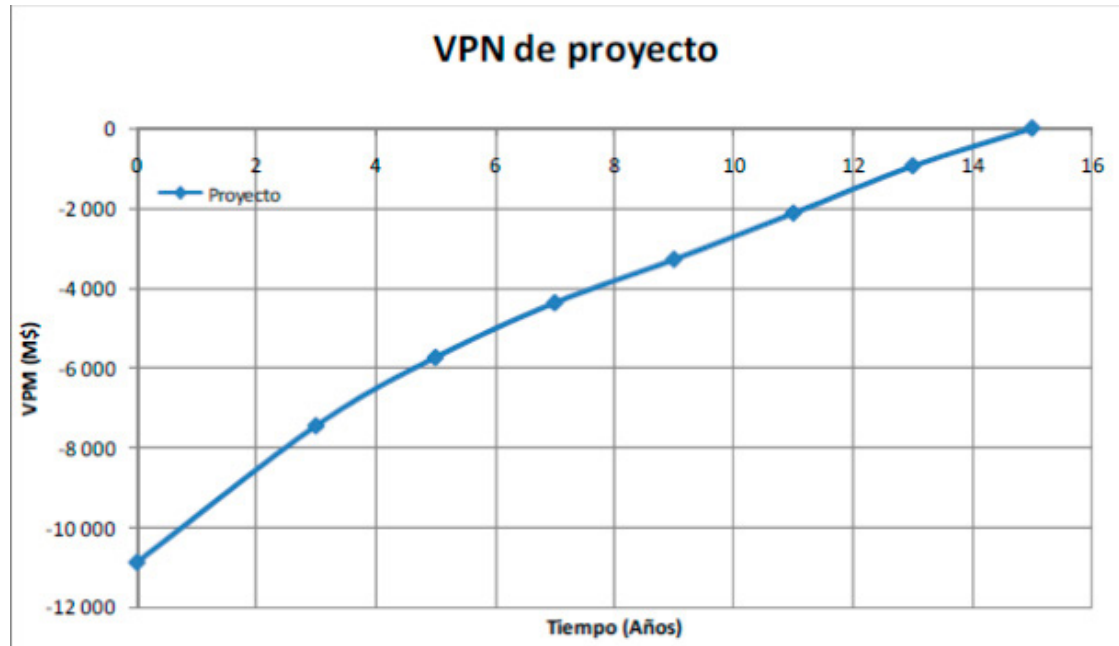

Figura 1 Ejemplo de análisis de factibilidad obtenido en una ingeniería conceptual (fuente elaboración propia)

Como resultado de la ingeniería conceptual y gracias al análisis de costo/beneficio, se logra tener una buena idea de las posibilidades futuras del proyecto y del estado de avance investigativo que tiene. Si se advierte una situación de rentabilidad nula o pobre, no se debe proceder con las siguientes etapas de la ingeniería de proyectos. Más bien, será necesario replantear el trabajo de investigación, teniendo en cuenta los aspectos críticos detectados en la ingeniería conceptual. Si esto sucede, la empresa de ingeniería debe apoyar al grupo de investigación para continuar en marcha la investigación y brindar renovado apoyo de los patrocinadores del proceso, ya que con nuevos ensayos y exploraciones habrá formas novedosas para romper las limitaciones existentes y encontrar alternativas. La culminación del trabajo de ingeniería conceptual permite estudiar con mayor facilidad las nuevas alternativas además de ofrecer el fortalecimiento de las relaciones establecidas entre los actores del proceso.

Cuando la naturaleza del proyecto lo amerite, especialmente si se advierte que hay posibilidades de desarrollo rentable y factible, conviene incluir en la ingeniería conceptual un diseño de concepto de planta piloto para fundamentar el trabajo desarrollado y demostrar diversos asuntos que se asocian al proyecto. Uno muy importante es contar con producciones en cantidades suficientes para realizar ensayos de aplicación y análisis de estabilidad y confiabilidad de los procesos desarrollados. Otro es el poder demostrar la tecnología a terceros y facilitar el proceso de conseguir financiación para las etapas futuras.

Una vez, el proyecto resulte factible, se podrá someter a las siguientes etapas de la ingeniería que deberán aplicarse igualmente a cualquier posible planta piloto que sea aprobada para ejecución.

El segundo estadio en la ingeniería de proyectos es la ingeniería básica que busca forjar una idea clara de la apariencia del proyecto a partir de la mejor alternativa seleccionada 
en la ingeniería conceptual. Para ello se utilizan descripciones, planos, esquemas, maquetas y bocetos. Se elaboran listados de equipos, rutas de redes y suministros y se ajusta la factibilidad técnica y económica a través de una mayor definición de los componentes del proyecto y una relación más estrecha con los proveedores de equipos, permitiendo aproximarse a las inversiones y a los costos de operación con mayor certeza (en esta etapa las aproximaciones a inversiones y costos se pueden estimar en el $15 \%$ ).

La consecuencia más importante de desarrollar esta etapa es la determinación de la factibilidad técnica y económica. La idea es evitar que se ejecute la siguiente etapa (ingeniería de detalle) a proyectos inviables. La ingeniería conceptual muestra la probabilidad de realización pero, es la ingeniería básica la que define realmente el proyecto.

En la tercera etapa, encontramos la ingeniería de detalle, en donde se elaboran los documentos que materializan el proyecto, asegurando el éxito operativo y previendo eventuales contratiempos. Se incluyen aspectos de seguridad industrial, la preservación del medio ambiente y el confort laboral. Se perfecciona el presupuesto y el plan de ejecución y se ajustan los parámetros financieros y temporales a altos niveles de precisión (dentro de un $5 \%$ ) que faciliten la asignación de recursos de operación y de control.

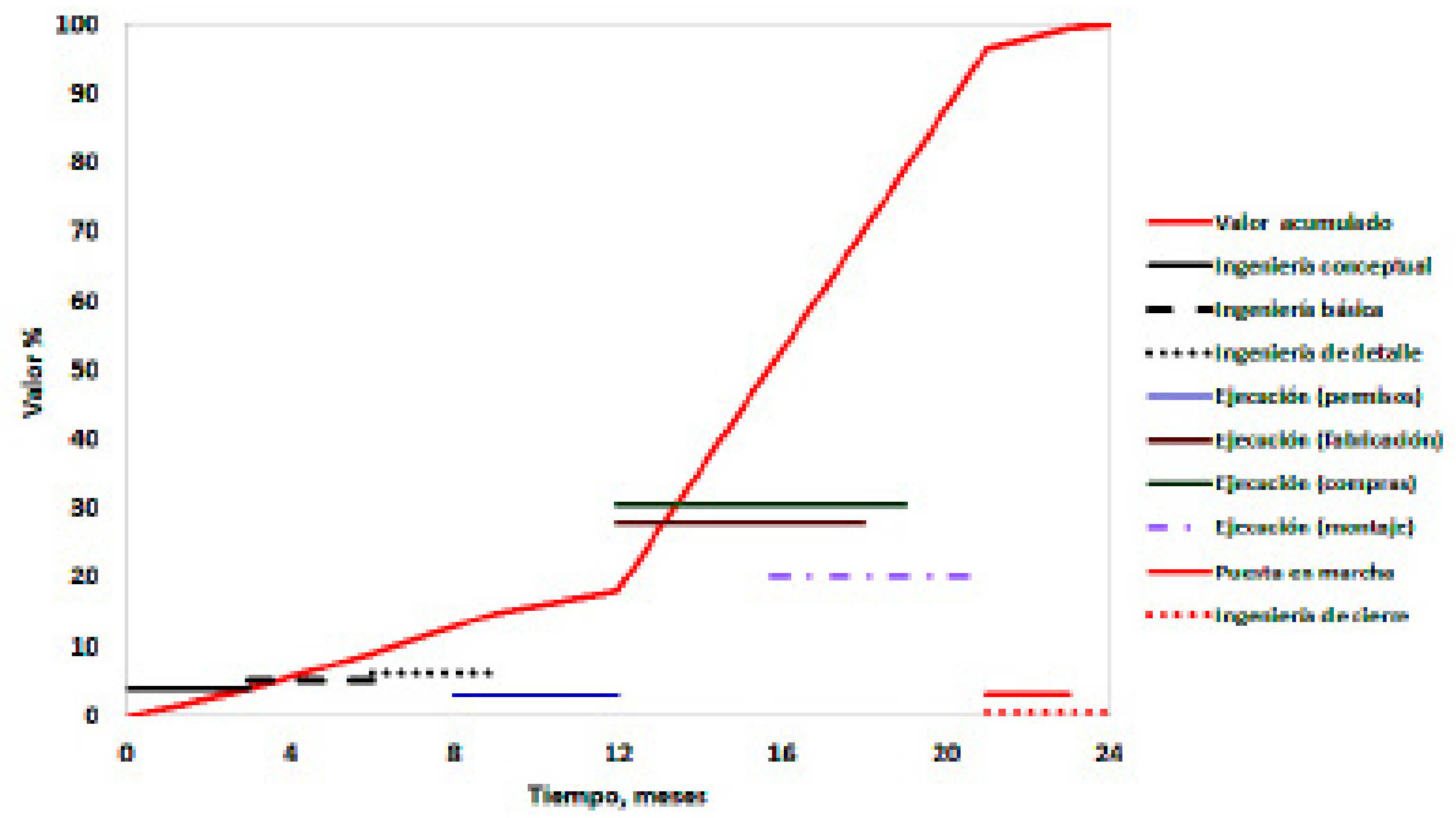

Figura 2. Cómo se comportan los costos potenciales en las distintas etapas de la ingeniería de proyectos (fuente elaboración propia)

La cuarta etapa, la ingeniería de ejecución, tiene un carácter diferente al de sus etapas antecesoras. En la ingeniería conceptual, básica y de detalle, todo lo realizado es de carácter virtual en planos, bocetos, descripciones, libros y documentos, por ello los errores y modificaciones representan un costo bajo comparado con el costo real en esta nueva etapa. En la ejecución, la corrección de un error representa sobrecostos generalmente muy altos (Figura 3), haciendo que la dirección, la administración y el control asuman un rol de vital importancia.

La ingeniería de puesta en marcha, tiene como objetivo definir las actividades complementarias de ingeniería que son fundamentales para que el proyecto salga bien, adicionalmente, se verifica la concordancia entre lo presupuestado para la correcta operación del proyecto. La ingeniería de interventoría, se presenta como un elemento transversal que tiene que ver con las diversas etapas, especialmente a partir de la ingeniería de detalle, donde se contemplan las diferentes implementaciones de control de calidad, de presupuesto, de logística, entre otras dentro del proyecto. La ingeniería de cierre del proyecto, tiene como finalidad reunir todos los documentos y evidencias que sean necesarios para la entrega del proyecto. 


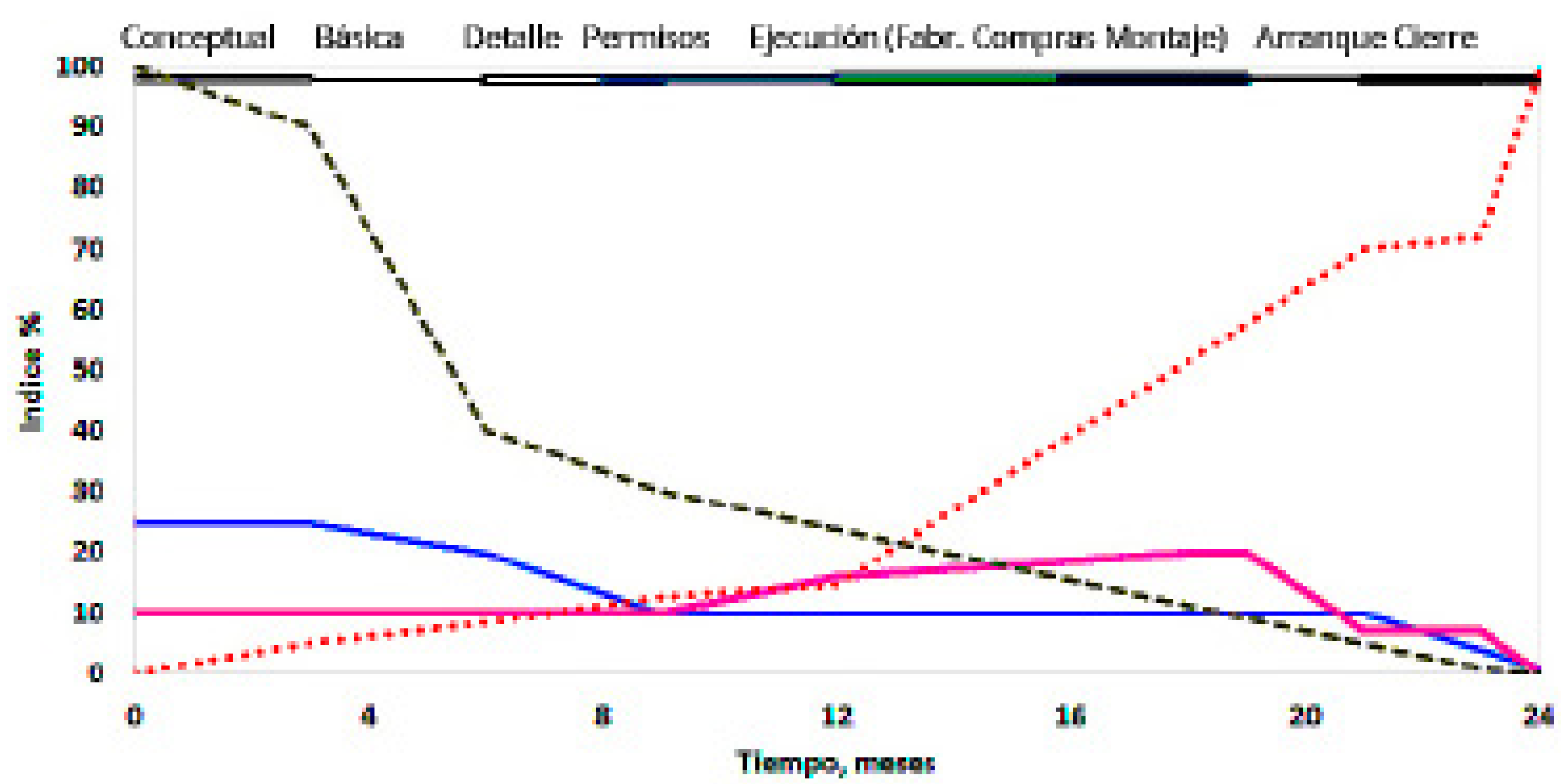

CIfumo doplomadis

w w - Ente do ameres y varialones
- Ifuers ds ositred

=-- Akundende do orrors, altorntums y varholones

Figura 3. Esfuerzos de planeación y de control e impacto de variaciones en las distintas etapas de la ingeniería de proyectos (fuente elaboración propia)

\section{RESULTADOS Y EXPERIENCIAS}

Siguiendo la metodología anteriormente mencionada, en INDISA S.A se han llevado a cabo una serie de proyectos de ingeniería originados en grupos de investigación universitaria, asociados con la sostenibilidad, y en algunos casos, se ha avanzado hasta la etapa de ejecución. Entre ellos se pueden mencionar los siguientes:

El estudio de concepto y la ingeniería conceptual para una planta de producción de aceite a partir del cultivo in-vitro de células vegetales. Allí, se seleccionaron varias posibilidades de producción de aceite, se realizaron balances de masa y energía para identificar los requerimientos de materias y energía, se estimaron las eficiencias y costos de operación de la planta y se calculó el presupuesto requerido para la planta de producción industrial con una capacidad de 55 ton/mes de aceite. Además, se propusieron procesos y productos que se podrían generar y que podrían ampliar el espectro y el alcance de la investigación. Se incluyó el diseño de una planta piloto para dar mayor avance a los desarrollos de este proyecto.

Otro caso desarrollado fue el estudio de concepto y la ingeniería conceptual para una planta de producción de alco- hol carburante a partir de material lignocelulósico. En este proceso, se analizaron diferentes alternativas de producción y alternativas de fermentación, se identificaron los requerimientos de materias primas y energía y se estimaron las eficiencias y costos de operación de la planta. Se desarrolló a nivel conceptual, un cálculo del presupuesto requerido para la implementación de la planta de producción industrial, determinando la viabilidad económica del proyecto. En la actualidad, este proyecto está enfocándose hacia el diseño y la puesta en marcha de una planta piloto.

Otro proyecto de interés fue el de la ingeniería conceptual para determinar la factibilidad económica de una planta para la producción de gas de síntesis a partir de residuos sólidos (biosólidos) generados en el tratamiento de aguas residuales. El proyecto contempló un proceso de gasificación de una mezcla carbón/biosólidos con una capacidad de 100 ton/día, con la intención de emplear el gas obtenido como combustible en la generación de energía eléctrica. En este proyecto se destacaron los resultados de la revisión y análisis de los balances de masa y energía, recomendaciones y reformas sobre el proceso mismo, la presentación de diagramas de flujo, instrumentación y control conceptuales y finalmente, la evaluación económica del proyecto. 
Proyectos que han incluido todas las etapas de la ingeniería, incluyendo la ejecución final, fueron el del diseño de un equipo para controlar emisiones de NOx en un horno industrial y el de un horno regenerativo para fundiciones no ferrosas.

\section{CONCLUSIONES}

El desarrollo de proyectos originados en grupos universitarios de investigación de la mano con empresas de ingeniería de proyectos, permite una visión amplia, realista y rápida. Una gran ventaja es el desarrollo de elementos suficientes para llegar razonablemente al análisis de factibilidad y de costo beneficio, con base en el desarrollo de ingenierías conceptuales de bajo costo y ejecución rápida. De esta forma, las entidades que patrocinan y apoyan los proyectos, pueden contar con bases para continuar el proceso hacia la aplicación mientras que, los grupos de investigación pueden contar con una retroalimentación de alta calidad para enfocar sus objetivos y sus investigaciones hacia la aplicabilidad de sus esfuerzos investigativos.

El mejoramiento continuo y creativo de las estrategias para el desarrollo de proyectos es fundamental para la resolución efectiva de los problemas y desafíos, dentro de parámetros de costo beneficio, tecnología, sostenibilidad y recursos disponibles. Plantear esquemas novedosos de trabajo en equipo, de comunicación y retroalimentación, permite visiones estratégicas convenientes para el país. Así, se generan desafíos, compromisos, acciones, sentimientos unitarios y transferencias de conocimiento, que permiten establecer un trabajo integrado, en el cual cada proyecto es dimensionado para entender sus desafíos y su realismo. A medida que se realizan proyectos en conjunto, la interacción se vuelve más efectiva, los investigadores formulan y realizan proyectos con base en aspectos de ingeniería y las empresas de ingeniería comprenden mejor las necesidades de la investigación, los métodos, el escalado y los aspectos comunes entre proyectos.

\section{AGRADECIMIENTOS}

INDISA hace un reconocimiento a diversos grupos de investigación de las universidades de la ciudad de Medellín, especialmente de la Universidad de Antioquia, y a las entidades que patrocinan los proyectos, en especial a Empresas Públicas de Medellín por facilitar que la empresa haga parte de importantes desarrollos, con sus servicios de diseño y fabricación y montajes.

\section{REFERENCIAS}

Resolución Ministerio de Minas y Energía de Colombia, 90325 (25 de Marzo de 2014).

INDISA SA. (2009). Generalidades sobre el manejo de proyectos de ingeniería. Medellín.

Posada, E. (2012). Reflexiones sobre el presente y futuro de la ingeniería de proyectos. DYNA, 1-6.

Valencia, G. (2013). PROPUESTA DE LOS LINEAMIENTOS TEÓRICO-CONCEPTUALES PARA EL DISEÑO DE UN MODELO DE GESTIÓN DE I+D+i EN LA INDUSTRIA DE BIOINSUMOS. Medellín, Colombia.

Yunna, W., \& Ruhang, X. (2013). Current status,future potentials and challenges of renewable energy. Renewable and Sustainable Energy Reviews, 73-86.

Zhana, L., Jua, M., \& Liua, J. (2011). Improvement of China Energy Label System to Promote Sustainable Energy Consumption. ENERGY PROCEDIA, 2308-2315. 


\title{
PANORAMA DE LA EFICIENCIA ENERGÉTICA EN LA INDUSTRIA ALIMENTARIA DEL VALLE DEL CAUCA
}

\author{
Judith Rodriguez Salcedo ${ }^{1,2}$ \\ Jenny Lorena Ibarguen Valverde ${ }^{1,3}$ \\ Jorge Eduardo Angulo López ${ }^{1,4}$ \\ ${ }^{1}$ Universidad Nacional de Colombia sede Palmira, Colombia \\ 2jrodriguezs@unal.edu.co \\ 3 ylibarguenv@unal.edu.co \\ ‘jeangulol@unal.edu.co
}

\begin{abstract}
RESUMEN
La Eficiencia Energética en el escenario del Valle del Cauca ha tomado importancia a causa del impacto de la demanda de energía como resultado del crecimiento económico regional. En el año 2003 se crea la Red Colombiana de Investigación en Eficiencia EnergéticaRECIEE, apoyada por Colciencias e integrada por 12 grupos de investigación, con el propósito de intercambiar experiencias y presentar avances en el uso racional y eficiente de energías renovables y no renovables. Entre los años 2010 y 2013, se establece un Modelo de Gestión para el fortalecimiento de la Competitividad de la Industria Colombiana y se origina el "Programa Estratégico para la Innovación en la gestión empresarial-PEN-SGIE". En el Valle del Cauca, se registran 628 empresas dedicadas a la elaboración de productos alimenticios y de bebidas; y menos del 1\% tienen establecido un sistema de gestión integral de la Energía. Estudios realizados en el marco del programa PEN-SGIE de pre-caracterización energética permitieron identificar potenciales de ahorro por gestión en: i) 3 empresas de alimentos de 6-16\% de Energía Eléctrica; y ii) 7 ingenios azucareros de 6-10\% de Energía Térmica y 6-9\% de Energía Eléctrica. Los potenciales de ahorro en el ámbito de la gestión están enfocados a la disminución de tiempos improductivos en equipos, cambios en los planes de mantenimiento y los esquemas de producción que impactan negativamente en el consumo. Este estudio tiene como objetivo presentar los avances en el ámbito de la eficiencia energética en la industria del valle del Cauca.
\end{abstract}

Palabras claves: Agroindustria, SGIE, Valle del Cauca, eficiencia energética, potenciales de ahorro. 


\section{INTRODUCCIÓN}

La Eficiencia Energética tiene su origen con la crisis petrolera; cuando los países importadores de petróleo y sus derivados se vieron en la necesidad de disminuir el consumo de los combustibles (Vásquez, C. et al. 2009). Esta ha venido cobrando gran importancia a nivel mundial, debido principalmente a: los objetivos del Protocolo de Kyoto para los países miembros de la Organización para la Cooperación y el Desarrollo Económico-OCDE; y a las barreras que presentan los países importadores en materia de seguridad energética. (World Energy Council, 2010).

En Colombia, el tema de eficiencia energética está enmarcado en la ley 697 de 2001. En esta ley se promueve el uso racional y eficiente de la energía, la utilización de energías alternativas, y además estable, en el artículo $\mathrm{N}^{\circ} 4$, al Ministerio de Minas y Energía como la entidad responsable de impulsar, emprender, organizar e inspeccionar programas de uso eficiente y racional de la energía.

En el año 2003 se crea: i) la comisión intersectorial para el Uso Racional y Eficiente de la Energía y Fuentes No convencionales de Energía-CIURE mediante el decreto 3683, modificado por el decreto 139 en el 2005; y ii) la Red Colombiana de Investigación en Eficiencia EnergéticaRECIEE, apoyada por Colciencias e integrada por doce grupos de investigación. Tres de estos grupos, pertenecientes a la región del Valle del Cauca: a) Grupo de Investigación en Energía-GIEN de la Universidad Autónoma de Occidente, 2) Grupo de Investigación en Conversión de Energía-CONVERGÍA de la Universidad del Valle, y 3) Grupo de Eficiencia Energética y Energías Alternativas-G.E.A.L de la Universidad Nacional de Colombia-Sede Palmira.

En el año 2004 y 2006, con el propósito de intercambiar experiencias y presentar avances en el uso racional y eficiente de energías renovables y no renovables, fue llevado a cabo en la ciudad de Cali el I y II Congreso Internacional sobre el Uso Racional y Eficiente de la Energía-CIUREE, liderado por los 3 grupos de investigación anteriormente mencionados. Este encuentro es resultado de la experiencia de la red, de órganos productivos y estatales como Colciencias y la UPME. Allí, se genera un Modelo de Gestión para el fortalecimiento de la Competitividad de la Industria Colombiana y se origina el "Programa Estratégico para la Innovación en la gestión empresarial, mediante la asimilación, difusión y generación de nuevos conocimientos en gestión energética y nuevas tecnologías e implementación del Sistema de Gestión Integral de la Energía en empresas de cinco regiones PEN-SGIE", el cual tuvo una duración de 3 años contados a partir del 2010.

Mediante Resolución 180919 del 01 de junio de 2010, se adopta el Plan de Acción Indicativo 2010-2015 con visión al 2020 para desarrollar el Programa de Uso Racional y Eficiente de la Energía y demás Formas de Energía no Convencionales-PROURE, se definen sus objetivos y subprogramas y se adoptan otras disposiciones. Este programa está contemplado en el artículo $N^{\circ} 5$ de la ley 697 de 2001

Simultáneamente, desde el año 2008, el Comité Técnico de Normalización 228 de ICONTEC en Sistemas de Gestión Energética venía trabajando en la elaboración de la Norma Técnica Colombiana ISO 50001: Eficiencia Energética. Esta norma fue lanzada a finales del 2011. A nivel mundial, 6912 empresas han sido certificadas (datos hasta marzo de 2014), Alemania es el país que cuenta con el $46,9 \%$ de las certificaciones. En América Latina, los países con más certificaciones en ISO 50001 son Chile y Brasil los cuales representan el $62.7 \%$ del total. Colombia cuenta actualmente con cuatro certificaciones en ISO 50001; la primera certificación que fue otorgada en el año 2012 corresponde a la filial alemana HENKEL; el siguiente año logró certificarse también como filial Schneider Colombia; la tercera y cuarta certificación la alcanzaron las empresas colombianas: Energía de Bogotá y la industria antioqueña Tronex respectivamente (Boletín $\mathrm{N}^{\circ} 7$ Avances Certificaciones ISO 50001 en Colombia y el Mundo del PEN-SGIE).

En el 2012 se establecen incentivos tributarios en Eficiencia Energética mediante resolución 563 de la UPME. Según datos de la Unidad de Planeación Minero Energética-UPME, hasta el momento, en la regional del Valle del Cauca en el sector de alimentos, se han aprobado dos de trece solicitudes recibidas. Estas se encuentran enmarcada en los subprogramas de optimización de uso de la energía eléctrica para fuerza motriz, y optimización de procesos de combustión, cuyas líneas de acción están adscritas respectivamente a: promover la sustitución de los motores actuales por motores de alta eficiencia, y promover el aprovechamiento del calor residual generado en procesos de combustión. En cuanto a las fallas más comunes que presentan las industrias que no son beneficiadas, cabe mencionar que muchos de los proyectos por los cuales se lleva a cabo las solicitudes no se enmarcan en las líneas de acción de la resolución 186 de 2012, y adicionalmente, la información requerida como memorias de cálculo es insuficiente o no es presentada (Incentivos Tributarios-EEFNCE).

El Valle del Cauca está catalogado como uno de los departamentos más ricos de Colombia, no sólo porque está dotado de recursos naturales renovables y por su tejido empresarial, sino por su capacidad productiva en casi todas las ramas de la actividad económica, especialmente en los sectores industrial, agroindustrial y de servicios (Agencia de Promoción de Inversión en el pacifico colombiano-investpacific, 2012). Se registran 628 empresas dedicadas a la elaboración de productos alimenticios y de bebidas (Directorio de Empresas. Informe de todas las empresas de Colombia, 2014) en donde menos del 1\% han establecido un sistema de gestión energética.

Este estudio permitirá conocer los adelantos en materia de eficiencia energética y los resultados del proyecto PENSGIE regional del Valle del Cauca, en el que bajo el modelo 
del Sistema de Gestión Integral de la Energía, se caracterizaron energéticamente dos empresas lácteas, siete ingenios azucareros y una empresa de comestibles, lográndose estimar los potenciales de ahorro energético por cambio tecnológico y gestión.

\section{MATERIALES Y MÉTODOS}

En este estudio de carácter exploratorio-descriptivo e investigativo, se hizo una revisión bibliográfica de la situación y las perspectivas de la eficiencia energética en el ámbito mundial, nacional y regional del Valle del Cauca. Para ello, se examinó el marco normativo, las políticas de uso racional y eficiente de energía, los actores claves y su rol y los incentivos tributarios. Además, se analizaron los resultados del programa PEN-SGIE que fue desarrollado en 3 etapas:

- Etapa 1: creación y consolidación de capacidades académicas en gestión energética.

- Etapa 2: implementación del SGIE mediante transferencia de nuevos conocimientos en empresas.

- Etapa 3: caracterización energética en industrias y desarrollo de estrategias para la sostenibilidad del SGIE.

Para la presente investigación, las fuentes consultadas fueron:

- Revista Colombia Energía

- Comisión Económica para América Latina y el Caribe - CEPAL.

- Unidad De Planeación Minero-Energética - UPME

- Universidad Nacional de Colombia, Universidad del Atlántico, Universidad Autónoma de Occidente, Universidad Pontificia Bolivariana y Universidad Industrial de Santander.

- Informe Proyecto PEN-SGIE entregado a Colciencias. Programa Estratégico para la Innovación en la gestión empresarial, mediante la asimilación, difusión y generación de nuevos conocimientos en gestión energética y nuevas tecnologías e implementación del Sistema de Gestión Integral de la Energía en empresas de cinco regiones del País. Código 1101-454-22024-CONTRATO RC No. 700-2008.

- World Energy Council.

El estado de la eficiencia energética en la industria alimentaria del Valle del Cauca fue evaluado a través de la pre-caracterización de siete ingenios azucareros y tres empresas de alimentos, y fue ejecutado dentro del marco del proyecto PEN-SGIE. La metodología aplicada comprendió las dos etapas basadas en el modelo de Gestión Integral de la Energía (Campos, Figueroa, Meriño \& Tovar, 2008):

- Etapa 1: caracterización y diagnóstico de energía eléctrica y térmica en las industrias.

- Etapa 2: plan de uso y consumo eficiente de la energía eléctrica.

En la caracterización o diagnóstico energético se llevó a cabo una revisión técnica en todas las industrias. Para la obtención de potenciales de ahorro, se utilizaron datos de consumo de energía y producción de un año, y se aplicó el modelo matemático de correlación, mediante el método de mínimos cuadrados. En el plan de uso eficiente de la energía, se desarrolló el listado de oportunidades de mejora del consumo energético.

\section{RESULTADOS}

En el marco del PEN-SGIE para la región del Valle del Cauca, se formaron 31 gestores energéticos avanzados, 43 gestores energéticos básicos y 36 auditores internos en la Norma ISO 50001 entre docentes, profesionales y estudiantes. A la fecha, se estima que se ha duplicado la cifra de personas capacitadas en gestión energética, y que cerca del 90\% han sido formadas en algunas de las instituciones acreditadas a nivel nacional.

En la tabla 1 se muestran los resultados obtenidos en las caracterizaciones realizadas a las empresas de alimentos en el Valle del Cauca. En la tabla 2 se presenta el diagnóstico y las oportunidades de mejora en las empresas pre caracterizadas energéticamente.

Tabla 1. Resultados de Potenciales de Ahorro energético en Empresas Pre-caracterizadas Energéticamente

\begin{tabular}{|c|c|}
\hline SECTOR & $\begin{array}{c}\text { \% POTENCIALES DE AHORRO } \\
\text { POR GESTIÓN ENERGETICA }\end{array}$ \\
\hline $\begin{array}{c}\text { Azucarero } \\
\text { (7 Ingenio) }\end{array}$ & $69 \%$ Energía Eléctrica \\
\hline $\begin{array}{c}\text { Alimentos } \\
(3 \text { Empresas })\end{array}$ & $610 \%$ Energía Térmica \\
\hline
\end{tabular}

Fuente: Quispe E.C. 2012. Región Valle: Resultados y Avances Oportunidades para la Industria.

Los potenciales de ahorro por gestión están enfocados a la disminución de tiempos improductivos en equipos, cambios en los planes de mantenimiento y los esquemas de producción que impactan negativamente en el consumo. 
Tabla 2. Resultados del Diagnóstico de Recorrido en las empresas del sector de alimentos del valle del cauca.

\begin{tabular}{|c|c|c|}
\hline SEC & STICO DE RECORRIDO & OPOR \\
\hline $\begin{array}{l}\text { Azucarero } \\
\text { (7 ingenios) }\end{array}$ & 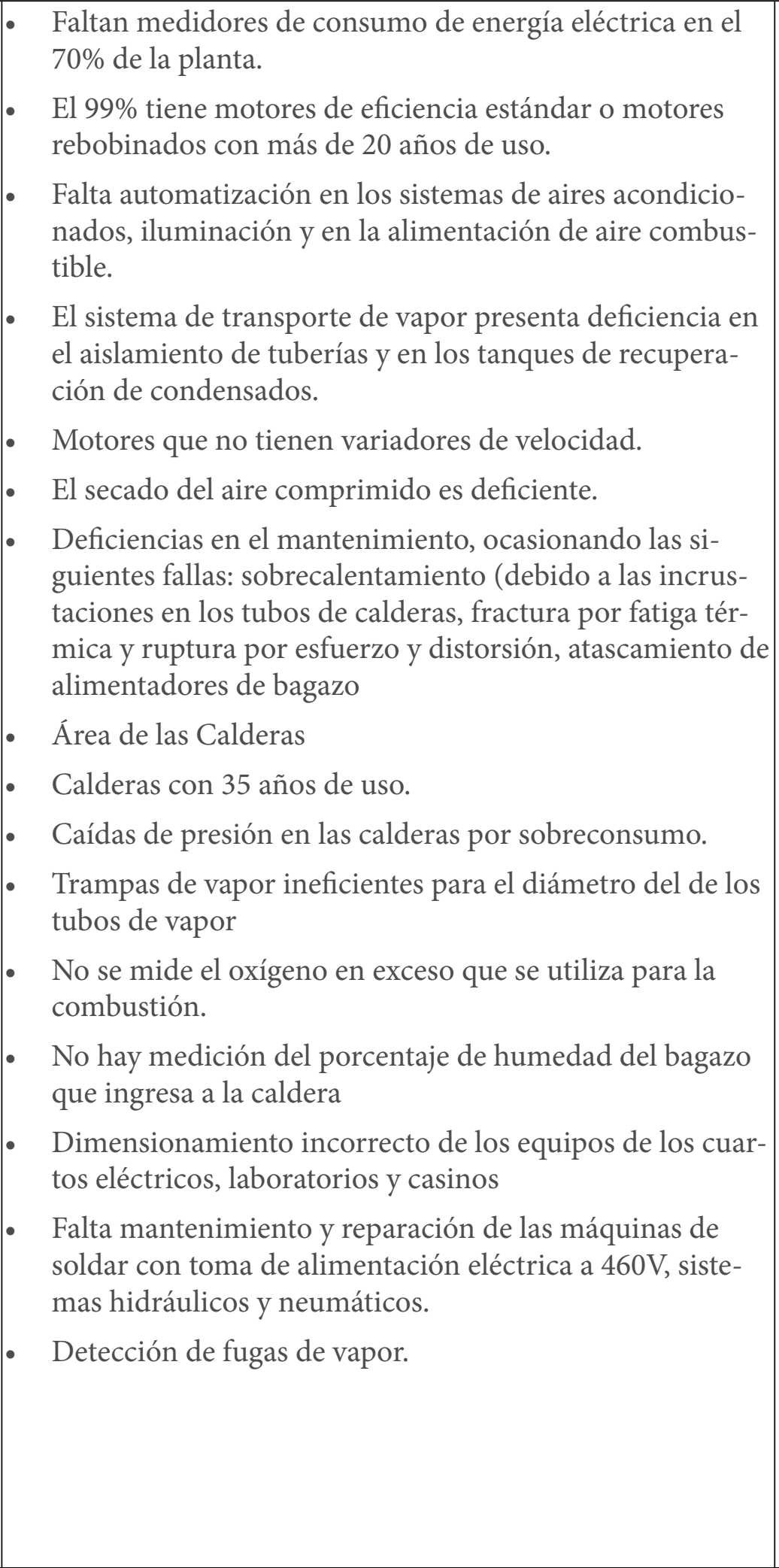 & 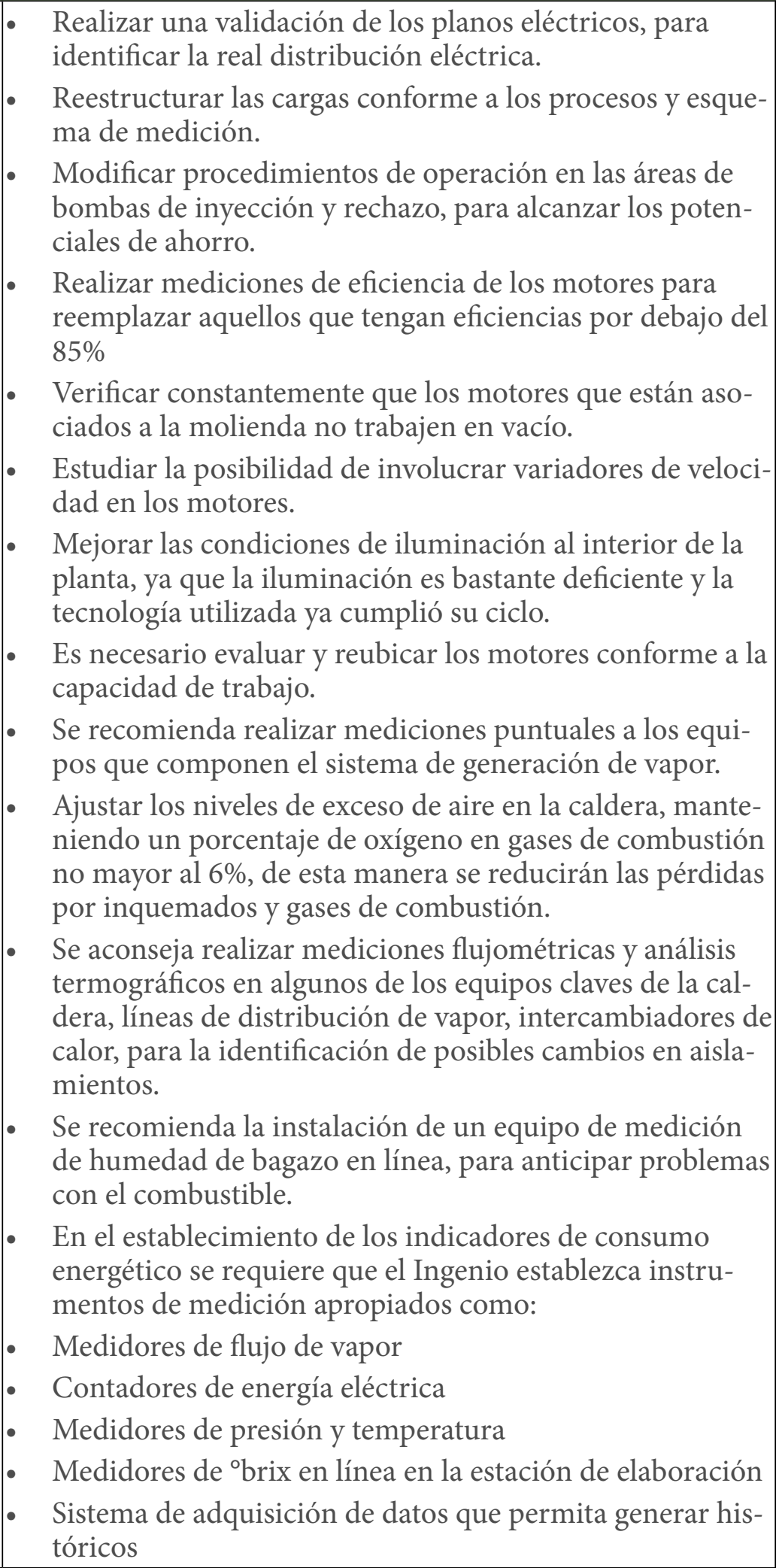 \\
\hline
\end{tabular}


Tabla 2. Resultados del Diagnóstico de Recorrido en las empresas

del sector de alimentos del valle del cauca. (Continuación)

\begin{tabular}{|c|c|c|}
\hline SECTOR & DIAGNÓSTICO DE RECORRIDO & OPORTUNIDADES DE MEJORA \\
\hline $\begin{array}{c}\text { Alimentos } \\
\text { (3 Empresas) }\end{array}$ & 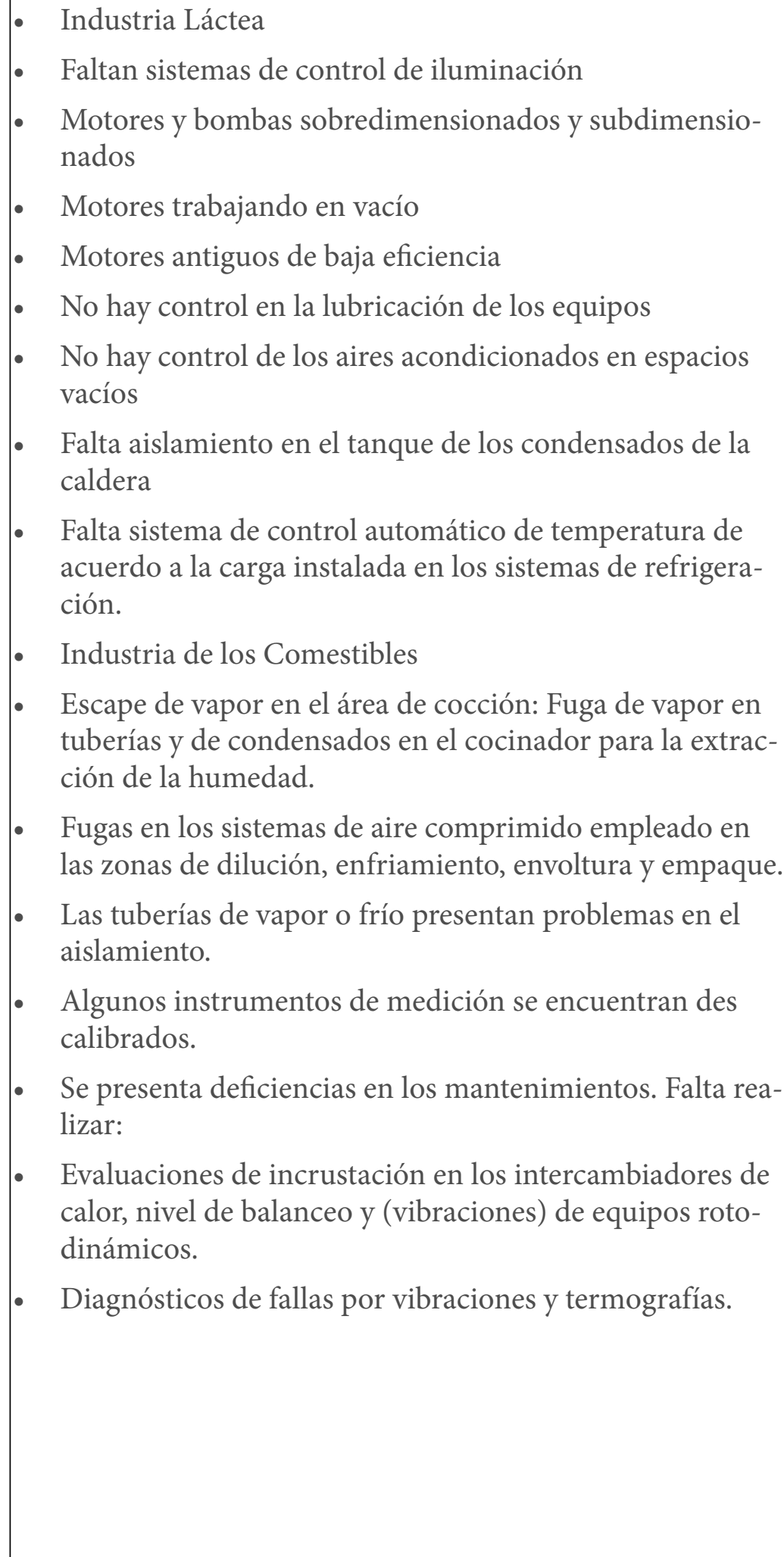 & 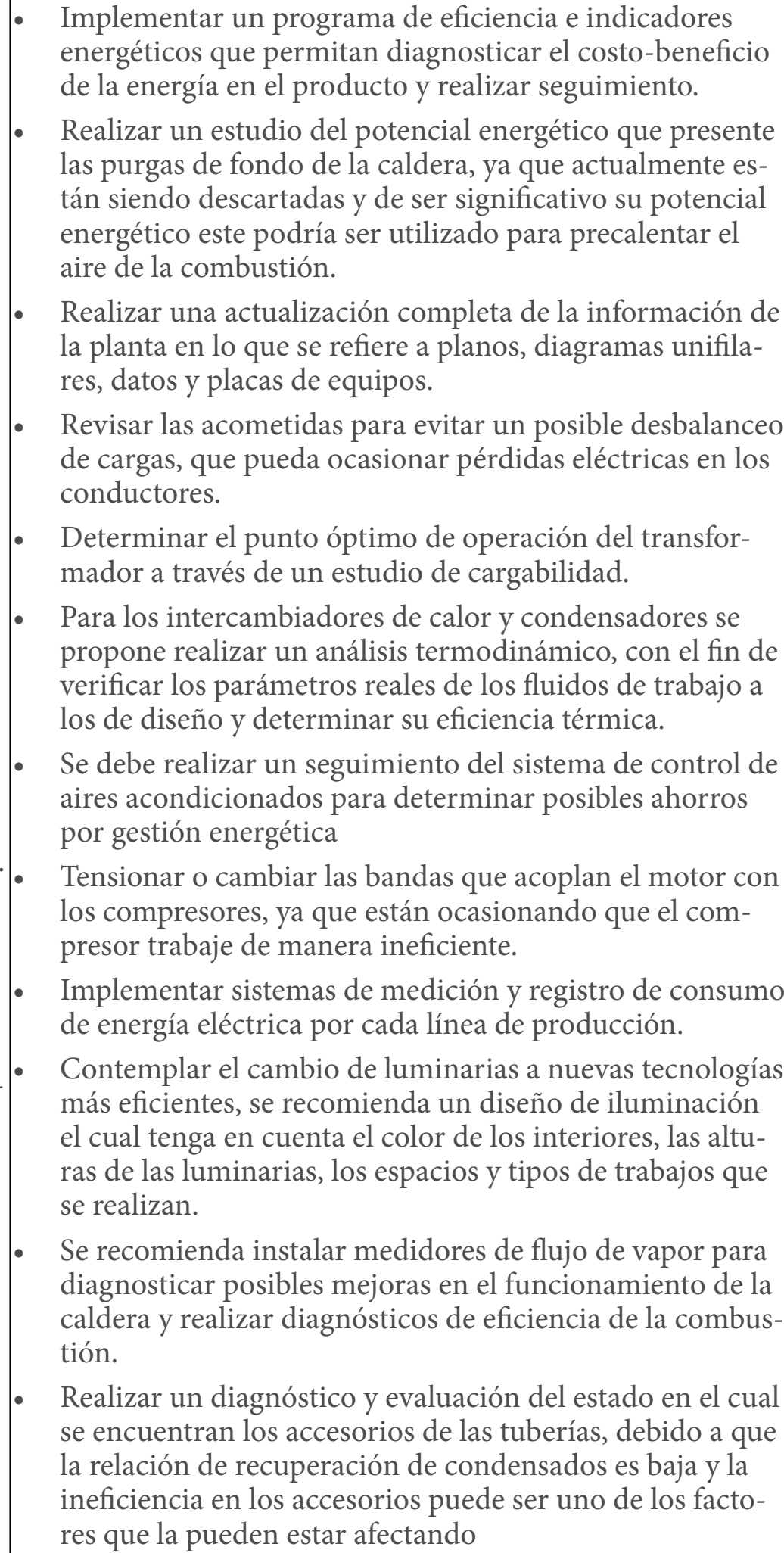 \\
\hline
\end{tabular}

Fuente: Informe proyecto PEN: SGIE 
Entre las primeras empresas que ha implementado satisfactoriamente el SGIE en el Valle del Cauca se encuentran Fagrave S.A, Biofilm S.A., Cerrejón y Cementos Argos (Botero L. 2012). Se ha comprobado que las empresas reducen su consumo energético entre un 3\% y $15 \%$, articulando una filosofía de mejoramiento continuo (ciclo PHVA) que genera una cultura energética ambiental (Botero L. 2012).

En la segunda fase del proyecto "Desarrollo e implementación de sistemas de gestión integral de la energía en el sector productivo nacional" se sensibilizaron 400 empresarios. En esta actividad se socializó la Norma ISO 50001 y se resaltó la importancia de implementar un sistema de gestión energética y el papel que juega la alta dirección, el cual permitirá que el sistema de gestión de la Energía se constituya en la mayoría de las industrias.

La eficiencia energética a nivel industrial tiene un alto impacto que se asocia no solo con los ahorros energéticos y económicos que se logran alcanzar, sino con las oportunidades de desarrollo tanto para la industria como para el país, la apertura de nuevos mercados de carácter internacional y la sostenibilidad a largo plazo de los recursos energéticos.

En la mayoría de las empresas se encontró que el nivel de gestión energética es, en general, débil, y la medición del consumo es incipiente o inexistente. Los indicadores de consumo energético son establecidos de manera incorrecta, es decir no se tienen en cuenta aspectos como los sistemas o equipos que no hacen parte de la producción ni el grado de eficiencia en el proceso.

Es común encontrar en las empresas que el consumo de energía eléctrica, en muchos casos, solo se verifica a través de la factura mensual y no como un recurso administrable, y que la eficiencia energética no involucra áreas importantes como la compra, el diseño y el talento humano.

Carecen de un área y un personal responsable de la eficiencia energética que cumpla con tareas concretas y responsabilidades frente a la implementación y el seguimiento del SGIE, y a las políticas energéticas establecidas en las empresas. En muchas ocasiones, la gestión energética depende de contratistas externos a la empresa, ocasionando discontinuidad, insuficiencia en ahorros cuantificables y la falta de seguimiento y control.

Colombia ha desarrollado en los últimos trece años, normativas y programas que permiten promover y desarrollar el Uso Racional y Energético-URE y las Fuentes No Convencionales de Energía-FNCE. Sin embargo, su aplicación no ha sido tan eficaz, como se verá en el análisis DOFA que se presenta en la tabla 3.

Tabla 3. Matriz DOFA - Aplicación proyectos URE y FNCE al DML

\begin{tabular}{|c|c|c|}
\hline & FACTORES POSITIVOS & FACTORES NEGATIVOS \\
\hline FACTORES EXTERNOS & $\begin{array}{c}\text { OPORTUNIDADES } \\
\text { La existencia de las normas y políticas son una } \\
\text { oportunidad para su desarrollo. }\end{array}$ & $\begin{array}{c}\text { AMENAZAS } \\
\text { Los tratados de libre comercio pueden impedir la } \\
\text { definición de estándares de equipos con mínimos } \\
\text { de eficiencia. }\end{array}$ \\
\hline FACTORES INTERNOS & $\begin{array}{c}\text { FORTALEZAS } \\
\text { Existen políticas y normas } \\
\text { para desarrollar los programas. } \\
\text { Existen políticas orientadas al URE y a las FNCE. }\end{array}$ & $\begin{array}{l}\text { DEBILIDADES } \\
\text { Existen normas a nivel nacional pero no hay desa- } \\
\text { rrollos regulatorios de obligatorio cumplimiento. } \\
\text { No hay mecanismos que vigilen el cumplimiento de } \\
\text { las normas. } \\
\text { Las normas presentan deficiencia en su } \\
\text { estructura, es decir todavía hace falta incorporar } \\
\text { aspectos importantes de la eficiencia energética } \\
\text { como por ejemplo: la etiqueta de eficiencia } \\
\text { energética en equipos. } \\
\text { La CREG considera que el URE y el desarrollo de } \\
\text { FNCE se logra solo con la señal económica de pre- } \\
\text { cios, sin considerar costos ambientales. } \\
\text { Resistencia a desarrollar normas obligatorias. }\end{array}$ \\
\hline
\end{tabular}

Fuente: UPME, informe final. 2007. Recuperado

http://www.simec.gov.co/Portals/0/Documental/bases\%20programa\%20URE.pdf

\section{CONCLUSIONES}

Establecidas en la Resolución 186 del Ministerio de Ambiente y Desarrollo Sostenible para los años 2015 y 2020, que propone aplicar la eficiencia energética y las energías renovables, las metas ambientales obligan a las empresas vallecaucanas a emplear este sistema de Gestión Integral de la
Energía que les permitirá aumentar la productividad y competitividad y trazar el camino hacia un desarrollo sostenible.

Cambiar la cultura de las empresas hacia el uso racional y eficiente de energía permitirá implementar eficazmente un sistema de gestión energética, que logre generar ahorros energéticos, económicos, ambientales y sociales. 


\section{AGRADECIMIENTOS}

A las siguientes instituciones: Colciencias, UPME, Universidades Autónoma de Occidente, Universidad del Valle y Universidad Nacional de Colombia por el financiamiento y apoyo, Al Grupo de Investigación en Eficiencia Energética y Energías Alternativa por el respaldo en el estudio. A la profesora Rosaura Castrillón Mendoza M.Sc., coordinadora de caracterizaciones energéticas en las cinco industrias. Al Profesor Omar Prías, director del "Programa estratégico para la innovación e implementación del Sistema de Gestión Integral de la Energía-PEN-SGIE", donde se llevó a cabo la investigación.

\section{REFERENCIAS}

ACOPI Valle del Cauca. (2014). Pymes buscan la eficiencia energética. [Articulo]. Consultado de: http://pruebas.acopivalle.com.co/pruebas2/pymes-buscan-la-eficiencia-energetica/

Agencia de Promoción de Inversión en el pacifico colombiano-investpacific. (2012). Consultado el día 12 de Septiembre de 2014 en la página web: http://www.investpacific.org/node/1349

Boletín N 7 Avances Certificaciones ISO 50001 en Colombia y el Mundo. (2013) Programa estratégico para la innovación en la gestión empresarial mediante la asimilación, difusión y generación de nuevos conocimientos en gestión energética y nuevas tecnologías e implementación del Sistema de Gestión Integral de la Energía en empresas de cinco regiones del país. Código: 1101-454-22024-Contrato RC No. 700-2008PEN-SGIE

Botero L. (2012). Eficiencia Energética: una alternativa verde [Articulo]. Recuperado de http://caliescribe.com/servicios-y-medioambiente/2012/09/22/3319-eficiencia-energetica-alternativa-verde\#sthash.xjyRm9En.dpuf

Campos, J.C., Figueroa, E., Meriño, L. y Tovar, I. (2008). Sistema de Gestión Integral de la Energía Guía para la Implementación. Ministerio de Minas y Energía. Unidad de Planeación Minero Energética -UPME, Bogotá, DC.

Comisión Económica para América Latina y el Caribe - CEPAL (2009). Situación y Perspectivas de la Eficiencia Energética en América Latina y el Caribe. Santiago de Chile. Autor

Directorio de Empresas. Informe de todas las empresas de Colombia. http://www.informacion-empresas.co/D_IN-
DUSTRIAS-MANUFACTURERAS/Departamento_VALLE.html.

El uso racional y el consumo eficiente de energía, una tendencia en ascenso. (2014). Colombia Energía. La Revista de la Industria Energética Colombiana, pp. 63-69.

Incentivos Tributarios-EEFNCE, comunicación personal, incentivosEEFNCE@upme.gov.co, 18 de Septiembre de 2014.

Ministerio de Minas y Energía. Unidad de Planeación Minero Energética. Estrategia de uso racional de energía en el sector Industrial Colombiano. Informe final. Recuperado: http://www.si3ea.gov.co/Portals/0/Gie/Docs/estrategiaUREind.pdf

Quispe, E.C. (2012). Región Valle: Resultados y Avances Oportunidades para la Industria. Foro de Sensibilización Gerentes. Programa Estratégico Nacional PEN-SGIE. Comité de Energía ANDI Cauca, Ingenio del Cauca, 28 noviembre (Presentación)

Unidad de Planeación Minero Energética - UPME. Consultoría para la Formulación Estratégica del Plan de Uso Racional de Energía y de Fuentes No Convencionales de Energía 2007 - 2025. Contrato 1517-33-2006. Bogotá D.C., Junio 15 de 2007. Recuperado: http://www.simec.gov. co/Portals/0/Documental/bases\%20programa\%20URE.pdf

Universidad Nacional de Colombia, Universidad del Atlántico, Universidad Autónoma de Occidente, Universidad Pontificia Bolivariana y Universidad Industrial de Santander. Informe Proyecto PEN-SGIE entregado a Colciencias. Programa estratégico para la innovación en la gestión empresarial mediante la asimilación, difusión y generación de nuevos conocimientos en gestión energética y nuevas tecnologías e implementación del Sistema de Gestión Integral de la Energía en empresas de cinco regiones del país. Código: 1101-454-22024-Contrato RC No. 700-2008.

Vásquez, C., Yépez, W., Ramírez, R., Osal, W., Parra, E., Doyharzabal, J., Sudriá, A., Sánchez, I., Llosas, Y. (2009). 1er taller "Eficiencia energética para la seguridad y la sostenibilidad de Iberoamérica (EFESOS)". Universidad, Ciencia y Tecnología, vol.13, No.53, p. 346

World Energy Council. (2010). Eficiencia Energética: Una Receta para el Éxito-Para la energía sostenible, p.8. Consultado 2 de septiembre de 2014 en la página web: http://www.worldenergy.org/. 


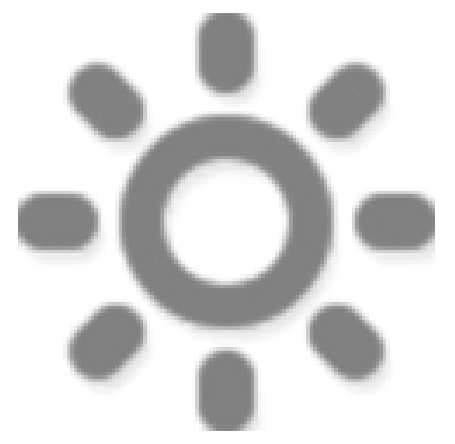

ENERGÍAS ALTERNATIVAS 


\title{
Energía en Latinoamérica y el Caribe
}

\author{
M. Garcíal, M. Moya ${ }^{1}$ \\ ${ }^{1}$ Instituto Nacional de Eficiencia Energética y Energías Renovables, Av. 6 de diciembre \\ N33-32 e Ignacio Bossano, Quito, Ecuador.
}

\begin{abstract}
RESUMEN
América Latina y el Caribe es una región que posee un importante potencial energético de energías renovables, en especial en la explotación de fuentes de energía como la, hidroelectricidad y los biocombustibles. De estas fuentes de energía, la más explotada es la hidráulica, mientras que las energías como, la eólica, solar fotovoltaico, solar térmico y geotérmico se encuentran en sus inicios de aprovechamiento. El aporte energético en la región por hidroeléctricas corresponde al $62 \%$ y llegando al 90\% en países como Brasil y Paraguay, seguido por los biocombustibles que representan un 36\%. Latinoamérica posee un gran potencial en energías limpias como lo es, la eólica que se encuentra instalada en Brasil, México, Colombia, Argentina entre otros; en Ecuador la energía eólica aporta con 20MW al sistema nacional interconectado a través del Parque Eólico Villonaco, el cual posee un factor de planta del 51.3\%, siendo uno de los más altos con respecto a los países anteriormente citados. La energía fotovoltaica en Latinoamérica se encuentra en pleno desarrollo en países como, México, Brasil, Chile y Perú, los cuales poseen una mayor radiación solar promedio anual. En el caso de Perú se encuentra construyendo una planta de 20 MW pico, siendo la de mayor potencia instalada, mientras que México está construyendo una planta solar térmica con una capacidad de 650 MW, este recurso es previsible y confiable, con relación a otras energías, como la mareomotriz que se tiene un gran potencial pero su tecnología para el aprovechamiento se encuentra en sus inicios de investigación y desarrollo. La implementación en Latinoamérica de energías renovables tiene una alta dependencia de las políticas y regulaciones que posee cada país de la región, las cuales no representan barreras ni obstáculos para inversiones futuras, lo cual representaría una columna vertebral para la integración latinoamericana. Es por eso que se utiliza ciertos mecanismos establecidos en el Protocolo de Kioto, como el comercio de emisiones, mecanismos de implementación conjunta y mecanismos para un desarrollo limpio, esto ofrece oportunidades para el impulso de proyectos de energía limpia. La inclusión de las energías renovables en Latinoamérica y el Caribe depende de las diferentes políticas que se apliquen en programas de apoyo, incentivos y estímulos fiscales que generen propuestas para futuras inversiones y financiamiento con lo cual se pude hacer frente al problema del cambio climático.
\end{abstract}

Palabras Clave: Energías renovables, Producción energética, Energía. 


\title{
APROVECHAMIENTO DE LAS FUENTES NO CONVENCIONALES DE ENERGÍA EN LA COSTA NORTE COLOMBIANA
}

\author{
Dianeth Silva Zapata ${ }^{1,2}$ \\ Natalia Núñez Fuentes ${ }^{1,3}$ \\ Guillermo Valencia Ochoa ${ }^{1,4}$ \\ ${ }^{1}$ Universidad del Atlántico - Barranquilla, Colombia \\ 2silvazapata.d@gmail.com \\ nataly1026@hotmail.com \\ ‘uillermoevalencia@mail.uniatlantico.edu.co
}

\begin{abstract}
RESUMEN
Actualmente, la generación de electricidad en nuestro país a partir de fuentes renovables (sin incluir a las grandes hidroeléctricas) es muy baja, siendo la eólica la de mayor participación. Para lograr una seguridad energética más robusta a mediano y largo plazo, el país debe tener un soporte tecnológico que tenga en cuenta la adecuada complementariedad e implementación de todas las tecnologías y fuentes de energía con que cuenta. En la zona norte colombiana, específicamente en el departamento de La Guajira, los recursos renovables son amplios y variados, lo que favorece la transición a este nuevo modelo de generación energética. Podría intuirse que los niveles de radiación registrados y la fuerte velocidad del viento dan indicios de que podría abastecerse la demanda energética de la región a partir de sistemas termosolares, fotovoltaicos o molinos eólicos, sin embargo, su aprovechamiento es reducido, debido principalmente a factores de índole económico, político-social y técnico. Por medio del presente artículo se pueden observar algunos resultados parciales del programa integral de evaluación y aprovechamiento de energía solar y eólica en la región Caribe colombiana con énfasis en la Guajira, en la cuales se destacan zonas de la región con radiación de $6 \mathrm{kWh} / \mathrm{m} 2$ y lugares donde los vientos son persistentes y superiores a $5 \mathrm{~m} / \mathrm{s}$ durante todo el año.
\end{abstract}

Palabras claves: Gestión del conocimiento, energía solar, energía eólica, eficiencia energética, fuentes no convencionales de energía (FNCE) 


\section{INTRODUCCIÓN}

Debido a la ubicación geográfica de nuestro país, Colombia posee una amplia riqueza en diversos recursos que le permiten satisfacer su demanda energética en la actualidad. Sin embargo los procesos de producción y el uso irracional de la energía constituyen la causa fundamental del deterioro ambiental en nuestro planeta. El inevitable agotamiento de los combustibles fósiles y el daño irreversible que se ocasiona al medio ambiente exige la adopción de nuevas estrategias en materia de generación de energía. Estas estrategias deben considerarse como la base de un modelo de desarrollo sostenible, el cual permita satisfacer las necesidades energéticas de la generación actual y preservar las posibilidades para que las futuras generaciones puedan también encontrar soluciones para satisfacer las suyas.

El modelo de desarrollo sostenible debe contribuir al mejoramiento de la calidad de la vida en la tierra, con más y mejores servicios energéticos, pero de una forma racional y segura que permita respetar y preservar las comunidades de seres vivos, no sobrepasar los límites de la capacidad del planeta para suplir fuentes de energía y asimilar los residuos de su producción y uso. En definitiva, este modelo sostenible debe integrar el desarrollo de las poblaciones y debe contribuir a la conservación del medio ambiente. Lo anterior justifica el hecho de realizar estudios en Colombia y en especial, sobre el recurso eólico y solar en la región Caribe.

Dichos estudios del recurso solar se han realizado a través de mediciones de radiación solar, brillo solar, temperatura y humedad en las estaciones meteorológicas del Instituto de Hidrología, Meteorología y Estudios Ambientales (IDEAM), convirtiendo la información meteorológica recogida en información energética disponible a la comunidad. Importantes resultados han sido divulgados en documentos como el Manual de la Radiación solar en Colombia, que en su primer volumen publicado en el año de 1992 [1], muestra los promedios mensuales diarios en superficies planas de la radiación solar y en su segundo volumen publicado en 1994, muestra la radiación solar a diferentes orientaciones para datos de brillo solar de los años 1970 y 1980 [2].

Los mapas de radiación solar más reciente, fueron desarrollados por la Unidad de Planeación Minero Energética (UPME) y COLCIENCIAS y publicados en el año 2005[3], fundamentándose en datos provenientes de 550 estaciones de medición localizadas en toda la extensión del país, resumiendo los resultados de potencial de energía solar del país como muestra la tabla 1 . Se concluye que la región más atractiva es la región Caribe, principalmente el departamento de La Guajira.

Tabla 1. Potencial de la energía solar en Colombia por regiones. [3]

\begin{tabular}{|c|c|}
\hline Región & $\mathrm{kWh} / \mathrm{m} 2 /$ año \\
\hline Guajira & 2190 \\
\hline Región Caribe & 1825 \\
\hline Orinoquía & 1643 \\
\hline
\end{tabular}

\begin{tabular}{|c|c|}
\hline Región & $\mathrm{kWh} / \mathrm{m} 2 / \mathrm{año}$ \\
\hline Amazonía & 1551 \\
\hline Andina & 1643 \\
\hline Costa Pacifica & 1278 \\
\hline
\end{tabular}

En el año 1999, se realizó un estudio detallado del potencial eólico en el país y se realizaron mesas de trabajo en donde confirmaron las bondades de la guajira para la implementación del primer parque eólico colombiano llamado "JEPIRACHI" [4], cuya construcción se inició años más tarde. La instalación del primer aerogenerador del territorio colombiano culminó el 17 de noviembre del 2003 y la inauguración oficial el 21 de diciembre del 2003 [5]. Posteriormente, se construyó el parque eólico WAYÚU, ubicado entre el Cabo de la Vela y Puerto Bolívar, con capacidad para 20MW, con características similares a las del parque eólico JEPIRACHI.

Otra zona de la región Caribe con proyectos de energía eólica es la población de Nazaret, localizada en la alta guajira, donde se instalaron dos generadores utilizando como combustible diésel. Posteriormente el Instituto de Planificación y Promoción de Soluciones es Energéticas para las Zonas No Interconectadas (IPSE) instalo un generador de 150kw a GLP (Gas Licuado del Petróleo) y dos aerogeneradores de 100kw cada uno.

Por lo anterior, un conjunto de instituciones educativas de educación superior, por medio de sus grupos de investigación, se encuentran desarrollando la evaluación del potencial eólica y solar de la región caribe colombiana con énfasis en la guajira, por medio de la cual se espera contribuir en gran parte a la formulación de estrategias para el desarrollo sostenible de la región con el aprovechamiento de FNCE para mejorar la calidad de vida de sus habitantes.

\section{DESARROLLO METODOLÓGICO}

\section{Descripción de la región y datos}

La región Caribe está ubicada en el norte del país y está constituida por siete departamentos en la llanura continental, y un departamento en la parte marítima localizada entre los $12^{\circ} 60$ y $7^{\circ} 80$ de latitud norte y los $75^{\circ}$ y $71^{\circ}$ de longitud al oeste de Greenwich, representa el $11.6 \%$ de la extensión total del país y comprende desde el occidente, el golfo de Urabá, hasta el oriente de la península de la Guajira, siendo zona con alto potencial eólico y solar para la implementación de proyectos de fuentes no convencionales de energía [6]. La región cuenta con 9.7 millones de habitantes que corresponde aproximadamente al 21,4\% de la población de Colombia, se caracterizada por climas cálidos, costa y playas en la zona norte, mientras que en la economía se trabaja en la agricultura y el turismo que prevalecen en las zonas limítrofes al mar [7].

Con el objetivo de determinar del potencial de energía solar y eólica de la región caribe de Colombia, en especial 
del departamento de la guajira, se ha dedicado importantes esfuerzos consolidar una base de datos validada proveniente de las estaciones de medición del Instituto De Hidrología, Meteorología Y Estudios Ambientales (IDEAM) que contenga todos los parámetros climatológicos de sol y viento. El proceso consta de varias etapas, entre las que se destacan la digitalización de datos existentes, el inventario de los registros climatológicos de las estaciones de la región Caribe, el procesamiento de información manual por medio de aplicaciones asistidas por computador en ArcView, el desarrollo de cálculos de modelos matemáticos y el posterior manejo de las técnicas de interpolación geoestadística para la generación de los mapas de radiación, brillo solar y rosas de viento.

\section{Evaluación del potencial solar de la región caribe}

En lo referente a la evaluación del potencial solar, se han aplicado modelos para la predicción de la radiación solar debido a que el número de estaciones de medición instaladas en la región Caribe no son suficientes [8]. Se han empleado importantes esfuerzos en desarrollar modelos más robustos que calculen la radiación solar a partir de datos meteorológicos medidos con estaciones convencionales [9]. En 1924 Angstrom [10] propuso el primer modelo teórico para la estimación de la radiación solar global basado en brillo solar, la cual es una variable que se mide actualmente en la región Caribe colombiana. Page [11] y Prescott [12] complementaron el modelo para estimar la radiación solar mensual $\mathrm{H}(\mathrm{Mj} / \mathrm{m} 2$ día) sobre una superficie horizontal, a partir de la radiación extraterrestre promedio sobre una superficie horizontal a través de la ecuación (1).

$$
\frac{H}{H o}=a+b \frac{n}{N},(1)
$$

\section{Dónde:}

$\mathrm{H}=$ Radiación diaria promedio mensual en una superficie horizontal.

Ho = Radiación fuera de la atmósfera (Extraterrestre) para la misma localidad promediada en el periodo de interés.

$\mathrm{a}$ y $\mathrm{b}=$ Constantes empíricas.

$\mathrm{N}=$ Promedio mensual de horas diarias de brillo solar.

$\mathrm{N}$ = Promedio mensual de las horas máximas de brillo solar diarias (es decir, la duración del día promedio del mes)
En términos generales, para la evaluación del potencial solar, se calculan los promedios mensuales de la duración astronómica del día (longitud del día u horas máximas de luz solar diarias), posteriormente se realiza el cálculo del promedio mensual de la radiación solar extraterrestre en superficie horizontal, se desarrolla el modelo Angstrom y finalmente, se realiza la evaluación de la energía solar disponible para lugares que poseen o sólo brillo solar o radiación solar global.

\section{Evaluación del potencial eólico}

Para la evaluación de las distribuciones de velocidades del viento y la frecuencia de variación de las direcciones del viento se ha realizado la rosa de los vientos, la cual se divide en 12 sectores cada uno de $30^{\circ}$ del horizonte. Tener en cuenta la rosa de los vientos es de mucha importancia para determinar la orientación de un aerogenerador. Es importante considerar que si la mayoría de energía del viento viene de una dirección en particular, el generado eólico debe ser ubicado en una dicha dirección, por lo que en esta dirección hay los menores obstáculos y el terreno es más liso.

Adicionalmente, se muestran unas gráficas de velocidad promedio del viento mensual para tres estaciones de la región Caribe colombiana para los años 2011 y 2012.

\section{RESULTADOS}

\section{Evaluación del potencial solar de la región Caribe}

La evaluación del potencial solar en la región Caribe permite medir la disponibilidad de la radiación solar como fuente no convencional de energía, al mismo tiempo que brinda información del comportamiento termodinámico de todos los componentes que absorben la radiación extraterrestre. Los datos provenientes de las estaciones del IDEAM, sirven como base para el estudio de la radiación solar global y brillo solar, información requerida para el diseño de proyectos de energía solar térmica y fotovoltaica. La tabla 1 muestra los valores promedios totales de radiación solar global en $\left[\mathrm{W} / \mathrm{m}^{2}\right]$ y brillo solar para un conjunto de estaciones ubicadas en la Región Caribe con información histórica del 2005 a 2013. 


\begin{tabular}{|l|r|r|r|r|r|}
\hline ESTACIÓN & IATITUD & LONGITUD & \multicolumn{1}{c|}{ ALTITUD } & \multicolumn{1}{c|}{ BRIUO } & RADIACIÓN \\
\hline ESTACIÓN BATALLÓN NO. 6 (MAGDALENA) & 10.450 & -73.917 & 1384.000 & 190.105 & 4489.833 \\
\hline ESTACIÓN CARMEN DE BOLIVAR (BOLIVAR) & 9.633 & -75.100 & 190.000 & 175.598 & 5334.225 \\
\hline ESTACIÓN FEDEARROZ (VALLEDUPAR) & 10.460 & -73.250 & 183.700 & 222.582 & 5270.360 \\
\hline ESTACIÓN PAICI GRANJA (URIBIA-GUAJIRA) & 11.590 & -72.317 & 14.870 & 240.389 & 5542.337 \\
\hline ESTACIÓN INCODER (MONTERIA-CÓRDOBA) & 8.833 & -75.833 & 37.000 & 180.458 & 3746.181 \\
\hline ESTACIÓN LA GRAN VIA (MAGDALENA) & 10.850 & -74.130 & 30.000 & 193.575 & 4957.458 \\
\hline ESTACIÓN LAS FLORES (BARRANOULIA) & 11.040 & -74.820 & 2.000 & 201.617 & 6015.922 \\
\hline ESTACIÓN SAN MARCOS (SUCRE) & 8.600 & -75.140 & 27.000 & 184.455 & 4917.737 \\
\hline ESTACIÓN UNISUCRE (SUCRE) & 9.200 & -75.390 & 221.000 & 173.756 & 4613.401 \\
\hline
\end{tabular}

Tabla 1. Tabla Estaciones Meteorológicas en la Costa Norte Colombiana.

Para cada una de las estaciones antes mencionadas, se han procesado los datos promedios mensuales, como se muestra en la tabla 2. Este es el caso particular de la estación de LAS FLORES, ubicada en el departamento del Atlántico, donde se observan las mayores radiaciones en los meses de julio y agosto alrededor de la 1:00 de la tarde.

\begin{tabular}{|c|c|c|c|c|c|c|c|c|c|c|c|c|}
\hline \multicolumn{13}{|c|}{ PROMEOIO HORARIO DE LA RADIACIÓN $\left(w^{*} h / m^{2}\right)$} \\
\hline HORA & Ene & Feb & Mar & Abr & May & Jun & Jul & Ago & Sep & Oet & Nov & Dic \\
\hline $0-1$ & 0.0 & 0.0 & 0.0 & 0.0 & 0.0 & 0.0 & 0.0 & 0.0 & 0.0 & 0.1 & 0.0 & 0.0 \\
\hline $1-2$ & 0.0 & 0.0 & 0.0 & 0.0 & 0.0 & 0.0 & 0.0 & 0.0 & 0.0 & 0.0 & 0.0 & 0.0 \\
\hline $2-3$ & 0.0 & 0.0 & 0.0 & 0.0 & 0.0 & 0.0 & 0.0 & 0.0 & 0.0 & 0.0 & 0.0 & 0.0 \\
\hline $3-4$ & 0.1 & 0.0 & 0.0 & 0.0 & 0.0 & 0.1 & 0.0 & 0.1 & 0.0 & 0.0 & 0.0 & 0.0 \\
\hline $4-5$ & 0.0 & 0.0 & 0.0 & 0.0 & 0.0 & 0.0 & 0.0 & 0.1 & 0.0 & 0.0 & 0.0 & 0.0 \\
\hline $5-6$ & 0.1 & 0.1 & 0.5 & 5.0 & 10.9 & 11.4 & 7.4 & 5.2 & 5.0 & 4.0 & 1.8 & 0.3 \\
\hline $6-7$ & 24.3 & 27.8 & 47.0 & 83.3 & 96.1 & 106.3 & 89.0 & 83.7 & 91.7 & 80.7 & 70.7 & 40.8 \\
\hline 78 & 143.6 & 151.8 & 183.4 & 243.7 & 224.4 & 258.4 & 229.3 & 246.7 & 255.2 & 243.6 & 224.0 & 186.7 \\
\hline $8-9$ & 322.0 & 334.2 & 351.2 & 427.1 & 359.2 & 433.9 & 394.7 & 423.0 & 429.5 & 406.7 & 368.8 & 358.0 \\
\hline $9-10$ & 520.9 & 546.5 & 506.5 & 603.7 & 463.8 & 564.5 & 533.2 & 601.1 & 601.6 & 564.2 & 505.4 & 520.1 \\
\hline $10-11$ & 681.7 & 731.3 & 628.5 & 729.7 & 571.2 & 661.2 & 607.2 & 702.7 & 749.3 & 691.6 & 619.9 & 657.4 \\
\hline $11-12$ & 802.4 & 842.1 & 754.8 & 839.9 & 800.0 & 825.8 & 832.0 & 837.3 & 793.8 & 753.7 & 692.4 & 731.7 \\
\hline $12-13$ & 836.6 & 885.5 & 802.4 & 854.5 & 813.7 & 824.0 & 873.0 & 856.1 & 822.9 & 734.0 & 673.5 & 705.6 \\
\hline $13-14$ & 776.0 & 829.8 & 745.4 & 766.8 & 749.8 & 777.5 & 812.8 & 800.3 & 737.1 & 613.2 & 604.3 & 649.6 \\
\hline $14-15$ & 656.6 & 096.0 & 634.1 & 620.9 & 817.0 & 649.0 & 685.2 & 849.0 & 573.5 & 456.3 & 482.9 & 547.6 \\
\hline $16-16$ & 480.1 & 526.3 & 462.5 & 457.2 & 448.3 & 473.1 & 519.3 & 483.5 & 396.5 & 291.4 & 309.8 & 380.0 \\
\hline $16-17$ & 256.2 & 302.8 & 246.3 & 238.1 & 242.7 & 273.2 & 312.2 & 257.1 & 192.9 & 116.6 & 120.9 & 164.5 \\
\hline $17-18$ & 43.2 & 68.0 & 55.6 & 61.6 & 69.8 & 88.0 & 107.1 & 73.2 & 34.3 & 9.5 & 4.6 & 14.2 \\
\hline $18-19$ & 0.1 & 0.2 & 0.3 & 0.6 & 0.8 & 2.5 & 4.2 & 1.5 & 0.2 & 0.0 & 0.0 & 0.2 \\
\hline $19-20$ & 0.0 & 0.0 & 0.0 & 0.1 & 0.1 & 0.1 & 0.2 & 0.1 & 0.0 & 0.1 & 0.1 & 0.0 \\
\hline $20-21$ & 0.0 & 0.0 & 0.0 & 0.0 & 0.0 & 0.0 & 0.1 & 0.1 & 0.0 & 0.0 & 0.0 & 0.1 \\
\hline 21.22 & 0.0 & 0.0 & 0.0 & 0.0 & 0.0 & 0.0 & 0.0 & 0.0 & 0.0 & 0.0 & 0.0 & 0.0 \\
\hline $22-23$ & 0.0 & 0.0 & 0.0 & 0.1 & 0.0 & 0.0 & 0.0 & 0.0 & 0.0 & 0.0 & 0.0 & 0.0 \\
\hline 23.0 & 0.0 & 0.0 & 0.0 & 0.0 & 0.0 & 0.0 & 0.0 & 0.0 & 0.0 & 0.1 & 0.0 & 0.0 \\
\hline \begin{tabular}{|c|}
$\begin{array}{c}\text { Acumula da } \\
\text { diaria }\end{array}$ \\
\end{tabular} & 5643.8 & 5942.2 & 5418.6 & 59321 & 5466.6 & 6948.8 & 6006.7 & 6020.3 & 6683.3 & 4965.7 & 4669.1 & 4956.6 \\
\hline
\end{tabular}

Tabla 2. Datos promedios horario de la radiación $\left(\mathrm{W}^{\star} \mathrm{h} / \mathrm{m} 2\right)$ en estación las flores.

A partir de la información de los promedios mensuales de la radiación global de las estaciones antes mencionadas, se han desarrollado un conjunto de mapas preliminares multianuales (promedios mensuales y promedio anual) de radiación global y brillo solar, tal como se muestran en la figura 1 , los cuales fueron generados con información del recurso con pocos puntos para región, obteniendo una información que se espera mejorar y depurar en la medida en que se obtenga una evaluación del modelo de Angstrom para el cálculo de la radiación en distintos puntos de la región.

En el caso del brillo solar en el territorio de la Guajira, tener en cuenta que al color verde oscuro se le asocia el rango de 173 a 184 horas/mes, seguido por el verde tenue, en el rango de 184 a 195, y así sucesivamente hasta llegar al color rojo, con un rango de 229 a 240 horas mes, para el territorio de la guajira. Sin embargo, para la radiación solar se obtuvieron datos para la estación LAS FLORES promedio mayores que la estación PAICI GRANJA, por lo que se sugiere incluir los datos de los radiómetros instalados en el departamento de la Guajira, de tal manera que se puedan obtener mapas más confiables, que puedan ser utilizados como referencia para estudios y futuros proyectos a desarrollar en la región. 

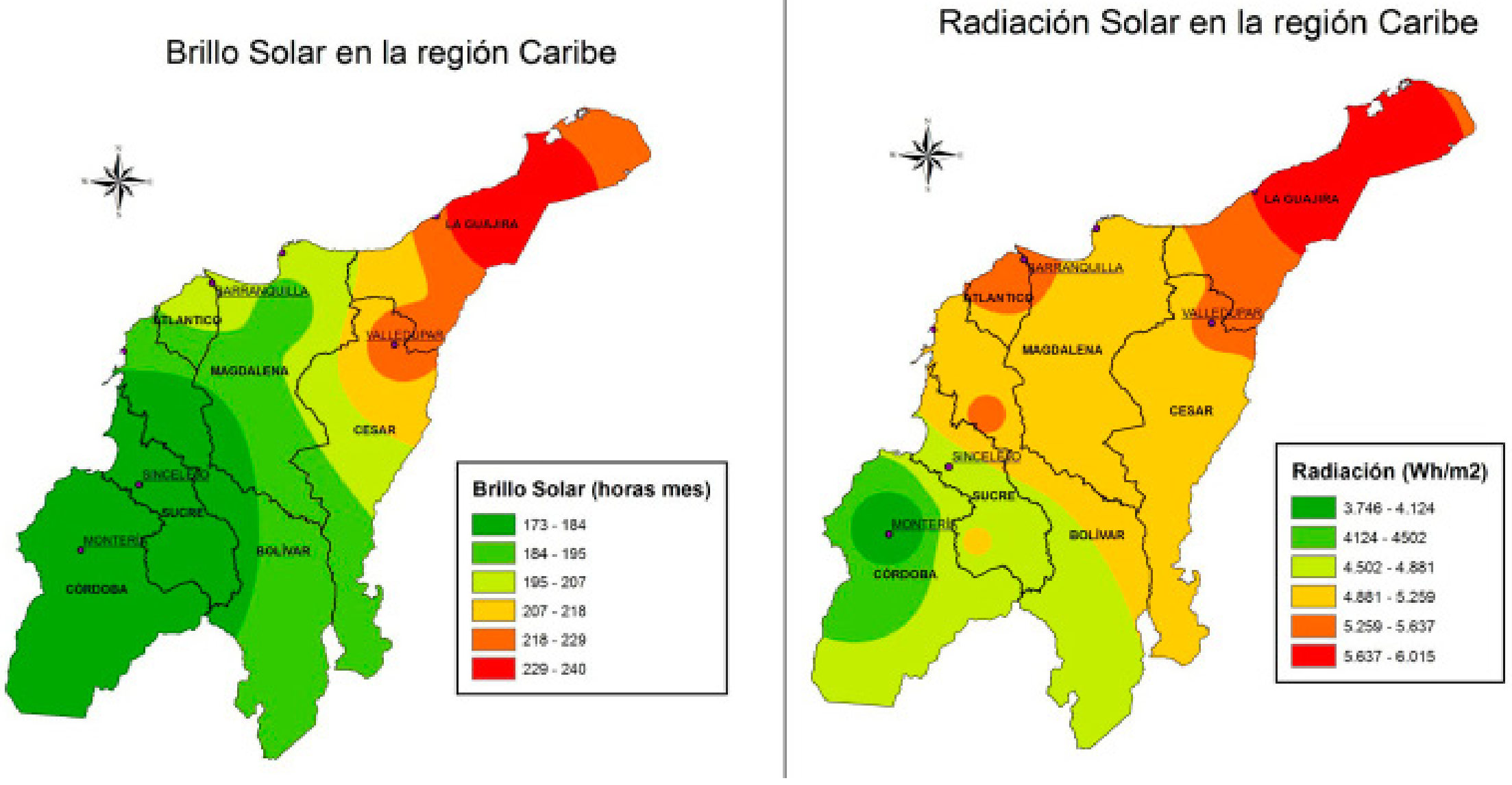

Figura 1. Mapa de a) Brillo Solar y b) Radiación Solar para Costa Norte Colombiana

\section{Evaluación del potencial eólico}

A partir de las frecuencias mensuales de las direcciones, se han elaborado rosas de vientos que se muestran en la Fig. 2 Rosa de vientos Barranquilla - Estación Aeropuerto Ernesto Cortissoz: a) enero 2013, b) febrero 2013, c) marzo 2013, d) abril 2013 que muestra la distribución de los rum- bos en dichos meses del año 2013 en la región, en la cual se observa en común que en los cuatro meses la orientación del viento y las mayores intensidades se presentan en el lado Este, y con menos intensidad en el lado noreste, lo cual se le asocia a la influencia del terreno árido, la cercanía e influencia del mar Caribe que bañan las costas colombianas, la poca vegetación y la planicie del terreno. a)

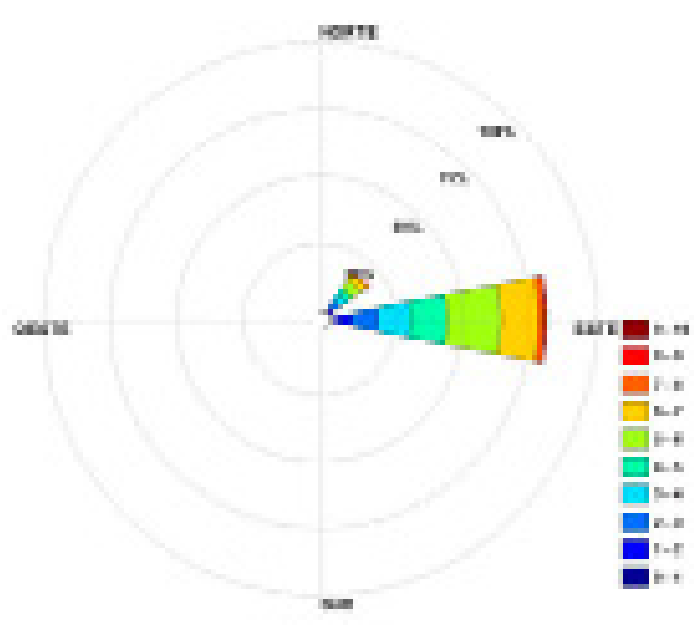

c)

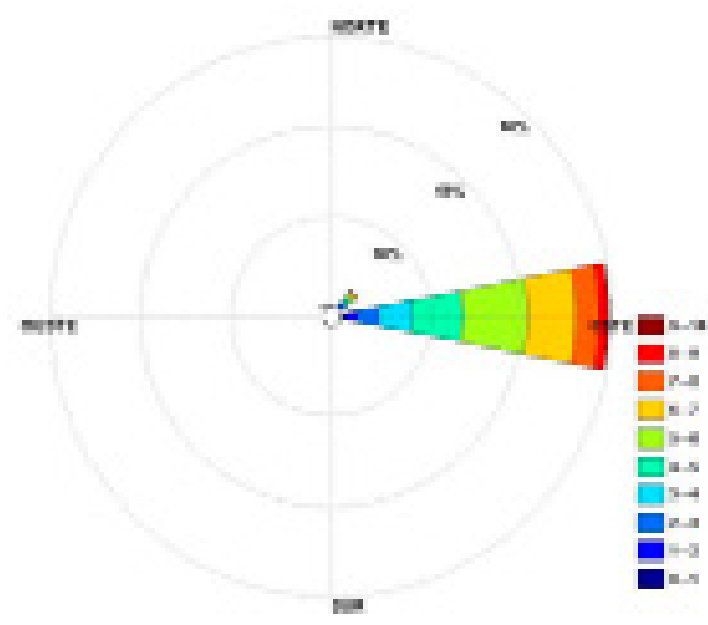

b)

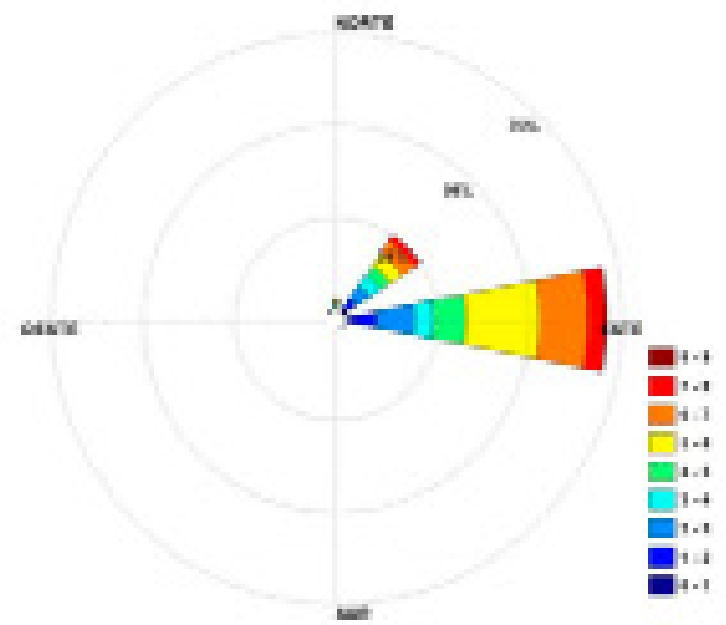

d)

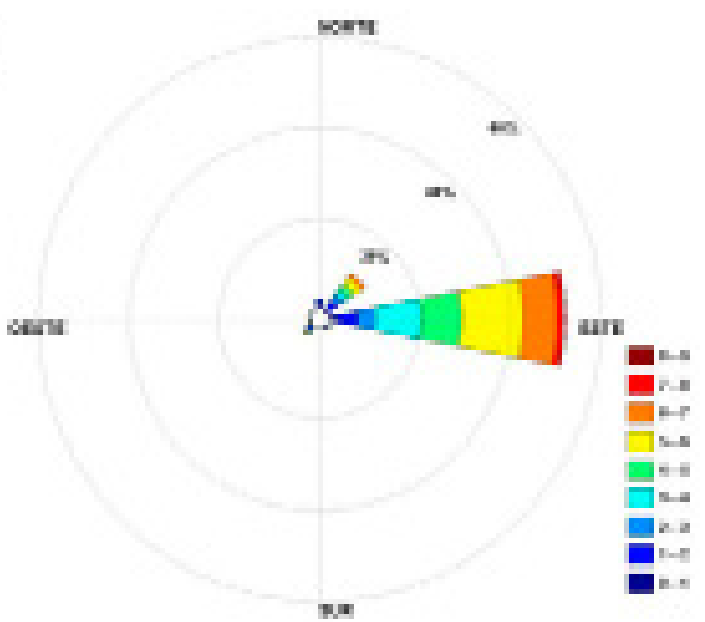

Figura 2. Rosa de los vientos Barranquilla - Estación Aeropuerto Ernesto Cortissoz: a) enero 2013, b) febrero 2013, c) marzo 2013, d) abril 2013. 
Un análisis complementario fue llevado a cabo al estudiar el comportamiento del viento el año 2012, en donde se observa que para los puntos de medición ubicados en los aeropuertos Barranquilla, Santa Marta y Guajira, el mes de marzo presenta los picos más altos con valores de hasta 4,6 $\mathrm{m} / \mathrm{s}, 3,8 \mathrm{~m} / \mathrm{s}$ y $2,9 \mathrm{~m} / \mathrm{s}$ respectivamente. También, se presenta

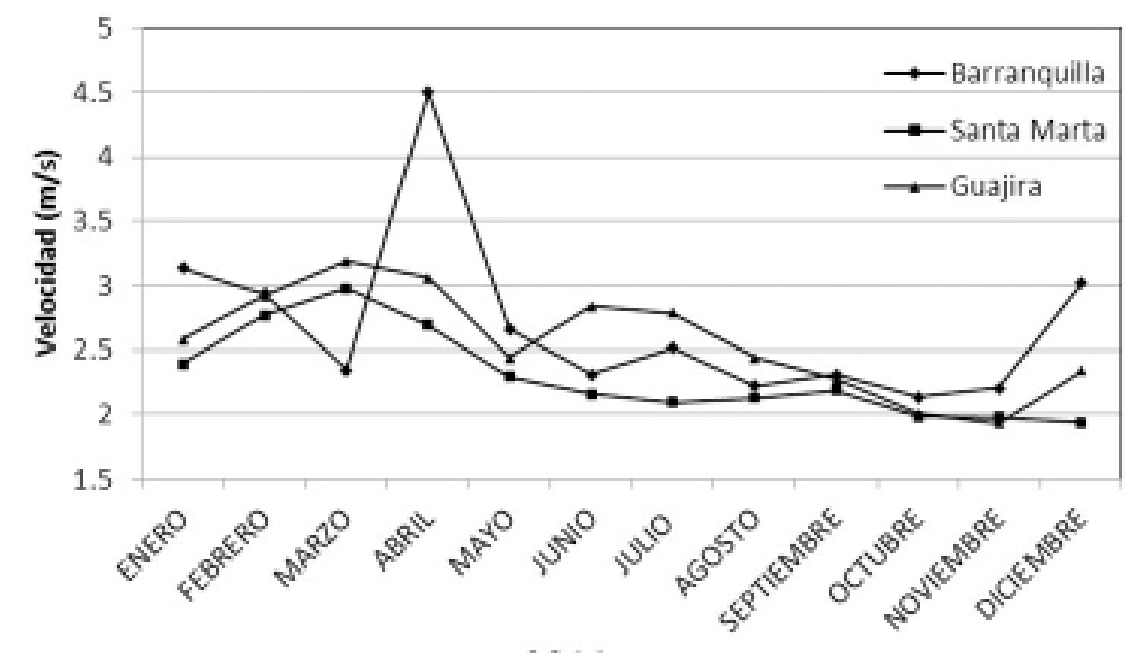

2011 disminución de las velocidades del viento a mediados del mes de abril, para tener nuevamente picos en julio y diciembre. Se presentan variaciones similares de las velocidades de viento en los puntos referenciados, con variaciones significativas en la Guajira julio, teniendo un máximo de 3,9m/s, como se observa en la figura 3 (b).

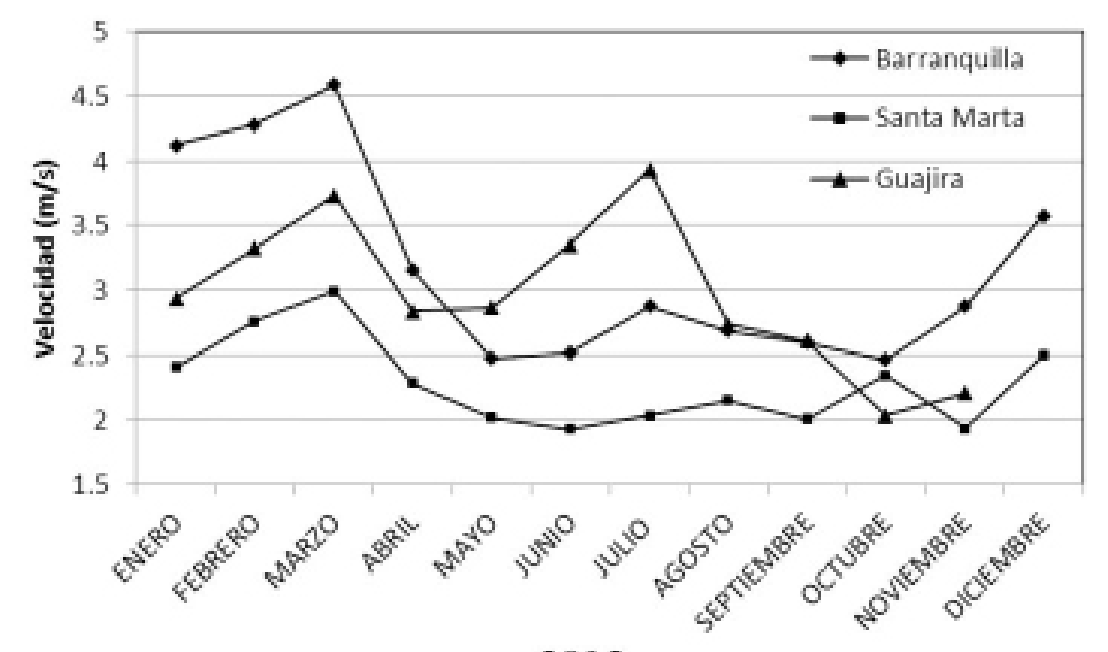

2012

Figura 3. Velocidad del viento promedio mensual para las estaciones del Aeropuerto Ernesto Cortissoz, Aeropuerto simón bolívar, Aeropuerto Almirante Padilla para: a) año 2011, b) año 2012.

Sin embargo, para el año 2011, como muestra la figura 3 (a) se tienen datos de velocidad de viento con comportamientos muy similares en los tres. Solamente, se presenta un pico de $4,5 \mathrm{~m} / \mathrm{s}$ en el mes de abril para la ciudad de Barranquilla, lo cual se le podría asociar a la influencia de alguna tormenta tropical que pudo golpear la costa norte colombiana para la fecha. Adicionalmente, se observan vientos muy estables y constantes a lo largo del año con pocos picos en los puntos ubicados en la ciudad de Santa Marta y Guajira, durante marzo y junio con velocidades de $3 \mathrm{~m} / \mathrm{s}$ y 2,8 $\mathrm{m} / \mathrm{s}$ respectivamente.

\section{CONCLUSIONES}

Para el desarrollo de los mapas parciales de radiación solar, se utilizaron datos de pocas estaciones de medición ubicadas en la costa Caribe colombiana, por lo que se espera mejorar dichos mapas con la aplicación de un modelo que permita utilizar la base de datos de brillo solar existente, la cual contiene información aproximada de 5 a 25 años de antigüedad, y se encuentran en estudio en el proyecto de evaluación del potencial eólico y solar en la región caribe colombiana, con el apoyo de la UPME, IDEAM y Colciencias. Además el uso de las herramientas de tecnología de SIG permitió generar los mapas de brillo y radiación global que deberán ser mejorados con el cálculo de las constantes del modelo de Angstrom con todas las estaciones que hoy en día cuenta con mediciones de luz solar únicamente, utilizando el método de interpolación IDW en el software SIG ArcGis.

Respecto al potencial solar es posible concluir que la costa norte colombiana goza del privilegio de tener altos valores de brillo solar a lo largo del año. La zona costera que presenta mayor brillo solar durante el año es la guajira como se puede observar en la figura 1(a), con valores de hasta 240 horas al mes, lo cual se mantiene en las zonas más al norte del país y a medida que nos vamos alejando va bajando el brillo solar en los departamentos de Valledupar, Cesar y parte del Magdalena alcanzado valores entre las 229 y 207 hr/mes. En zonas como Barranquilla, Bolívar y la parte sur del Magdalena se puede observar valores menores de brillo solar entre las 207 y $195 \mathrm{hr} / \mathrm{mes}$. Mientras que en los departamentos de Montería, Sincelejo y Sucre el brillo solar no supera las $184 \mathrm{hr} / \mathrm{mes}$, por lo que la costa norte en el sector de la Guajira presenta los mayores valores de brillo solar de toda la región Caribe. El recurso solar es uno de los que muestra mayor potencial en el tema de las FNCE, la costa caribe cuenta con excelente fuente de este recurso, los departamentos de la Guajira y Atlántico muestran los mejores valores de radiación solar global con valores de hasta $6.015 \mathrm{~W} / \mathrm{m} 2$. Buena parte de los departamentos del Cesar, Magdalena y parte de Bolívar muestran también buenos valores de dicho recurso con estimados de hasta $5.259 \mathrm{~W} / \mathrm{m} 2$, que podrían ser aprovechados de buena manera para la generación de energía alternativa en pro de la sostenibilidad del medio ambiente en nuestro país. Los departamentos de Montería y Córdoba son los que tienen menores valores de radiación solar de máximo $4.502 \mathrm{~W} / \mathrm{m} 2$, pero no son descartables para el aprovechamiento del recurso en dichos departamentos.

Respecto al potencial eólico se concluye que para la ciudad de Barranquilla los vientos se encuentran claramente marcados hacia el este. Con respecto al año 2012 observamos que las velocidades de estos años son menores siendo en el 2011 3,1 m/s la máxima velocidad, exceptuando el pico 
de 4,5m/s del mes de abril en Barranquilla, y en el 2012 una máxima de 4,6 m/s. Observando una diferencia significativa de las velocidades de viento del 2011 al 2012, y un aumento de la variabilidad entre cada punto de las 3 ciudades comparadas.

\section{AGRADECIMIENTOS}

Los autores agradecen la importante gestión, discusión de ideas y cesión del equipo de trabajo de la UPME e IDEAM como entidades nacionales encargadas del planeamiento energético y de la mediación de variables ambientales. Al mismo tiempo, por el apoyo económico de Colciencias como entidad que busca brindar soluciones innovadoras desde la ciencia y la tecnología a las necesidades básicas de las comunidades. Adicionalmente, agradecemos el apoyo recibido del grupo de investigación en Gestión Eficiente De La Energía KAÎ, de la Universidad del Atlántico.

\section{REFERENCIAS}

[1] H. Rodríguez y F. González. Manual de Radiación Solar en Colombia - Vol. I. Bogotá: Universidad Nacional de Colombia, 1992.

[2] Investigación Científica RO Ltda. Evaluación de sistemas solares de calentamiento de agua. Bogotá: INEA (Instituto de Ciencias Nucleares y Energías Alternativas), 1996, pp.50-53.

[3] Fundación PESENCA. Evaluación de sistemas fotovoltaicos en Colombia. Bogotá: INEA (Instituto de Ciencias Nucleares y Energías Alternativas), 1995, pp. 35, 85-94.

[4] CORPOEMA, CONSORCIO ENERGÉTICO. FORMULACIÓN DE UN PLAN DE DESARROLLO PARA LAS FUENTES NO CONVENCIONALES DE ENERGÍA EN COLOMBIA (PDFNCE). Bogotá: s.n., 2010.
[5] reve. evwind. [En línea] 4 de octubre de 2009. http:// www.evwind.com/2009/10/04/la-energia-eolica-en-colombia-40-megavatios-eolicos-instalados-y-un-potencial-desaprovechado-y-poco-estudiado/.

[6] Climatología. Centro de Investigaciones Oceanográficas e Hidrográficas - C I O H. Climatología [en línea]. Actualizada: 2013. [Fecha de consulta: 07 agosto 2014]. Disponible en: http://www.cioh.org.co/meteorologia/Climatologia/ClimatologiaCaribe2.php.

[7] Regulación Sector Eléctrico (2013). Grupo de trabajo CIER 08 "Regulación del Sector Eléctrico". Climatología [en línea]. Actualizada: 2012. [Fecha de consulta: 07 agosto 2014]. Disponible en: https://sites.google.com/site/regulacionsectorelectrico/colombia Informe Operacional de XM $-2011$.

[8] T. Munner, S. Younes, and S. Munawwar, "Discourses on solar radiation modelin", Renewablw and Sustainable Energu Reviews, vol. 11, no. 4, pp. 551-602, 2007.

[9] T. Munner, S. Younes, and S. Munawwar, "Discourses on solar radiation modelin", Renewablw and Sustainable Energu Reviews, vol. 11, no. 4, pp. 551-602, 2007.View at Publisher.

[10] A. Angstrom, “Solar and terrestrial radiation”, Quaterly Journal of the Royal Meteorological Society, vol. 50, no. 210, pp. 121-126, 1924.

[11] J.K. Page, "The estimation of monthly mean values of daily total short wave radiation onvertical and inclined surfaces from sun shine records for latitudes 400 N-400 S", in Proceeding of the United Nations Conference on New Sources of Energy, vol. 98, no. 4, pp 378-390, 1961.

[12] J. A. Prescott, "Evaporation from water surface in relation to solar radiation", Transactions of the Royal Society of south Australia, vol. 64, pp. 114- 118, 1940. 


\title{
CELDAS DE COMBUSTIBLE MICROBIANAS: DESARROLLO, APLICACIONES Y MEDIO AMBIENTE
}

\author{
Carlos Fernando Hernández Prada ${ }^{1,2}$ \\ Francisco José Román Campos ${ }^{1}$ \\ Néstor Ariel Algecira Enciso ${ }^{1}$ \\ ${ }^{1}$ Universidad Nacional de Colombia \\ ${ }^{2}$ cfhernandezp@unal.edu.co
}

\begin{abstract}
RESUMEN
Las tecnologías electroquímicas microbianas han tenido un acelerado desarrollo durante la última década. Dentro de estas tecnologías, las celdas de combustible microbianas se caracterizan por abordar dos problemáticas de interés general: el tratamiento de residuos y la generación de energía eléctrica. Su funcionamiento se basa en la oxidación de materia orgánica en un ambiente anaerobio gracias a la acción de microorganismos. Estos, a su vez, actúan como catalizadores formando una biopelícula en un electrodo (ánodo) aceptor de electrones. Simultáneamente, una especie (por ejemplo oxígeno) es reducida en un ambiente aerobio que se comunica a través de una membrana de intercambio de protones con la cámara anaerobia. Estos microorganismos tienen la característica de liberar electrones e iones positivos de hidrógeno al degradar la materia orgánica. Los electrones que fluyen por un circuito eléctrico externo, se recombinan con el oxígeno y los iones positivos de hidrógeno que llegan al medio aerobio, para formar agua. Este trabajo presenta los principales desarrollos de esta tecnología en cuanto a materiales usados, tipos de sustratos, configuraciones, características eléctricas y distintos microorganismos empleados. También, muestra algunos resultados experimentales realizados por los autores. El uso de materiales más catalíticos, un mejor entendimiento de los procesos de transferencia de electrones en la célula microbiana y el mejoramiento genético de estos microorganismos permitirán en un futuro que esta tecnología pueda ser empleada por ejemplo, en el autoabastecimiento energético de plantas de tratamiento de aguas residuales.
\end{abstract}

Palabras claves: Celdas de combustible microbianas, energía eléctrica, tratamiento de residuos, biopelícula. 


\section{INTRODUCCIÓN}

Uno de los retos más importantes que la humanidad afronta es el tratamiento de aguas residuales y la generación de energía eléctrica de forma sostenible. Las proyecciones muestran que la humanidad pasará de 7 billones de habitantes a 9.2 billones en el año 2050 (Theis \& Tomkin, 2012). Esto implica que el consumo de agua potable y energía eléctrica crecerá de forma significativa en los próximos años. Las aguas residuales domésticas contienen un alto contenido de materia orgánica (biomasa) y, por lo tanto, un alto potencial energético que, de acuerdo con Logan ( 2008), al ser transformadas en energía eléctrica permitirían alimentar 1700 casas en un pueblo pequeño.

Las celdas de combustible microbianas son dispositivos bioelectroquímicos que utilizan la materia orgánica como combustible, y mediante la acción de biocatalizadores (cierto tipo de bacterias) transforman su energía química en energía eléctrica. Los productos generados en este proceso son primordialmente agua y energía eléctrica.

\section{DESARROLLO Y APLICACIONES}

En el año 1911 Potter (1911) estudió los efectos eléctricos de la fermentación bajo la influencia de algunas levaduras como la Saccharomyces o bacterias como la Escherichia Coli. Esta es considerada como la primera publicación sobre esta tecnología. Sin embargo, el estudio sobre las Celdas de Combustible Microbianas (MFCs) comienza a interesar a la comunidad de expertos hasta principios de los 90s. En 1986, Lovley estudia la disponibilidad de óxido de hierro y su reducción por medios microbianos en sedimentos de agua dulce en el rio Potomac (Lovley \& Phillips, 1986). Al siguiente año, el mismo autor identifica y aísla una bacteria capaz de degradar materia orgánica y utilizar óxidos de hierro u otros metales como aceptores de electrones. Sin embargo, hasta el año 1993 es propuesto el nombre de Geobacter metallireducens para este tipo de bacterias (Lovley et al., 1993), convirtiéndose en una de las cepas bacterianas más investigadas en la tecnología de las MFCs. Estos microorganismos conocidos como exoelectrógenos (exo, por exocelular y electrógenos debido a su habilidad de transferir directamente electrones a un reactivo químico o material) también se han encontrado en sedimentos marinos, en el suelo y en aguas residuales. Dentro de estos, se destacan: Shewanella Putrefaciens, Geobacter Metallireducens, Pseudomonas Aeruginosa y algunas fermentativas como Clostridium Butyricum reportada por Park et al., (2001).

La función principal de este tipo de bacterias es formar una biopelícula microbiana que actue como catalizador en el ánodo para facilitar la transferencia de electrones hacia dicho electrodo. Se han encontrado cuatro formas de transferencia de electrones (Lovley, 2012) de acuerdo al tipo de bacteria; la pimera de ellas, la trasferencia de electrones utilizando mediadores o reactivos químicos que faci- litan el transporte de los electrones desde la pared celular hacia el electrodo; la segunda, la transferencia por medio de mediadores autogenerados por las bacterias; la tercera, la transferencia por contacto directo entre la pared celular de la bacteria (gracias a proteínas del tipo Citocromo C) y el electrodo; y la última,la transferencia de electrones por medio de ciertas estructuras o vellosidades conductoras denominadas pilis, que ciertas bacterias presentan como en el caso de Shewanella Oneidensis (Gorby et al., 2006).

De acuerdo a lo anterior una celda de combustible microbiana puede ser considerada como un bioreactor anaerobio (cámara anódica). El proceso biológico estaría unido por medio de una membrana de intercambio de protones con una cámara aerobia (cámara catódica). En conjunto, se tienen dos semireacciones electroquímicas combinadas con un proceso biológico. En la cámara anaerobia se presenta un proceso de oxidación de materia orgánica por medio biológico en donde electrones son transferidos del microorganismo al ánodo o electrodo negativo. En la cámara aerobia se presenta un proceso de reducción del oxígeno a agua. La diferencia de potencial de una MFC se define como la diferencia entre el potencial del cátodo menos el potencial del ánodo. Para calcular dicho potencial es necesario conocer o medir los potenciales estándares de reducción de las especies activas. Estos potenciales de media celda suelen medirse con respecto a un electrodo de referencia como el electrodo estándar de hidrógeno o el electrodo de plata/cloruro de plata. Los valores típicos medidos del potencial de circuito abierto en MFCs se encuentran entre $0.5 \mathrm{~V}$ y $0.8 \mathrm{~V}$.

De acuerdo a la aplicación, diferentes modelos o configuraciones de MFCs han sido implementados. En la figura 1 se aprecian las dos configuraciones más usadas en experimentación, sin embargo, otros modelos como el de flujo ascendente, configuraciones cilíndricas y stacks han sido desarrollados (Du, Li, \& Gu,2007).

Las MFCs tienen un amplio rango de aplicación que depende en gran medida del sustrato o residuo orgánico utilizado.

A nivel de laboratorio, las fuentes de carbón más utilizadas son la glucosa y el acetato, que puede ser un producto intermedio en un proceso de fermentación. Otros sustratos que han sido usados son aguas residuales domésticas sintéticas y residuos agroindustriales (Algecira, Hernández, \& Ibáñez, 2010), aguas residuales domésticas industriales reales, celulosa, ethanol, lactato, residuos de cervecerías, residuos de la industria del chocolate, entre otros (Pant, Van Bogaert, Diels \& Vanbroekhoven, 2010). Pant et al., también presenta las respectivas densidades de corriente máximas obtenidas con cada uno de los sustratos.

Con base en lo anterior, las MFCs se presentan como una alternativa al tratamiento de residuos orgánicos con la ventaja de la conversión directa de energía química a energía eléctrica. 

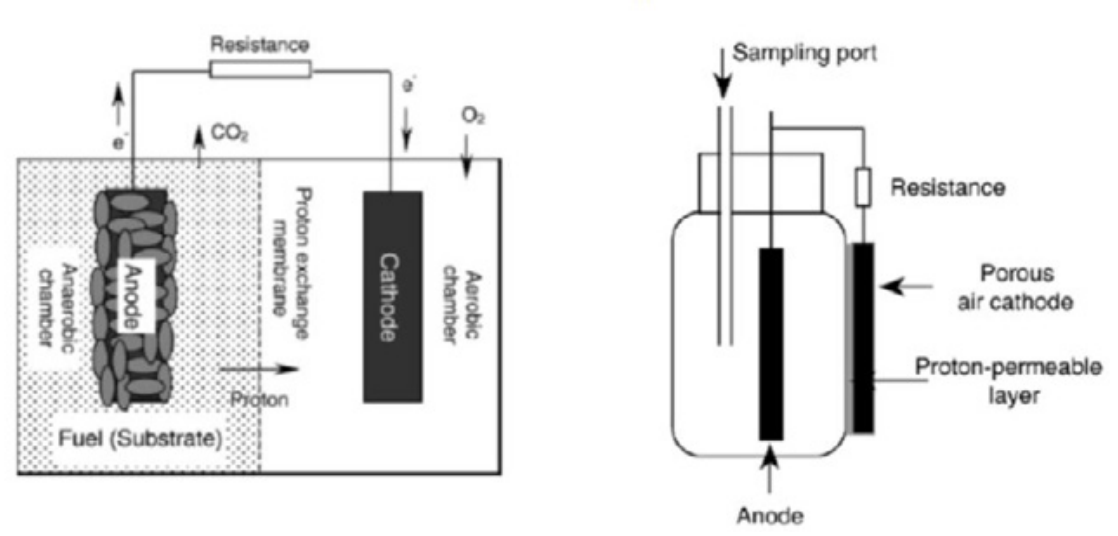

Figura 1. Configuraciones de celdas de combustible microbianas:

A. de doble cámara, B. de cámara sencilla (Du et al., 2007).

Los materiales usados en las MFCs han tenido una gran influencia en el desempeño de este tipo de celdas. Mejoras en los materiales han permitido obtener eficiencias coulómbicas (número de electrones disponibles en el sustrato convertidos en corriente eléctrica) hasta del 90\% (Cheng, Liu \& Logan, 2006). Además, han sido reportadas densidades de potencia de hasta $6.9 \mathrm{~W} / \mathrm{m} 2$ (Logan, 2009).

Los electrodos de grafito al ser porosos y tener buenas propiedades de biocompatibilidad han sido ampliamente utilizados como ánodo. Electrodos de felpa de grafito, tela de carbón, papel de carbón, carbono vítreo reticulado y cepillos de grafito también han sido reportados (Zhou, Chi, Luo, He, \& Jin, 2011). El uso de cepillos de grafito ha permitido obtener las mayores densidades de corriente debido a su elevada área efectiva de contacto, lo cual implica mayor espacio para la formación de biopelícula.

En el cátodo han sido usados los mismos materiales que en el ánodo. Sin embargo, el uso de papel de carbón con recubrimiento de platino ha reducido las pérdidas de activación del cátodo y mejorado la reducción de oxígeno a agua. Las membranas de intercambio de protones o separadores son componentes fundamentales en las MFC. La membrana más utilizada es Nafion que también ha sido usada en celdas de combustible de hidrógeno. El área de estas membranas influye en la densidad de corriente obtenida y los valores de resistencia interna de la celda.

La mayoría de las aplicaciones en esta tecnología han sido desarrolladas en laboratorio, por ejemplo en la implementación de sistemas electrónicos para el aprovechamiento de la energía generada por las celdas (Algecira \& Hernández, 2012), como fuente de alimentación para aplicaciones de muy baja potencia en iluminación, redes de sensores inalámbricos (Guzmán et al., 2010) o energización de sensores oceanográficos (Nielsen, Reimers, White, Sharma, \& Girguis, 2008). Algunos autores basados en el concepto de las bioceldas han diseñado celdas de combustible que utilizan la glucosa de la sangre como fuente de energía para la alimentación de dispositivos biomédicos (Rapoport, Kedzierski \& Sarpeshkar, 2012).

Una de las aplicaciones más recientes de las MFCs es la desalinización de agua de mar (Shehab, Amy, Logan, \& Sai- kaly, 2014). Su funcionamiento se basa en el uso de tres cámaras en lugar de dos. En la cámara anaerobia se produce la oxidación de un sustrato por medio de bacterias y la transferencia de electrones al ánodo, en la cámara aerobia ocurre el proceso de reducción de oxígeno a agua, y en una cámara intermedia dividida por dos membranas se adiciona el agua salada. La membrana ubicada hacia la cámara anaerobia es una membrana selectiva a aniones y la membrana ubicada hacia la cámara aerobia es selectiva a cationes. Debido a que esta cámara intermedia está expuesta a un campo eléctrico, los aniones fluirán hacia el ánodo y los cationes hacia el cátodo, logrando la desalinización del agua en la cámara intermedia.

Dentro de las tecnologías electroquímicas microbianas, cabe resaltar las celdas de electrólisis microbianas. En este tipo de celdas, el principal objetivo es obtener productos químicos de alto contenido energético en lugar de la transformación directa a energía eléctrica. La aplicación con mayor potencial en el momento es la producción de hidrógeno (Ditzig, Liu, \& Logan, 2007). El principio consiste en mantener el cátodo en condiciones anaerobias de tal forma que los cationes y los electrones que se recombinan en la superficie del electrodo, formen hidrógeno. Sin embargo, este proceso en la mayoría de los casos es endodérmico y por lo tanto, es necesario adicionar un potencial al ánodo que suministre la energía necesaria para establecer la reacción de interés. La ventaja, con respecto alos procesos de electrólisis de agua convencionales, es que los potenciales necesarios para establecer la reacción, en general deben ser mayores o iguales a $0.2 \mathrm{~V}$.

El interés en esta tecnología también se ha enfocado en el modelamiento de las biopelículas en el ánodo (Torres, $\mathrm{Ri}$ ttmann, \& Marcus, 2007), la influencia del pH en la reacción (Picioreanu, van Loosdrecht, Curtis, \& Scott, 2010), el comportamiento eléctrico de la celda (Hernández, Algecira, \& Rodriguez, 2013) y la producción de hidrógeno (Pinto, 2011).

De acuerdo con la herramienta bibliográfica Scopus, el número de citaciones sobre Celdas de Combustible Microbianas ha pasado de 7 en el año 1987 a 3584 en el año 2013 en distintos documentos académicos. Esto indica que esta tecnología se perfila como una fuente de energía alternativa flexible, con aplicabilidad en diversos sectores y de bajo impacto para el medio ambiente.

\section{MATERIALES Y MÉTODOS}

Este trabajo presenta los resultados iniciales de la implementación de una celda de combustible microbiana, utilizando una cepa nativa del género Clostridium facilitada por el Cepario del Instituto de Biotecnología de la Universidad Nacional de Colombia.

Se utilizó un medio tipo industrial con glucosa como la principal fuente de carbón compuesto de los siguientes re- 
activos: glucosa (50g/l), extracto de levadura (5g/l), triptona $(5 \mathrm{~g} / \mathrm{l})$, fosfato dibásico de potasio $(1 \mathrm{~g} / \mathrm{l})$ y cisteína $(0.5 \mathrm{~g} / \mathrm{l})$.

Se diseñó un prototipo en acrílico como se observa en la figura 2. La cámara anaerobia tuvo unas dimensiones de $8 \times 10 \times 9 \mathrm{~cm}$ y un volumen útil de $500 \mathrm{ml}$ y la cámara aerobia contó con unas dimensiones de 4x10x9 cm. Ambas cámaras fueron divididas por una membrana Nafion $\mathrm{N} 117$ de $30 \mathrm{~cm} 2$ como medio para el transporte de los cationes del ánodo hacia el cátodo. Se utilizó un electrodo de grafito para el ánodo de $5 \times 6 \times 0.7 \mathrm{~cm}$ y para el cátodo se utilizó tela de carbón con dimensiones de 5x10x 0.041 $\mathrm{cm}$ con un recubrimiento de platino de $0.3 \mathrm{mg} / \mathrm{cm} 2 \mathrm{como}$ principal catalizador en la reducción del oxígeno. Para los colectores de corriente se utilizó aluminio insertado en los electrodos.

Para la instrumentación del prototipo se utilizó un potenciostato para medir la tensión eléctrica de la celda, un $\mathrm{pH}$ metro, un conductímetro, un selector de resistencias para variar la carga a la salida de celda y obtener la curva de polarización, un baño termostatado y un controlador para mantener la temperatura de operación a 37 oC, un espectrofotómetro para medir la densidad óptica y evaluar el crecimiento microbiano y un computador para la adquisición de datos.
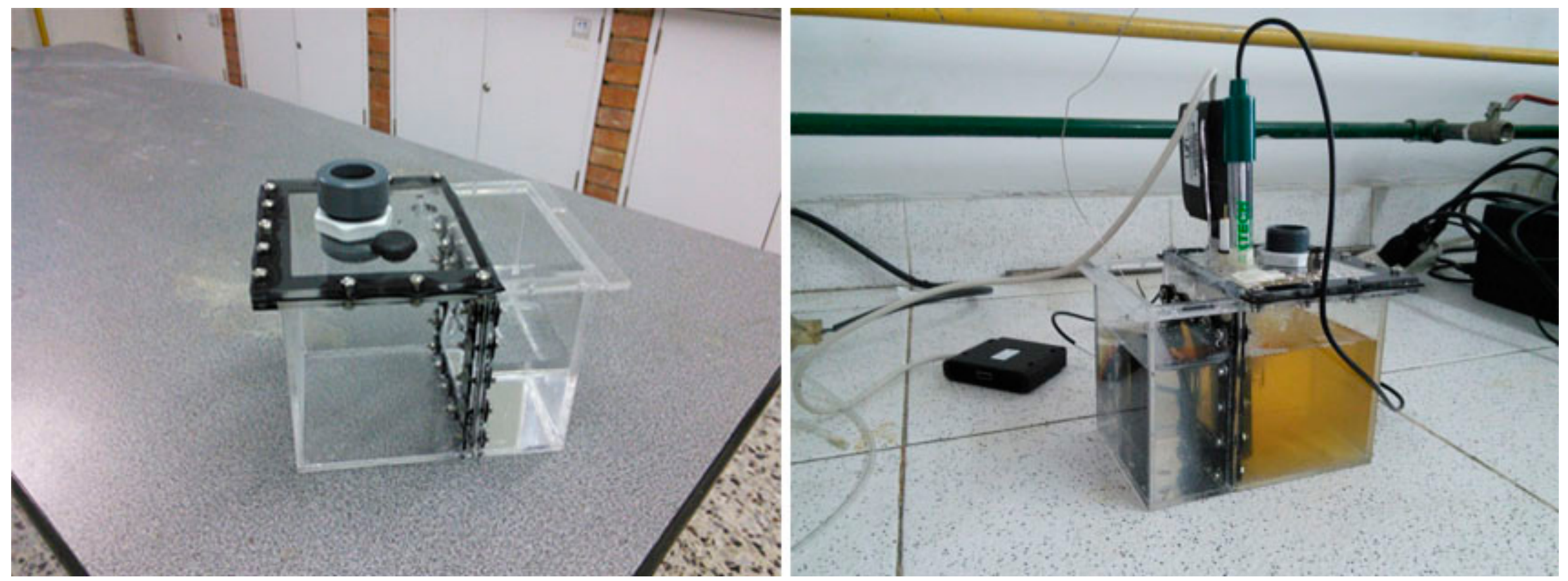

Figura 2. Prototipo de celda de combustible microbiana diseñado para el experimento izquierda, Prototipo después de la fase experimental (el medio más oscuro representa la cámara anaerobia o anódica).

El experimento se desarrolló durante 7 horas bajo condiciones controladas de temperatura. El tiempo se calculó con base en la curva de crecimiento de la bacteria para el sustrato usado. La diferencia de potencial de la celda fue medida durante todo el experimento al igual que la conductividad. El pH se midió al principio y final del experimento.

\section{RESULTADOS}

En la tabla 1 se muestran los valores de absorbancia a $600 \mathrm{~nm}$ medidos para las muestras de la cámara anaerobia. En el tiempo cero $(12: 00 \mathrm{pm})$ fue inoculado el reactor. Se observa un aumento en los valores de absorbancia con respecto al tiempo, lo cual supone un crecimiento microbiano hasta las 7:00 pm donde los valores empiezan a decrecer.

Tabla 1. Valores de absorbancia para las muestras durante el experimento

\begin{tabular}{|c|c|c|}
\hline Hora & Abs 1 & Abs 2 \\
\hline 12:00 pm & 0,224 & 0,208 \\
\hline $2: 00 \mathrm{pm}$ & 0,378 & 0,353 \\
\hline $3: 00 \mathrm{pm}$ & 0,421 & 0,419 \\
\hline $4: 00 \mathrm{pm}$ & 0,946 & 0,931 \\
\hline
\end{tabular}

\begin{tabular}{|c|c|c|}
\hline Hora & Abs 1 & Abs 2 \\
\hline 5:00 pm & 1,185 & 1,163 \\
\hline $6: 00 \mathrm{pm}$ & 1,36 & 1,368 \\
\hline $7: 00 \mathrm{pm}$ & 1,259 & 1,253 \\
\hline
\end{tabular}

Por otro lado, la tensión de salida de la celda se mantuvo entre $100 \mathrm{mV}$ y $400 \mathrm{mV}$. La corriente máxima medida fue de $335 \mathrm{uA}$ o una densidad de corriente de $5.8 \mathrm{uA} / \mathrm{cm} 2$ (con respecto al área proyectada del ánodo). La máxima potencia obtenida fue de $57.3 \mathrm{uW}$ y la resistencia interna aproximada fue de $510 \Omega$.

La conductividad del medio osciló entre $3778 \mathrm{uS} / \mathrm{cm}$ y $1220 \mathrm{uS} / \mathrm{cm}$. Algunos autores han mostrado que existe una relación directamente proporcional entre la conductividad y los sólidos totales disueltos (Atekwana, Atekwana, Rowe, Werkema \& Legall, 2004). Las variaciones observadas en la conductividad del medio el cual finalizó con $1220 \mathrm{uS} / \mathrm{cm}$ podrían interpretarse como una reducción de los sólidos totales disueltos con respecto al tiempo.

El pH inicial en la cámara anaerobia tuvo un valor de 6.9, y al final del experimento fue de 3.8. Debido a que no hubo un control de $\mathrm{pH}$ en el experimento, productos como ácido acético, lactato, formiato y el butirato reducen consi- 
derablemente el $\mathrm{pH}$ debido a la acidificación del medio. El $\mathrm{pH}$ en la cámara aerobia aumentó de 5.9 como condición inicial a 6.13. Esto muestra un leve incremento en la concentración de hidronios en la solución.

\section{CONCLUSIONES}

Las celdas de combustible microbianas son una tecnología con gran potencial en varios campos de aplicación. Para el caso colombiano, esta tecnología podría brindar beneficios en regiones aisladas del sistema eléctrico nacional. Por ejemplo, en aplicaciones de energización rural para sistemas de iluminación a bajas potencias, en la generación de productos con contenido energético como el hidrógeno o en la desalinización de agua de mar como alternativa ante la escases de agua potable en ciertas zonas del país.

Respecto al experimento realizado, no es posible concluir si hubo formación de biopelícula en el electrodo negativo de la celda. Sin embargo, la actividad microbiana y las corrientes eléctricas medidas muestran que hay una relación entre los procesos cinéticos microbianos y la producción de energía eléctrica.

De esta forma, y con el fin de entender y llegar a optimizar el proceso de producción de energía, es importante estudiar con detalle los procesos de transferencia de electrones en la bacteria utilizada en el experimento.

\section{AGRADECIMIENTOS}

Agradecemos a Colciencias por el beneficio de la beca de Joven Investigador al autor Carlos Hernández durante el desarrollo de la investigación. Igualmente, a la División de Investigación de la sede Bogotá de la Universidad nacional de Colombia por la financiación del proyecto. Al Instituto de Biotecnología de la Universidad Nacional de Colombia por todo su apoyo y asesoría. Finalmente, a la Universidad Nacional de Colombia Sede Bogotá por el respaldo, préstamo de equipos, infraestructura y apoyo académico.

\section{REFERENCIAS}

Algecira, N.A., Hernández, C.F., Ibáñez, A., (2010), Tratamiento de aguas residuales y generación simultánea de energía eléctrica mediante celdas de combustible microbianas, Memorias II Congreso Internacional de Gestión Tecnológica e Innovación, ISBN: 978-958-719-569-9, Bogotá-Colombia.

Algecira, N.A., Hernández, C.F., (2012), Tratamiento biológico de aguas residuales y generación simultánea de energía eléctrica para aplicaciones de baja potencia en iluminación mediante celdas de combustible microbianas, Memorias XI Congreso Iberoamericano de Iluminación
Luxamérica, ISBN: 978-958-46-0110-0, Cartagena-Colombia.

Algecira, N.A., Hernández, C.F., (2012), Aprovechamiento de la energía liberada en procesos biológicos de tratamiento de aguas residuales mediante celdas de combustible microbianas, Memorias 1er Congreso de Energía Sostenible, ISBN: 978-958-57711-0-9, Bogotá Colombia.

Atekwana, E. a., Atekwana, E. a., Rowe, R. S., Werkema, D. D., \& Legall, F. D. (2004). The relationship of total dissolved solids measurements to bulk electrical conductivity in an aquifer contaminated with hydrocarbon. Journal of Applied Geophysics, 56(4), 281-294. doi:10.1016/j.jappgeo.2004.08.003

Cheng, S., Liu, H., \& Logan, B. E. (2006). Increased performance of single-chamber microbial fuel cells using an improved cathode structure, 8, 489-494. doi:10.1016/j. elecom.2006.01.010

Ditzig, J., Liu, H., \& Logan, B. (2007). Production of hydrogen from domestic wastewater using a bioelectrochemically assisted microbial reactor (BEAMR). International Journal of Hydrogen Energy, 32(13), 2296-2304. doi:10.1016/j.ijhydene.2007.02.035

Du, Z., Li, H., \& Gu, T. (2007). A state of the art review on microbial fuel cells: A promising technology for wastewater treatment and bioenergy. Biotechnology advances, 25(5), 464-82. doi:10.1016/j.biotechadv.2007.05.004

Gorby, Y. A., Yanina, S., Mclean, J. S., Rosso, K. M., Moyles, D., Dohnalkova, A., Beveridge, T. J., et al. (2006). Electrically conductive bacterial nanowires produced by Shewanella oneidensis strain MR-1 and other microorganisms, 103(30).

Hernández, C.F., Algecira, N.A. \& Rodriguez, M.A., (2013), Modelling the equivalent electrical circuit of a Microbial Fuel Cell, PROCEEDINGS \& ABSTRACTS BOOK, 4th International Microbial Fuel Cell Conference, Cairns-Australia.

Guzman, J. J., Cooke, K. G., Gay, M. O., Radachowsky, S. E., Girguis, P. R., \& Chiu, M. a. (2010). Benthic Microbial Fuel Cells: Long-Term Power Sources for Wireless Marine Sensor Networks. (E. M. Carapezza, Ed.), 76662M-76662M-12. doi:10.1117/12.854896 216).

Logan, B. E. (2008). Microbial Fuel Cells. (Wiley, Ed.) (p.

Logan, B. E. (2009). Exoelectrogenic bacteria that power microbial fuel cells. Nat Rev Micro, 7(5), 375-381. Retrieved from http://dx.doi.org/10.1038/nrmicro2113

Lovley, D. R. \& Phillips E. J. (1986). Availability of Ferric Iron for Microbial Reduction in Bottom Sediments of the Freshwater Tidal Potomac River, 52(4), 751-757. 
Lovley, D. R., Giovannoni, S. J., White, D. C., Champine, J. E., Phillips, E. J. P., Gorby, Y. A., \& Goodwin, S. (1993). Geobacter metallireducens gen. nov. sp. nov., a microorganism capable of coupling the complete oxidation of organic compounds to the reduction of iron and other metals. Archives of Microbiology, 159(4), 336-344 LA - English. doi:10.1007/BF00290916

Lovley, D. R. (2012). Electromicrobiology. Annual review of microbiology, 66, 391-409. doi:10.1146/annurev-micro-092611-150104

Nielsen, M. E., Reimers, C. E., White, H. K., Sharma, S., \& Girguis, P. R. (2008). Sustainable energy from deep ocean cold seeps. Energy \& Environmental Science, 1(5), 584. doi:10.1039/b811899j

Pant, D., Van Bogaert, G., Diels, L., \& Vanbroekhoven, K. (2010). A review of the substrates used in microbial fuel cells (MFCs) for sustainable energy production. Bioresource technology, 101(6), 1533-43. doi:10.1016/j.biortech.2009.10.017

Park, H. S., Kim, B. H., Kim, H. S., Kim, H. J., Kim, G. T., Kim, M., Chang, I. S.,Park, Y. K. \& Chang, H., I, (2001). A Novel Electrochemically Active and Fe ( III ) -reducing Bacterium Phylogenetically Related to Clostridium butyricum Isolated from a Microbial Fuel Cell, 297-306. doi:10.1006/ anae.2001.0399

Picioreanu, C., van Loosdrecht, M. C. M., Curtis, T. P., \& Scott, K. (2010). Model based evaluation of the effect of $\mathrm{pH}$ and electrode geometry on microbial fuel cell performan- ce. Bioelectrochemistry (Amsterdam, Netherlands), 78(1), 8-24. doi:10.1016/j.bioelechem.2009.04.009

Pinto, R. P. (2011). Dynamic modelling and optimization of microbial fuel cells and microbial electrolysis cells, University Of Montreal, Phd Thesis.

Potter, A. M. C., Character, B., \& Sep, N. (1911). Electrical Effects Accompanying the Decomposition of Organic Compounds, 84(571), 260-276.

Rapoport, B. I., Kedzierski, J. T., \& Sarpeshkar, R. (2012). A glucose fuel cell for implantable brain-machine interfaces. PloS one, 7(6), e38436. doi:10.1371/journal.pone.0038436

Shehab, N. a., Amy, G. L., Logan, B. E., \& Saikaly, P. E. (2014). Enhanced water desalination efficiency in an air-cathode stacked microbial electrodeionization cell (SMEDIC). Journal of Membrane Science, 469, 364-370. doi:10.1016/j. memsci.2014.06.058

Theis, T., \& Tomkin, J. (2012). Sustainability : A Comprehensive Foundation (p. 600). Connexions, Rice University. Retrieved from http://www.earth.illinois.edu/sustain/ sustainability_text.html

Torres, I., Rittmann, B. E., \& Marcus, A. K. (2007). Conduction-Based Modeling of the Biofilm Anode of a Microbial Fuel Cell, 98(6), 1171-1182. doi:10.1002/bit

Zhou, M., Chi, M., Luo, J., He, H., \& Jin, T. (2011). An overview of electrode materials in microbial fuel cells. Journal of Power Sources, 196(10), 4427-4435. doi:10.1016/j. jpowsour.2011.01.012 


\title{
ENERGÍA SOLAR EN LA CIUDAD DE QUIBDÓ: EXPERIENCIA EN SISTEMAS FOTOVOLTAICOS AUTÓNOMOS DE LA UNIVERSIDAD TECNOLÓGICA DEL CHOCÓ
}

\author{
E. Banguero ${ }^{1,3}$ \\ W. Murillo ${ }^{1,4}$ \\ A.J. Aristizábal ${ }^{2,5}$ \\ ${ }^{1}$ Universidad Tecnológica del Chocó \\ ${ }^{2}$ Universidad de Bogotá Jorge Tadeo Lozano \\ ${ }^{3}$ d-edison.banguero@utch.edu.co \\ ${ }^{4}$ d-william.murillo@utch.edu.co \\ 5andresj.aristizabalc@utadeo.edu.do
}

\begin{abstract}
RESUMEN
En el año 2012 fue instalado un sistema solar fotovoltaico autónomo de 800W en el despacho de la rectoría de la Universidad Tecnológica del Chocó, en la ciudad de Quibdó. La confiabilidad de ésta planta solar ha permitido respaldar el suministro de fluido eléctrico en momentos de corte de electricidad por parte de la empresa de energía local. El sistema fotovoltaico está compuesto por un arreglo de 10 paneles solares de silicio mono-cristalino, un inversor dc/ac de $1500 \mathrm{~W}$, un regulador de carga de $20 \mathrm{~A}$ y cuatro baterías de $255 \mathrm{Ah}$.

Se describe el proceso de dimensionamiento de la planta solar mencionada; así como el análisis de las variables meteorológicas de radiación solar global, temperatura ambiente y precipitación desde el año 2007 hasta el año 2011. Se establece mediante los datos analizados, una amplitud mensual del brillo solar de $3.5 \mathrm{~h} /$ día; una media de temperatura de $28^{\circ} \mathrm{C}$ y un máximo de hasta $153 \mathrm{~mm}$ de precipitación al día.

A pesar que el departamento del Chocó, está considerado la segunda parte más lluviosa en el mundo, se demuestra con este piloto y otros que se encuentran instalados en la región, que las energías renovables se pueden convertir en un generador de desarrollo y mejora de la calidad de vida de nuestros habitantes.
\end{abstract}

Palabras claves: Energía solar, radiación solar, temperatura, sistema fotovoltaico. 


\section{INTRODUCCIÓN}

La energía solar fotovoltaica (FV) es única dentro de las diversas tecnologías de generación de electricidad. No requiere consumo de combustible y a menudo no involucra partes móviles, genera electricidad libre de emisiones con costos de operación y mantenimiento relativamente bajos; aún en lugares remotos. Adicionalmente, la energía FV es altamente modular y escalable, con rangos de instalación desde a escala de potencia de luces de jardín hasta a escala de potencia del orden de los megavatios de grandes centrales de electricidad [1].

Los sistemas de energía eléctrica han experimentado dramáticos cambios en los últimos 20 años. Las variaciones sobre la principal fuente de energía mundial - el petróleo causó efectos severos tanto para países importadores como exportadores de petróleo incluyendo los países del GCC (Gulf Cooperative Council) [2]. Como resultado, existe una gran oportunidad para desarrollar nuevas tecnologías energéticas. Adicionalmente, existe el hecho de que el petróleo tiene muchos más usos vitales que la combustión para extracción de energía térmica [3].

Los problemas medio ambientales asociados con la quema de combustibles y el suministro a largo término, especialmente de petróleo y gas; crean el escenario para hacer de la economía de la energía renovable un aspecto deseable y necesario. Es claro que la cantidad de dióxido de carbono en la atmósfera está incrementando y los cambios en el clima, tanto a nivel regional como local son claramente medibles [4].

\section{MATERIALES Y MÉTODOS}

Para llevar a cabo el dimensionamiento del sistema fv autónomo, debemos conocer el consumo medio de energía diario, representado por la siguiente expresión:

$$
L_{m d}=\frac{L_{m d, D C}+\frac{L_{m d, A C}}{\eta_{i n v}}}{\eta_{\text {bat }} * \eta_{c o n}}
$$

Siendo (Lmd) el consumo medio de energía diario, (Lmd,DC) el consumo medio de energía diario de las cargas en continua y (Lmd,AC) el de las cargas en alterna. El consumo total anual (LT) es:

\section{$\mathrm{LT}=\mathrm{Lmd} * 365$ días}

$\mathrm{LT}=\mathrm{Lmd} * 365$ días Cálculo del número total de módulos necesarios:
Dónde:

$$
N_{T}=\frac{L_{\text {mdcrit }}}{P_{M P P} * H P S_{\text {crit }} * P R}
$$

Lmdcrit el consumo medio diario mensual para el mes crítico.

PMPP la potencia pico del módulo en condiciones estándar de medida. HPScrit son las horas de sol pico del mes crítico.

PR el factor global de funcionamiento que varía entre 0.65 y 0.90 . Usaremos 0.90 por defecto. La conexión de los módulos calculados en serie o paralelo es:

$$
\begin{gathered}
N_{\text {serie }}=\frac{V_{\text {bat }}}{V_{M O D, M P P}} \\
N_{\text {paralelo }}=\frac{N_{T}}{N_{\text {serie }}}
\end{gathered}
$$

El consumo de energía medio en Ah/día es:

$$
Q_{A h}=\frac{L_{m d}}{V_{B A T}}
$$

La corriente que debe generar el campo de captación fotovoltaico es:

$$
I_{G F V, M P P}=\frac{Q_{A h}}{H P S_{c r i t}}
$$

Por su parte, la capacidad nominal de la batería en función de la descarga máxima diaria (Cnd) se calcula como:

$$
\begin{aligned}
& C_{n d}(W h)=\frac{L_{m d}}{P_{D \max , d} * F_{C T}} \\
& C_{n d}(A h)=\frac{C_{n d}(W h)}{V_{B A T}}
\end{aligned}
$$

La capacidad nominal de la batería en función de la descarga máxima estacional (Cne):

$$
C_{n e}(W h)=\frac{L_{m d} * N}{P_{D \max , e} * F_{C T}}
$$

$$
C_{n e}(A h)=\frac{C_{n e}(W h)}{V_{B A T}}
$$


La profundidad de descarga máxima estacional (PD$\max , \mathrm{e})=70 \%=0,7$.

La profundidad de descarga máxima diaria (PDmax,d) $=15 \%=0,15$ El número de días de autonomía $(\mathrm{N})=3$

Para el cálculo de la corriente de entrada al regulador, usaremos:

$$
I_{\text {entrada }}=1.25 * I_{M O D, S C} * N_{P}
$$

Acá, (IMOD,SC) es la corriente unitaria del módulo fotovoltaico en condiciones de cortocircuito.

(NP) el número de ramas en paralelo.

1,25 es un factor de seguridad para evitar daños ocasionales al regulador. Para el cálculo de la corriente de salida, tenemos:

$$
I_{\text {salida }}=\frac{1.25 *\left(P_{D C}+\frac{P_{A C}}{\eta_{i n v}}\right)}{V_{B A T}}
$$

Siendo,

(PDC), potencia de las cargas en continua. (PAC), potencia de las cargas en alterna.

(ninv), rendimiento del inversor, en torno a $90-95 \%$. Cálculo del inversor:

$$
P_{\text {inv }}=1.2 * P_{A C}
$$

\section{RESULTADOS}

\section{Radiación solar horaria}

Las horas de mayor radiación solar en Quibdó se dan entre las 11:00 HL y las 15:00 HL, con una media de 550 W/ $\mathrm{m} 2$, presentándose su mayor pico a la 13:00 HL hora local, con una media de $650 \mathrm{~W} / \mathrm{m} 2$ (ver figura 1 ).

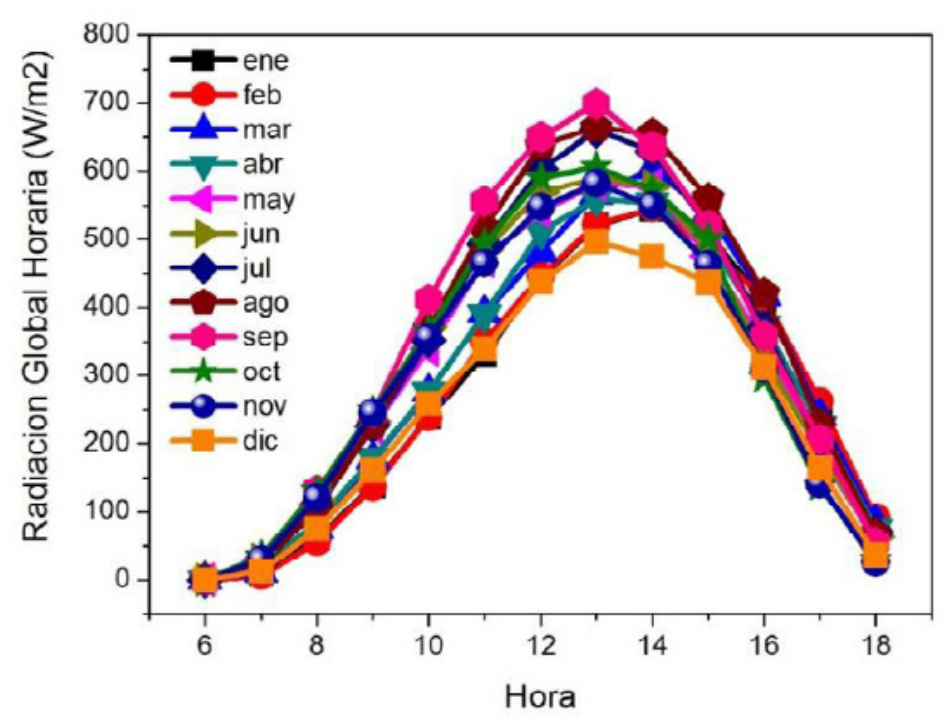

Figura 1. Radiación Solar Global Horaria, municipio de Quibdó - Chocó.

\section{Radiación solar global mensual}

Para la obtención de estos datos se utilizó un piranómetro Epply modelo PSP. De acuerdo con la gráfica 2, la media para media de radiación global, para el municipio de Quibdó es de $3700 \mathrm{~W} / \mathrm{m} 2$. Siendo Julio, Agosto y Septiembre, los meses que registran una mayor radiación solar, con una media de $4300 \mathrm{w} / \mathrm{m} 2$, mientras que el mes de Diciembre, registra una media de $3000 \mathrm{w} / \mathrm{m} 2$.

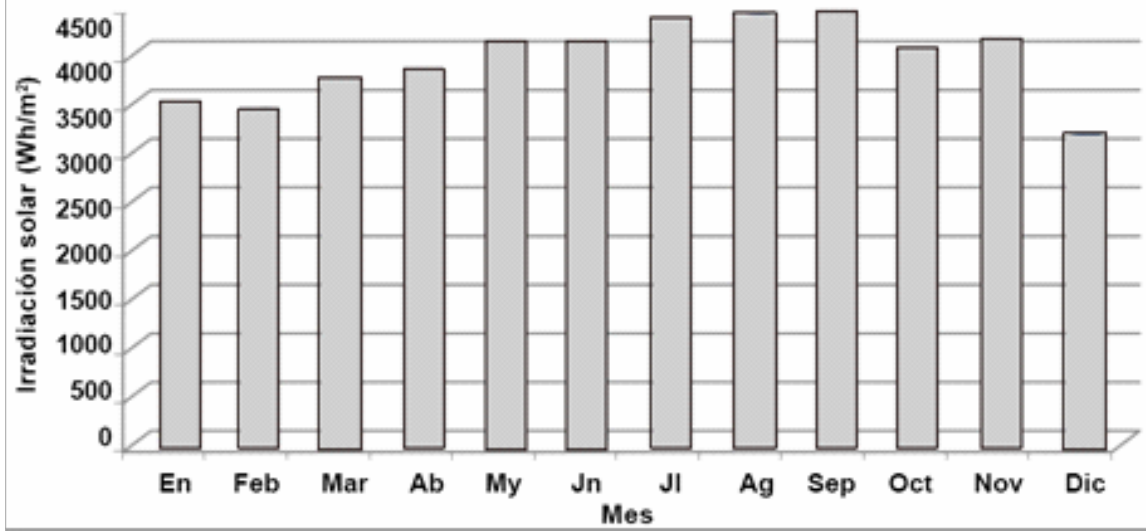

Figura 2. Media de la Radiación Solar Global, en el municipio de Quibdó - Chocó.

\section{Brillo Solar}

El heliógrafo Campbell-Stokes es una esfera de cristal, la cual hace las veces de lente, permitiendo que los rayos solares se concentren en un solo punto, quemando así una cinta que está químicamente preparada. Este instrumento, permite medir las horas de brillo solar presentes en el día. [5]. La quemadura de la banda ocurre cuando la irradiación solar directa supera un límite variable de 120 a $210 \mathrm{~W} / \mathrm{m} 2$ (WMO, 1992)

En la región pacífica, el comportamiento del brillo solar, se ve influenciado por el alto régimen de nubosidad y precipitación [6]. La media mensual de brillo solar para la ciudad de Quibdó es de 3.5 horas sol (figura 3), siendo Julio y Agosto, los meses en que se registra una mayor radiación, mientras que Febrero y Marzo, son los meses de menor radiación solar, coincidiendo esto con los estudios realizados por Eslavas [7].

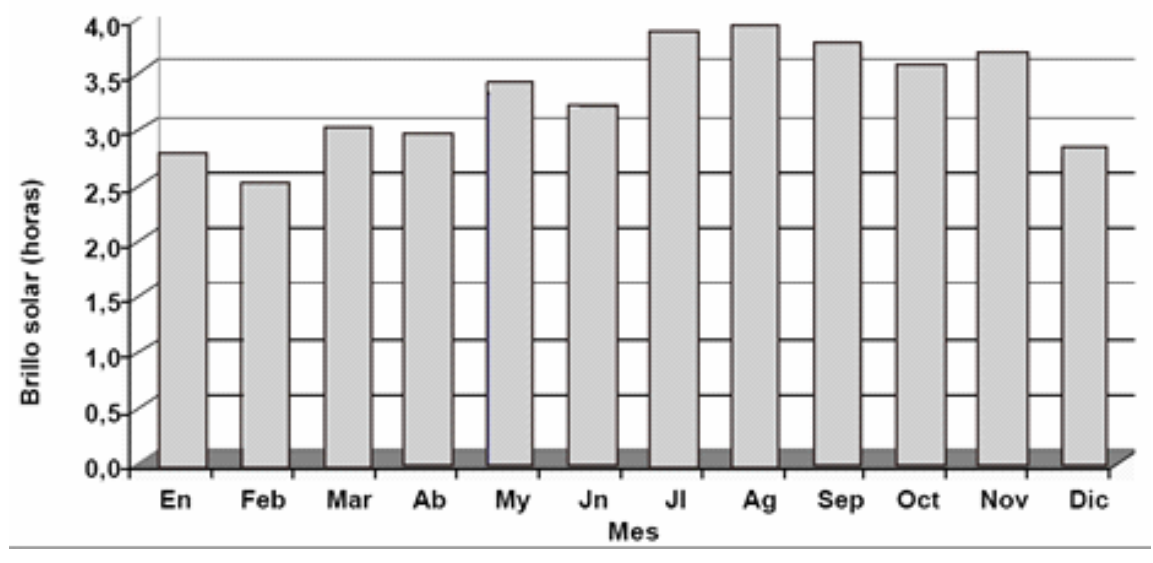

Figura 3. Horas de Brillo Solar en el municipio de Quibdó - Chocó. 
De otro lado, en cuanto a los valores acumulados mensuales, se confirma que el brillo solar en la ciudad de Quibdó, es de baja incidencia por estar por debajo de las $200 \mathrm{~h} /$ día, confirmando lo expresado por Bernal 1986.

\section{Temperatura}

La medida de los datos de temperatura es tomada con un higrómetro marca Vaisala modelo P45C conectado a un sistema de adquisición de datos tipo datalogger.
El máximo horario de temperatura se registra a las 15:00 HL (Hora Local), mientras que el mínimo valor se registra alrededor de las 6:30 HL. Observando la media mensual de la temperatura, se encuentra que los meses más calurosos se dan entre Enero y Mayo $\left(28.78{ }^{\circ} \mathrm{C}-29 \mathrm{oC}\right)$, mientras que los menos calurosos son Noviembre y Diciembre con una media 26.85 oC y 23.87 oC respectivamente. Por lo tanto se registra para la ciudad de Quibdó una media de $28^{\circ} \mathrm{C}$, (ver figura 4).

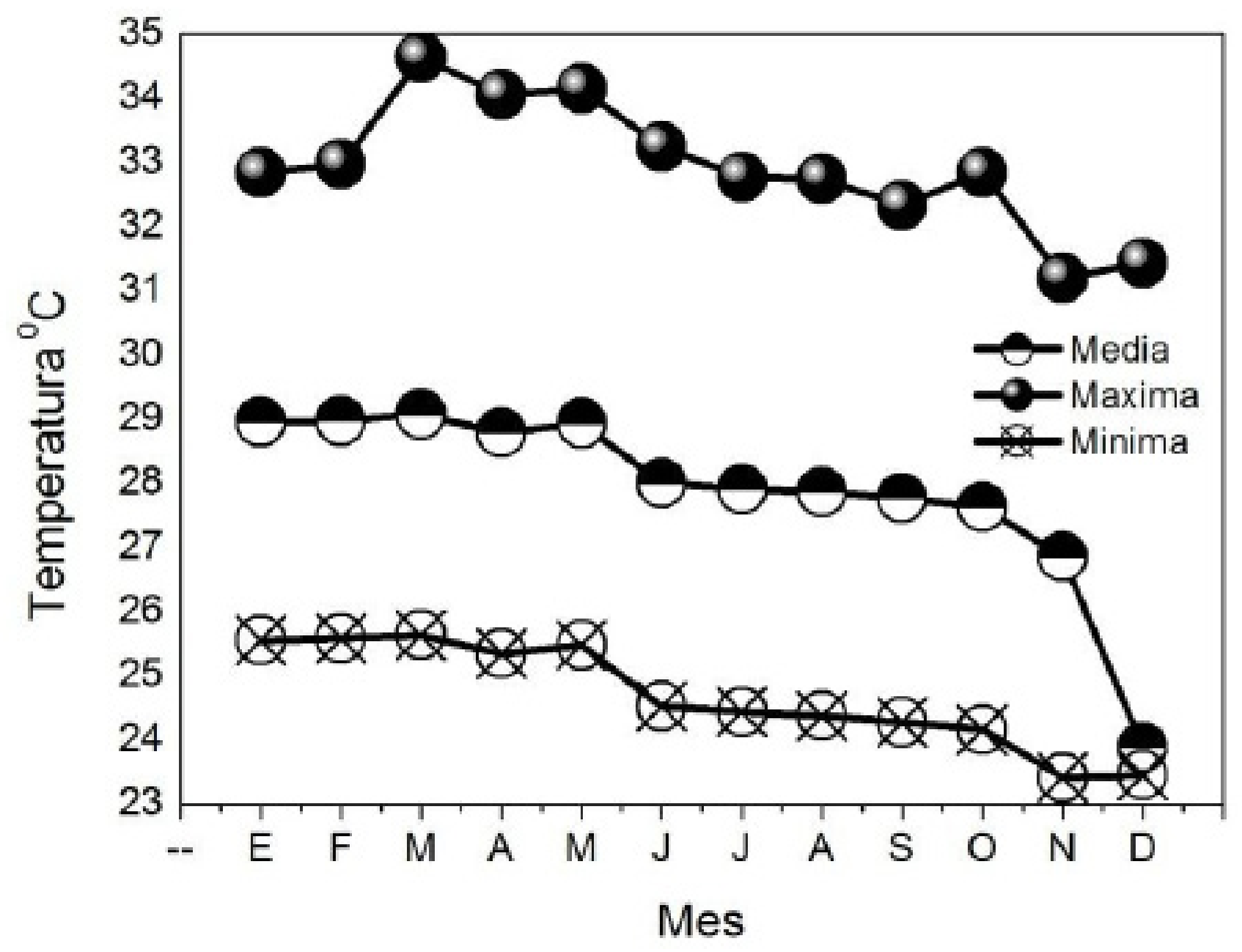

Figura 4. Temperatura media, máxima y mínima, en el municipio de Quibdó - Chocó.

\section{Precipitación}

La precipitación es registrada por un pluviómetro electrónico de balancín CS700-L; el cual suministra un pulso equivalente a $0,254 \mathrm{~mm}$ de lluvia que es almacenada en un sistema automático de adquisición de datos (DATA LOGGER). Las altas precipitaciones que se registran en la ciudad de Quibdó son del orden de los $8050.3 \mathrm{~mm}$ al año, lo que es equivalente 8050.3 litros de agua en un metro cuadrado.
$\mathrm{Al}$ analizar el comportamiento del ciclo diario de la precipitación utilizando los promedios horarios, se confirma que las precipitaciones más fuertes en la región se presentan al finalizar la tarde y en horas de la noche y la madrugada, (figura 5). Además, se puede apreciar un comportamiento bimodal con lluvias máximas entre las 01:00 HL y las 05:00 HL (hora local) y entre las 18:00 y las 22:00 HL, siendo el segundo máximo el de mayor amplitud y el que presenta las mayores cantidades de lluvia. Las lluvias son poco abundantes entre las 10:00 y las 16:00 HL. 

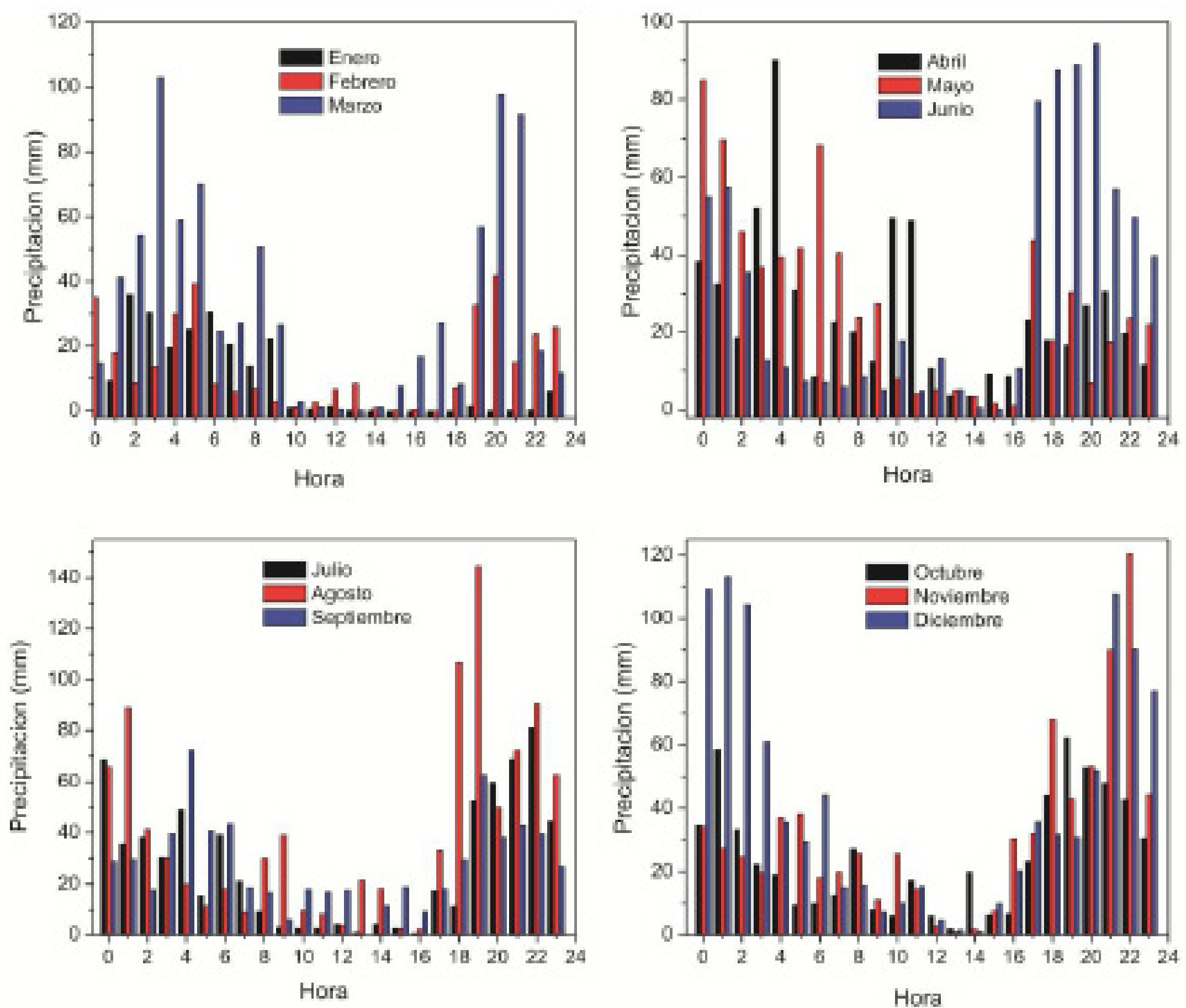

Figura 5. Ciclo horario de la precipitación en el municipio de Quibdó - Chocó.

Los valores medios de precipitación máxima acumulada oscilan entre 40 y $160 \mathrm{~mm} / \mathrm{h}$ (aunque las máximas absolutas pueden alcanzar los $253 \mathrm{~mm} / \mathrm{h}$ ); y los promedios de precipitación mínima acumulada oscilan alrededor de los 0,70 y 7,87 mm. Así, la amplitud del ciclo diario de la precipitación promedio acumulada en Quibdó es de 152 mm.

\section{Sistema Fotovoltaico Autónomo}

El cálculo de la demanda energética de los equipos se presenta en la tabla 1.

\begin{tabular}{|l|c|c|c|c|}
\hline $\begin{array}{c}\text { Descripción del } \\
\text { equipo }\end{array}$ & $\begin{array}{c}\mathbf{N}^{\mathbf{0}} \text { de } \\
\text { equipos }\end{array}$ & $\begin{array}{c}\text { Potencia nominal } \\
(\mathbf{W})\end{array}$ & $\begin{array}{c}\text { Horas-Días } \\
\text { (h) }\end{array}$ & $\begin{array}{c}\text { Energía consumida } \\
\text { (Wh/día) }\end{array}$ \\
\hline CPU + Impresora & 2 & 230 & 3 & 1380 \\
\hline Puntos de luz & 10 & 20 & 3 & 600 \\
\hline Fax & 1 & 30 & 3 & 90 \\
\hline TOTAL & \multicolumn{3}{|r|}{} \\
\hline
\end{tabular}

Tabla 1. Consumo energético de los equipos que representan la carga.

Al consumo medio diario de la instalación se le ha aplicado un $20 \%$ como margen de seguridad recomendado. Debemos también tener en cuenta, que en la instalación habrá pérdidas por rendimiento de la batería y del inversor y esto influye en la energía necesaria final. Generalmente, para el buen dimensionamiento, tomaremos un rendimiento de la batería de un 95\%, del inversor un 90\% y de los conductores un $100 \%$. 
Teniendo en cuenta el procedimiento descrito previamente, se realizó el dimensionamiento del sistema fotovoltaico autónomo:

- Un banco de baterías (4 x $255 \mathrm{Ah}$ ) conectadas en paralelo.

- Un generador fotovoltaico (10 paneles monocristalino de $80 \mathrm{Wp}$ ) conectados en paralelo.
- Un inversor de corriente de $1500 \mathrm{~W}$.

- Un regulador de $20 \mathrm{~A}, 12 \mathrm{~V}$.

- Otros (cables dúplex - calibre 8, conectores, varillas de Copper-Weld, estructura metálica). La tensión del sistema es de $24 \mathrm{~V}$.

Las figuras 6 y 7 presentan las conexiones del generador fotovoltaico y del banco de baterias respectivamente.

BORNEFA POSITNOS

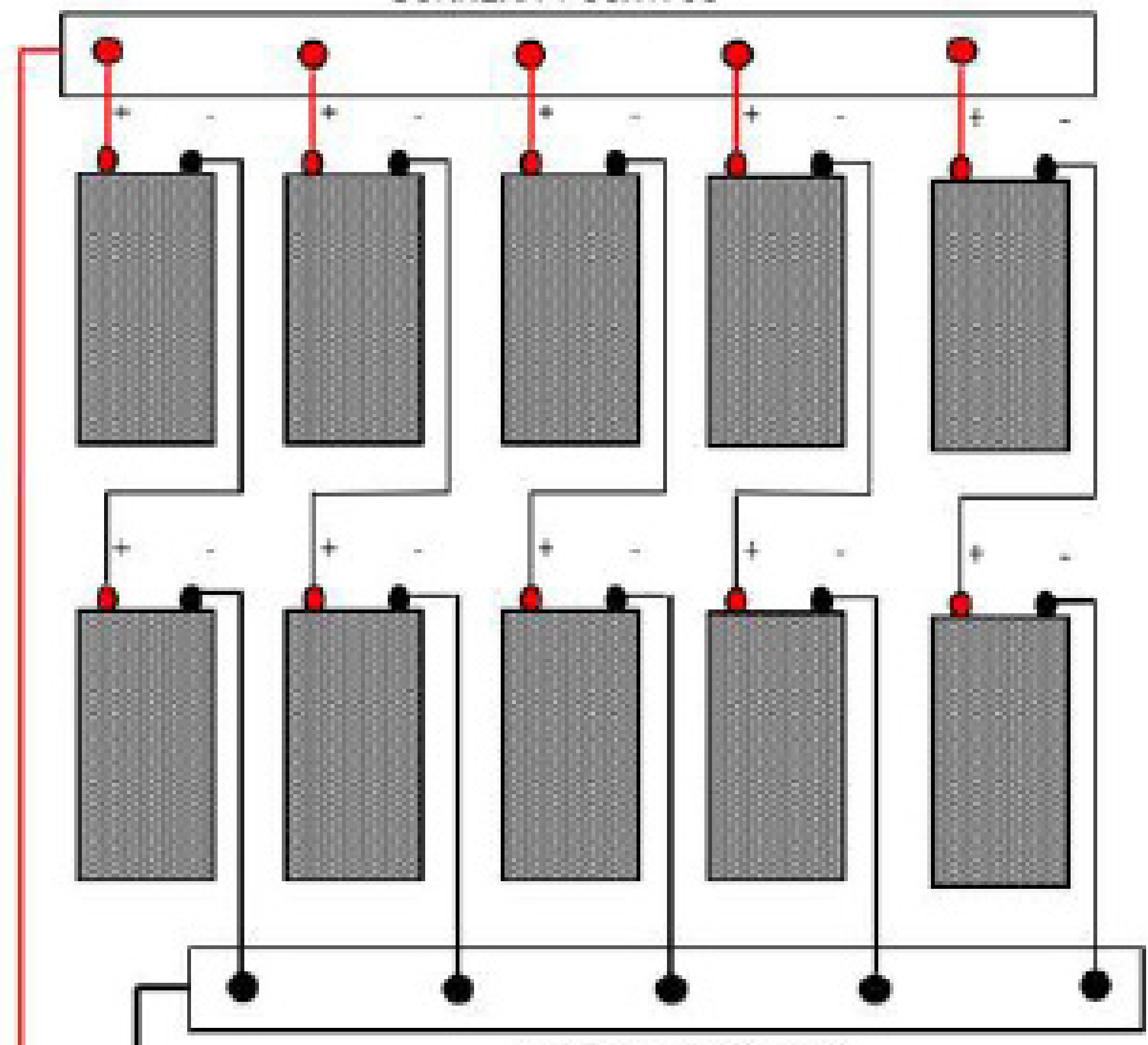

BOFNERA, NEGATMOS

HORWAA KFGATWO BATHRIA

POREFA FOETINO BATEPLS

Figura 6. Diagrama de conexiones del generador fotovoltaico. 


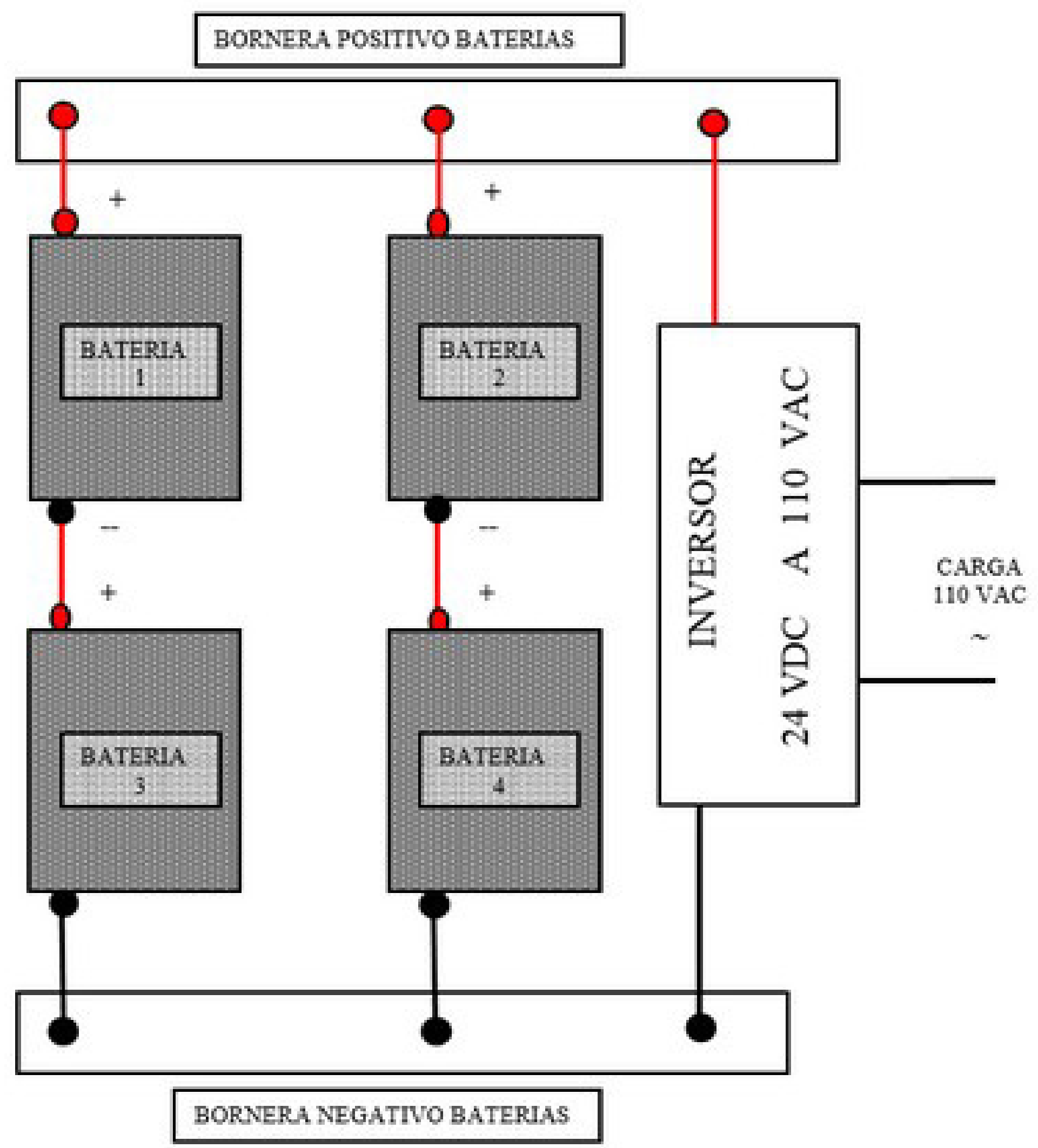

Figura 7. Diagrama de conexiones del banco de baterías.

\section{CONCLUSIONES}

Los resultados obtenidos del monitoreo de radiación, temperatura y lluvia realizado, se mostraron bastante congruentes de acuerdo a la información arrojada por otros estudios para el Pacífico Colombiano.

El sistema de medición de las variables, es eficiente, de acuerdo a los factores ambientales, el análisis de los resultados indica como la ciudad de Quibdó cuenta con periodos cortos de radiación causados por la constante lluvia y la cantidad de nubes que atraviesan diariamente el espacio entre el sol y las celdas solares, demostrando así, que la implementación de este tipo de energías limpias, pueden ser un factor de desarrollo y mejora de la calidad de vida de los habitantes del departamento del Chocó, el cual cuenta en su territorio con muchas Zonas no Interconectadas.

Se demostró la eficacia del procedimiento de dimensionamiento de sistemas fotovoltaicos presentado, gracias a que el sistema implementado; ha logrado suministrar de forma confiable, la energía eléctrica requerida por la carga; en especial durante los cortes del fluido eléctrico por parte de la empresa prestadora del servicio.

Aunque como se demostró, Quibdó tiene un alto régimen de lluvias ( $8050.3 \mathrm{~mm}$ al año) y una media de temperatura de 28 oC; el valor de horas de radiación solar calculado de 3.5 HSS es igual al registrado para la ciudad de Bogotá y representa un recurso solar aprovechable por la tecnología fotovoltaica. 


\section{REFERENCIAS}

[1] R. Ponoum, M. Rutberg, A. Bouza. Energy storage for pv power. ASHRAE Journal, Noviembre 2013.

[2] B.M.A. Mohandes, L. El-Chaar, L.A. Lamont. Application study of $500 \mathrm{~W}$ photovoltaica (pv) system in the UAE. Applied Solar Energy, 2009.

[3] B. Sorensen. Renewable Energy, its physics, engineering, environmental impacts, economics and planning. Elsevier, 2004.
[4] F. Antony, C. Durschner, K.A. Remmers. Photovoltaics for professionals, Solar Electric Systems Marketing, Design and Installations, Earthscan, 2007.

[5] LEDESMA M. 2000. Climatología y Meteorología Agrícola Paraninfo.

[6] BERNAL G. 1986. Régimen del Brillo Solar en Colombia. Ministerio de Agricultura HIMAT.

[7] ESLAVAS, J. 1994. Climatología del Pacifico Colombiano Nol Academia Colombiana de Ciencias Geofísicas. Colombia. Bogotá. 


\title{
ESTUDIO DE PRE FACTIBILIDAD PARA LA OBTENCIÓN DE BIOETANOL COMBUSTIBLE DE SEGUNDA GENERACIÓN EN EL DEPARTAMENTO DE SANTANDER
}

\author{
Quintana B. Dario ${ }^{1,2}$ \\ Castellanos Cala Edwin ${ }^{1}$ \\ Quintero Dallos Viviana ${ }^{1}$ \\ Peña Javier ${ }^{1}$
}

${ }^{1}$ Universidad Santo Tomas de Aquino - Sede Bucaramanga

²dario771010@hotmail.com

\section{RESUMEN}

El objetivo principal del presente trabajo fue el estudio de pre factibilidad para la producción de bioetanol combustible de segunda generación en el Departamento de Santander, Colombia. El estudio contemplo como actividades específicas: La selección del Bagazo de caña como materia prima residuo del proceso de extracción del jugo de la caña, teniendo en cuenta que para el año 2011 su disponibilidad en la región era de 183.001 Toneladas; como segunda etapa se llevó a cabo un estudio bibliométrico basado en fuentes secundarias para la definición del diagrama de procesamiento (pretratamiento, hidrólisis, fermentación y separación); seguido por un análisis de mercado teniendo en cuenta el comportamiento de la oferta y demanda del producto en el país; posteriormente se realizó un estudio técnico para, la síntesis de una ruta de procesamiento de acuerdo a las condiciones de la materia prima y la zona de estudio; también incluyó la capacidad instalada y utilizada, cantidad de insumos requeridos, maquinaria, equipos y descripción del proceso productivo; Finalmente una evaluación financiera, que muestra en detalle la inversión, las proyecciones de ventas, los costos e ingresos, el estado de resultados, el flujo de caja y el balance general.

Palabras claves: Bioetanol lignocelulosico, caña panelera, bagazo, ruta de proceso. 


\section{INTRODUCCIÓN}

La base para la industrialización de los países desarrollados fue el uso de forma masiva y paulatina de combustibles fósiles, que en la actualidad siguen siendo un elemento principal en los procesos de cambio económico de los países más poblados del mundo (Roca \& Fernández, 2010).

La dependencia del uso de combustibles fósiles ha generado dos tipos de preocupaciones: por un lado, los impactos ambientales asociados como las emisiones de $\mathrm{CO}_{2}$, que para el año de 2013 fueron de 36.000 millones de toneladas (Key, Kozir Sabine \& CO, 2011) y sus efectos en el cambio climático del planeta; por otro lado, existe la posibilidad de que se agoten las reservas petrolíferas, por lo cual se realizan explotaciones de yacimientos petroliferos en zonas no convencionales para satisfacer la demanda de la poblacion.

Es así como los esfuerzos a nivel mundial giran en torno a las energías renovables, que tienen como ventaja principal la disminución de la cantidad de gases contaminantes a la atmosfera. Con ello se logra una disminución de los impactos ambientales en lo que se refiere a emisiones de $\mathrm{CO}_{2}$ y se alcanza un mayor rendimiento en combustible por hectárea, en tanto es posible aprovechar la Biomasa disponible y la materia prima de alto potencial, de los residuos o desechos de las industrias y ciudades (FOCER, 2002).

Una de las estrategias planteadas a nivel mundial es la producción y uso de los denominados biocombustibles líquidos, siendo el bioetanol el biocarburante con mayor aplicación. Este combustible se obtiene de los cultivos de caña de azúcar y maíz, principalmente. Los principales productores a nivel mundial son Estados Unidos, con una producción de 52.800 Millones de litros utilizando el maíz como materia prima, y Brasil, con una producción de $24.800 \mathrm{mi}$ llones de litros para el año 2012 (García, 2012), utilizando la caña de azúcar como materia prima. Estos biocombustibles son llamados de primera generación.

Los biocombustibles están en pleno desarrollo. Cada día se está considerando la posibilidad de su uso, pues podrían sustituir momentáneamente a los combustibles fósiles, brindando una solución a los problemas anteriormente mencionados; como se ha dicho, generan un menor impacto ambiental y tienen la posibilidad de crear un ciclo energético que disminuye las emisiones de $\mathrm{CO}_{2}$ (Carlos \& Lorena, 2010).

En la actualidad, a nivel mundial se están diversificando la producción de biocombustibles, en particular el bioetanol, dado que se ha generado un debate global por la utilización de los cultivos, que tienen valor alimenticio, como fuentes energéticas. Debido a esta polemica, aparece el concepto de Biocombustibles de segunda generación, en el cual se utilizan como materias primas desechos agrícolas como lo el bagazo de la caña, que no tiene valor alimenticio y ofrece altos rendimientos. Sólo en Colombia se pueden obtener aproximadamente 31 tonelada de bagazo por 100 toneladas de caña procesada (Cenicaña, 2013). Cabe resaltar que este tipo de biocombustibles se encuentra aún en etapa de investigación y desarrollo, y que no se producen aún comercialmente.

El bioetanol, también llamado alcohol carburante, es un líquido claro, incoloro que puede ser producido por la fermentación de prácticamente cualquier fuente de azúcar o almidón, las fuentes que más se utilizan son la caña de azúcar, maíz, trigo y remolacha azucarera, esto depende de la disponibilidad de cultivos que tenga cada país. La biomasa celulósica (desechos agrícolas y desechos orgánicos) también se pueden utilizar para producir bioetanol a través de técnicas de procesamiento avanzadas, lo que se conoce como bioetanol de segunda generación.

Teniendo en cuenta lo anterior, en el presente estudio se pretende analizar la viabilidad del proceso de obtención de bioetanol de segunda generación a partir del bagazo de la caña. El estudio se llevó a cabo en la región de la Hoya del Rio Suarez en el municipio de Barbosa, ubicado en el departamento de Santander en Colombia, con un area cultivada de 8.117 héctareas.

En la primera fase de esta investigación se realizó un ejercicio de bibliometría, que tiene el fin de consolidar la información a nivel mundial concerniente a la utilización de materias primas, procesos productivos y tecnologias de procesamiento de bietanol de primera y segunda generación.

Posteriormente se realizó un estudio de Pre factibilidad, consolidando información sobre aspectos del mercado, aspectos técnicos, aspectos ambientales y legales, todo esto con el fin de desarrollar la evaluación financiera y técnica del proceso productivo escogido y realizar una discusión sobre su viabilidad.

\section{MATERIALES Y MÉTODOS}

El estudio que se plantea incluye dos etapas: la primera es la elaboración del estado del arte sobre producción de bioetanol, que incluye materias primas, tecnologías para cada etapa de procesamiento, procesos actuales en demostración, entre otros. Con el fin de medir la produccion bibliografica, se utilizarón dos herramientas de mineria de datos y bases de datos, The Vantage Point y SciVerse Scopus. La materia prima evaluada fue el Bagazo de la caña panelera, presente en al región objeto de estudio. Se trabajó con el rendimiento que pueden generar 8.117 hectareas. La ruta de producción de bioetanol escogida es la de sintesis.

En la segunda etapa se realizó un estudio de pre-factibilidad para la ruta sintetizada, en el que se detallaron aspectos de mercado, aspectos técnicos, aspectos ambientales para poder consolidar la evaluación fianaciera, teniendo en cuenta las condiciones de la región de la Hoya del Rio Sua- 
rez en el municipio de Barbosa, Departamento de Santander. El diseño de investigación para este estudio fue de tipo exploratorio, dado que se quería profundizar sobre el problema planteado, sus alternativas de decisión y las variables que se debían considerar.

\section{RESULTADOS}

\section{Análisis Bibliométrico}

La bibliometría se centra esencialmente en el cálculo y en el análisis de los valores cuantificables en la producción y en el consumo de la información científica (Ardanuy, 2012). Para el presente estudio bibliométrico se utilizaron dos herramientas para la consolidación de la información: en primer lugar, se utilizó una base de datos llamada SciVerse
Scopus, la cual nos permitió el análisis de los documentos pertenecientes al tema de búsqueda; en segundo lugar, se utilizó una herramienta de Minería de Datos llamada The Vantage Point, gracias a la cual pudimos interpretar los datos introducidos en Scopus para crear gráficas y matrices de la información bibliográfica analizada.

En un principio, se determinaron los términos de búsqueda o palabras clave para aplicar en el estudio, los cuales fueron: Bioetanol, Materias primas Bioetanol, Proceso Productivo y Bioetanol Lignocelulosico.

A continuación, la búsqueda se dirigió a la revisión de la información consignada en artículos científicos, siendo estos el principal tipo de documento. Los parámetros utilizados para clasificar la información fueron: Autor, País, Nombre de la Institución, Lenguaje, Año de Publicación.

Tabla 1. Ficha tecnica de la Investigación.

\begin{tabular}{|c|c|}
\hline ORGANIZACIÓN & UNIVERSIDAD SANTO TOMAS - BUCARAMANGA \\
\hline Objetivo & $\begin{array}{l}\text { Presentar los indicadores bibliométricos y cienciométricos de la publicación de } \\
\text { artículos de investigación sobre la producción de bioetanol, que incluye materias } \\
\text { primas, tecnologías para cada etapa de procesamiento, y procesos actuales en } \\
\text { demostración. }\end{array}$ \\
\hline Tema & Bioetanol de Primera y Segunda Generación. \\
\hline Palabras Clave: & $\begin{array}{l}\text { "Bioethanol", "Feedstock Bioethanol", "Production Process", } \\
\text { "Lignocellulosic Bioethanol". }\end{array}$ \\
\hline Período de consulta: & 2007 a 2014 \\
\hline $\begin{array}{l}\text { Herramientas } \\
\text { de consulta y } \\
\text { tratamiento de la } \\
\text { información }\end{array}$ & $\begin{array}{c}\text { Bases de datos bibliográficas } \\
\text { Scopus (Elsevier, B.V. 2013)Software especializado para minería de textos } \\
\text { VantagePoint (Versión académica 8.0, Search Technology), disponible a través de } \\
\text { la Biblioteca de la USTABUCA. }\end{array}$ \\
\hline Dirigido por: & $\begin{array}{c}\text { Viviana Quintero Dallos. } \\
\text { Director(A) } \\
\text { Docente USTA }\end{array}$ \\
\hline Realizado por: & $\begin{array}{l}\text { Darío Quintana Ballén } \\
\text { Edwin Castellanos Cala }\end{array}$ \\
\hline
\end{tabular}

\section{Tipos de Documentos}

Usando las palabras claves para Bioetanol, denotadas en la tabla 1, encontramos en la base de datos de Scopus 3.595 artículos de Investigación, en el periodo comprendido del 2007 al 2014. El tamaño de la muestra sugiere que esta área ha sido de gran importancia investigativa.

\section{Los Autores que más publicaron}

A partir de una muestra constituida por 3.595 artículos, obtenidos mediante el ejercicio bibliometrico, se definieron los 10 autores que más publicaciones han realizado sobre bioetanol. En primer lugar se encuentran Kondo y Yu ambos con 27 artículos publicados. En segundo lugar, Zacchi con 24 artículos publicados. En la gráfica 1 se presentan los autores que han escrito más de 15 articulos sobre temas relacionados.

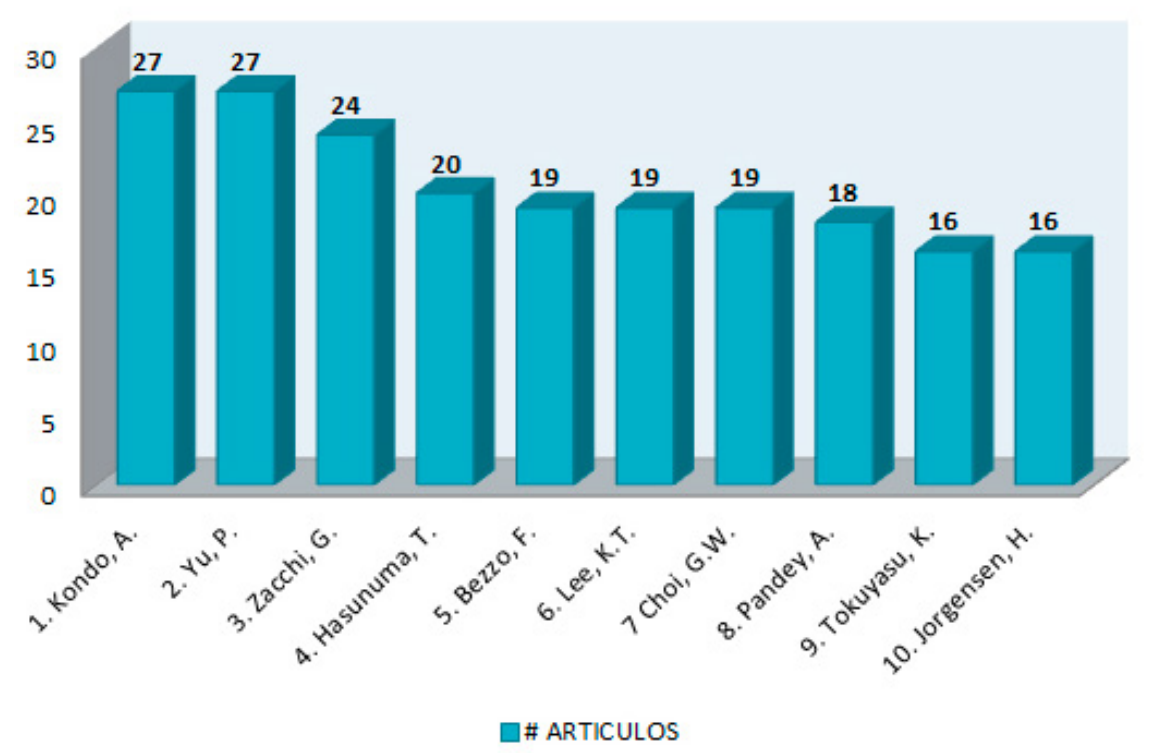

Figura 1. Autores con más publicaciones. 


\section{Países que más publicaron}

Este ejercicio se llevó a cabo para determinar los 10 países que más han contribuido con la publicación de artículos. En la grafica 2 se muestra que el país con más publicaciones de artículos fue Estados Unidos, con 473 Artículos, que corresponde al 13,1\% del total de publicaciones. Lo siguen China con 350 artículos publicados, correspondientes al 9,7\%, Japón, con 312 Artículos correspondientes al 8,6 \%, y, siendo el únicopaís suramericano en la lista, Brasil, con 252 artículos publicados correspondientes al 7\% del total de publicaciones.

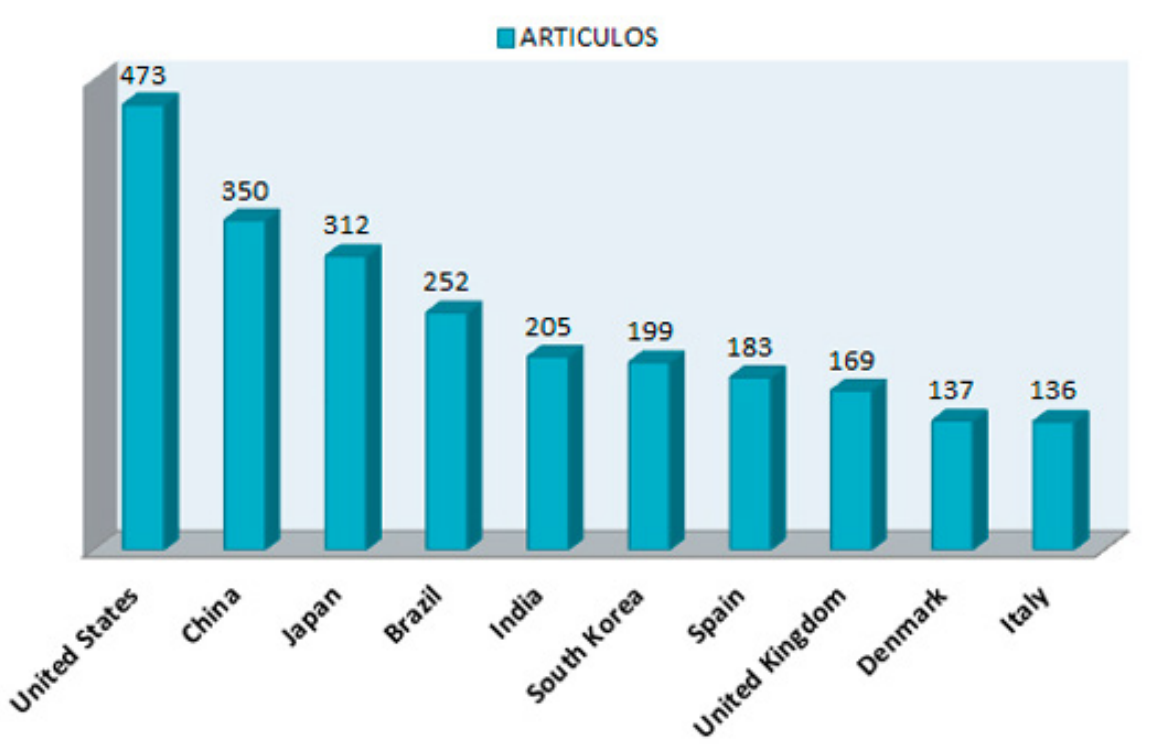

Figura 2. Países con más publicaciones sobre el Tema.

Fuente: Autores, información obtenida de la base de datos Scopus utilizando la herramienta The Vantage Point.

\section{Universidades que más publicaron}

La tabla 2 muestra las 10 instituciones de investigación o universidades que han publicado más artículos sobre el tema bioetanol. En primer lugar, se encuentra la Universidad Estatal de Campiñas, con 67 publicaciones; en segundo lugar, la Universidad Técnica de Dinamarca, con 58 publicaciones; en tercer lugar, la Universidad de Sao Paulo, con 52 publicaciones. Cabe resaltar que entre los primeros lugares predominan las Universidades de Brasil.

Tabla 2. Universidades que han publicado más artículos sobre el tema bioetanol.

\begin{tabular}{|c|c|}
\hline Universidad & Publicaciones \\
\hline 1. Universidade Estadual de Campinas & 67 \\
\hline 2. Danmarks Tekniske Universitet & 58 \\
\hline 3. Universidade de Sao Paulo & 52 \\
\hline 4. Lunds Universitet & 52 \\
\hline 5. University of Novi Sad & 37 \\
\hline 6. Imperial College London & 34 \\
\hline 7. Chonnam National University & 33 \\
\hline 8. North Carolina State University & 31 \\
\hline 9.Kobe University & 31 \\
\hline 10. Kyoto University & 28 \\
\hline
\end{tabular}

\section{Lenguaje de Comunicación}

El principal tipo de comunicación fue el inglés. Es interesante notar que la mayoría de las publicaciones fueron hechas por autores Asiáticos. Esto es coherente con la producción industrial a nivel mundial, pues Brasil es el segundo productor de bioetanol a partir de caña de azúcar.

\section{Histórico de la Investigación}

En la figura 3 se puede observar como el número de publicaciones ha venido aumentando desde el 2007, año de inicio de la búsqueda, con una producción de 148 artículos correspondientes al 4,11\% del total de publicaciones, hasta el año 2013, con una producción de 740 artículos correspondientes al $20,5 \%$. Se observó que la producción de artículos en este lapso de tiempo aumentó 5 veces, con un incremento del $16,47 \%$ del total de publicaciones.

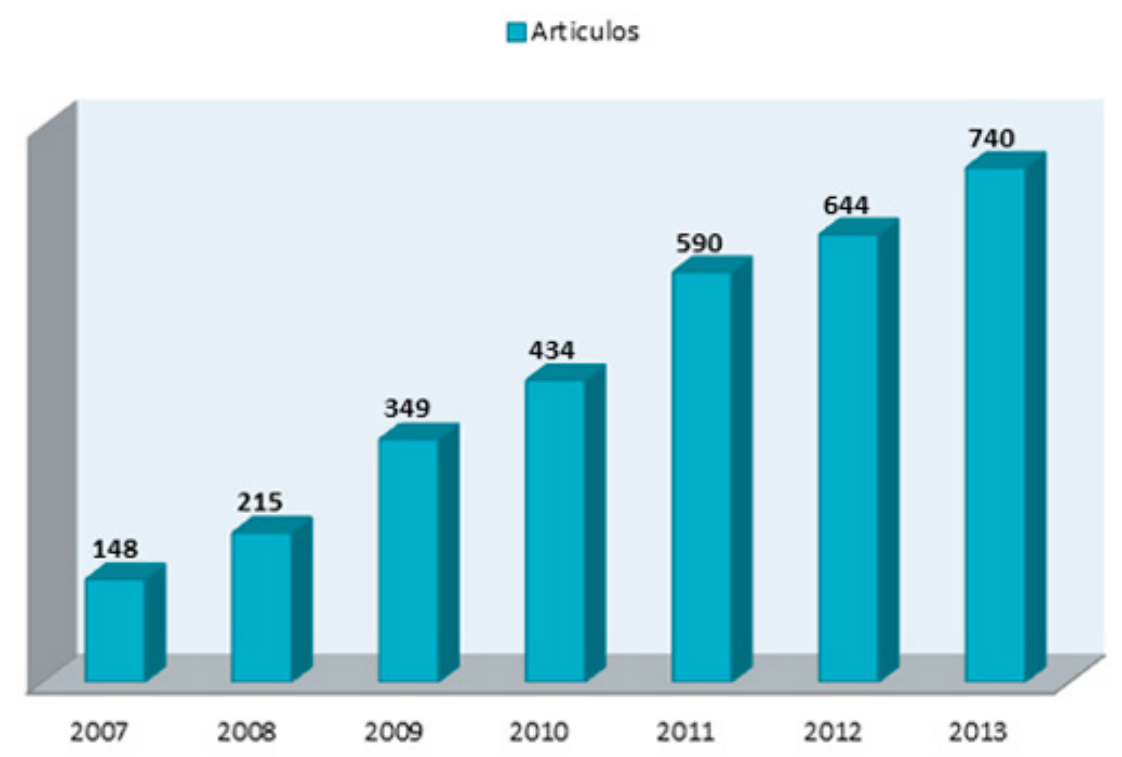

Figura 3. Histórico de la Investigación.

\section{Consolidacion de la Información}

-Materias primas: Bioetanol de Primera Generación. A nivel mundial se utilizan materias primas como la caña de azucar, el maiz, la remolacha dulce, el sorgo, entre otros, para la producción de bioetanol de primera generación. Estas materias primas se obtienen de cultivos agrícolas que corresponden a la producción industrial a nivel mundial. Dependiendo de los cultivos potenciales que tiene cada país productor, se escoge la materia prima; por ejemplo, Brasil es el segundo productor mundial de bioetanol a partir de caña de azúcar.

La tabla 3 presenta el rendimiento por tonelada y hectarea de diferentes materias primas utilizadas en la producción de bioetanol combustible. 
Tabla 3. Materia primas de Primera Generación

\begin{tabular}{|c|c|c|c|c|c|}
\hline \multirow{2}{*}{ Materia prima } & $\begin{array}{c}\text { Rendimiento } \\
\text { Agrícola (Ton/ } \\
\text { Ha) }\end{array}$ & $\begin{array}{c}\text { Rendimiento en } \\
\text { Alcohol (L etanol// } \\
\text { Ton) }\end{array}$ & $\begin{array}{c}\text { Rendimiento en } \\
\text { Alcohol (L etanol// } \\
\text { Ha) }\end{array}$ & $\begin{array}{c}\text { Países producto- } \\
\text { res }\end{array}$ & Brasil \\
\hline Caña de Azúcar & 120 & 84,5 & 10140 & Flurry \& Jungblut, 2012 \\
\hline Maíz & 85 & 409 & 34765 & $\begin{array}{c}\text { Guerra F. J., Mallen C., } \\
\text { Struck A. \& Varela T., 2008 }\end{array}$ \\
\hline Remolacha dulce & 60 & 200 & 12000 & Francia, Alemania & $\begin{array}{c}\text { Guerra F. J., Mallen C., } \\
\text { Struck A. \& Varela T., 2008 }\end{array}$ \\
\hline
\end{tabular}

Materias primas. Bioetanol de Segunda Generación. A nivel mundial se han adelantado investigaciones con respeto a la producción de bioetanol de segunda generación. Se han evaluado diferentes esquemas de producción en donde sus etapas de procesamiento varian de acuerdo al tipo de materia prima escogida. En este caso, las materias primas para la producción de bioetanol de segunda generación provienen de material lignocelulosico, residuos agrícolas y residuos forestales que no tiene un valor alimenticio, a diferencia de las materias primas de primera generación. La tabla 4 denota el rendimiento por hectarea y tonelada de materias primas para la producción de bioetanol combustible de segunda generación.

Tabla 4. Materias primas de Segunda Generación

\begin{tabular}{|c|c|c|c|c|c|}
\hline \multicolumn{6}{|c|}{ Materias Primas Bioetanol SegundaGeneración } \\
\hline Materia prima & $\begin{array}{l}\text { Rendimiento } \\
\text { Agrícola (Ton/ } \\
\text { Ha) }\end{array}$ & $\begin{array}{c}\text { Rendimiento en } \\
\text { Alcohol (L etanol/ } \\
\text { Ton) }\end{array}$ & $\begin{array}{c}\text { Rendimiento en } \\
\text { Alcohol (L etanol/ } \\
\text { Ha) }\end{array}$ & $\begin{array}{c}\text { Países produc- } \\
\text { to-res }\end{array}$ & Referencia \\
\hline Bagazo de Caña & 30 & 282.62 & 8.478 & Brasil & $\begin{array}{c}\text { Lima MA, Lavorente GB, } \\
\text { da Silva H., Bragatto J. \& } \\
\text { Rezende CA, } 2013\end{array}$ \\
\hline Rastrojo de Maíz & 18 & 227 & 1.400 & USA & Wyman, 1996 \\
\hline Bagazo o Rastrojo de Sorgo & 42.5 & 158 & 3.865 & Europa & $\begin{array}{c}\text { Chuck-Hernández C., } \\
\text { Pérez-Carrillo E., Here- } \\
\text { dia-Olea E. \& Serna-Saldívar } \\
\text { S. O., } 2011\end{array}$ \\
\hline
\end{tabular}

\section{Aspectos de Mercado.}

De acuerdo con un estudio realizado por la Comisión Económica para América Latina y el Caribe (CEPAL, 2013), en Latinoamérica, países como Brasil, Argentina y Colombia se están consolidando como pioneros en la producción de bioetanol. Brasil es la potencia latinoamericana, con una producción en el 2012 de 25.000 millones de litros al año; mientras que Colombia y Argentina, para el mismo año, produjeron 387 y 354 millones de litros respectivamente (vease tabla 5). (Martínez J. ,2012).

Tabla 5. Países Productores

\begin{tabular}{|c|c|}
\hline Países & Producción (Miles de litros) \\
\hline Brasil & 25000000 \\
\hline Colombia & 387850 \\
\hline Argentina & 354850 \\
\hline Paraguay & 205000 \\
\hline Perú & 180000 \\
\hline Otros Suramérica & 205000 \\
\hline
\end{tabular}

Fuente: F.O Licht, cifras de Asocaña, Año 2013.
Las tecnologías para la obtención de bioetanol de segunda generación a nivel mundial están en etapa de investigación, debido a los elevados costos de producción que se generan en algunas etapas del proceso. Como consecuencia, se plantean diferentes rutas de producción a través de investigaciones científicas y documentos académicos, realizando simulaciones en plantas experimentales o en plantas piloto. Esto con el fin de evaluar la viabilidad económica de producir bioetanol combustible de segunda generación a nivel comercial.

En Colombia, la producción de bioetanol como combustible de primera generación asciende a 387.850.000 litros durante el año 2013, con lo cual logra posicionarse como el segundo productor en Latinoamérica (vease figura 4). La materia prima utilizada es la caña de azúcar, que actualmente cuenta con un área cultivada de 426.051 héctareas (Proexport, 2012). 


\section{Producción de Bioetanol en Colombia}

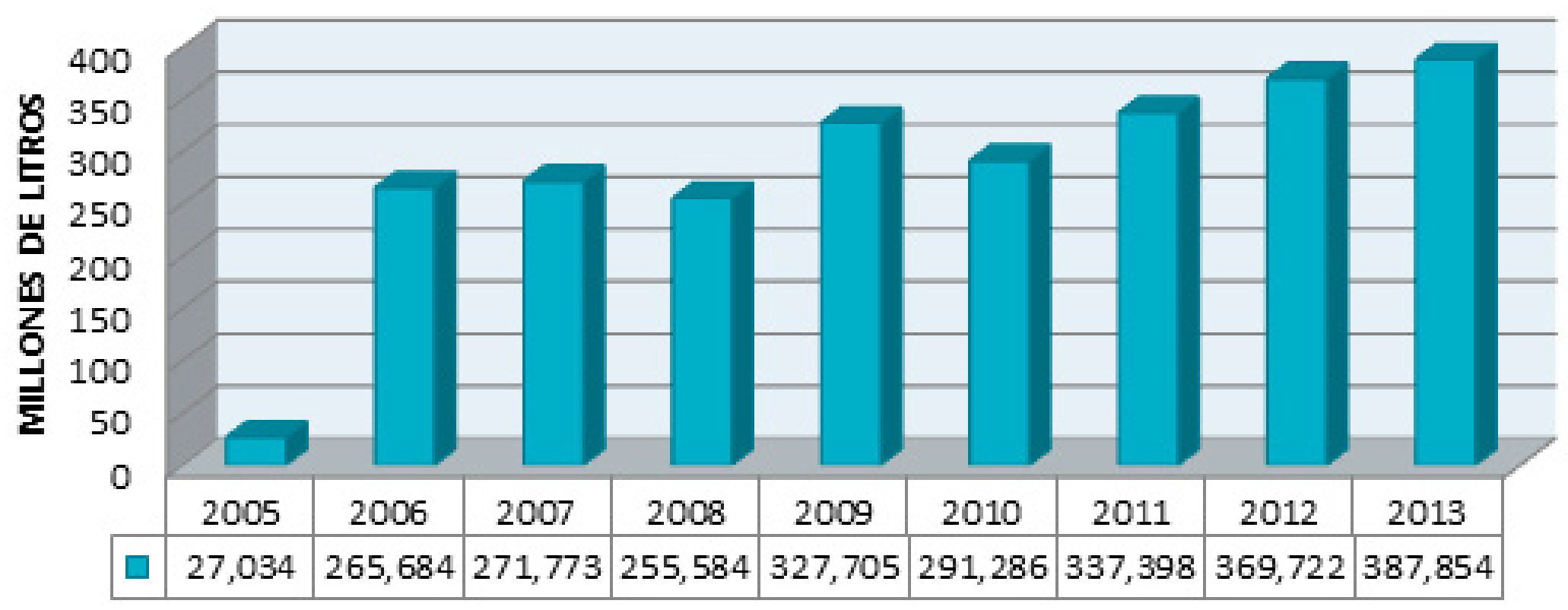

Figura 4. Producción de Bioetanol.

Fuente: Datos estadísticos de Asocaña.

El valle del rio cauca es la zona del país donde actualmente se está produciendo bioetanol comercial de primera generación partir de caña azucarera- En Santander se tiene un área cultivada de 8.117 hectáreas en caña de azúcar, las cuales se utilizan para la producción de panela únicamente. Es allí donde en el presente estudio se analizó la obtención de bioetanol combustible de segunda generación a partir del bagazo de la caña panelera.

En la tabla 6 se puede observar el área cultivada en caña panelera para los municipios influenciados en el estudio.

Tabla 6. Municipios de Cultivo de caña panelera en Santander

\begin{tabular}{|c|c|c|c|c|c|c|c|}
\hline \multicolumn{7}{|c|}{ Caña Panelera } \\
\hline Municipios/Hectárea de cultivo & 2005 & 2006 & 2007 & 2008 & 2009 & 2010 & 2011 \\
\hline Barbosa & 600 & 535 & 470 & 490 & 570 & 500 & 540 \\
\hline Chipata & 550 & 900 & 600 & 800 & 599 & 599 & 639 \\
\hline Guavata & 58 & 58 & 100 & 150 & 15 & 34 & 67 \\
\hline Guepsa & 1450 & 1300 & 1700 & 1800 & 990 & 950 & 2400 \\
\hline Puente Nacional & 200 & 198 & 197 & 196 & 110 & 163 & 163 \\
\hline San Benito & 1200 & 2200 & 2100 & 1830 & 1910 & 2000 & 2598 \\
\hline Suaita & 3850 & 2400 & 1735 & 1070 & 600 & 880 & 9085 \\
\hline Vélez & 800 & 810 & 857 & 837 & 797 & 787 & 805 \\
\hline
\end{tabular}

Fuente: cifras del Instituto colombiano de desarrollo rural (Incoder, 2012).

De esta forma se infiere un potencial significativo de producción como se muestra en la tabla 7.

Tabla 7. Potencial de Producción

\begin{tabular}{|c|c|c|c|c|}
\hline \multicolumn{5}{|c|}{ Bagazo de Caña Panelera } \\
\hline Zona de Estudio & Año & Hectáreas Cultivadas & $\begin{array}{c}\text { Potencial de Bagazo } \\
\text { en Toneladas }\end{array}$ & $\begin{array}{c}\text { Potencial de Producción de } \\
\text { Bioetanol en Litros }\end{array}$ \\
\hline Hoya del Rio Súarez & 2011 & 8.117 & 183.001 & 51.719 .742 \\
\hline
\end{tabular}




\section{Oferta y Demanda}

A continuación se mencionan las marcas de bioetanol de primera generación registradas en colombia (ver tabla 8).

Tabla 8. Marcas de Bioetanol

\begin{tabular}{|c|c|}
\hline Marca & Titular \\
\hline Castilla & Rio Paila Castilla SA \\
\hline $\begin{array}{c}\text { Alcohol Rio } \\
\text { paila }\end{array}$ & Rio Paila Castilla SA \\
\hline Manuelita & Manuelita SA \\
\hline Biocas & Rio Paila Castilla SA \\
\hline BioRio & Rio Paila Castilla SA \\
\hline Agrocom & Rio Paila Castilla SA \\
\hline
\end{tabular}

Fuente: Boletín "Bioetanol, Biotecnología Aplicada".

Superintendencia de Industria y comercio.

Dado la demanda de bioetanol combustible depende de la demanda existente de gasolina, al analizar el mercado del bioetanol combustible en Colombia se debe conocer también la demanda de gasolina. Actualmente en Colombia la normatividad exige una mezcla E8, Lo que quiere decir que un 92\% de la mezcla es Gasolina y 8\% Bioetanol.

\section{PROYECCION DE GASOLINA EN COLOMBIA}

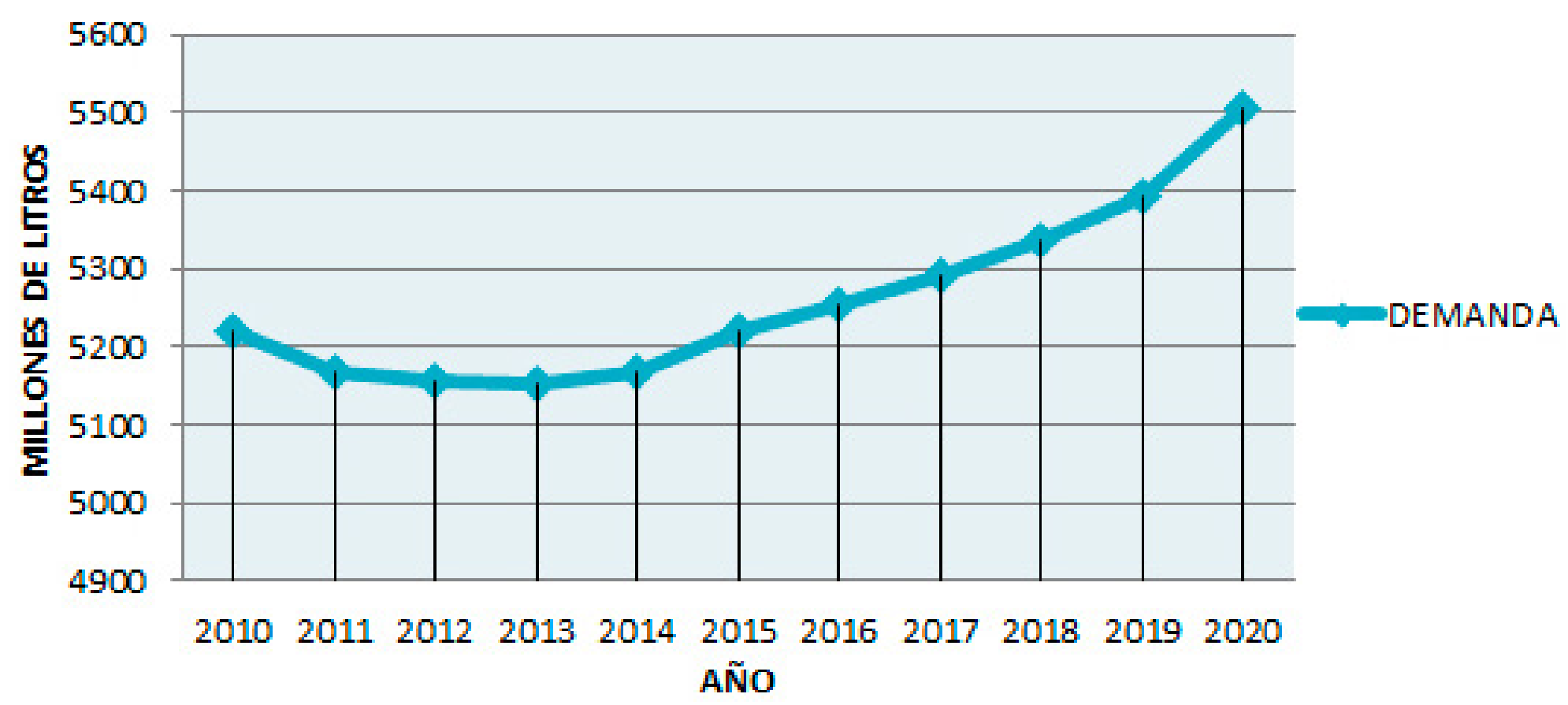

Figura 5. Proyección de Gasolina.

Fuente: Cifras de la Unidad de Planeación Minero Energética (UPME).

El mercado va dirigido principalmente a la industria automotriz, que, para el año 2013, tenía un total de 165.365 vehículos en Bucaramanga (capital del Departamento de Santander) y 478.880 vehículos en el área metropolitana; cabe resaltar que para este mercado se requiere la mezcla de bioetanol en un $8 \%$.

En la tabla 9 se muestra las plantas de producción de etanol a base de caña de azúcar que actualmente están en funcionamiento y su capacidad instalada en Colombia

Tabla 9. Plantas de Produccion de Bioetanol en Colombia

\begin{tabular}{|c|c|c|c|}
\hline Región & Inversionista & $\begin{array}{c}\text { Capacidad instalada } \\
\text { (litros/día) }\end{array}$ & $\begin{array}{c}\text { Área sembrada } \\
\text { (Ha) }\end{array}$ \\
\hline Cauca, Miranda & INCAUCA & 300000 & 10781 \\
\hline Valle, Palmira & PROVIDENCIA & 300000 & 8984 \\
\hline Valle, Palmira & MANUELITA & 250000 & 8984 \\
\hline Valle, Candelaria & MAYAGUEZ & 350000 & 5390 \\
\hline Risaralda, La Virginia & RISARALDA & 15000 & 3593 \\
\hline TOTAL & & 1250000 & 37732 \\
\hline
\end{tabular}

Fuente: Cifras de la Federación Colombiana Biocombustibles (FEDEBIOCOMBUSTIBLES, 2012). 
La capacidad instalada es de 1.250.000 litros por día. Esta cifra puede ir en aumento gracias a la ampliación de plantas ya existentes y a la construcción de nuevas plantas de bioetanol. Todo esto dentro del marco legal del alza del porcentaje de etanol en el combustible fósil.
Con base en las proyecciones estimadas, dadas por la federación nacional de biocombustibles, en Colombia se debe continuar con el programa de biocombustibles, pero mejorando la eficiencia productiva. Esto con el fin de poder competir con los combustibles tradicionales.

Tabla 10. Demanda y Oferta Potencial

\begin{tabular}{|c|c|c|c|c|}
\hline & 2009 & 2010 & 2015 & 2020 \\
\hline Total Ha/Miles & 121 & 233 & 433 & 770 \\
\hline $\begin{array}{c}\text { Total Producción Mi- } \\
\text { les Litros/Día }\end{array}$ & 2.420 & 4.650 & 8.650 & 15.400 \\
\hline$\%$ Mezcla & 10 & 15 & 25 & 25 \\
\hline $\begin{array}{c}\text { Consumo Nacional } \\
\text { Miles Litros/Día }\end{array}$ & 1.500 & 2.390 & 4.410 & 4.850 \\
\hline $\begin{array}{c}\text { Número de Plantas } \\
\text { Exportación Miles L/ }\end{array}$ & 11 & 19 & 32 & 55 \\
\hline
\end{tabular}

Fuente: Cifras de la Federación Nacional de Biocombustibles (FEDEBIOCOMBUSTIBLES, 2012).

En la tabla 11 se realiza una comparación entre la demanda real y el consumo aparente del bioetanol combustible en Colombia. Observando la tabla, se concluye que existió un déficit de bioetanol combustible de 10.660.000 litros, en el año 2009; en 2010 el deficit fue de 800.000 Litros; en 2011 de 13.690.000 litro y 13.690.000 Litros en el año 2013. Con la obtención de bioetanol combustible de segunda generación se estaría contribuyendo a suplir este déficit de biocombustible, optando por una opción de combustible renovable y con menos emisiones contaminantes.

Tabla 11. Demanda Vs Oferta

\begin{tabular}{|c|c|c|}
\hline AÑOS & $\begin{array}{c}\text { Demanda real } \\
\text { (millones de } \\
\text { litros) }\end{array}$ & $\begin{array}{c}\text { Oferta real } \\
\text { (millones de } \\
\text { litros) }\end{array}$ \\
\hline 2.008 & 247 & 255 \\
\hline 2.009 & 338 & 327 \\
\hline 2.010 & 292 & 291 \\
\hline 2.011 & 351 & 337 \\
\hline 2.012 & 368 & 369 \\
\hline 2.013 & 393 & 387 \\
\hline
\end{tabular}

\section{Aspectos Técnicos}

Tabla 12. Ficha Técnica del bioetanol

\begin{tabular}{|c|c|c|}
\hline \multicolumn{3}{|c|}{ Ficha técnica del Bioetanol } \\
\hline \multicolumn{2}{|c|}{ Propiedades Fisico Quimicas } \\
\hline PÁRAMETRO & UNIDAD & BIOETANOL \\
\hline Poder calorífico & $\mathrm{kJ} /$ Litro & 22.350 \\
\hline Densidad & $\mathrm{kg} /$ Litro & 0,792 \\
\hline Octanaje ROM & & $102-130$ \\
\hline Octanaje MOM & & $89-96$ \\
\hline Calor Latente de Vaporización & $\mathrm{kJ} / \mathrm{kg}$ & $842-930$ \\
\hline Presión de Vapor & $\mathrm{kpa}$ & $15-17$ \\
\hline Temperatura de ignición & ${ }^{\circ} \mathrm{C}$ & 420 \\
\hline Solubilidad en Agua & $\%$ en Volumen & 100 \\
\hline Temperatura de Ebullición & ${ }^{\circ} \mathrm{C}$ & 78 \\
\hline Relación Aire/ Combustible & & 9 \\
\hline
\end{tabular}

Fuente: Bioetanol de caña de azúcar para el desarrollo sostenible. 


\section{Micro Localización del Estudio}

Para el funcionamiento de la planta de producción de bioetanol de segunda generación propuesta en el proyecto de estudio se seleccionó la zona rural del municipio de Barbosa, ya que este municipio se encuentra ubicado en el epi- centro de la región de la Hoya del Rio Suarez (véase figura 6); su posición geográfica facilita la recepción de materias primas provenientes de los cultivos. En esta misma zona se realizó un proyecto para el montaje de una planta de bioetanol combustible de primera generación, proyecto que nos permitió hacer una integración de procesos.

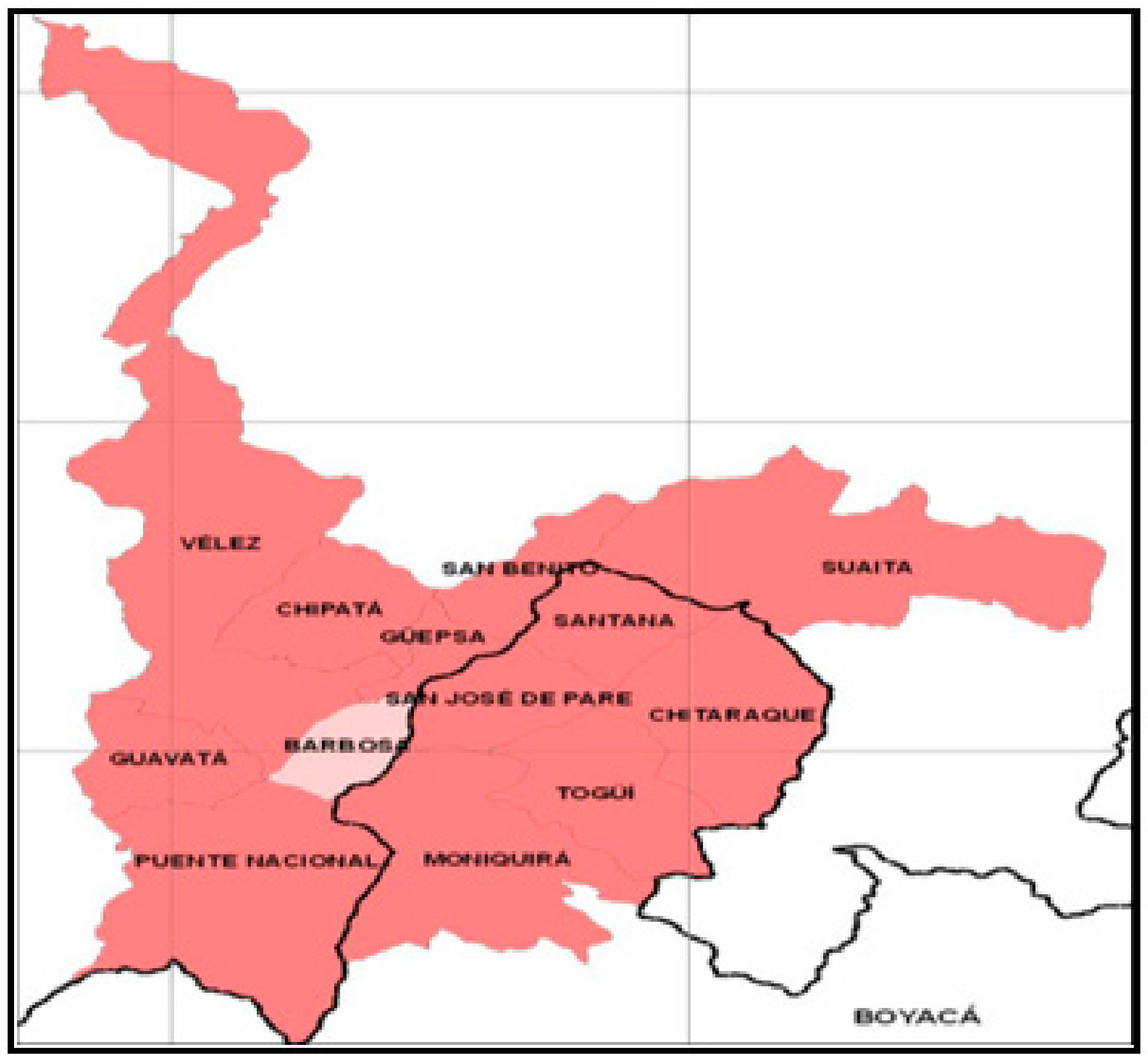

Figura 6. Micro Localización.

Fuente: Instituto Colombia de Desarrollo Rural. INCODER. ADR de la Hoya del Rio Suarez.

\section{Capacidad del Proyecto}

La tabla 13 y 14 presenta la capacidad instalada y utilizada del proyecto en estudio. Con la capacidad instalada se cubrirán al año un $12.50 \%$ del mercado nacional, manteniendo un mezcla de E8, con una producción anual de de 51.719 .742 litros.

Tabla 13. Capacidad instalada

\begin{tabular}{|c|c|}
\hline \multicolumn{2}{|c|}{ Capacidad Instalada } \\
\hline Demanda Gasolina 2014 [L/año] & 5'168.000.000 \\
\hline 8\% bioetanol [L/año] & 413.440 .000 \\
\hline
\end{tabular}

\begin{tabular}{|c|c|}
\hline \multicolumn{2}{|c|}{ Capacidad Instalada } \\
\hline $\begin{array}{c}\text { Producción planta bioetanol [L/ } \\
\text { año] }\end{array}$ & $51^{\prime} 719.742$ \\
\hline Porcentaje mercado [\%] & $12.50 \%$ \\
\hline
\end{tabular}

Tabla 14. Capacidad Utilizada

\begin{tabular}{|c|c|}
\hline \multicolumn{2}{|c|}{ Capacidad Utilizada } \\
\hline Demanda Gasolina 2014 [L/año] & $5^{\prime} 168.000 .000$ \\
\hline $\begin{array}{c}\text { 8\% bioetanol [L/año] } \\
\text { Producción planta bioetanol [L/ } \\
\text { año] }\end{array}$ & 413.440 .000 \\
\hline Porcentaje mercado [\%] & $10.00 \%$ \\
\hline
\end{tabular}


La tabla 14 muestra la capacidad utilizada propuesta en el proyecto, la cuál cubrirá al año un $10.00 \%$ del mercado nacional, manteniendo un mezcla de E8, con una producción anual de 41.375.793 litros.

\section{Proceso}

El proceso consiste en cuatro etapas principales: Pre-tratamiento, Hidrólisis Enzimática, Fermentación y Destilación. La materia prima empleada es el bagazo de la caña panelera, obtenido de una fábrica de azúcar o de panela. Una parte considerable de la materia prima es utilizada como combustible en la caldera, mientras la sobrante puede tener varios usos, entre los que se encuentra la producción de bioetanol de segunda generación.
Tabla 15. Descripción del proceso

\begin{tabular}{|c|c|c|c|}
\hline Etapa de proceso & $\begin{array}{c}\text { \# De } \\
\text { Equipos }\end{array}$ & $\begin{array}{c}\text { Tiempo Total Pro- } \\
\text { cesamiento (h) }\end{array}$ & V $\left(\mathrm{m}^{3}\right)$ \\
\hline Pre-Tratamiento Acido & 3 & 2,54 & 99 \\
\hline Pre-Tratamiento Básico & 6 & 2,76 & 57 \\
\hline Hidrólisis Enzimática & 28 & 29,0 & 143 \\
\hline Pre-Fermentación & 2 & 4,28 & 10 \\
\hline Fermentación & 12 & 30,0 & 85 \\
\hline
\end{tabular}

Fuente: Elaboración de los Autores del Proyecto.

En la figura 7 se presenta el diagrama de bloques de proceso y análisis de proceso. En la tabla 16 se observa el diagrama de análisis de procesos, donde detalla que para el proceso se requiere de 27 operaciones, una inspección y finalmente un almacenamiento. El proceso dura un tiempo total de 65 horas.

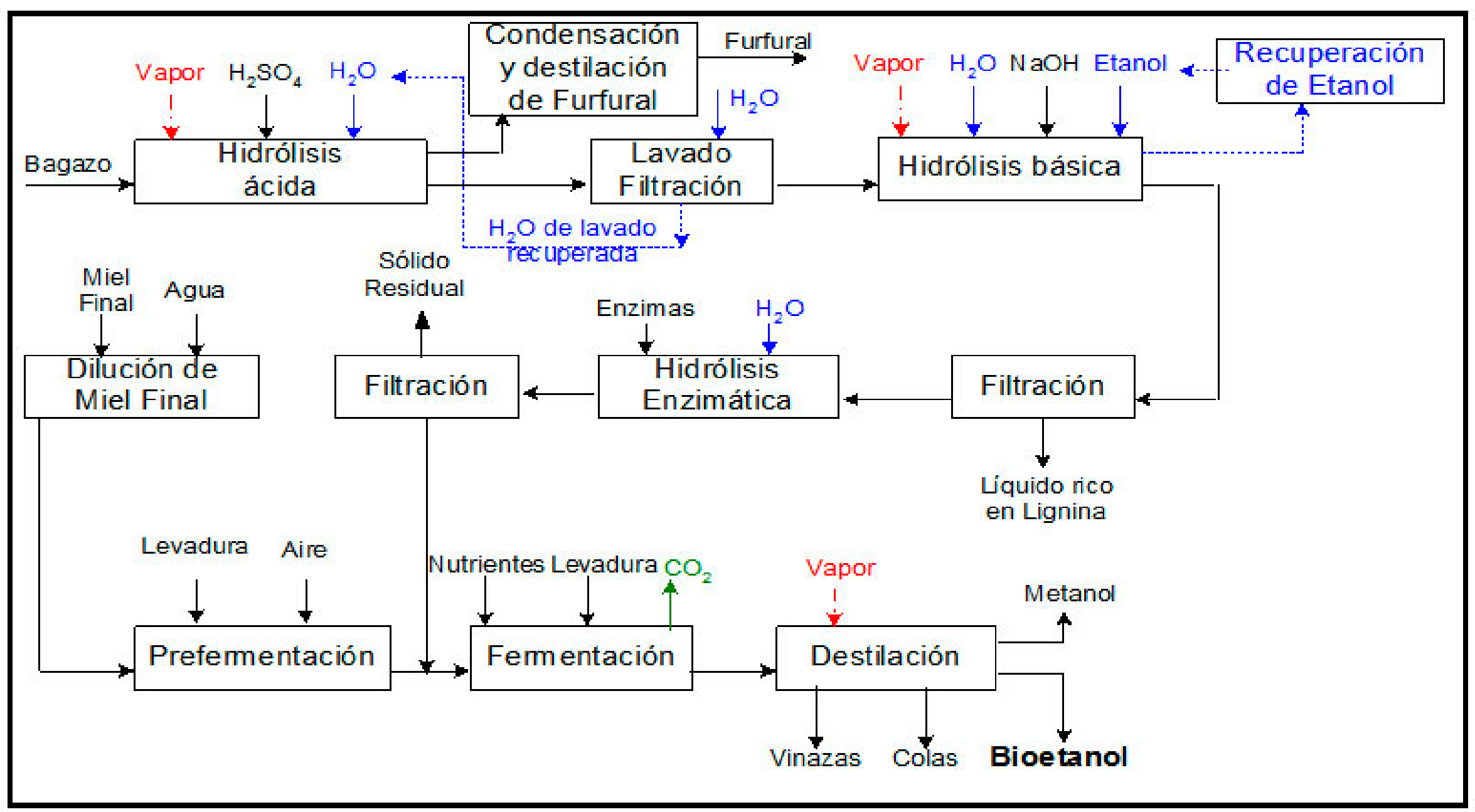

Figura 7. Diagrama de Bloques 


\begin{tabular}{|c|c|c|c|c|c|c|c|c|}
\hline $\begin{array}{l}\mathbf{P} \\
\mathbf{A} \\
\mathbf{S} \\
\mathbf{D}\end{array}$ & \multicolumn{2}{|c|}{ ETAPAS DEL PROCEDIMIENTO } & 起政 & 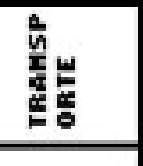 & 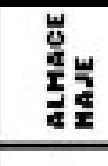 & 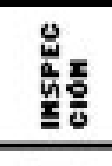 & 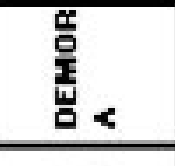 & TIEMPO(Min) \\
\hline 1 & \multicolumn{2}{|c|}{ Carga del hidrolizador ácido } & $\mathrm{x}$ & & & & & 15 \\
\hline 2 & \multicolumn{2}{|c|}{ Calentamiento del hidrolizador ácido } & $x$ & & & & & 30 \\
\hline 3 & \multicolumn{2}{|c|}{ Hidrólisis ácida } & $\mathrm{x}$ & & & & & 40 \\
\hline 4 & \multicolumn{2}{|c|}{ Enfriamiento del hidrolizador ácido } & $x$ & & & & & 15 \\
\hline 5 & \multicolumn{2}{|c|}{ Descarga del hidrolizador ácido } & $\mathrm{x}$ & & & & & 15 \\
\hline 6 & \multicolumn{2}{|c|}{ Condensación de furfural } & $x$ & & & & & 40 \\
\hline 7 & \multicolumn{2}{|c|}{ Lavado-Filtración } & $x$ & & & & & 10 \\
\hline 8 & \multicolumn{2}{|c|}{ Carga del hidrolizador básico } & $\mathrm{x}$ & & & & & 15 \\
\hline 9 & \multicolumn{2}{|c|}{ Calentamiento del hidrolizador básico } & $x$ & & & & & 30 \\
\hline 10 & \multicolumn{2}{|c|}{ Hidrólisis básica } & $x$ & & & & & 60 \\
\hline 11 & \multicolumn{2}{|c|}{ Enfriamiento del hidrolizador básico } & $\mathrm{x}$ & & & & & 15 \\
\hline 12 & \multicolumn{2}{|c|}{ Descarga del hidrolizador básico } & $x$ & & & & & 15 \\
\hline 13 & \multicolumn{2}{|c|}{ Recuperación de Etanol } & $x$ & & & & & 10 \\
\hline 14 & \multicolumn{2}{|c|}{ Filtración } & $\mathrm{x}$ & & & & & 10 \\
\hline 15 & \multicolumn{2}{|c|}{ Carga del hidrolizador enzimático } & $x$ & & & & & 15 \\
\hline 16 & \multicolumn{2}{|c|}{ Hidrólisis enzimática } & $\mathrm{x}$ & & & & & 1440 \\
\hline 17 & \multicolumn{2}{|c|}{ Descarga del hidrolizador enzimático } & $x$ & & & & & 15 \\
\hline 18 & \multicolumn{2}{|c|}{ Filtración } & $x$ & & & & & 10 \\
\hline 19 & \multicolumn{2}{|c|}{ Dilución de la miel } & $\mathrm{x}$ & & & & & 120 \\
\hline 20 & \multicolumn{2}{|c|}{ Prefermentación } & $x$ & & & & & 240 \\
\hline 21 & \multicolumn{2}{|c|}{ Siembra del fermentador } & $x$ & & & & & 60 \\
\hline 22 & \multicolumn{2}{|c|}{ Llenado del fermentador } & $x$ & & & & & 480 \\
\hline 23 & \multicolumn{2}{|c|}{ Agotamiento del fermentador } & $x$ & & & & & 720 \\
\hline 24 & \multicolumn{2}{|c|}{ Destilación del fermentador } & $x$ & & & & & 360 \\
\hline 25 & \multicolumn{2}{|c|}{ Limpieza del fermentador } & $x$ & & & & & 60 \\
\hline 26 & \multicolumn{2}{|c|}{ Revisar la calidad del producto } & & & & $x$ & & 30 \\
\hline 27 & Alma & iento & & & $\mathrm{x}$ & & & 60 \\
\hline & & & & & $\mathrm{N}^{-T C}$ & $\overline{\mathrm{DEOF}}$ & ACIONES & 25 \\
\hline & DEPENDENCIA & DEPARTAMENTC & DEPR & JCCIÓN & $\frac{N \cdot T C}{1 \cdot T O T A}$ & DE TF & PORTES & $\frac{0}{1}$ \\
\hline & & & & & $\mathrm{N}^{\prime} \mathrm{TC}$ & $\underline{E A L M}$ & $\begin{array}{l}\text { NAMIENTS } \\
\text { CCIONES }\end{array}$ & $\frac{1}{1}$ \\
\hline & & & & & & TTALD & RAS & 0 \\
\hline & FECHA & & & & & EMPO & & $\begin{array}{c}3900(\mathrm{MIN}) \\
65(\text { HORAS) } \\
2.7 \text { (dias) }\end{array}$ \\
\hline
\end{tabular}




\section{Evaluación Financiera}

Inversión Incial. En la tabla 17 se observa el monto de cada una de las inversiones que se deben realizar para la puesta en marcha del proyecto. Para el montaje y puesta en marcha del proyecto se requiere una inversión total de \$ 59.911.047.410 en el primer año.

Tabla 17. Inversión Inicial

\begin{tabular}{|c|c|}
\hline \multicolumn{2}{|c|}{ Inversion Inicial } \\
\hline \multicolumn{2}{|c|}{ Capital Fijo Depreciable } \\
\hline Descripción & Total \\
\hline Maquinaria y equipo & $\$ 22.778 .147 .736$ \\
\hline Muebles y enseres & $\$ 25.750 .000,00$ \\
\hline Equipos de oficina & $\$ 66.160 .000,00$ \\
\hline Sub Total & $\$ 22.870 .057 .736$ \\
\hline \multicolumn{2}{|c|}{ Capital Fijo no Depreciable } \\
\hline \multirow{3}{*}{ Terrenos } & $\$ 150.000 .000,00$ \\
\hline & Total \\
\hline & $\$ 150.000 .000,00$ \\
\hline \multicolumn{2}{|c|}{ Capital de Trabajo } \\
\hline $\begin{array}{c}\text { Materias primas } \\
\text { e Insumos }\end{array}$ & $\$ 30.666 .325 .263,00$ \\
\hline Pagos de nomina & $\$ 1.551 .342 .736,00$ \\
\hline Servicios públicos & $\$ 4.673 .321 .675,00$ \\
\hline Sub Total & $\$ 36.890 .989 .674,00$ \\
\hline Total Inversion Inicial & $\$ 59.911 .047 .410$ \\
\hline
\end{tabular}

Costos totales de producción. En la tabla 18 se describen los costos para la fabricación o producción del Bioetanol. Como se puede observarm, para el primer año de funcionamiento de la planta se requiere de un capital de \$ 40.505.745.557, capital que cubrirá los costos de producción.

Tabla 18. Costos de Producción

\begin{tabular}{|c|c|}
\hline \multicolumn{2}{|c|}{ Presupuesto Costo de Producción } \\
\hline \multicolumn{2}{|c|}{ Costos de Fabricación } \\
\hline Costos Directos & Precio Total \\
\hline Materia Prima & $\$ 13.176 .000 .000,00$ \\
\hline Insumos & $\$ 17.510 .418 .301,46$ \\
\hline Mano de Obra Directa & $\$ 1.220 .242 .624,00$ \\
\hline Total Costo Directo & $\$ 31.906 .660 .925,46$ \\
\hline \multicolumn{2}{|c|}{} \\
\hline Costos Indirectos & $\$ 331.100 .112,00$ \\
\hline Mano de Obra Indirecta & $\$ 4.673 .321 .675,00$ \\
\hline Servicios públicos & $\$ 3.594 .662 .844,58$ \\
\hline Otros Costos Indirectos & $\$ 8.599 .084 .631,58$ \\
\hline Total Costo Indirecto & $\$ 40.505 .745 .557,04$ \\
\hline \multicolumn{2}{|c|}{} \\
\hline $\begin{array}{c}\text { Total Costo directo } \\
\text { + Indirectos }\end{array}$ \\
\hline
\end{tabular}

\section{Balance general inicial}

Tabla 19. Balance General Inicial

\begin{tabular}{|c|c|c|c|}
\hline \multicolumn{5}{|c|}{ Balance General Inicial } \\
\hline Activo & & Pasivo & \\
\hline Activo circulante & & Pasivo circulante & \\
\hline Inversiones & $\$ 6.224 .664 .411,00$ & $\begin{array}{c}\text { Sueldos, deudores, } \\
\text { impuestos }\end{array}$ & \$ 0 \\
\hline Inventarios & $\$ 30.666 .325 .263,00$ & & \\
\hline Cuentas por cobrar & & Pasivo fijo & \\
\hline Subtotal & $\$ 36.890 .989 .674,00$ & Préstamo a 5 años & $\$ 29.911 .047 .410,00$ \\
\hline Activo fijo & & & $49,93 \%$ \\
\hline Equipo de producción & $\$ 22.778 .147 .735,69$ & & \\
\hline $\begin{array}{c}\text { Equipo de oficinas y } \\
\text { ventas }\end{array}$ & $\$ 91.910 .000,00$ & CAPITAL & \\
\hline Terreno y obra civil & $\$ 150.000 .000,00$ & Capital de Inversión & $\$ 30.000 .000,00$ \\
\hline Subtotal & $\$ 23.020 .057 .735,69$ & & $50,07 \%$ \\
\hline & & & \\
\hline Activo diferido & & & \\
\hline & & & \\
\hline Total de activos & $\$ 59.911 .047 .409,69$ & Pasivo + Capital & $\$ 59.911 .047 .409,69$ \\
\hline
\end{tabular}


De los \$ 59.911.047.410 correspondiente de la inversion inicial, el 49,93\% será financiado por terceros (ver tabla 19).

Punto de Equilibrio

Tabla 20. Equilibrio

\begin{tabular}{|c|c|}
\hline \multicolumn{2}{|c|}{ Punto de Equilibrio } \\
\hline COSTO DE VENTA UNITARIO & $\$ 1.644,91$ \\
\hline UNIDADES VENDIDAS & 41.375 .793 \\
\hline INGRESO TOTAL & $\$ 68.059 .455 .663,63$ \\
\hline COSTO FIJO TOTAL & $\$ 9.125 .106 .128,28$ \\
\hline COSTO VARIABLE TOTAL & $\$ 32.836 .418 .301,46$ \\
\hline $\begin{array}{c}\text { COSTO VARIABLE UNITARIO }=- \\
\text { CVT/UNIDADES VENDIDAS }\end{array}$ & $\$ 745,28$ \\
\hline RENTABILIDAD & $120,71 \%$ \\
\hline $\begin{array}{c}\text { CANTIDAD DE EQUILI- } \\
\text { BRIO=CFT/(PVU-CVU) }\end{array}$ & $10.143 .140,62$ \\
\hline $\begin{array}{c}\text { VALOR MONETARIO } \\
\text { DE EQUILIBRIO }\end{array}$ & $\$ 16.684 .553 .437,19$ \\
\hline
\end{tabular}

El punto de equilibrio se encontrará cuando la planta produzca 10.143.140,62 Litros, lo que equivale a $\$ 16.684 .553 .437,19$ (ver figura 7).

\section{Valoración}

Se procedio a calcular el valor actual neto (VNA), la (TIR) y el PRI. Como se muestra en la tabla 21, la tasa interna de rentabilidad (TIR) es del 13,30\%, con la cual el valor actual neto (VAN) del capital para la inversión obtenido del préstamo es igual a cero. En este caso, la evaluación determina un Valor Presente Neto positivo equivalente a \$ 919.357.731,64 y un Periodo de Recuperación de la Inversión de 3,65 Años.

Tabla 21. Valoración

\begin{tabular}{|c|c|}
\hline \multicolumn{2}{|c|}{ VALORACIÓN } \\
\hline Inversión Inicial & $\$ 30.000 .000 .000,00$ \\
\hline $\begin{array}{c}\text { Tasa de Descuento } \\
\text { ( Costo de Capital) }\end{array}$ & $12 \%$ \\
\hline TIR & $13.30 \%$ \\
\hline $\begin{array}{c}\text { VPN + VP ( Valor de } \\
\text { Continuidad) }\end{array}$ & $\$ 919.357 .731,64$ \\
\hline PRI(Años) & 3,65 \\
\hline
\end{tabular}

\section{CONCLUSIONES}

El estudio realizado evaluó y comprobó la viabilidad técnica del proceso de obtención de bioetanol combustible de segunda generación en el departamento de Santander, teniendo en cuenta su entorno, ubicación y sector en el mercado.

A partir del estudio bibliométrico se puede afirmar que de la caña de azúcar se puede obtener 84,5 Litros de bioetanol por tonelada de caña procesada. No obstante, si se utilizara el bagazo como materia prima para producir bioetanol se podrían obtener teóricamente 282,62 litros, debido a que la caña panelera tiene una composición fisicoquímica muy similar que permite manejar rendimientos similares.

Con el estudio de mercados se logró determinar una zona de alto potencial para la producción de bioetanol lignocelulosico, se cuenta con 8.117 hectáreas equivalentes a 183.001 toneladas de bagazo de caña, lo que generaría una producción de 51.719.753 Litros.

De acuerdo con la evaluación financiera realizada, se concluye que se requiere de una inversión inicial de $\$$ 59.911.047.410. Los altos costos de la inversión inicial, asociados a tecnologías emergentes en etapas de pre tratamiento e hidrólisis, llevan a clasificar estos proyectos como de altos riesgo, ya que la Evaluación Financiera arrojó una TIR inferior al $20 \%$.

Finalmente, la composición del bagazo de caña permite integrar su esquema de procesamiento en términos de biorrefineria, que permite obtener otros productos de valor agregado como el furfural, proveniente de los azucares C5, y la lignina, que puede ser utilizada para la generación de energía.

\section{REFERENCIAS}

Ardanuy J. (2012). Breve Introducción a la Bibliometría. Disponible en: http://diposit.ub.edu/dspace/bitstream/2445/30962/1/breve\%20introduccion\%20bibliometria.pdf

Bioetanol de caña de azúcar para el desarrollo sostenible. Etanol como combustible vehicular. Capítulo 2. P 42. Disponible en: www.bioetanoldecana.org/es/download/ cap2.pdf

Carlos R. \& Lorena P. (2010). Aspectos Económicos, Sociales y Ambientales de la Industria de la Caña de Azúcar en Colombia. Reseña Bibliográfica. Bogotá, Colombia: Universidad Sergio Arboleda.

Cenicaña. Centro de investigación de la Caña de Azúcar.

Comisión Económica para América Latina y el Caribe. (2013). CEPAL. Disponible en: http://www.cepal.org/cgiin/ getProd.asp?xml=/prensa/noticias/comunicados/7/42937/ P42937.xml\&xsl=/prensa/tpl/p6f.xsl\&base $=/$ washington/ tpl-i/top-bottom.xslt.

Dirección de Transito del Área. Fondo de Prevención Vial, Programa Bucaramanga ¿Cómo Vamos? Disponible en: http://www.vanguardia.com/santander/bucaramanga/ infografia-228398-conozca-los-numeros-del-parque-automotor-de-bucaramanga.

FOCER: Fortalecimiento de la capacidad de energía renovable para America Latina. Manuales sobre energía renovable: Biomasa/ Biomass Users Network (BUN-CA). San José, Costa Rica: Biomass.

Garcia J.M. (2012). Bioetanol. Perspectivas para Organización Internacional del Azúcar. 
Incoder. Instituto Colombiano de Desarrollo Rural.

Key R.M, Kozir A., Sabine C.L \& CO. Global Carbon Project. Norwich, Inglaterra: University of East Anglia.

Martínez J. (2012). Bioetanol en el sector Azucarero Colombiano. Disponible en: http://es.slideshare.net/martinezjohan/bioetanol-en-el-sector-azucarero-colombiano-una-vision-integral.
Proexport Colombia. (2012). Biocombustibles Perfil Sectorial. (Boletín Informativo). P 14. Disponible en: http:// www.inviertaencolombia.com.co/images/Perfil_Biocombustibles_2012.pdf

Roca J. \& Fernández S. (2010). Agotamiento de los Combustibles fósiles y emisiones de CO2. Barcelona, España: Universidad de Barcelona, Departamento de Teoría Económica. 


\title{
GENERACIÓN DISTRIBUIDA DE ENERGÍA ELÉCTRICA MEDIANTE ENERGÍA SOLAR FOTOVOLTAICA EN LA RED DE BAJA TENSIÓN DE LA UNIVERSIDAD DE BOGOTÁ JORGE TADEO LOZANO
}

\author{
A. J. Aristizábal ${ }^{1}$ \\ I. Dyner ${ }^{2}$ \\ C. A. Páez ${ }^{3}$
}

Universidad de Bogotá Jorge Tadeo Lozano

landresj.aristizabalc@utadeo.edu.do 2isaac.dynerr@utadeo.edu.co

${ }^{3}$ carlosa.paezch@utadeo.edu.co

\section{RESUMEN}

En éste trabajo se presenta una propuesta que aspira hacer aportes al desarrollo de nuevas formas de generación eléctrica, especialmente a partir de fuentes limpias y renovables. La meta es dimensionar, instalar y poner en operación sistemas de generación de potencia eléctrica fotovoltaica distribuida en la red de baja tensión de 208Vac. La instalación de dichas plantas permitirá evaluar la factibilidad del uso de sistemas de conversión fotovoltaica para la alimentación eléctrica de cargas de tipo residencial y eventualmente de tipo industrial.

Las plantas fotovoltaicas se diseñarán para que operen embebidas con la red local, dentro del concepto BIPVS (Building Integrated Photovoltaic Systems) que es una forma típica de generación distribuida que se está usando masivamente a nivel mundial. En este tipo de sistemas, el arreglo de módulos fotovoltaicos se instala en el techo de una casa o edificio y éste se interconecta a través de un inversor con la red local. El inversor debe permitir exportar energía eléctrica a la red cuando haya un excedente e importar energía de la red en las horas de la noche cuando no hay radiación solar.

Se presenta la evaluación del recurso solar en la ciudad de Bogotá para un período de 6 años y se realiza el dimensionamiento de dos plantas solares fotovoltaicas (FVs) a instalarse en el Centro de Investigación de los Programas de Ingeniería - CIPI y en el Centro de Biosistemas de la Universidad de Bogotá Jorge Tadeo Lozano. El análisis de la radiación solar y la temperatura ambiente para un período comprendido entre 2004 y 2010, revela que en Bogotá existen 3.65 HSS (horas de sol estándar) y $13.66^{\circ} \mathrm{C}$. Con éste recurso solar, las plantas solares de $6 \mathrm{~kW}$ cada una; estarían en condiciones de aportar aproximadamente

$525.6 \mathrm{kWh} / \mathrm{mes}$ para cada uno de los sitios de instalación.

Palabras claves: Energía solar, radiación solar, temperatura, sistema fotovoltaico. 


\section{INTRODUCCIÓN}

Los BIPVS constituyen una de las aplicaciones de la Energía Solar Fotovoltaica que más atención están recibiendo en los últimos años, dado su elevado potencial de utilización en zonas urbanizadas próximas a la red eléctrica. Estos sistemas están compuestos por un generador fotovoltaico que se encuentra interconectado a la red eléctrica convencional a través de un inversor; produciéndose un intercambio energético entre ésta y el sistema fotovoltaico, característico de este tipo de instalaciones [1].

Un BIPVS está diseñado para entregar energía a un usuario en particular con el fin de reducir el consumo que este tiene de la red que le provee el servicio y en dado caso, la venta de la energía sobrante, todo con el objetivo de reducir costos en su factura. El dimensionamiento de este tipo de sistemas se basa en encontrar los dos parámetros principales que lo componen, previo conocimiento del presupuesto disponible y de las características eléctricas de los módulos fotovoltaicos seleccionados [2].

En Colombia, en el año 2001 se decretó la Ley 697 mediante la cual se declara el uso racional y eficiente de la energía (URE) con el objetivo de fomentar el uso de energías renovables como un asunto de interés nacional y de compromiso con el medio ambiente. Posteriormente, en Mayo de 2014 se decreta la Ley 1715 con el fin de regular la integración de las energías renovables no convencionales al sistema energético nacional. Estas acciones gubernamentales crean nuevos escenarios energéticos en materia de regulación, mercados, economía, instalación y tecnología en energía que representan un nuevo reto para el país.

\section{MATERIALES Y MÉTODOS}

El laboratorio de Sistemas Fotovoltaicos del Departamento de Física de la Universidad Nacional de Colombia, Sede Bogotá desarrolló e implementó un prototipo de sistema con facilidades para medir y monitorear parámetros eléctricos y ambientales que dan información tanto del desempeño de sistemas fotovoltaicos interconectados como de la calidad de la potencia eléctrica generada por ellos. El sistema de monitoreo fue desarrollado usando el concepto de instrumentación virtual, para lo cual fue empleado como software el paquete LabVIEW 7.1 y como hardware, un sistema SCXI, una DAQ PCMCIA 6024E y un computador portátil [3]. Resultados del análisis del monitoreo de la radiación solar y la temperatura ambiente de éste sistema han sido ampliamente divulgados $[4,5,6]$. El Grupo de Investigación en Energía y Sostnibilidad - GIES de la Universidad de Bogotá Jorge Tadeo Lozano ha procesado ésta información de radiación y temperatura entre los años 2004 y 2010 con el fin de determinar el potencial del recurso solar para Bogotá.

Para llevar a cabo el dimensionamiento de un BIPVS, se realiza el cálculo de la potencia pico que debe entregar el generador FV y el inversor:

$$
P_{G F V}=\frac{\sum_{i=1}^{12} \frac{E_{i}}{H S S_{i} \cdot N_{i} \cdot P R}}{12} \quad \text { (1) } F_{D I}=\frac{P_{\text {maxima }, \text { IInersor }}}{P_{\text {nominal,Generador }}}=\frac{P_{\text {max }, I}}{P_{\text {max }, G}}
$$

Donde Ei es la producción promedio de electricidad solar mensual (en $\mathrm{kWh} / \mathrm{mes}$ ) que se define por el usuario, y que en este caso sería la energía consumida en la instalación. HSS es el número de horas de radiación solar estándar promedio mensual de la localidad, Ni es el número de días del respectivo mes y PR es el factor de rendimiento del sistema: permite introducir un sobredimensionamiento del 10 $20 \%$ del generador FV por seguridad y oscila entre 0,7 y 0,9 .

Para llevar a cabo el dimensionamiento del inversor, se define el tamaño relativo Generador-Inversor (ecuación 2) de forma tal que se sobredimensione el generador fotovoltaico con respecto al inversor [7].

\section{RESULTADOS}

El sistema de monitoreo de radiación y temperatura realizaba una adquisición de datos entre las 6:00 am y las 6:00 pm durante los 365 días del año. Se realizaba la medición de cada variable tomando 60 muestras por minuto y posteriormente se calculaba el valor promedio que inmediatamente quedaba registrado en formato .xls. El análisis realizado permitió calcular el valor promedio diario, mensual y anual.

En la figura 1 se presenta el valor promedio anual de la temperatura ambiente medida en Bogotá.

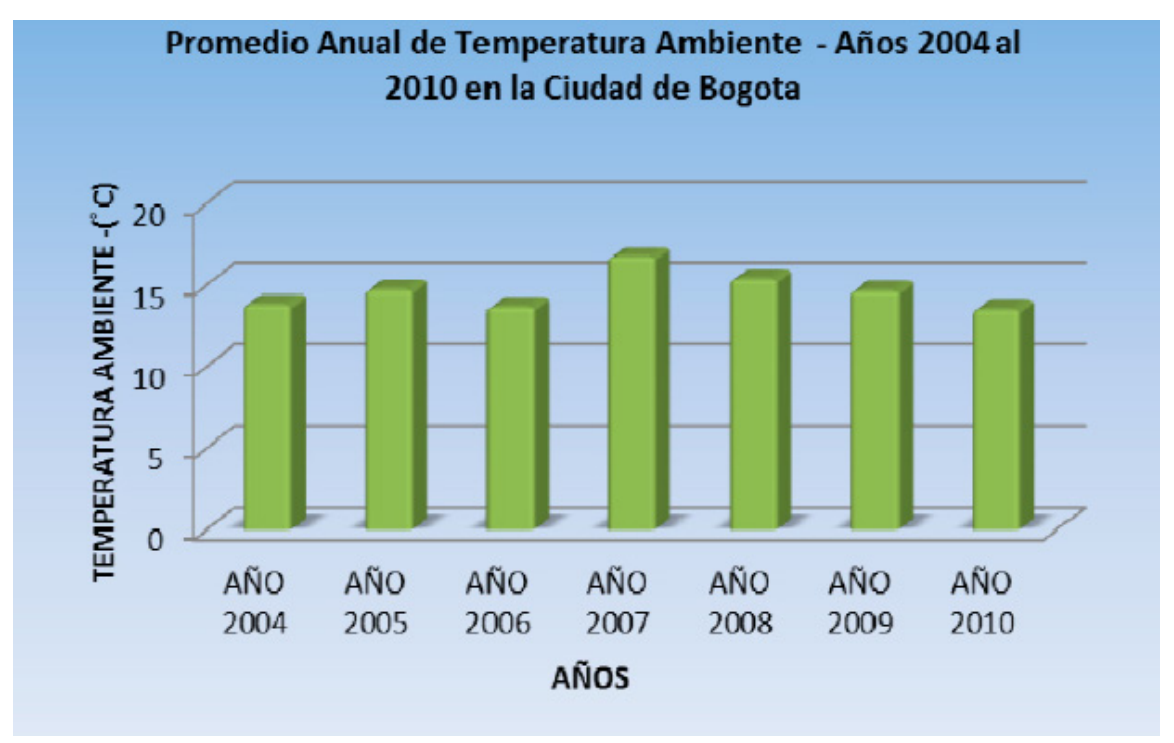

Figura 1. Registro Promedio Anual de la temperatura ambiente en Bogotá - Colombia, 2004 al 2010.

Con los datos de los promedios de temperaturas registrados en la base de datos, se obtuvo una media anual general para la temperatura ambiente medida en las cercanías del Departamento de Física de $14.67^{\circ} \mathrm{C}$ para los 6 años analizados, con una desviación estándar $\sigma \mathrm{de} \pm 1.42^{\circ} \mathrm{C}$. Esto significa que el rango de variación de la temperatura media diaria del sector, estimada con un intervalo de confianza del 95\%, es de: $13.48^{\circ} \mathrm{C}$ 
En esta base de datos se observa que la temperatura ambiente con el más bajo registro se presentó en el mes de enero de 2008 con una temperatura ambiente promedio de 12,36 ${ }^{\circ} \mathrm{C}$ y el más alto registro se presentó en el mes de diciembre de 2008 con $17,54{ }^{\circ} \mathrm{C}$. La temperatura ambiente con los mayores registros se encuentra oscilando entre 17,3 y $17,54^{\circ} \mathrm{C}$.

En la figura 2 se muestra el valor promedio anual de la radiación solar medida con el sistema.

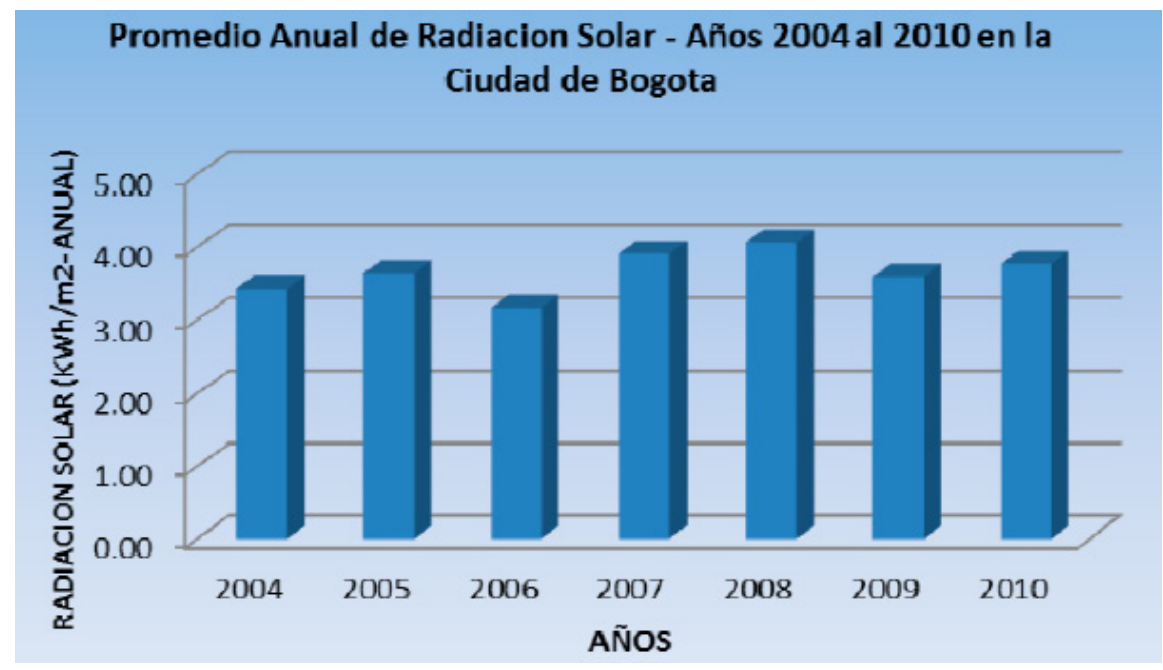

Figura 2. Registro Promedio Anual de la radiación solar en Bogotá - Colombia, 2004 al 2010.

Se observa que los años de mayor radiación solar en Bogotá son 2007, 2008 y 2010 durante los cuales se alcanzan valores superiores a $3.8 \mathrm{kWh} / \mathrm{m} 2$ y los de menor radiación solar son 2004, 2005, 2006 y 2009 en

los cuales la radiación promedio anual registra el valor más bajo de $3.17 \mathrm{kWh} / \mathrm{m} 2$. El promedio total del periodo analizado fue de $3.65 \mathrm{kWh} / \mathrm{m} 2$. Tomando como referencia el valor de radiación solar estándar de $1000 \mathrm{~W} / \mathrm{m} 2$, el número de horas de radiación solar en Bogotá es de 3.65 HSS.

Para el dimensionamiento de las plantas fotovoltaicas interconectadas, se tuvo en cuenta un factor de rendimiento del $20 \%$ y un FDI de 0.83 . De ésta manera, empleando la ecuación (1) con una potencia del generador de $6 \mathrm{~kW}$ por consideraciones económicas; cada planta fotovoltaica está en capacidad de generar aproximadamente $525.6 \mathrm{kWh} /$ mes. Utilizando la ecuación (2), el inversor a emplear sería de $5 \mathrm{~kW}$. Se decidió usar paneles solares de la marca Ligh- tway de 250W [8] c/u (24 paneles) e inversores de la marca SunnyBoy referencia 5000TL-US [9].

Las dimensiones del módulo son de 1650 mm x 990 mm x $50 \mathrm{~mm}$ y tiene un peso de $19 \mathrm{~kg}$.

Las especificaciones eléctricas y condiciones de funcionamiento de este tipo de modulo pueden observarse en la tabla 1.

\begin{tabular}{|c|c|}
\hline Datos eléctricos en condiciones STC & LW250 \\
\hline Potencia nominal - Pmáx (Wp) & 250 \\
\hline Tensión en el punto Pmáx- $\mathrm{V}_{\mathrm{MPP}}(\mathrm{V})$ & 29.95 \\
\hline Corriente en el punto Pmác- $\mathrm{I}_{\mathrm{MPP}}(\mathrm{A})$ & 8.36 \\
\hline Voltaje de circuito abierto-Voc (V) & 37.8 \\
\hline Corriente de corto circuito-Isc (A) & 8.78 \\
\hline Eficiencia módulo (\%) & 15.3 \\
\hline
\end{tabular}

Tabla 1. Especificaciones técnicas vmodulo fotovoltaico LW250.

En la figura 3 se puede observar la curva característica de funcionamiento del módulo en condiciones de prueba estándar.

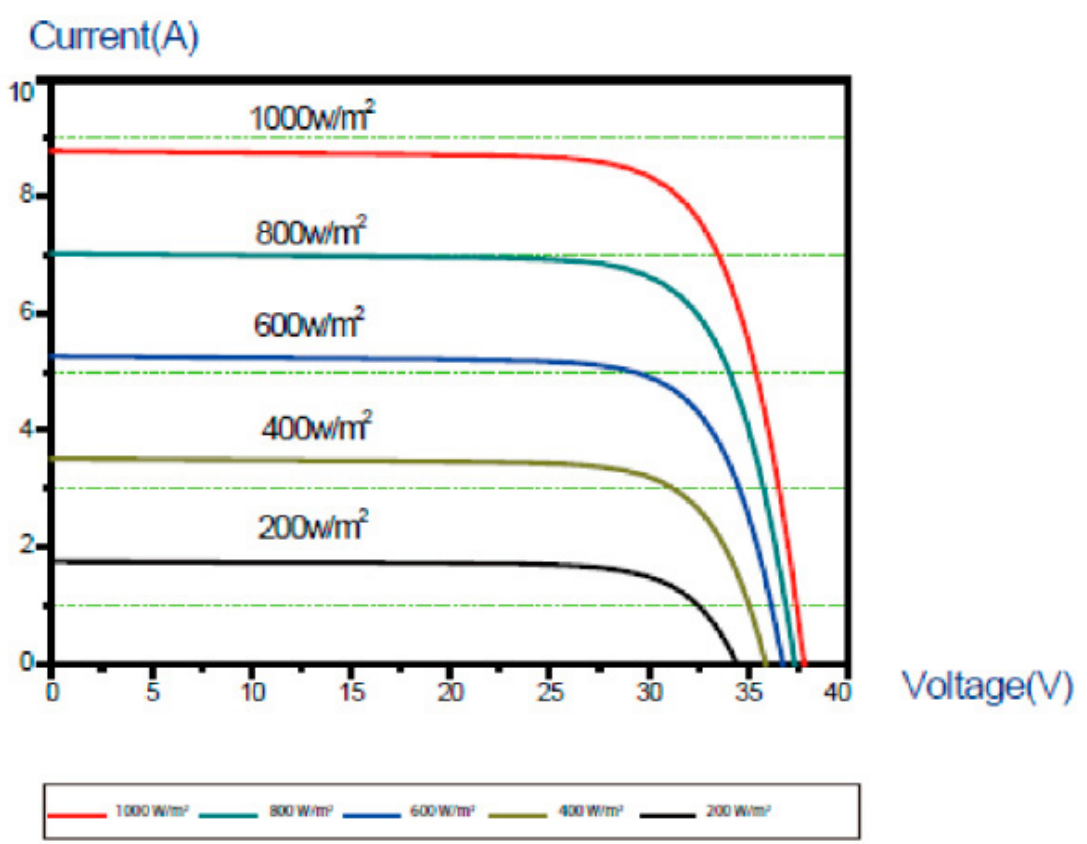

Figura 3. Curva característica del módulo fotovoltaico LW250. 


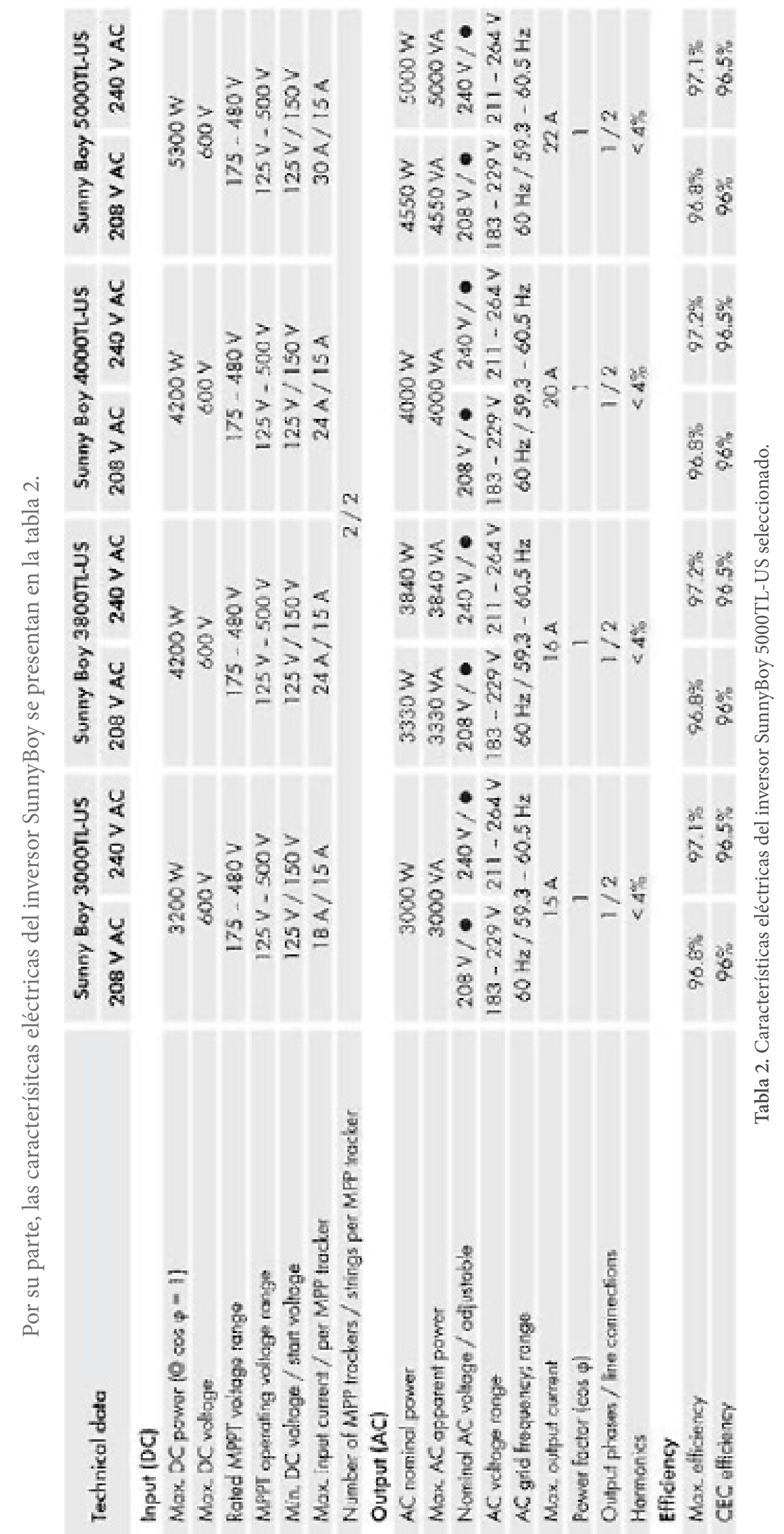


El inversor cumple con los requerimientos de la norma IEEE 929-2000 en cuanto a calidad de potencia eléctrica: distorsión armónica de tensión, componentes armónicos, variaciones de tensión y de frecuencia, presencia de flicker y factor de potencia. Cuenta además con un puerto de comunicaciones para la transferencia de información de interés hacia un pc.
La curva de eficiencia de este inversor puede verse en la figura 4. Se puede notar que se alcanza una eficiencia del 97\% cuando el voltaje DC proveniente del generador FV es superior a los $480 \mathrm{~V}$.

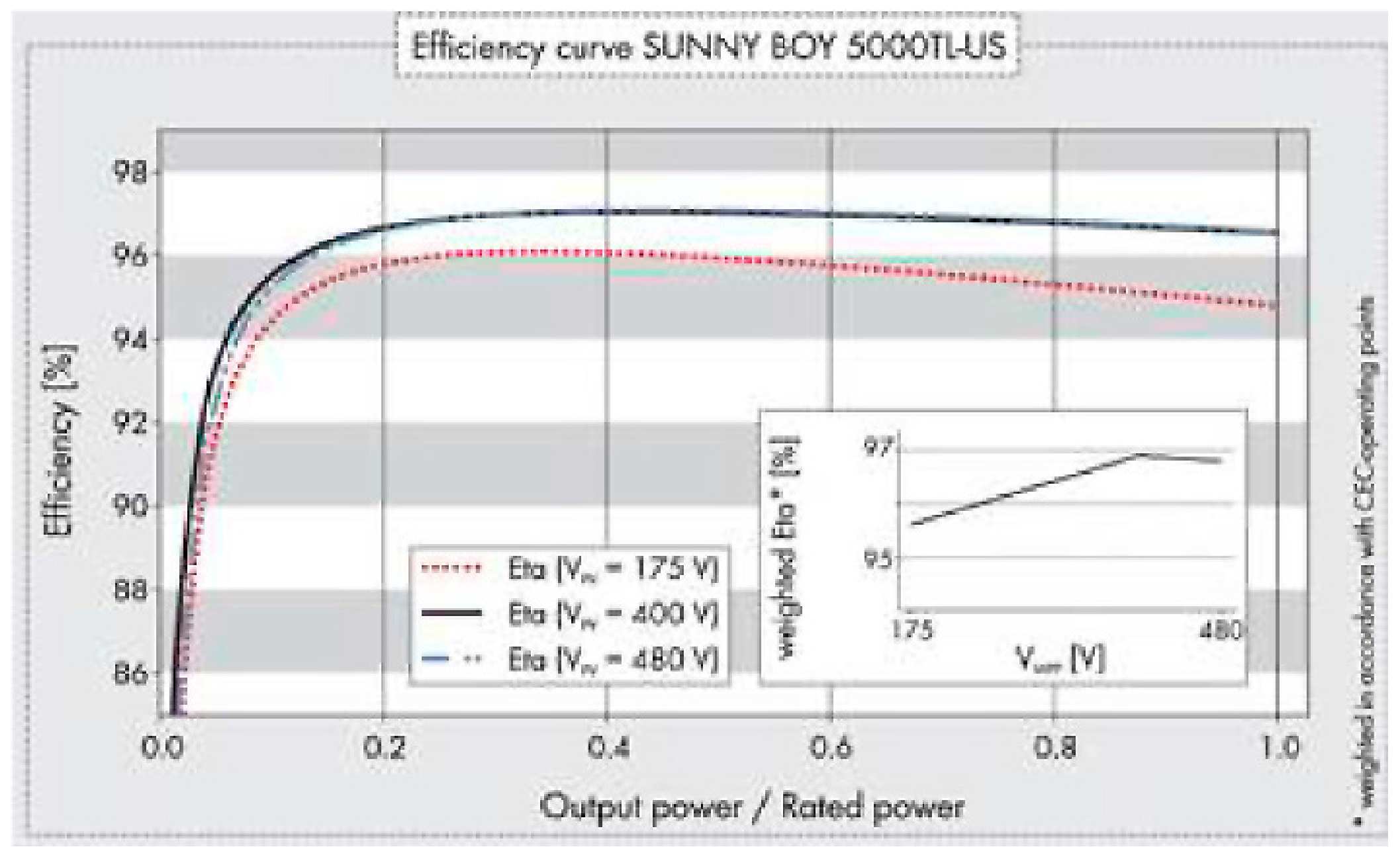

Figura 4. Perfiles de rendimiento del inversor Sunny Boy.

Con el fin de que el inversor se desempeñe a la máxima eficiencia posible, es necesario activar su circuito seguidor de máxima potencia (MPPT). Para ello se requiere que el voltaje DC del generador FV conectado

a su entrada se encuentre entre $125 \mathrm{~V}$ y $500 \mathrm{~V}$. Esto requiere que los 24 paneles de cada planta se interconecten así: 2 ramas en paralelo y cada rama contendrá 12 paneles en serie. Debido a que el voltaje de circuito abierto de cada panel es de $37.8 \mathrm{~V} \mathrm{dc}$, el voltaje de esta configuración será de $453.6 \mathrm{Vdc}$, el cual permitirá activar el circuito para el máximo desempeño del inversor.

La tabla 3 resume las principales características del dimensionamiento.

\begin{tabular}{|c|c|c|}
\hline Características & $\begin{array}{c}\text { Por sistema } \\
\text { individual }\end{array}$ & $\begin{array}{c}\text { Generación } \\
\text { de energía }\end{array}$ \\
\hline $\begin{array}{c}\text { Generador FV: } \\
\text { paneles Lightway 250W; } \\
8,78 \mathrm{~A} ; 37.8\end{array}$ & $\begin{array}{c}24 \text { paneles } \\
(6000 \mathrm{~W})\end{array}$ & \multirow{2}{*}{$\begin{array}{c}525.6 \\
\mathrm{kWh} / \mathrm{mes}\end{array}$} \\
\hline Voc. & 1 inversor de $5 \mathrm{~kW}$ & \\
\hline Inversor Sunny Boy & & \\
\hline
\end{tabular}

Tabla 3. Dimensionamiento del sistema FV interconectado y características de los equipos. 


\section{EVALUACIÓN ECONÓMICA}

Debido a que un SFV interconectado opera mediante un concepto de intercambio de energía bidireccional con la red eléctrica (entrega energía a la red cuando la generación fotovoltaica excede el consumo de la carga ó consume energía de la red cuando la generación fotovoltaica es inferior a la demandada por la carga) y a que los mayores beneficios económicos están representados en la menor cantidad de área de uso de celdas solares; se realiza el siguiente análisis económico.

En la tabla 4 se presentan en detalle los costos del proyecto solamente considerando paneles fotovoltaicos y el inversor.

\begin{tabular}{|c|c|c|}
\hline \multicolumn{2}{|c|}{ COSTOS DEL SISTEMA BIPVS UTADEO } \\
\hline ITEM & CANTIDAD & PESOS \\
\hline Paneles Solares fotovoltaico & 24 & $\$ 15.412 .800$ \\
\hline Inversor & 1 & $\$ 6.156 .000$ \\
\hline Total & & \multirow{2}{*}{$\$ 21.568 .800^{*}$} \\
\hline $\begin{array}{c}\text { * Este valor no incluye estructura, } \\
\text { cableado ni instalación }\end{array}$ & & \\
\hline
\end{tabular}

Tabla 4. Análisis de los costos relacionados con el proyecto.

Para éste análisis se consideró el precio actual de un panel marca Lightway 250W de \$260 USD y de un inversor Sunny Boy de 4kW de $\$ 2.700$ USD, puestos en Miami y un $20 \%$ gastos de transporte y nacionalización. Se utilizó el valor de \$2.040 por cada dólar según tasa representativa del mercado para el 24 de Febrero de 2014.

No se tiene en cuenta el costo del IVA ya que la ley colombiana establece que se puede inscribir el

proyecto ante el Ministerio de Ambiente para estar ser exonerado de este impuesto; debido a que representa un programa de energías limpias.

Un análisis sobre la planta solar, revela que costaría $\$ 3.595$ por cada vatio instalado.

Teniendo en cuenta un valor de potencia eléctrica hidráulica de $352 \$ / \mathrm{kWh}$, el ahorro anual mediante energía solar será de aproximadamente $\$ 2.595 .552$. De esta manera, en un período de 25 años que corresponde a la vida útil de los paneles fotovoltaicos, el ahorro económico alcanzaría $\$ 64.888 .800$, recuperando el $100 \%$ de la inversión inicial del proyecto.

\section{CONCLUSIONES}

Los resultados logrados en el marco de este trabajo constituyen una importante fuente de información, útil para el dimensionamiento óptimo de sistemas BIPVS en Colombia y para evaluar la conveniencia o no del desarrollo en el futuro de proyectos de generación FV de electricidad donde juegan un papel importante los aspectos técnicos y econó- micos pero sobre todo los aspectos medioambientales, ya que este tipo de generación no contamina el medio ambiente.

Adicionalmente, vale la pena mencionar los siguientes aportes:

- Apropiación y transferencia de nuevas tecnologías en el campo de la conversión fotovoltaica de la energía solar, que es de especial importancia para el país ya que se cuenta con un enorme potencial gracias a la ubicación del país en la zona ecuatorial y porque este tipo de generación no contamina el medio ambiente.

- Obtención de información confiable para poder establecer qué posibilidades tanto técnicas como financieras podría tener este tipo tecnología en el mercado energético Colombiano en el futuro.

- Implementación de la primera red solar fv para la generación de potencia eléctrica como fuente distribuida conectada a una red de baja tensión del país.

- Consolidación de un sistema de generación de energía renovable para el apoyo de laboratorios, tesis de grado de pregrado y posgrado, investigación e impacto social y ambiental de la universidad.

- Reducción económica para la universidad en la tarifa de consumo de electricidad generada de forma convencional (hidráulica) al utilizar fuentes de energía renovable.

- Posicionamiento nacional e internacional en cuanto al manejo de recursos naturales e implementación de estrategias para la reducción de la contaminación ambiental.

Es importante resaltar que con la implementación de éste tipo de proyectos se beneficiarán muchos sectores del país, pero en especial el sector eléctrico en general, ambiental y el sector académico.

\section{AGRADECIMIENTOS}

Los autores agradecen al Grupo de Materiales y Energía Solar - GMS\&ES del Departamento de Física de la Universidad Nacional de Colombia por la disponibilidad de los datos de radiación y temperatura para el análisis presentado.

\section{REFERENCIAS}

[1] J. A. CANO, E. G. CEDIEL, J. A. HERNANDEZ, Trabajo de grado, Dept. Ing. Eléctrica, Universidad Nacional. 1, pp. 28-34, Bogotá, Colombia, Abril 2003.

[2] A.J. Aristizábal, J. Hernández, G. Gordillo. Análisi de calidad de potencia para un sistema fotovoltaico inter- 
conectado, II Simposio Internacional sobre Calidad de la Energía Eléctrica. Bogotá, 2003.

[3] A.J. Aristizábal. Tesis de Doctorado, Dept. de Física, Universidad Nacional de Colombia. 3, pp. 24, Bogotá, Colombia, 2008.

[4]A. J. Aristizábal, G. Gordillo. Performance Monitoring Results of the First Grid-Connected BIPV Installation in Colombia", Renewable Energy, 2008.

[5] A. J. Aristizábal, G. Gordillo. Performance and economic evaluation of the first grid - connected installation in Colombia, over 4 years of continuous operation". International Journal of Sustainable Energy, 2011.

[6] A. J. Aristizábal, A. Chica, F. Rey. Application of Autoregressive Model with Exogenous Inputs (ARX) to Identify and Analyze Patterns of Solar Global Radiation and
Ambient Temperature". International Journal of Ambient Energy, 2012.

[7] A. J. Aristizábal, A. Torres, A. Pérez. Dimensionamiento de un sistema fotovoltaico interconectado para suplir las necesidades energéticas de la sala de tutorías de la Facultad de Ingeniería Ambiental de la Universidad Santo Tomás", 1er Congreso de Energía Sostenible, 2012.

[8] Módulo policristalino LW250, marca Lightway, [Citado el: 11 de Septiembre de 2014] http://www.lightwaysolar.com/page/list5.jsp?langpar=flag01

[9] Inversores dc/ac SunnyBoy de alta potencia, [Citado el: 11 de Septiembre de 2014]

http://www.sma-america.com/en_US/products/ grid-tied-inverters/sunny-boy/sunny-boy-5000-us-6000us- 7000-us-8000-us.html 


\title{
MODELO DE SISTEMA SOLAR FOTOVOLTAICO PARA SUMINISTRO ELÉCTRICO BÁSICO COMO APOYO A PLAN NUTRICIONAL EN LA ESCUELA EL CARDONAL DE TIBANÁ (BOYACÁ)
}

\author{
Andrea C. Alvarado Fajardo \\ Hernán Carvajal Osorio ${ }^{2}$ \\ William F. Álvarez Castañeda ${ }^{3}$ \\ 1'andrea.alvaradof@unilibrebog.edu.co \\ ${ }^{2}$ hernan.carvajal@ugc.edu.co \\ william.alvarez01@usantoto.edu.co
}

\begin{abstract}
RESUMEN
Un sistema solar fotovoltaico autónomo puede aprovechar el recurso solar disponible en una zona de estudio como la Escuela rural El Cardonal en Tibaná-Boyacá, para suministrar energía eléctrica a la misma, permitiendo el desarrollo de un programa nutricional para escolares en condición de vulnerabilidad. Mediante la utilización del software TRNSYS, se modeló y analizó el comportamiento que tendría dicho sistema ante las condiciones climáticas del lugar y las características de operación de la carga.
\end{abstract}

Palabras claves: Energía solar, escuela rural, fotovoltaico, TRNSYS 


\section{INTRODUCCIÓN}

En la vereda Ruche del Municipio de Tibaná (Boyacá), se encuentra la Escuela rural El Cardonal, donde se imparte educación básica primaria a campesinos de muy bajos recursos. Aunque cuenta con conexión a la red eléctrica, el suministro es altamente deficiente por el estado precario de la línea que presenta fallas muy frecuentes que llegan a prolongarse hasta por 10 días. Esta situación, además de afectar las actividades académicas, está poniendo en serio riesgo la salud de los niños estudiantes, a quienes por una deficiente nutrición en sus hogares, se les suministra alimentación complementaria en la Escuela como parte de un programa gubernamental. Esto exige garantizar refrigeración de los alimentos en el sitio, problema central de este trabajo. Resultando muy costosa la reconstrucción de la línea eléctrica de la red externa, se consideró aprovechar la energía solar disponible en el sitio para el suministro energético a la Escuela.

La energía solar fotovoltaica (FV) ha demostrado su bondad en numerosas aplicaciones rurales, actualmente con costos decrecientes. Sin embargo, estos últimos pasan a segundo plano frente a un alto beneficio social que, como en este caso, busca superar condiciones de pobreza y desigualdad.

El objetivo principal del proyecto fue diseñar un sistema solar FV autónomo suficiente para atender la carga básica de la Escuela, desarrollando, a la vez, un modelo sistematizado utilizando el software TRNSYS, con el fin de hacer análisis del comportamiento del sistema en respuesta al recurso solar disponible. Se emplearon características de paneles solares FV comerciales de marca conocida, al igual que para los otros elementos del sistema. Se consideró como carga básica la indispensable para la operación en la Escuela, consistente en un refrigerador pequeño e iluminación del salón principal.

Parte importante del trabajo fue la medición continua in situ de la radiación solar durante un año, para tener certeza del recurso energético disponible. También, tuvo el valor agregado de la participación de los niños de la Escuela, quienes dirigidos por la profesora, completaron registros muy sencillos sobre los cambios del clima en el lugar, aportándose una formación elemental sobre energías renovables.

\section{MATERIALES Y MÉTODOS}

Una vez hecho el registro en el sitio de la radiación solar incidente, la metodología consistió en el diseño y simulación del sistema solar apropiado para atender la demanda de la carga eléctrica de la escuela, utilizando el programa -TRNSYS para generar el perfil de simulación reproduciendo las condiciones de operación del sistema y la carga para su análisis de respuesta. El diseño del sistema se basó principalmente en Nina (2011), Ortega (2001) y Alonso (2014).

\section{Registro de radiación solar en el sitio}

Se efectuó registro continuo durante un año de la radiación solar y las condiciones climáticas en el sitio de la Escuela. Con este fin, se instaló una estación meteorológica, una vez verificado su funcionamiento y hecha su recalibración contra un piranómetro certificado marca KIPP \& ZONEN se ajustan los valores almacenados por la estación metereologica a cifras teóricamente válidas. La figura 1 muestra los valores en vatios sobre metro cuadrado $(\mathrm{W} / \mathrm{m} 2)$, promediados para cada mes del año.

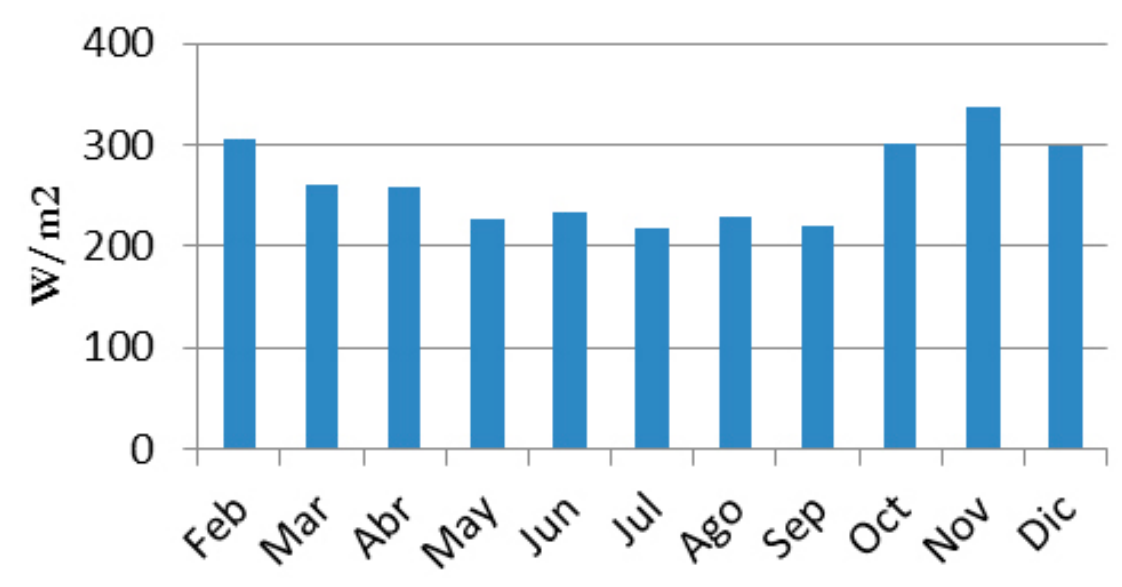

Figura 1. Radiación promedio mensual en la Escuela El Cardonal.

En general, se aprecia (figura 1) un recurso solar no muy importante, con valores máximos de potencia cercanos a $330 \mathrm{~W} / \mathrm{m} 2$ en los meses de fin de año y principio del siguiente, menos en los otros meses del año. Esto se debe principalmente a una relativa alta nubosidad y lluvias frecuentes en la región en los meses más soleados de octubre a febrero. Estas condiciones se pudieron verificar en parte, con la información registrada por los niños de la Escuela.

\section{Estimación de la demanda}

La carga eléctrica de la Escuela que se tuvo en cuenta para el diseño del sistema solar fotovoltaico fue la mínima de operación; correspondiente a un refrigerador pequeño (consumo indicado en placa de $0,86 \mathrm{kWh}$ diarios) y dos bombillas de $20 \mathrm{~W}$ cada una (usadas durante las seis horas diarias en que los niños asisten a la escuela, de 8 am a 2 pm).

El consumo de las dos bombillas se calcula por el producto de la potencia por el tiempo de funcionamiento (ecuación 1):

$$
E_{\text {bom }}=P_{\text {bom }} * t=2 \times 20 W \times \frac{6 h}{d}=240 \mathrm{Wh} / \text { día }
$$

Para el consumo de energía de la nevera se tuvo en cuenta la operación por ciclos del refrigerador. Se asumieron ciclos de operación a potencia nominal de duración 15 minutos cada hora, completando así seis horas diarias. Así, la energía consumida en el día, está dada por:

$$
E_{n e v}=P_{n e v} * t=150 \mathrm{~W} \times 6 \frac{h}{d}=900 \mathrm{Wh} / \mathrm{d}
$$


Donde la potencia de la nevera, $P_{n e v} P_{n e v}$, se calculó con el producto de los valores nominales de corriente y voltaje dados por el fabricante: $I_{\text {nev }} I_{n e v} \times V_{n e v} V_{n e v}=1,3 \mathrm{~A} \times 115 \mathrm{~V}=$ $150 \mathrm{~W}$.

La energía total de consumo diario en corriente alterna (AC), al incluir nevera y bombillos, es:

$$
E_{a c}=E_{n e v}+E_{b o m}=1140 \mathrm{Wh} / \text { día }
$$

Siendo necesario un inversor para convertir a corriente AC la corriente continua (DC) producida por los paneles solares, se estimó con un $20 \%$ de pérdidas, lo cual se aplica al valor en (4) con un factor de inversión $F_{a c-d c}=1,2$, $F_{a c-d c}=1,2$, para una energía total equivalente en DC:

$$
E_{d c}=F_{a c-d c} * E_{a c}=1368 \mathrm{Wh} / \mathrm{dí} a
$$

En cuanto a la potencia demandada por la carga (valor que se requiere para dimensionar el inversor-regulador), se suman (en 6) las potencias de la nevera y los dos bombillos. Para la primera, es necesario tener en cuenta el pico de carga que produce el compresor del refrigerador al iniciar cada ciclo que se estimó en $150 \%$ de la potencia (supuesto de duración de un segundo). Por tanto, se aplicó un factor del arranque de carga $F_{p}=1,5 F_{p}=1,5$, obteniendo para la nevera una potencia de:

$$
P_{M, n e v}=P_{n e v} * F_{P}=225 \mathrm{~W}
$$

Para un total, con los bombillos (40 W), de potencia máxima en $\mathrm{AC}$ :

$$
P_{a c, \text { max }}=P_{M, \text { nev }}+P_{b o m}=265 \mathrm{~W}
$$

Para parte del diseño del sistema solar, el consumo de energía conviene expresarlo en términos de Amperio-hora (A-h), lo cual se obtiene (ecuación 7) dividiendo la carga estimada en DC ( $E_{d c} E_{d c}$ en Wh, de 4$)$, entre el voltaje voltaje de referencia del sistema $V_{o p} V_{o p}$, establecido para todos los elementos DC en $24 \mathrm{~V}$ :

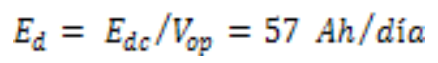

Aplicando un factor de seguridad FS de 1,2 por pérdidas de energía en los módulos fotovoltaicos, las baterías, el regulador, el inversor y por suciedad, se obtiene como carga total diaria:

$$
E_{T}=E_{d} * F_{5}=68,4 \text { Ah/día }
$$

\section{Dimensionamiento para la generación}

Para el suministro eléctrico, se consideró la tecnología solar fotovoltaica por ser una de las formas más apropiadas para el medio rural, en razón de sus propiedades de modularidad y autonomía además, de su bajo mantenimiento y contaminación en el sitio de uso (Egido, 2006).

Para determinar el tamaño de los paneles fotovoltaicos, la energía solar disponible en el sitio se especifica en Horas
Solar Pico (HSP). Según las mediciones de irradiación solar efectuadas en la Escuela (figura 1), con el promedio diario de potencia por metro cuadrado asumido durante doce horas de brillo solar (cerca del Ecuador), se obtiene un equivalente de HSP $=3$ horas.

Para la selección de la capacidad de generación de los paneles solares, se utiliza el valor de corriente máxima $I_{p} I_{p}$ del sistema solar fotovoltaico, el cual (según 9), se obtiene de la relación entre la carga total diaria (de 8) y las horas de sol pico:

$$
I_{p}=E_{\tau} / H S P=22,8 \mathrm{~A}
$$

Según dicha cifra, se escogieron paneles solares marca Suntech, de celdas de silicio monocristalino porque este material proporciona un rendimiento energético alto (REDFE, 2014) y de mayor duración respecto a módulos de otro tipo de materiales (Fernández, 2009) además, son el tipo de celdas más usadas a nivel mundial (Joachín, 2008).

De acuerdo a las especificaciones del fabricante, los valores nominales y máximos de potencia, voltaje y corriente máxima de operación son:

$$
\begin{gathered}
P_{r e f}=175 \mathrm{~W} \\
V_{r e f}=24 \mathrm{~V} \quad V_{m p, r e f}=35,2 \mathrm{~V} \\
I_{s c, r e f}=5,2 \mathrm{~A} \quad I_{m p, r e f}=4,95 \mathrm{~A}
\end{gathered}
$$

El número de módulos solares fotovoltaicos requeridos se determina según la relación (10), tomando el entero mayor más próximo al resultado de dividir la corriente máxima Ip demandada del sistema (en 9) entre la corriente Iop de operación del panel:

$$
N P=I_{p} / I_{o p}=4
$$

La forma de conexión de los paneles se establece de acuerdo a los voltajes: no se requiere conexión en serie al escoger paneles solares de $24 \mathrm{~V}$ (valor de referencia) que coinciden con el voltaje definido para todo el sistema en DC. Por tanto, los cuatro paneles deberán ser conectados en paralelo, como se muestra en la figura 2, para suministrar la energía requerida por la carga.

\section{Dimensionamiento de acumulación}

El banco de baterías se diseñó teniendo en cuenta que en aplicaciones a sistemas solares, los acumuladores deben mantener la corriente durante horas, y generalmente están sujetas a condiciones de cargas y descargas continuamente, con lo cual los periodos de reposo son casi nulos (Martínez, 2011). Se eligieron acumuladores de plomo ácido, debido a que son de fácil adquisición, relativamente no muy costosos y tienen buena duración y condiciones de bajo mantenimiento (Martínez, 2011).

Considerando cuatro días de reserva, debido a que la Escuela se encuentra en un sector con bastante nubosidad, la 
capacidad del banco de baterías, determinada sobre la demanda de energía total diaria de la carga, sería:

$$
Q_{\bar{B}}=E_{T} * N_{D}=273,6 \mathrm{Ah}
$$

Para evitar descargas pronunciadas del acumulador que reducen su vida útil, se limita su operación a una profundidad de descarga máxima del 50\%, por lo que la capacidad total del sistema de acumulación será

$$
Q_{T}=Q_{\bar{B}} / 0,5=547 \mathrm{Ah}
$$

Siendo recomendable utilizar varias baterías, es necesario realizar una configuración serie y/o paralelo, en donde los acumuladores deben ser del mismo tipo, con la misma capacidad e idéntico potencial eléctrico (UPME, 2003). Entre las baterías encontradas comercialmente, se eligen acumuladores de $12 \mathrm{~V}$ a $300 \mathrm{Ah}$, mediante una configuración serie-paralelo para obtener la capacidad de acumulación estimada (figura 2).

\section{Dimensionamiento del regulador-inversor}

Para que el regulador-inversor pueda manejar la potencia requerida por la carga sin forzar el equipo, su capacidad debe ser mayor en suficiente margen que la potencia máxima de la carga en AC:

$$
P_{r e g}>P_{a c, \max }
$$

Tomando de Pac, $\max =265 \mathrm{~W}$ (6), y un margen alto para el caso de que el usuario quisiera ampliar la carga, se consideró un regulador-inversor de $P_{r e g}=500 \mathrm{~W}$

La figura 2, muestra las características principales de los elementos requeridos para el sistema solar fotovoltaico de acuerdo al diseño calculado, así como todas las conexiones necesarias, las protecciones y la conexión a tierra.

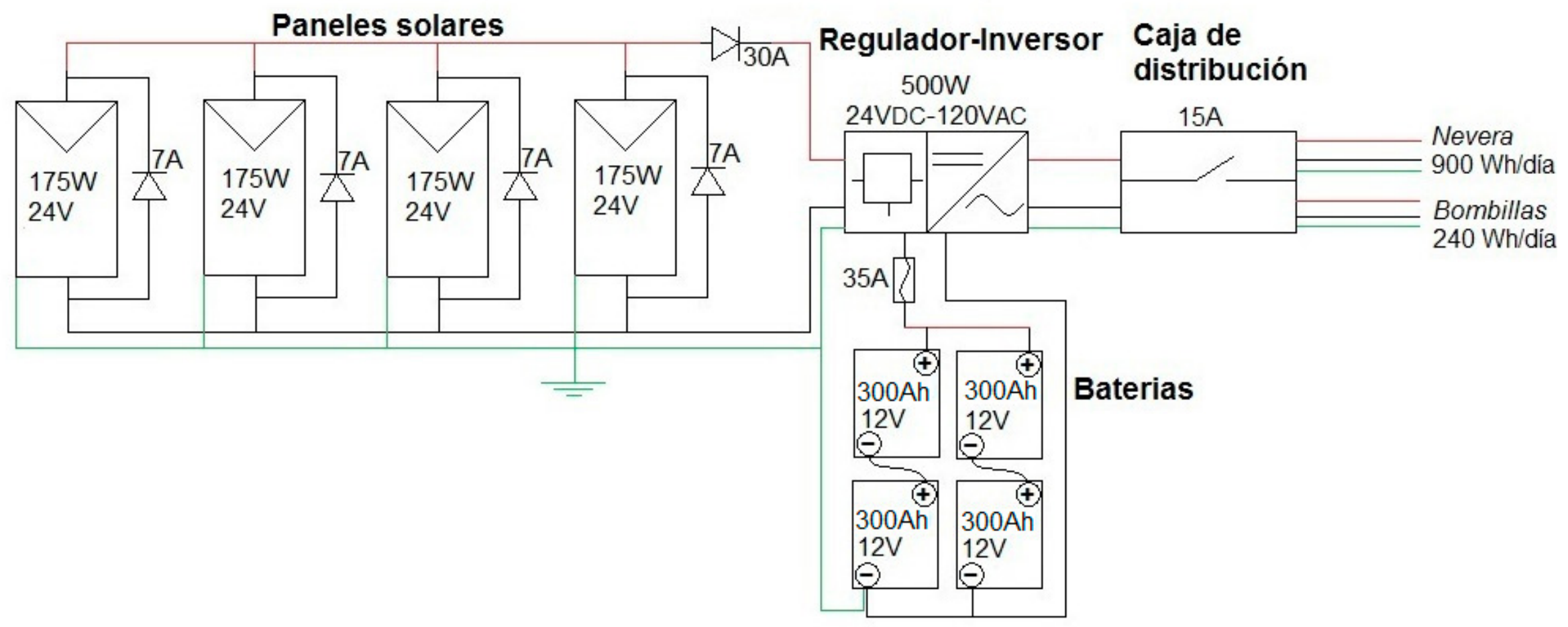

Figura 2. Plano eléctrico del diseño propuesto.

\section{RESULTADOS}

Realizado el dimensionamiento del sistema solar fotovoltaico, se generó una plataforma de simulación mediante el software TRNSYS 17, permitiendo analizar el funcionamiento del diseño con una carga difícil de manejar por la operación por ciclos de la nevera.

En la modelación, el programa se vale de módulos denominados "TYPEs" que contienen la información de entrada y características de cada uno de los componentes, según co- rresponda: archivo climático TYPE 109, los paneles solares TYPE 94a, el regulador - inversor TYPE 48d, el banco de baterías TYPE 47b y la carga TYPE 14h. Adicionalmente, se utilizaron módulos TYPE 57, necesarios para realizar los acoples entre los parámetros de los diferentes elementos.

La figura 3 muestra (en imagen de pantalla) el sistema completo configurado para el programa. A continuación, se detalla la forma como se preparó el modelo con TRNSYS para simular el sistema FV diseñado. 
"थव File Edit View Direct Access Assembly Calculate Tools Window ?

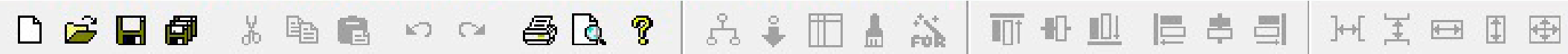
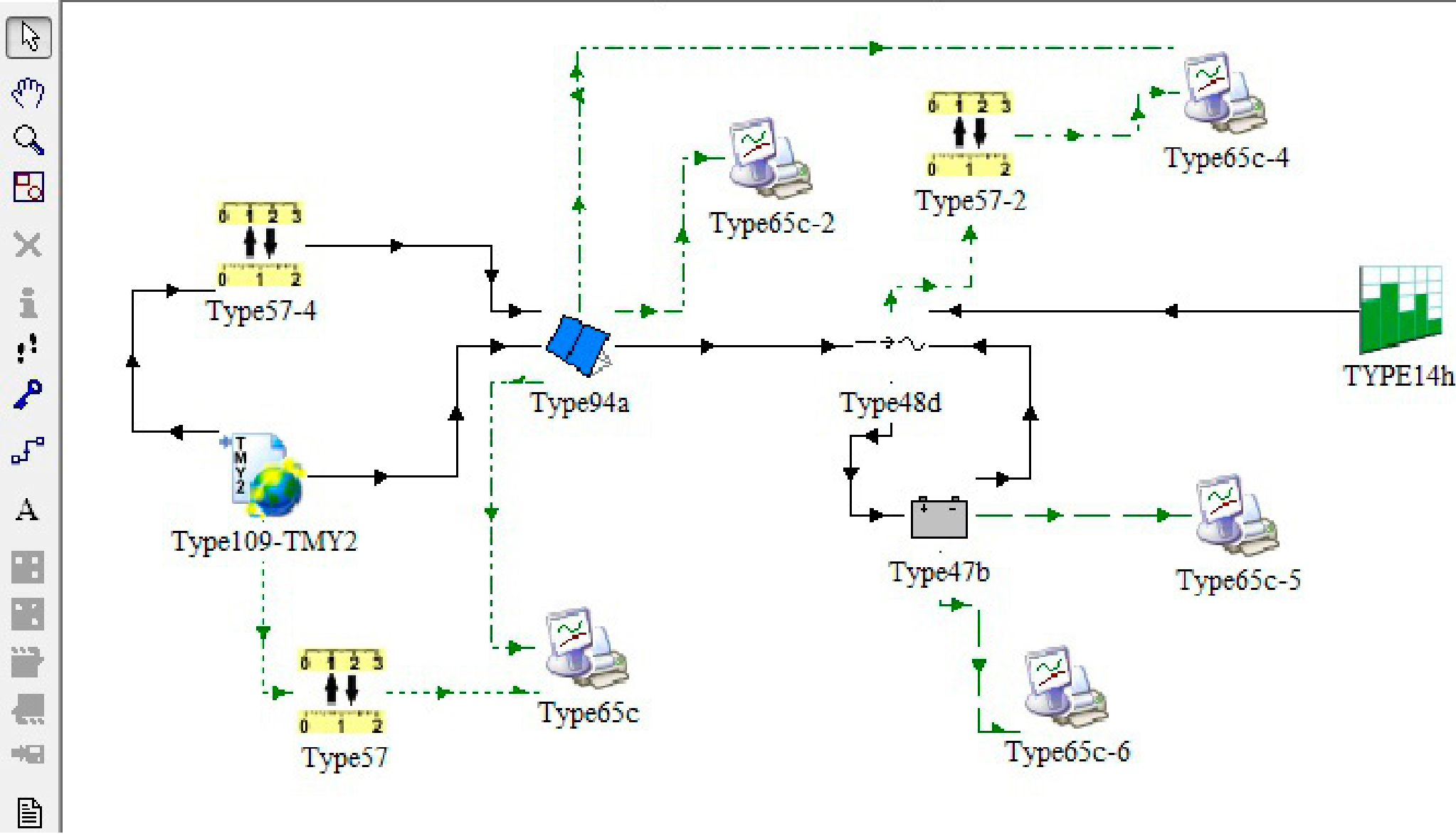

Figura 3. Sistema en TRNSYS.

Los resultados se indican habiendo escogido, a manera demostrativa, una semana con diferentes condiciones de radiación solar, como lo indica en la figura 4 el color azul. Estas condiciones varían desde $550 \mathrm{~W} / \mathrm{m} 2$ para el primer día y con un un valor máximo de $1040 \mathrm{~W} / \mathrm{m} 2$ en el cuarto día.

\section{Modelación matriz fotovoltaica (FV)}

La simulación de los paneles solares es hecha con el TYPE 94a, empleando características de celdas FV de silicio monocristalino y haciendo un seguimiento al punto de operación de máxima potencia. El módulo emplea ecuaciones para un tipo de circuito equivalente empírico que simula las características corriente-voltaje de un solo panel y luego, las extrapola para predecir el comportamiento de una matriz multi-módulo que representa la recolección de la energía solar (Solar E.L., 2012).

A continuación, se presentan los resultados del modelo y se comparan con los valores de referencia que el fabricante indica como respuesta de los paneles solares.

Teóricamente, la potencia de salida en la matriz fotovoltaica $P_{r e f, T} P_{r e f, T}$, está dada por la potencia para un módulo solar (especificada por el fabricate) ${ }^{P_{\boldsymbol{\theta} f}} P_{r \boldsymbol{\theta} f}$ y el número de paneles conectados en paralelo $N P N P$

$$
P_{r e f, T}=P_{r e f} * N P=175 \mathrm{~W} * 4=700 \mathrm{~W}
$$

La potencia máxima, que se puede conseguir a la salida del arreglo de paneles solares (de color rojo en la figura 4), ocurre a la hora 84 de simulación (momento de máxima radiacion solar) con un valor $\mathrm{de}^{P_{A, 94 h}}=576,6 \mathrm{~W}$. El comportamiento del arreglo de módulos fotovoltaicos es adecuado a la forma de operación esperada, la potencia máxima entregada $P_{\max , 84 h} P_{\max , 84 h}$ tiene una eficiencia del $82,7 \%$ en relación con el valor de la potencia máxima teórica, adecuada a la eficiencia estimada en $83 \%$.

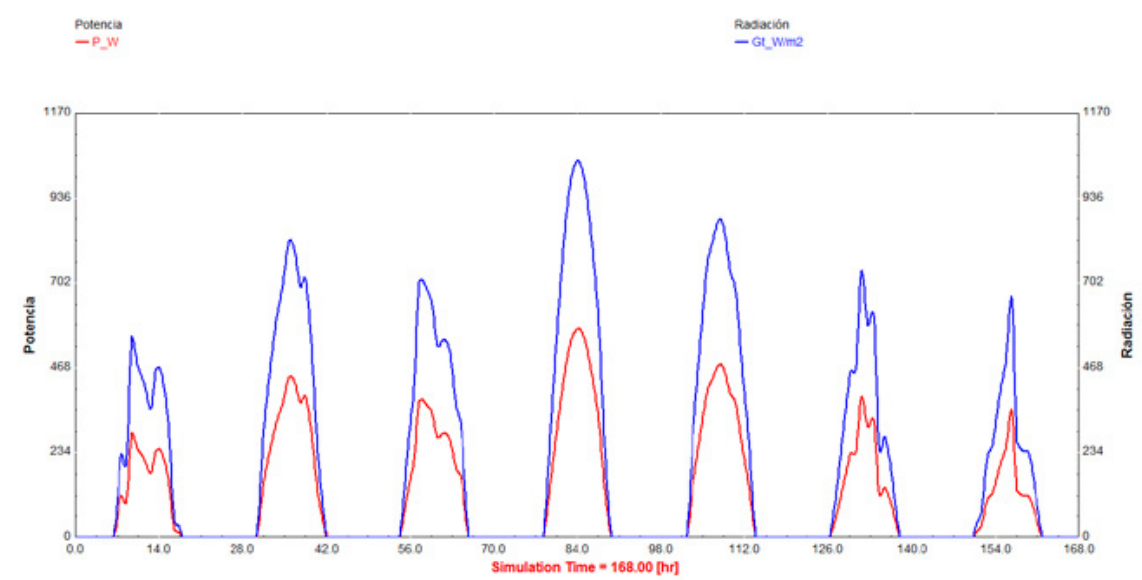

Figura 4. Radiación y potencia generadas respecto al tiempo.

\section{Modelación banco de baterías}

La simulación del sistema de acumulación diseñado describe las relaciones entre el voltaje, la corriente y el estado de carga. El TYPE 47b de TRNSYS modela la batería plomo-ácido, que opera conjuntamente con la malla FV y con componentes de acondicionamiento de la potencia (Solar E.L., 2012. Representa el comportamiento del acumulador 
en función del estado de carga y de la corriente (Burgos, 2013).

El voltaje a la salida del modelo del banco de baterías durante los ciclos de carga-descarga se muestra en la figura 5. Se aprecian los límites de voltajes: el máximo en carga C_Vc $=27,9 \mathrm{~V}$ (de color fucsia), muy cercano al valor estimado como voltaje máximo para cargar el acumulador VB $28 \mathrm{~V}$, y la tensión mínima de descarga (de color azul) D_Vcen 21,6 V.

En cuanto al voltaje de operación V (de color rojo) presenta tres estados de carga durante cada día, los cuales se aprecian claramente los días en óptimas condiciones de radación: durante la primera etapa, el voltaje aumenta rápidamente sobrepasando los $27 \mathrm{~V}$ hasta alcanzar el punto de saturación. En este momento el acumulador llega al 100 \% de carga y es entonces cuando el regulador reduce el paso de tensión a la batería.

Para el segundo periodo, el acumulador se mantiene en estado de carga total, conservando este lapso de tiempo un voltaje de $27 \mathrm{~V}$ hasta el momento en que es necesario abastecer a la carga por parte la batería.

En la última fase, el regulador permite la descarga del acumulador, conservando un valor levemente mayor a 25 $\mathrm{V}$. Este periodo se mantiene hasta que la potencia generada por los módulos solares pueda recargar nuevamente la batería o si se ha llegado al límite de descarga. En esta etapa, la tensión puede llegar a un valor mínimo de $24,77 \mathrm{~V}$, debido a que un voltaje menor haría que el acumulador se descargue más que el porcentaje diseñado del $50 \%$.

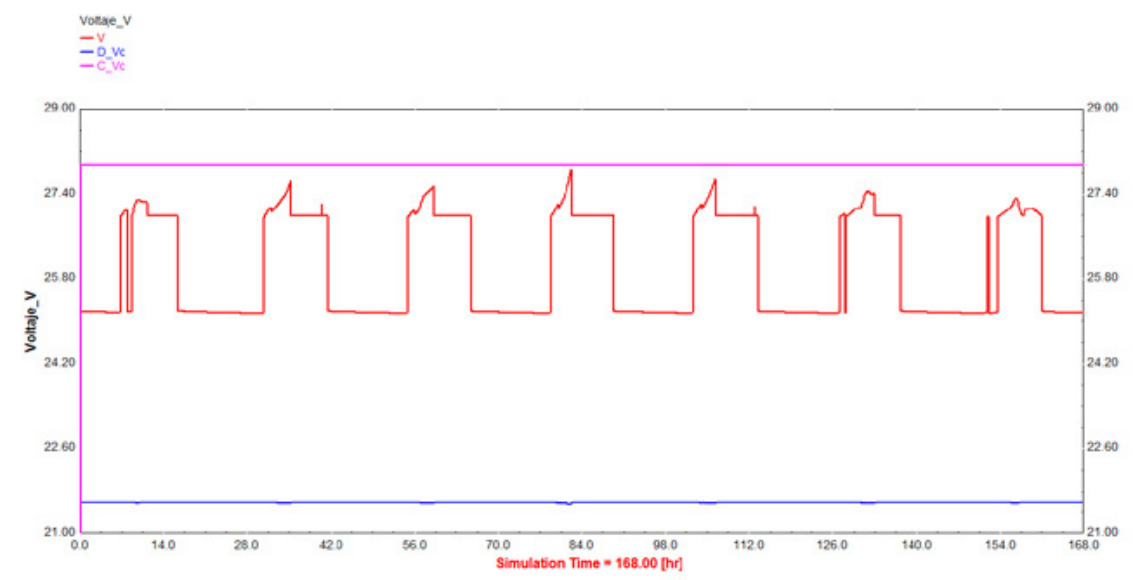

Figura 5. Voltajes en el banco de baterías - TYPE47b.

\section{Modelación carga eléctrica}

La simulación de la carga se genera a través de un perfil promedio diario de consumo de acuerdo al requerimiento eléctrico del refrigerador promediado y a las bombillas, como muestra la figura 6. Durante el tiempo en que la institución está inactiva, de las 0 horas hasta las 8 horas y de las 14 horas a las 24 horas, con un promedio calculado de potencia de 33,3 W (solo la nevera). En las seis horas de actividad escolar, de las 8 horas a las 14 horas, se suma un promedio de la nevera de $50 \mathrm{~W}$ más los $40 \mathrm{~W}$ de las dos bombillas, para un total de potencia de $90 \mathrm{~W}$ promedio.

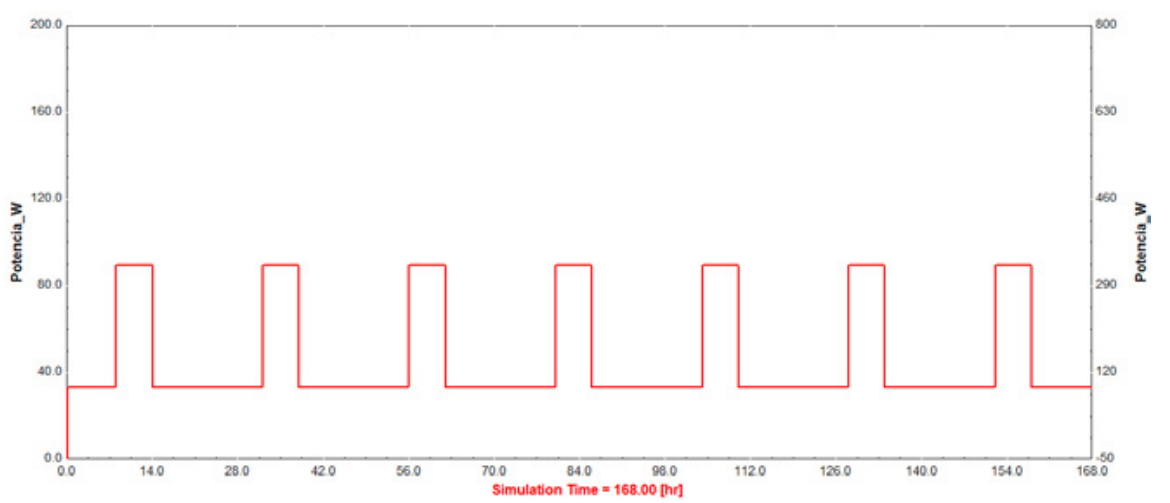

Figura 6. Perfil de consumo de potencia - TYPE $14 \mathrm{~h}$.

\section{Modelación regulador e inversor}

Se analiza en forma general el comportamiento de todo el sistema, debido a que el regulador-inversor distribuye la energía a través de los elementos que conforman el sistema. La figura 7 presenta la salida de potencia del modelo del regulador-inversor, desde o hacia la batería (de color fucsia). Cuando la potencia aumenta, indica el paso de energía al acumulador y en sentido contrario, el regulador controla la descarga.

De acuerdo a una eficiencia de inversión DC-AC del $83 \%$, durante las 18 horas en que no hay niños en la Escuela, el regulador permite una descarga continua en la batería de 40,1 W. Para ese periodo, el perfil (figura 7) indicó un requerimiento de 33,3 W. En las horas del día en que se presenta suficiente radiación solar, la potencia generada por el arreglo fotovoltaico (de color azul) es enviada desde el regulador para abastecer la carga directamente mientras estén cargadas las baterías. Cada mañana, de acuerdo a la potencia excedente generada por los paneles solares, el acumulador comienza a ser recargado.

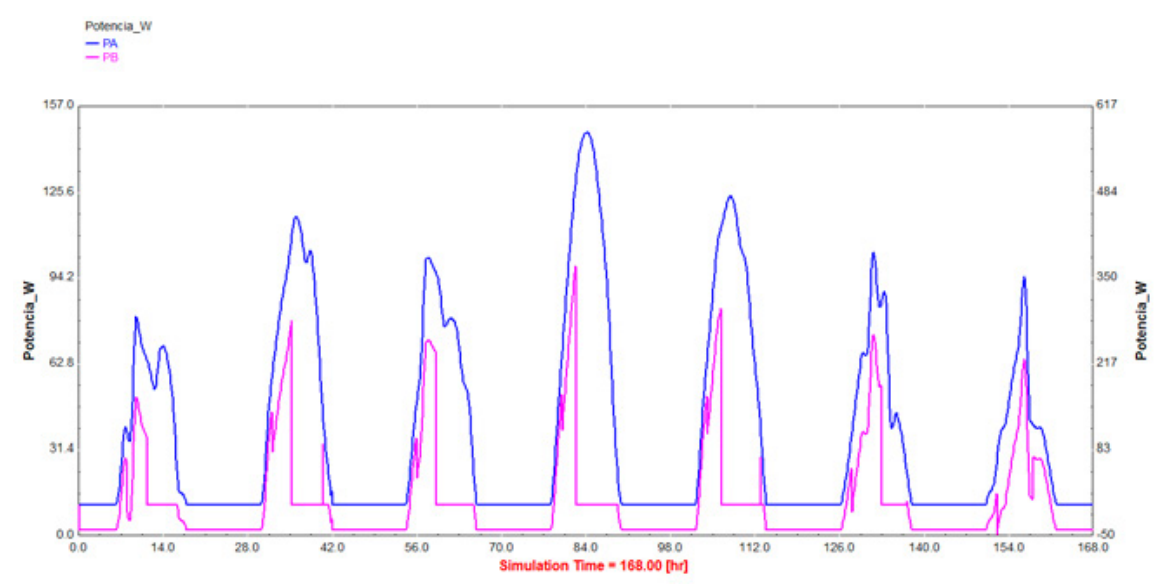

Figura 7. Potencia del Regulador-Inversor y de la malla FV

Nuevamente el modelo muestra un comportamiento adecuado a las condiciones de demanda de la carga y en operación conjunta con el banco de baterías. Cuando hay radiación solar en exceso y la energía generada es mayor que la demanda estando las baterías cargadas, el regulador-inversor está provisto de una resistencia eléctrica para disipar en forma de calor la energía sobrante. 


\section{CONCLUSIONES}

La simulación realizada con aplicación del software TRNSYS del modelo del sistema solar fotovoltaico, diseñado para satisfacer las necesidades eléctricas primordiales de la Escuela El Cardonal, demostró su conveniencia y efectividad para analizar y predecir el buen comportamiento del sistema. Es adecuado, en este caso, para dar continuidad al plan nutricional de los estudiantes, permitiendo mantener en condiciones refrigeradas los alimentos que lo requieren.

El diseño probado podría ahora ser implementado con alto grado de certeza para satisfacer la necesidad prevista. También, de ser aplicado en otras instituciones educativas rurales en situación similar, se estarían favoreciendo los escenarios de desarrollo de comunidades en condición de vulnerabilidad.

Fue posible el estudio detallado del comportamiento de la carga eléctrica y de la operación y respuesta del banco de baterías, bajo diferentes condiciones de radiación solar, al ser facilitado el análisis con el uso del software TRNSYS. Aún, en el caso no fácil de la nevera por su operación por ciclo, se pudo simular y evaluar la tendencia de esta, demostrando la capacidad suficiente del sistema solar fotovoltaico diseñado, operando adecuadamente ante los diferentes regímenes de funcionamiento de los paneles solares ante la demanda eléctrica de los dispositivos y de la carga.

Como herramienta para evaluar la producción de energía en sistemas solares fotovoltaicos y optimizar el diseño, la validez y conveniencia de TRNSYS se ha verificado. Por lo tanto, en caso de implementar el sistema, se tendrá mayor seguridad de la inversión y de la eficiencia obtenida al hacer uso de los recursos naturales renovables.

\section{AGRADECIMIENTOS}

A la Facultad de Tecnología de la Universidad Distrital Fransico José de Caldas, Bogotá, incluyendo las colaboraciones de: Ph.D.(c) Camilo Andrés Arias Henao, del grupo de investigación en energias alternativas - GIEAUD; Ing. John Alejandro Forero C., coordinador del programa de Tecnología e Ingeniería Mecánica, e Ing. Yisselle I. Acuña H., coordinadora anterior. Por permitir el uso de la licencia académica del software TRNSYS 17, con el propósito exclusivo del desarrollo de este trabajo.

A la Universidad Libre por facilitar los escenarios y equipos para el trabajo desarrollado. Y además a la maestra de la
Escuela El Cardonal, por su colaboración y, muy especialmente, a los escolares que participaron en la recolección de información.

\section{REFERENCIAS}

Alonso Abella, Miguel (2014). Dimensionamiento de sistemas fotovoltaicos autónomos. Madrid: Laboratorio de energía Solar, CIEMAT.

Burgos Mellado, C. (2013). Estimación del estado de carga para un banco de baterías basada en modelación difusa y filtro extendido de Kalman. Universidad de Chile, Santiago de chile, Chile.

Egido Aguilera, Miguel A. (2006). Energía solar fotovoltaica para la electrificación del medio rural. Energía Participación y sostenibilidad. Tecnología para el desarrollo humano. $1^{\text {a }}$ edición, p. 157 - 172.

Fernández Ferichola, J. (2009). Caracterización de módulos fotovoltaicos con dispositivo portátil. Universidad Carlos III de Madrid. España.

Joachín Barríos, Carmencita De Los Ángeles (2008). Diseño de un sistema solar fotovoltaico aislado, para el suministro de energía eléctrica a la comunidad rural Buena Vista, San Marcos. Universidad de San Carlos de Guatemala.

Martínez Cerro, B. (2011). Instalación solar fotovoltaica aislada. Universitat Politècnica de Catalunya, Barcelona, España.

Nina E., Edgar. (2011). “Dimensionamiento y evaluación económica de SFV”. En XVIII Simposio Peruano de Energía Solar. Universidad Nacional de Ingeniería, Lima, Perú.

Ortega Rodríguez, Mario (2001). Energías renovables. Ediciones Paraninfo.

REDFE (2014). Red de fuentes de energía CONACYT: Estado del arte de la investigación en fuentes de energía y políticas públicas.

Solar Energy Laboratory, (2012). TRNSYS 17 - Mathematical Reference, Vol. 4. Ed. Madison, University of Wisconsin-Madison. Wisconsin. USA.

UPME (Unidad de Planeación Minero Energética). (2003). Guía de Especificaciones de Sistemas Fotovoltaicos. Unión Temporal ICONTEC - AENE. Bogotá. 


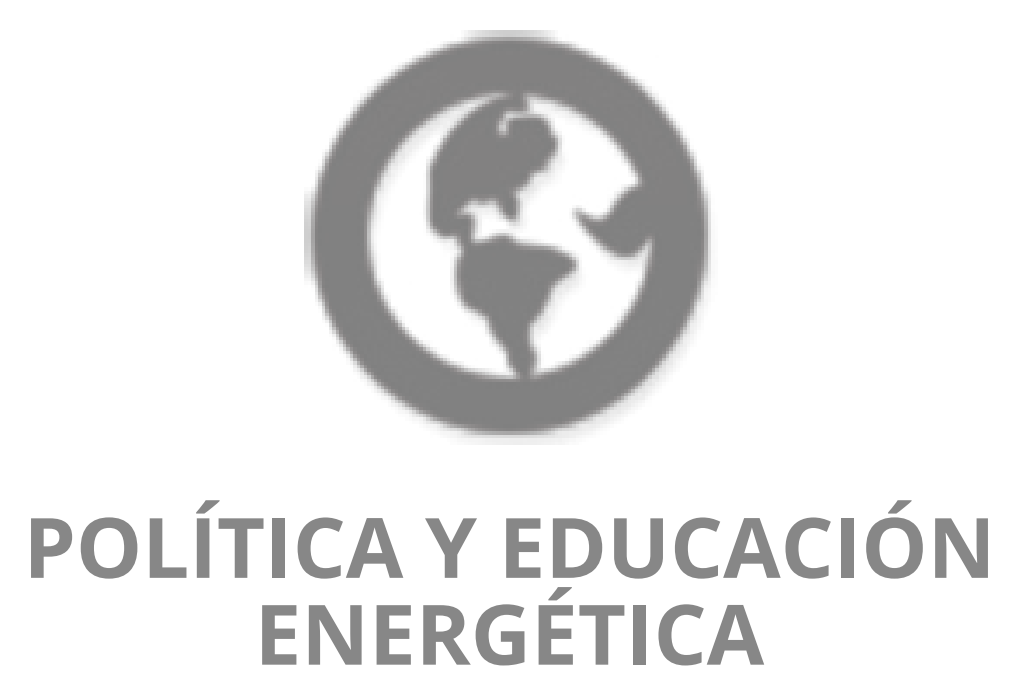




\title{
Política energética en Latinoamérica y el Caribe (LAC)
}

\author{
D. Jijón1, J.E. Constante ${ }^{1}$ \\ ${ }^{1}$ Instituto Nacional de Eficiencia Energética y Energías Renovables, Av. 6 de diciembre \\ N33-32 e Ignacio Bosano, Quito, Ecuador.
}

\begin{abstract}
RESUMEN
La política energética busca cumplir la satisfacción de las necesidades de los países Latinoamericanos y el Caribe (LAC), incrementando la eficiencia en el aprovechamiento de los recursos y la transformación de la matriz del sector energético. En este contexto, el cambio de la matriz productiva de los países vecinos apunta a la sostenibilidad energética mediante fuentes renovables. La energía generada en los países de (LAC) en el 2010 fue de 1.3 PWh (Pentavatios hora), y la demanda energética para el 2050 se podría incrementar a 3.5 (PWh) [1]. El potencial energético renovable de los países de (LAC) es aproximadamente 22 veces la demanda que se espera para el 2050, siendo esto un punto fundamental para la generación de electricidad a partir de técnicas como, eólica, geotérmica, solar fotovoltaica, solar CSP, marina, biomasa y nuclear. Actualmente, las hidroeléctricas son un pilar fundamental de los países de (LAC), siendo éstas las que proveen el 54\% total de toda la energía producida en el 2010 [1]. Por este motivo, la explotación de los recursos renovables para la generación de electricidad será fundamental para el desarrollo sostenible de los países de la región, por lo cual, la trasferencia tecnológica y fondos financieros deben ser una prioridad. Además, las grandes infraestructuras deberán incluir en sus estudios los impactos ambientales y su capacidad adaptativa a los cambios del clima, como es el caso de las hidroeléctricas. Las energías no renovables, y que en su gran mayoría son las que más grandes cantidades de gases de efecto invernadero han enviado a la atmósfera, en la actualidad son subsidiadas en algunos de los países de (LAC), lo cual se espera que para los próximos años se hayan eliminado. La recomendación a los países de la región es en los subsidios y el precio real de la energía, en el cual debe considerarse los gastos por emisiones de gases como el CO2, metano y óxido nitroso. Las políticas deben estar dirigidas a mitigar el cambio climático, y así, todos los esfuerzos de los países deben estar enfocados a la reducción de emisiones.
\end{abstract}

Palabras Clave: Energías renovables, Política energética (LAC), Cambio Climático.

\section{REFERENCIAS:}

[1] Walter Vergara, Paul Isbell, Ana R. Rios, José Ramon Gómez and Leandro Alves, "Societal benefits from renewable energy in Latin America and the Caribbean". Inter-American Development Bank, Climate Change and Sustainability Division, Energy Division, TECHNICAL NOTE No. IDB-TN-623, 2014: 1-16. 
CONGRESO DE ENERGÍA SOSTENIBLE 2014 @ 